NIST Special Publication 260-201

\title{
Certification of Standard Reference Material ${ }^{\circledR}$ 1450e Fibrous Glass Board
}

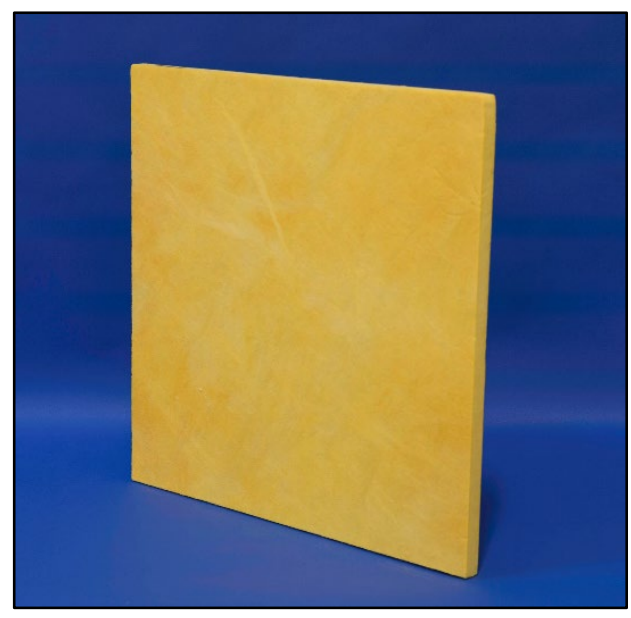

Robert R. Zarr

N. Alan Heckert

This publication is available free of charge from: https://doi.org/10.6028/NIST.SP.260-201

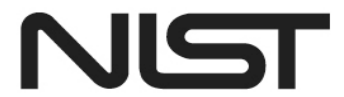

National Institute of Standards and Technology U.S. Department of Commerce 
NIST Special Publication 260-201

\title{
Certification of Standard Reference Material ${ }^{\circledR}$ 1450e Fibrous Glass Board
}

\author{
Robert R. Zarr \\ Energy and Environment Division \\ Engineering Laboratory \\ N. Alan Heckert \\ Statistical Engineering Division \\ Information Technology Laboratory
}

This publication is available free of charge from:

https://doi.org/10.6028/NIST.SP.260-201

April 2020

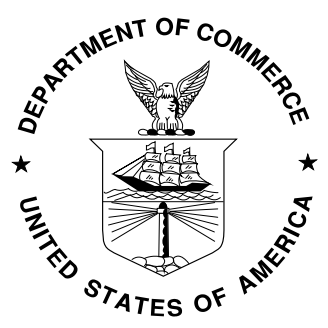

U.S. Department of Commerce Wilbur L. Ross, Jr., Secretary

National Institute of Standards and Technology Walter Copan, NIST Director and Undersecretary of Commerce for Standards and Technology 
Certain commercial entities, equipment, or materials may be identified in this document in order to describe an experimental procedure or concept adequately. Such identification is not intended to imply recommendation or endorsement by the National Institute of Standards and Technology, nor is it intended to imply that the entities, materials, or equipment are necessarily the best available for the purpose.

National Institute of Standards and Technology Special Publication 260-201 Natl. Inst. Stand. Technol. Spec. Publ. 260-201, 139 pages (April 2020) CODEN: NSPUE2

This publication is available free of charge from: https://doi.org/10.6028/NIST.SP.260-201 


\section{Foreword}

The National Institute of Standards and Technology (NIST), formerly the National Bureau of Standards (NBS), was established by the U.S. Congress in 1901 and charged with the mission of establishing national standards used in scientific investigations, engineering, manufacturing, and commerce. Standard Reference Materials originated in 1905 with a standard sample program - the array of materials maintained by NIST and certified for their chemical composition, or physical or chemical properties. In response to pressing demands, the early program grew and, with time, NIST has issued several thousand different Standard Samples or Standard Reference Materials ${ }^{\circledR}(\mathrm{SRMs})$. Many of these have been renewed several times; others have been replaced or discontinued as technology changed. Today, over 1300 SRMs are available, together with a large number of scientific publications related to the fundamental and applied characteristics of these materials. Each SRM is provided with a Certificate or a Certificate of Analysis that contains the essential data concerning its properties or characteristics. The SRMs currently available cover a wide range of chemical, physical, and mechanical properties, and a corresponding wide range of measurement interests of fundamental and applied science. These SRMs constitute a unique and invaluable means of transferring to the user accurate data obtained at NIST and provide essential tools that can be used to improve accuracy in areas where measurements are performed. 


\section{Preface}

Standard Reference Materials (SRMs) as defined by the National Institute of Standards and Technology (NIST) are well-characterized materials, produced in quantity, and certified for one or more physical or chemical properties. They are used to assure the accuracy and compatibility of measurements throughout the nation. SRMs are widely used as primary standards in many diverse fields in science, industry, and technology, both within the United States and throughout the world. They are also used extensively in the fields of environmental and clinical analysis. In many applications, traceability of quality control and measurement processes to the national measurement system is carried out through the mechanism and use of SRMs. For many of the Nation's scientists and technologists, it is therefore more than a passing interest to know the details of the measurements made at NIST in arriving at the certified values of the SRMs produced.

The NIST Special Publication 260 Series (SP 260) is reserved for this purpose. The SP 260 Series is dedicated to the dissemination of information on all phases of the preparation, measurement, certification, and use of NIST SRMs. In general, much more detail will be found in these publications than is generally allowed, or desirable, in scientific journal articles. This level of detail enables the user to assess the validity and accuracy of the measurement processes employed, to judge the statistical analysis, and to learn details of techniques and methods utilized for work entailing greatest care and accuracy. The publications also provide additional information so SRMs can be utilized in new applications in diverse fields not foreseen at the time the SRM was originally issued.

Appendix A of this document is a Change Log that contains amendments to this publication relative to the version published in 2020. Inquiries concerning the technical content of this paper should be directed to the author(s). Other questions concerned with the availability, delivery, price, and so forth, will receive prompt attention from:

NIST Office of Reference Materials

100 Bureau Drive, Stop 2300

Gaithersburg, MD 20899-2300

Telephone: (301) 975-2200

FAX: (301) 948-3730

Email: srminfo@nist.gov

Steven J. Choquette, Chief

Office of Reference Materials 


\begin{abstract}
Thermal conductivity measurements at and near room temperature are presented as the basis for certified values of thermal conductivity for SRM 1450e, Fibrous Glass Board. The measurements have been conducted in accordance with a randomized full factorial experimental design with three variables (bulk density, mean temperature, and ambient pressure) using the NIST $500 \mathrm{~mm}$ guarded-hot-plate apparatus. The thermal conductivity of the SRM specimens was measured over a range of bulk densities from $110 \mathrm{~kg} \cdot \mathrm{m}^{-3}$ to $154 \mathrm{~kg} \cdot \mathrm{m}^{-3}$, mean temperatures from $280 \mathrm{~K}$ to $360 \mathrm{~K}$, and ambient pressure of $60 \mathrm{kPa}$ to $100 \mathrm{kPa}$. Uncertainties of the measurements, consistent in format with current international guidelines, have been prepared. Statistical analyses of the physical properties from the SRM are presented and include variations between boards, as well as within board.

Each unit of SRM 1450e is individually certified for bulk density, $\rho$, and batch certified for thermal conductivity with the following equation:

$$
\lambda=-1.9731 \times 10^{-3}+1.9923 \times 10^{-5} \rho+1.0792 \times 10^{-4} T_{m}
$$

where $\lambda$ is the predicted thermal conductivity $\left(\mathrm{W} \cdot \mathrm{m}^{-1} \cdot \mathrm{K}^{-1}\right), \rho$ is the bulk density $\left(\mathrm{kg} \cdot \mathrm{m}^{-3}\right)$, and $T_{m}$ is the mean temperature $(\mathrm{K})$ valid over the temperature range of $280 \mathrm{~K}$ to $360 \mathrm{~K}$. Certified values of $\lambda$ are valid for barometric pressures from $60 \mathrm{kPa}$ to $101.3 \mathrm{kPa}$ (sea-level pressure). There is no pressure dependence on the thermal conductivity included in the certification equation above because no statistically significant relationship between $\lambda$ and pressure was determined over the studied range from $60 \mathrm{kPa}$ to $100 \mathrm{kPa}$. The expanded uncertainty for $\lambda$ values from the above equation is $1 \%$ with a coverage factor of approximately $k=2$.
\end{abstract}

\title{
Key words
}

calibration; bulk density; fibrous glass board; guarded-hot-plate apparatus; heat-flow-meter apparatus; standard reference material; SRM 1450e; thermal conductivity; thermal insulation; uncertainty. 


\section{Table of Contents}

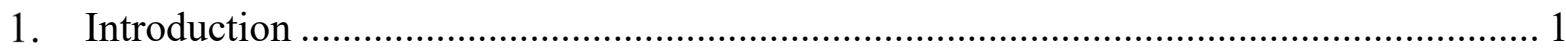

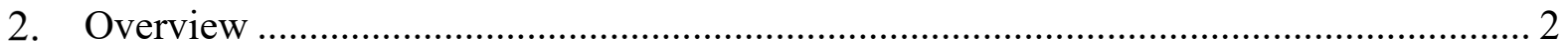

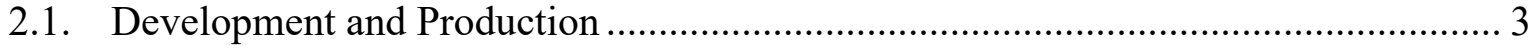

2.2. Historical Progress ……………………………...................................... 3

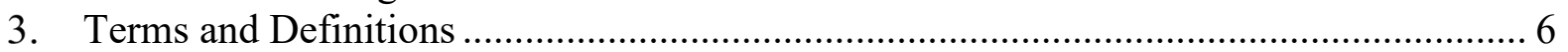

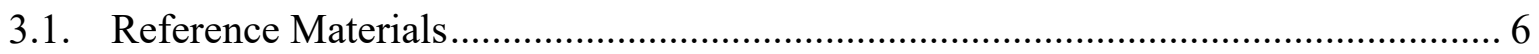

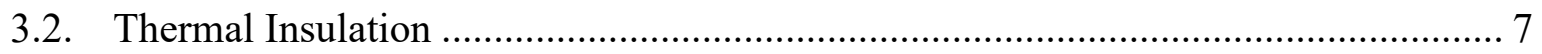

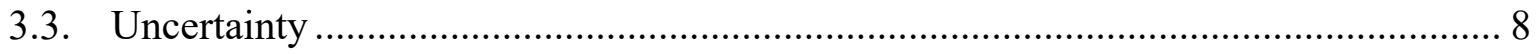

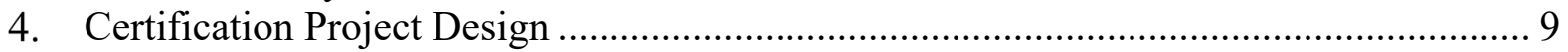

4.1. Project Definition and Scope for Intended Use .................................................. 9

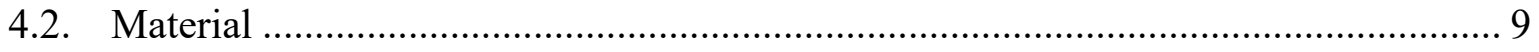

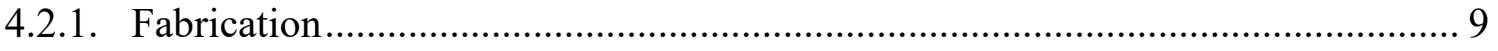

4.2.2. Production Control ................................................................................. 10

4.3. Delivery, Inspection, and Storage ……………............................................... 10

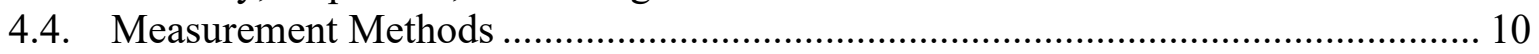

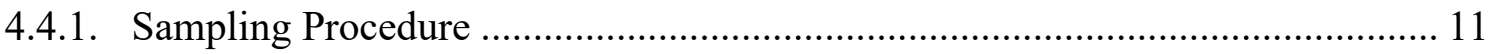

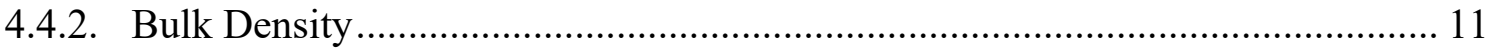

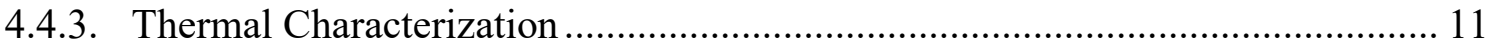

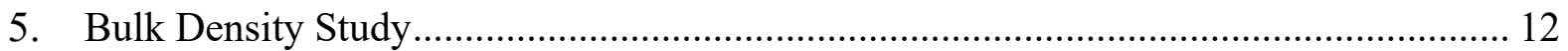

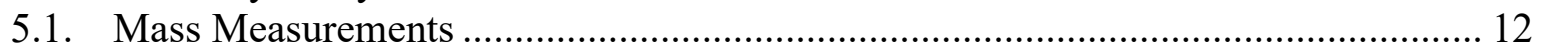

5.2. Dimensional Measurements .............................................................................. 12

5.2.1. Lateral Panel Dimensions - Length and Width.................................................. 12

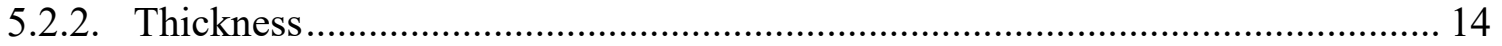

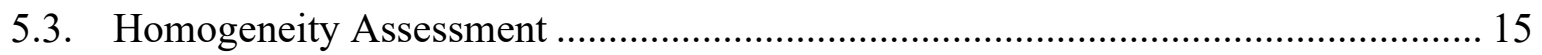

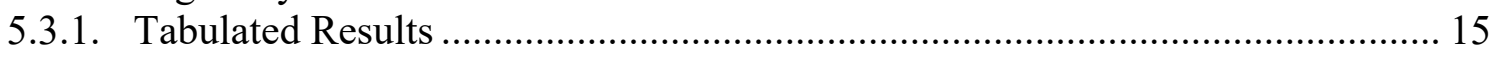

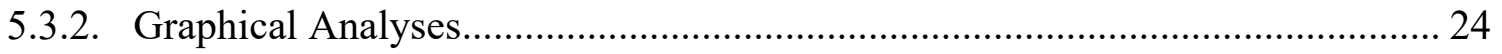

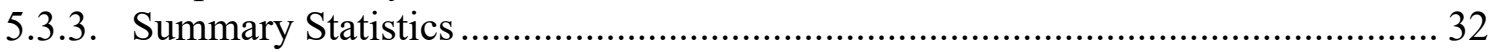

5.3.4. Between- and Within-Panel Thickness Variations............................................. 32

5.3.5. Between-Panel Bulk Density Variations ........................................................... 34

5.3.6. Rejected Panels................................................................................................ 34

5.4. Uncertainty Assessment Panel Density ..................................................................... 34

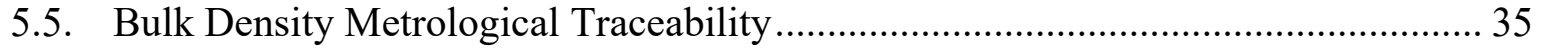

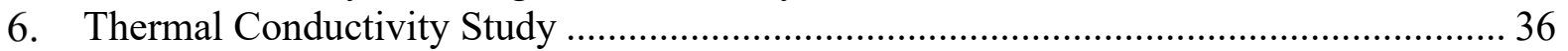

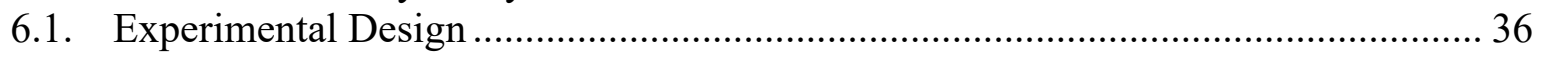

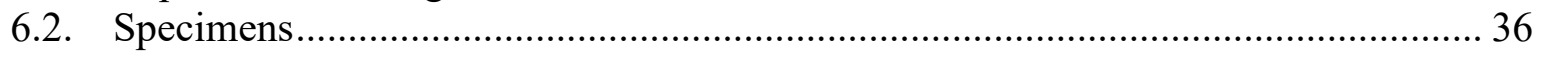

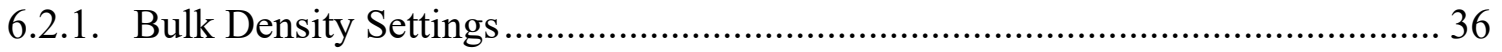

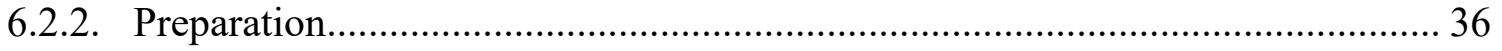

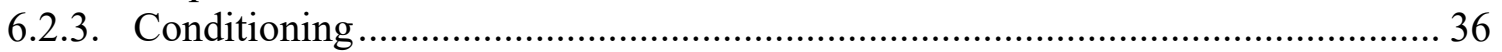

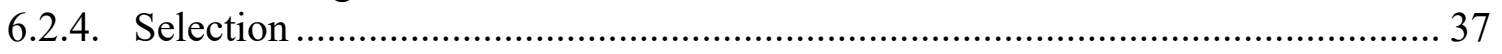

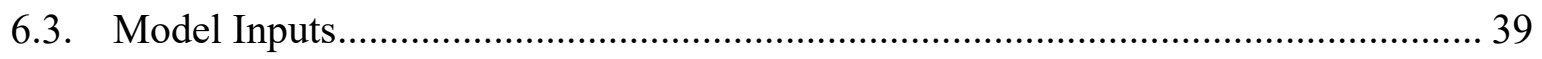

6.3.1. Temperature and Bulk Density .................................................................. 39

6.3.2. Atmospheric Pressure ................................................................................ 40

6.3.3. Supplementary Quantities ............................................................................ 41

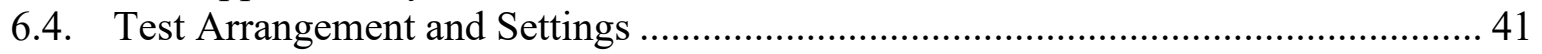

6.5. Guarded-Hot-Plate Method ............................................................................... 42 
6.6. NIST Guarded-Hot-Plate Facility ............................................................................. 44

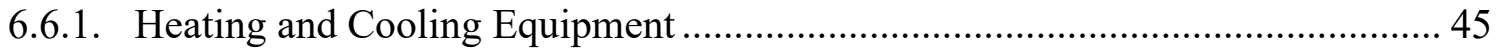

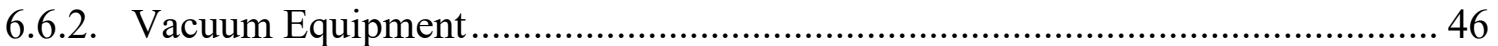

6.6.3. Specimen Installation and Operation ............................................................... 46

6.7. Guarded-Hot-Plate Measurements ....................................................................... 47

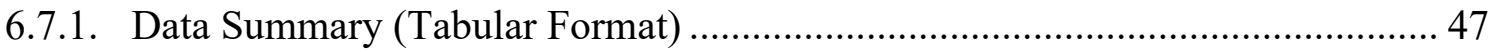

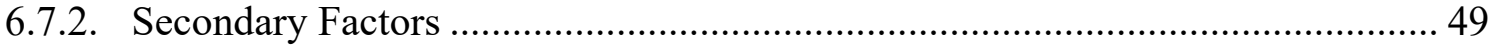

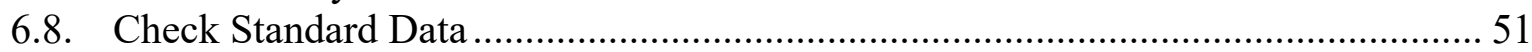

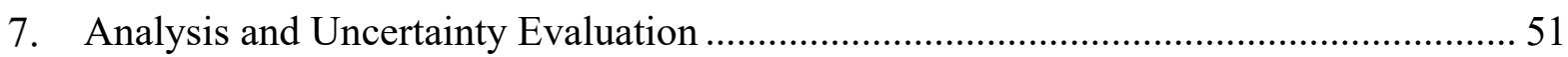

7.1. Data Screening (Graphical Analysis) .................................................................... 51

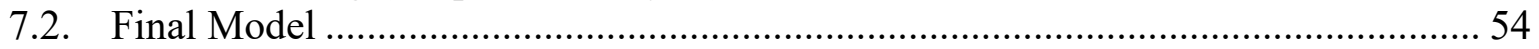

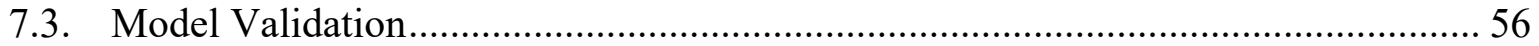

7.4. Thermal Conductivity Uncertainty Assessment .....................................................56

7.5. Thermal Conductivity Metrological Traceability.................................................... 57

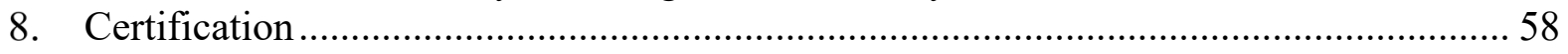

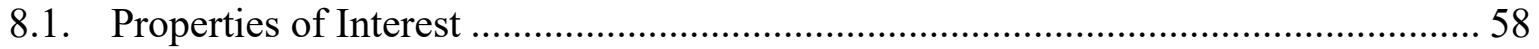

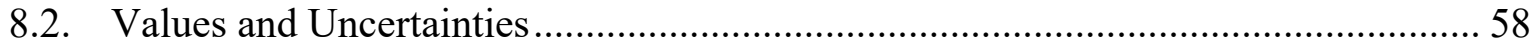

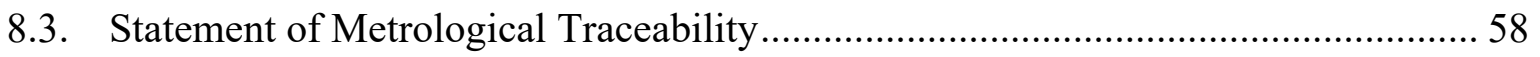

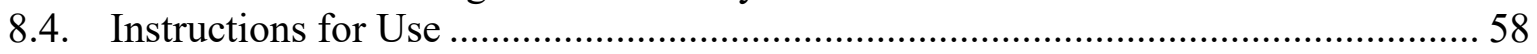

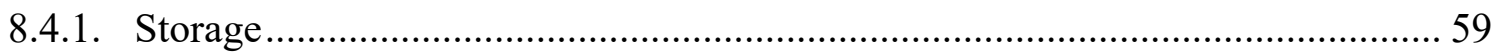

8.4.2. Preparation and Conditioning Before Measurement .......................................... 59

8.4.3. Thermal Conductivity Measurement............................................................... 59

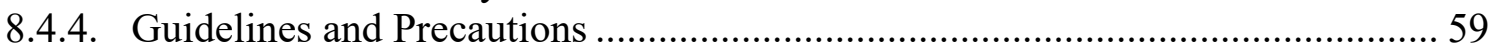

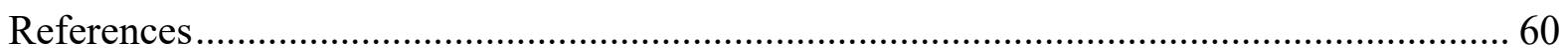

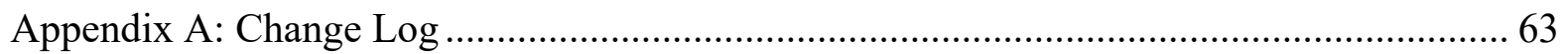

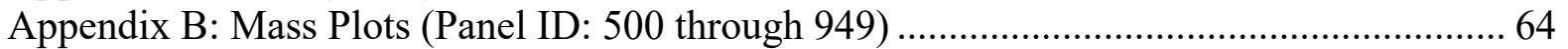

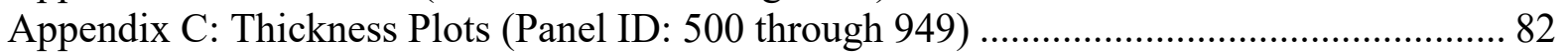

Appendix D - Bulk Density Uncertainty, Extensive Details.............................................. 100

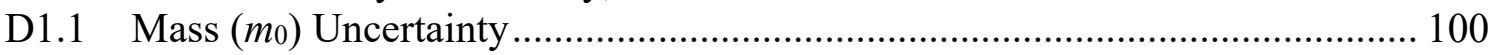

D1.2 Height Gage Uncertainty Assessment ............................................................ 100

D1.3 Panel Uncertainty Assessment (Type A Evaluation) …………………............ 102

D1.4 Dimensional $\left(l_{2}, l_{5}\right.$, and $\left.L\right)$ Uncertainties.................................................... 103

Appendix E - Thermal Conductivity Uncertainty, Extensive Details................................... 104

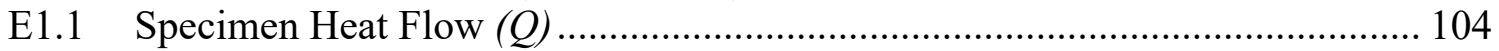

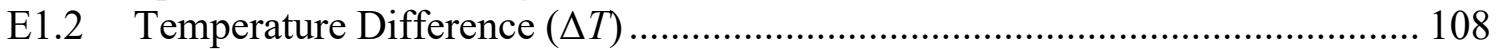

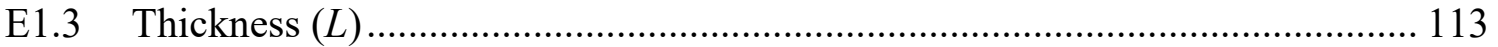

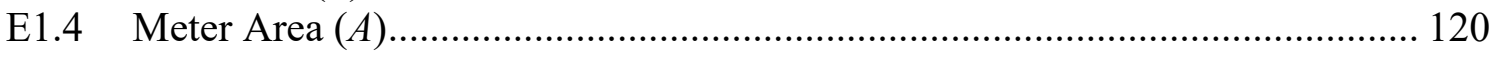




\section{List of Tables}

Table 1. Chronology of SRM 1450, Fibrous Glass Board................................................... 4

Table 2. Physical properties of SRM 1450e units (450 panels)......................................... 16

Table 3. Summary statistics for the SRM 1450e production run (450 panels) ..................... 32

Table 4. Calibration information for the bulk density measurements. ................................ 35

Table 5. Ranked bulk densities of the 30 test specimens................................................. 38

Table 6. Random test sequence and settings for the 15 pairs of test specimens.................. 42

Table 7. Status of heating and cooling equipment........................................................... 46

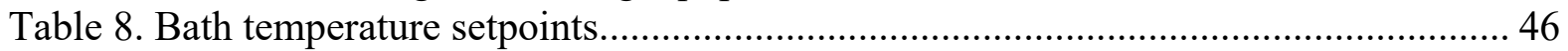

Table 9. SRM 1450e sub-sample thermal conductivity data.......................................... 48

Table 10. SRM 1450e sub-sample secondary test factors. .......................................... 50

Table 11. Thermal conductivity data for SRM 1450d check standard............................... 51

Table 12. Summary of linear profiles for $\lambda$ exp versus $\rho$ (Fig. 19)........................................ 53

Table 13. Summary of linear profiles for $\lambda_{\exp }$ versus $T_{m}$ (Fig. 20). ................................... 53

Table 14. Summary of linear profiles for $\lambda$ exp versus $p$ (Fig. 21) ....................................... 54

Table 15. Thermal conductivity uncertainty budget.................................................... 57

Table 16. Calibration information for the thermal conductivity measurements................... 57

Table 17. Uncertainty budgets for dimensional measurements.................................... 101

Table 18. Length, width dimensional data for nine panels (multiple measurements)......... 102

Table 19. Thickness dimensional data for multiple measurements of nine panels.............. 103

Table 20. Combined standard uncertainties for meter-plate power input........................... 106

Table 21. Relative standard uncertainties for guard temperature imbalances. .................... 107

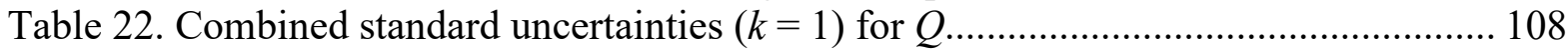

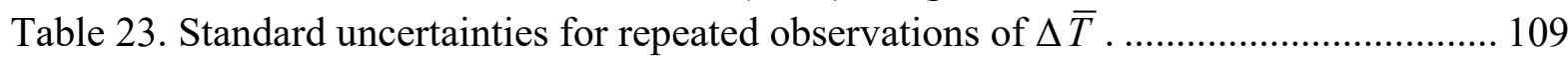

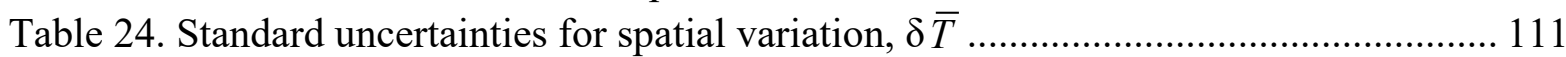

Table 25. Standard uncertainties due to the midplane-to-surface $\delta T$ correction. ................ 111

Table 26. Combined standard uncertainties for the temperature measurement................... 112

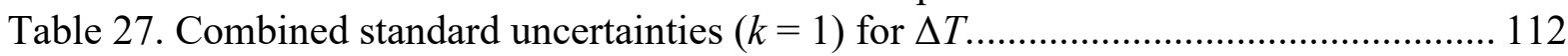

Table 28. Thickness corrections and corresponding standard uncertainties...................... 115

Table 29. Standard uncertainties for repeated observations of $\bar{L}$.................................. 115

Table 30. Calibration data for $25.4 \mathrm{~mm}$ diameter balls. ............................................... 116

Table 31. Short-term replication data for the in-situ thickness measurement. .................... 117

Table 32. Flatness variation of cold plates \#1 and \#2 .................................................... 119

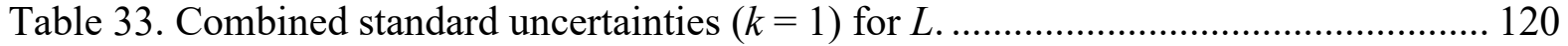

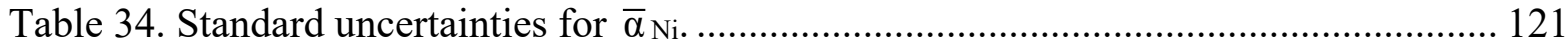

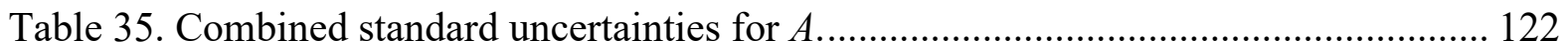




\section{List of Figures}

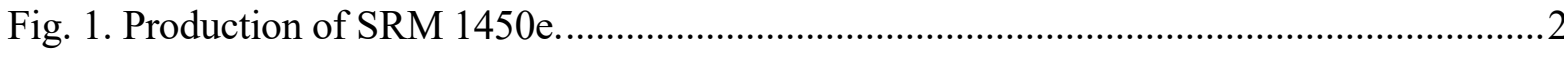

Fig. 2. a) Side view shows height gage and right-angle fixture with insulation panel clamped between the aluminum jig plate and aluminum sheet. b) Front view shows panel length measurements at locations $l_{1}, l_{2}, l_{3}, l_{4}, l_{5}$, and $l_{6}$ (clamp fixture and height gage are not shown).....

Fig. 3. a) Front view shows $305 \mathrm{~mm}$ height gage and insulation panel, with workpiece, on granite surface plate. b) Top view shows the eight measurement locations ( $L_{1}$ through $L_{8}$ ) each in the geometric center of a $203 \mathrm{~mm}$ by $203 \mathrm{~mm}$ subdivision of the insulation panel.14

Fig. 4. a) Graphical analysis of panel mass $(n=450)$ : (a) run sequence plot, (b) lag plot, (c) histogram, (d) normal probability plot (normality index). Summary statistics: mean = $1.2059 \mathrm{~kg}$, standard deviation $=0.0784 \mathrm{~kg}$, range $=0.3811 \mathrm{~kg}$.

Fig. 5. a) Graphical analysis of panel length $(n=450)$ : (a) run sequence plot, (b) lag plot, (c) histogram, (d) normal probability plot (normality index). Summary statistics: mean = $610.40 \mathrm{~mm}$, standard deviation $=1.30 \mathrm{~mm}$, range $=6.27 \mathrm{~mm}$.

Fig. 6. a) Graphical analysis of panel width $(n=450)$ : (a) run sequence plot, (b) lag plot, (c) histogram, (d) normal probability plot (normality index). Summary statistics: mean = $610.42 \mathrm{~mm}$, standard deviation $=1.35 \mathrm{~mm}$, range $=7.53 \mathrm{~mm}$.

Fig. 7. a) Graphical analysis of panel area $(n=450)$ : (a) run sequence plot, (b) lag plot, (c) histogram, (d) normal probability plot (normality index). Summary statistics: mean = $0.37260 \mathrm{~m}^{2}$, standard deviation $=0.00118 \mathrm{~m}^{2}$, range $=0.00497 \mathrm{~m}^{2}$. 28

Fig. 8. a) Graphical analysis of panel thickness $(n=450)$ : (a) run sequence plot, (b) lag plot, (c) histogram, (d) normal probability plot (normality index). Summary statistics: mean =

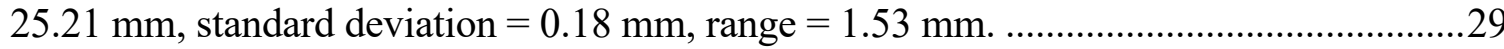

Fig. 9. a) Graphical analysis of panel bulk density $(n=450)$ : (a) run sequence plot, (b) lag plot, (c) histogram, (d) normal probability plot (normality index). Summary statistics: mean = $128.4 \mathrm{~kg} \cdot \mathrm{m}^{-3}$, standard deviation $=8.2 \mathrm{~kg} \cdot \mathrm{m}^{-3}$, range $=40.9 \mathrm{~kg} \cdot \mathrm{m}^{-3}$.

Fig. 10. a) Graphical analysis of between-panel thickness variation represented by the means of the individual panel thickness measurements. Panels outside the control limits of three times the standard deviation ( $\pm 3 \mathrm{~s}$, where $s$ equals $0.18 \mathrm{~mm}$ from Table 3 ) were removed. b) Graphical analysis of within-panel thickness variation represented by the standard deviations of the individual panel thickness measurements. The upper limit cutoff of 0.55 mm was selected arbitrarily.....

Fig. 11. Graphical analysis of between-panel bulk density variation........................................34

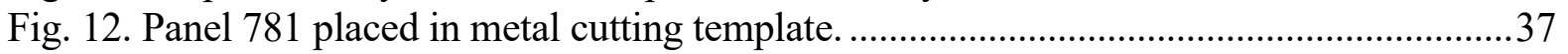

Fig. 13. Test specimens (500 mm diameter) in a large conditioning chamber..........................37

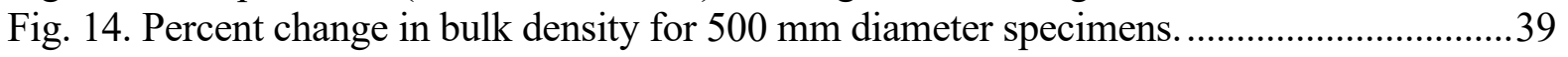

Fig. 15. Model inputs for mean temperature and bulk density............................................... 40

Fig. 16. Atmospheric pressure as a function of elevation (NACA standard [23])....................41

Fig. 17. Schematic illustration of a guarded-hot-plate apparatus (vertical plates) with a specimen pair installed. The numbers " 1 " and " 2 " (subscripts (1) and (2) in the text) refer to

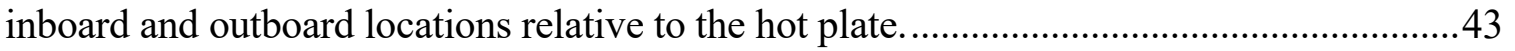

Fig. 18. NIST $500 \mathrm{~mm}$ diameter guarded-hot-plate apparatus: plates and edge guard (foreground), vacuum bell jar (background). The edge guards are partially separated

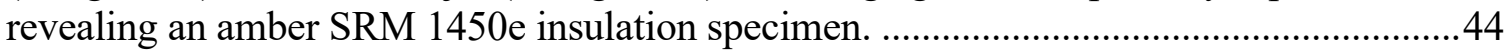

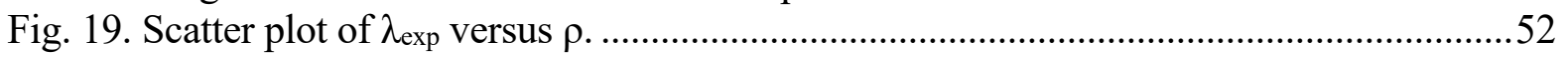




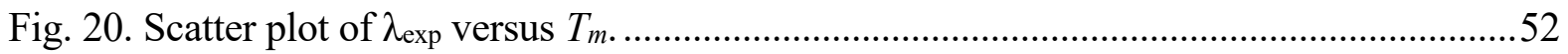

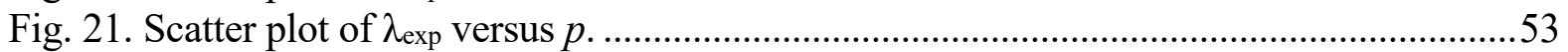

Fig. 22. Graphical analysis of deviations (in \%) for the fit given in Eq. (21)............................55

Fig. 23. Graphical analysis of deviations (in \%) for the fit given in Eq. (21)............................55

Fig. 24. Re-measured thermal conductivity versus mean temperature for specimen pair

$(594,769)$. The solid line represents the fitted model given in Eq. (21)............................56

Fig. 25. Panel $\mathrm{ID}=500-524$ : Multiple mass observations (in kilograms) as a function of elapsed time (in seconds) for insulation panels 500 through 524. Linear fit for data (shown as solid line) was back-extrapolated to elapsed time zero $\left(t_{0}\right)$ to determine $m_{0}$ for each panel. 64

Fig. 26. Panel ID=525-549: Multiple mass observations (in kilograms) as a function of elapsed time (in seconds) for insulation panels 525 through 549. Linear fit for data (shown as solid line) was back-extrapolated to elapsed time zero $\left(t_{0}\right)$ to determine $m_{0}$ for each panel. .........65

Fig. 27. Panel $\mathrm{ID}=550-574$ : Multiple mass observations (in kilograms) as a function of elapsed time (in seconds) for insulation panels 550 through 574. Linear fit for data (shown as solid line) was back-extrapolated to elapsed time zero $\left(t_{0}\right)$ to determine $m_{0}$ for each panel. ........66

Fig. 28. Panel $\mathrm{ID}=575-599$ : Multiple mass observations (in kilograms) as a function of elapsed time (in seconds) for insulation panels 575 through 599. Linear fit for data (shown as solid line) was back-extrapolated to elapsed time zero $\left(t_{0}\right)$ to determine $m_{0}$ for each panel. 67

Fig. 29. Panel $I D=600-624$ : Multiple mass observations (in kilograms) as a function of elapsed time (in seconds) for insulation panels 600 through 624. Linear fit for data (shown as solid line) was back-extrapolated to elapsed time zero $\left(t_{0}\right)$ to determine $m_{0}$ for each panel. ........68

Fig. 30. Panel $\mathrm{ID}=625-649$ : Multiple mass observations (in kilograms) as a function of elapsed time (in seconds) for insulation panels 625 through 649. Linear fit for data (shown as solid line) was back-extrapolated to elapsed time zero ( $\left.t_{0}\right)$ to determine $m_{0}$ for each panel. Note that only 6 observations are included for panel 629 due to an interruption in the measurement process.

Fig. 31. Panel ID=650-674: Multiple mass observations (in kilograms) as a function of elapsed time (in seconds) for insulation panels 650 through 674. Linear fit for data (shown as solid line) was back-extrapolated to elapsed time zero $\left(t_{0}\right)$ to determine $m_{0}$ for each panel. .........70

Fig. 32. Panel ID=675-699: Multiple mass observations (in kilograms) as a function of elapsed time (in seconds) for insulation panels 675 through 699. Linear fit for data (shown as solid line) was back-extrapolated to elapsed time zero $\left(t_{0}\right)$ to determine $m_{0}$ for each panel. .........71

Fig. 33. Panel ID=700-724: Multiple mass observations (in kilograms) as a function of elapsed time (in seconds) for insulation panels 700 through 724. Linear fit for data (shown as solid line) was back-extrapolated to elapsed time zero $\left(t_{0}\right)$ to determine $m_{0}$ for each panel. .........72

Fig. 34. Panel ID=725-749: Multiple mass observations (in kilograms) as a function of elapsed time (in seconds) for insulation panels 725 through 749. Linear fit for data (shown as solid line) was back-extrapolated to elapsed time zero $\left(t_{0}\right)$ to determine $m_{0}$ for each panel. .........73

Fig. 35. Panel ID=750-774: Multiple mass observations (in kilograms) as a function of elapsed time (in seconds) for insulation panels 750 through 774. Linear fit for data (shown as solid line) was back-extrapolated to elapsed time zero $\left(t_{0}\right)$ to determine $m_{0}$ for each panel. .........74

Fig. 36. Panel ID=775-799: Multiple mass observations (in kilograms) as a function of elapsed time (in seconds) for insulation panels 775 through 799. Linear fit for data (shown as solid line) was back-extrapolated to elapsed time zero $\left(t_{0}\right)$ to determine $m_{0}$ for each panel. .........75 
Fig. 37. Panel ID=800-824: Multiple mass observations (in kilograms) as a function of elapsed time (in seconds) for insulation panels 800 through 824. Linear fit for data (shown as solid line) was back-extrapolated to elapsed time zero $\left(t_{0}\right)$ to determine $m_{0}$ for each panel.........76

Fig. 38. Panel ID=825-849: Multiple mass observations (in kilograms) as a function of elapsed time (in seconds) for insulation panels 825 through 849. Linear fit for data (shown as solid line) was back-extrapolated to elapsed time zero $\left(t_{0}\right)$ to determine $m_{0}$ for each panel. ........77

Fig. 39. Panel $I D=850-874$ : Multiple mass observations (in kilograms) as a function of elapsed time (in seconds) for insulation panels 850 through 874. Linear fit for data (shown as solid line) was back-extrapolated to elapsed time zero $\left(t_{0}\right)$ to determine $m_{0}$ for each panel.........78

Fig. 40. Panel ID=875-899: Multiple mass observations (in kilograms) as a function of elapsed time (in seconds) for insulation panels 875 through 899. Linear fit for data (shown as solid line) was back-extrapolated to elapsed time zero $\left(t_{0}\right)$ to determine $m_{0}$ for each panel.........79

Fig. 41. Panel ID=900-924: Multiple mass observations (in kilograms) as a function of elapsed time (in seconds) for insulation panels 900 through 924. Linear fit for data (shown as solid line) was back-extrapolated to elapsed time zero $\left(t_{0}\right)$ to determine $m_{0}$ for each panel. ........80

Fig. 42. Panel ID=925-949: Multiple mass observations (in kilograms) as a function of elapsed time (in seconds) for insulation panels 925 through 949. Linear fit for data (shown as solid line) was back-extrapolated to elapsed time zero $\left(t_{0}\right)$ to determine $m_{0}$ for each panel.........81

Fig. 43. Panel $\mathrm{ID}=500-524$ : Thickness measurements (in millimeters) at locations 1 through 8 (Fig. 3) for insulation panels 500 through 524. Mean is shown as solid line (with numerical values for mean and standard deviation (SD) in the title of each frame).

Fig. 44. Panel ID=525-549: Thickness measurements (in millimeters) at locations 1 through 8 (Fig. 3) for insulation panels 525 through 549. Mean is shown as solid line (with numerical values for mean and standard deviation (SD) in the title of each frame). 83

Fig. 45. Panel $\mathrm{ID}=550-574$ : Thickness measurements (in millimeters) at locations 1 through 8 (Fig. 3) for insulation panels 550 through 574. Mean is shown as solid line (with numerical values for mean and standard deviation (SD) in the title of each frame). 84

Fig. 46. Panel ID=575-599: Thickness measurements (in millimeters) at locations 1 through 8 (Fig. 3) for insulation panels 575 through 599. Mean is shown as solid line (with numerical values for mean and standard deviation (SD) in the title of each frame).

Fig. 47. Panel ID=600-624: Thickness measurements (in millimeters) at locations 1 through 8 (Fig. 3) for insulation panels 600 through 624. Mean is shown as solid line (with numerical values for mean and standard deviation (SD) in the title of each frame). .86

Fig. 48. Panel ID=625-649: Thickness measurements (in millimeters) at locations 1 through 8 (Fig. 3) for insulation panels 625 through 649. Mean is shown as solid line (with numerical values for mean and standard deviation (SD) in the title of each frame). 87

Fig. 49. Panel $\mathrm{ID}=650-674$ : Thickness measurements (in millimeters) at locations 1 through 8 (Fig. 3) for insulation panels 650 through 674. Mean is shown as solid line (with numerical values for mean and standard deviation (SD) in the title of each frame). 88

Fig. 50. Panel ID=675-699: Thickness measurements (in millimeters) at locations 1 through 8 (Fig. 3) for insulation panels 675 through 699. Mean is shown as solid line (with numerical values for mean and standard deviation (SD) in the title of each frame). .89

Fig. 51. Panel ID=700-724: Thickness measurements (in millimeters) at locations 1 through 8 (Fig. 3) for insulation panels 700 through 724. Mean is shown as solid line (with numerical values for mean and standard deviation (SD) in the title of each frame). .90 
Fig. 52. Panel ID $=725-749$ : Thickness measurements (in millimeters) at locations 1 through 8 (Fig. 3) for insulation panels 725 through 749. Mean is shown as solid line (with numerical values for mean and standard deviation (SD) in the title of each frame).

Fig. 53. Panel ID=750-774: Thickness measurements (in millimeters) at locations 1 through 8 (Fig. 3) for insulation panels 750 through 774. Mean is shown as solid line (with numerical values for mean and standard deviation (SD) in the title of each frame).

Fig. 54. Panel ID=775-799: Thickness measurements (in millimeters) at locations 1 through 8 (Fig. 3) for insulation panels 775 through 799. Mean is shown as solid line (with numerical values for mean and standard deviation (SD) in the title of each frame). 93

Fig. 55. Panel ID=800-824: Thickness measurements (in millimeters) at locations 1 through 8 (Fig. 3) for insulation panels 800 through 824. Mean is shown as solid line (with numerical values for mean and standard deviation (SD) in the title of each frame).

Fig. 56. Panel ID $=825-849$ : Thickness measurements (in millimeters) at locations 1 through 8 (Fig. 3) for insulation panels 825 through 849 . Mean is shown as solid line (with numerical values for mean and standard deviation (SD) in the title of each frame). 95

Fig. 57. Panel ID $=850-874$ : Thickness measurements (in millimeters) at locations 1 through 8 (Fig. 3) for insulation panels 850 through 874 . Mean is shown as solid line (with numerical values for mean and standard deviation (SD) in the title of each frame). .96

Fig. 58. Panel ID $=875-899$ : Thickness measurements (in millimeters) at locations 1 through 8 (Fig. 3) for insulation panels 875 through 899. Mean is shown as solid line (with numerical values for mean and standard deviation (SD) in the title of each frame).

Fig. 59. Panel ID=900-924: Thickness measurements (in millimeters) at locations 1 through 8 (Fig. 3) for insulation panels 900 through 924. Mean is shown as solid line (with numerical values for mean and standard deviation (SD) in the title of each frame). 98

Fig. 60. Panel ID=925-949: Thickness measurements (in millimeters) at locations 1 through 8 (Fig. 3) for insulation panels 925 through 949. Mean is shown as solid line (with numerical values for mean and standard deviation (SD) in the title of each frame)..............................99

Fig. 61. Electrical schematic for the meter-plate power measurement. ....................................104

Fig. 62. Temperature sensor locations for NIST $500 \mathrm{~mm}$ diameter plates. .............................109

Fig. 63. a) Calibration and b) Measurement principles for in-situ thickness determination. ...113

Fig. 64. Locations for surface flatness measurements for NIST $500 \mathrm{~mm}$ diameter plates.......118

Fig. 65. Schematic illustration of the puncture hole located in the guard gap........................122 


\section{Glossary}

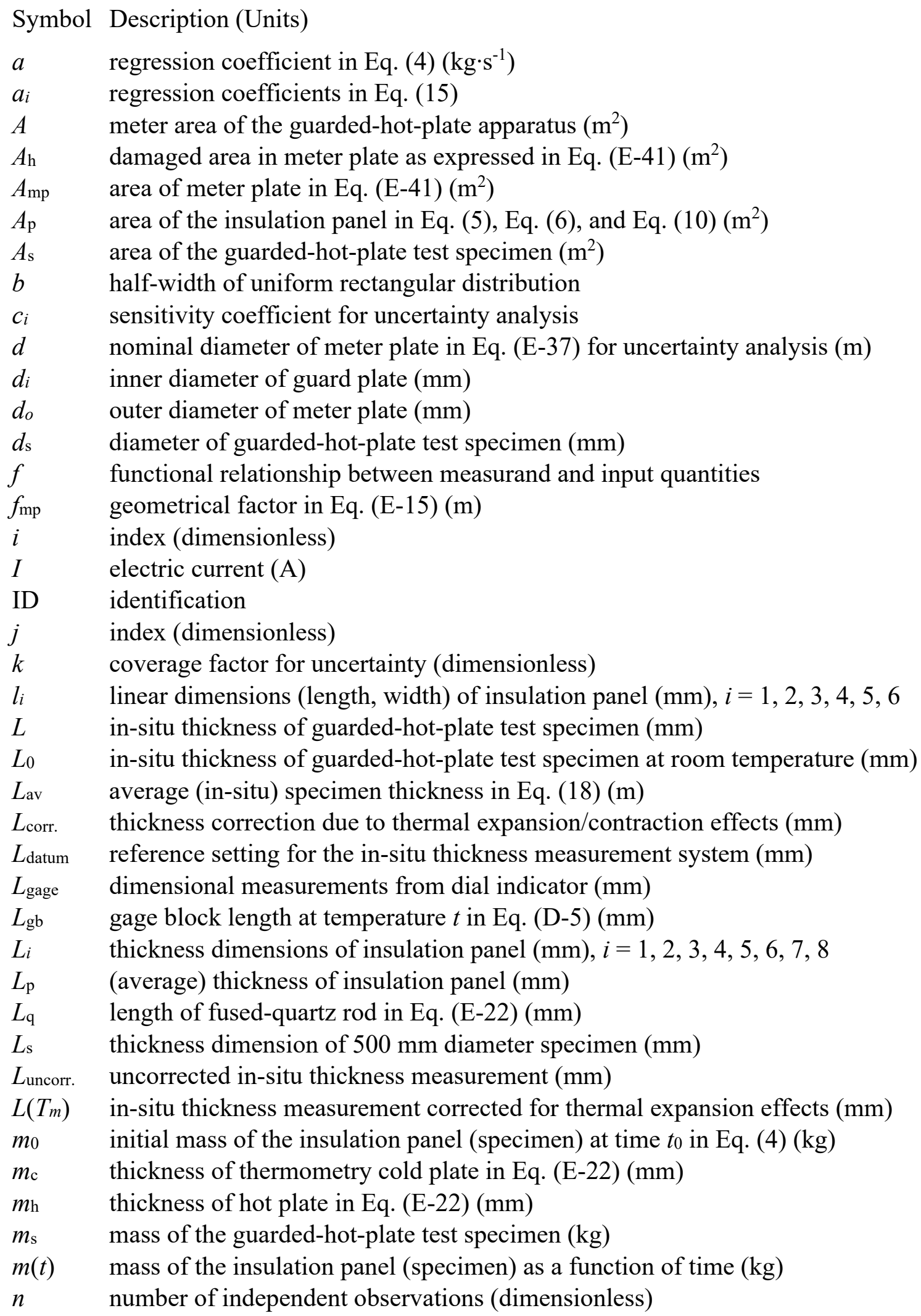




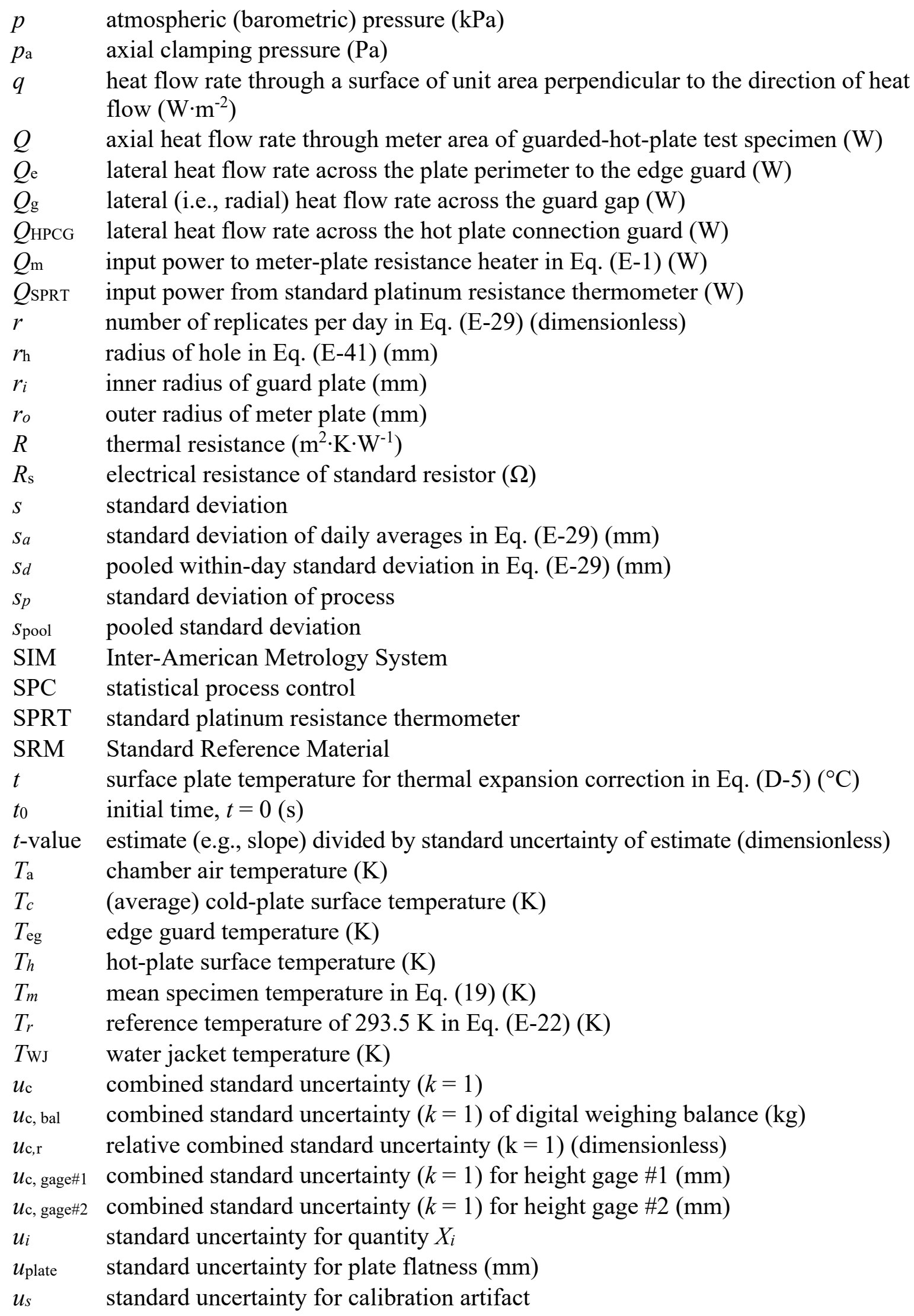




\begin{tabular}{|c|c|}
\hline$U$ & expanded uncertainty $(k=2)$ \\
\hline$U_{\mathrm{r}}$ & relative expanded uncertainty $(\mathrm{k}=2)$ (dimensionless) \\
\hline$V_{\mathrm{m}}$ & voltage difference across meter-plate resistance heater (V) \\
\hline$V_{\mathrm{s}}$ & voltage difference across standard resistor $(\mathrm{V})$ \\
\hline$x_{i}$ & input estimate ( $x$-value for graphical analysis) \\
\hline$x_{i-1}$ & previous $x$-value for graphical analysis \\
\hline$x_{j}$ & input value (coded as -1 or +1 ) for imbalance model in Eq. $(E-7)$ \\
\hline$X_{1}$ & output from inboard length gage (mm) \\
\hline$X_{2}$ & output from outboard length gage $(\mathrm{mm})$ \\
\hline$X_{i}$ & input quantity \\
\hline$\alpha$ & coefficient of thermal expansion $\left(\mathrm{K}^{-1}\right)$ \\
\hline$\beta_{j i}$ & regression coefficients for imbalance model in Eq. (E-7) \\
\hline$\delta \rho$ & difference in bulk density of insulation panel and $500 \mathrm{~mm}$ diameter specimens $(\%)$ \\
\hline$\delta L$ & change in combined reading of length gages relative to $293.15 \mathrm{~K}(\mathrm{~mm})$ \\
\hline$\delta T_{\text {corr. }}$ & temperature correction due to SPRT location at midplane of plate $(\mathrm{K})$ \\
\hline$\delta T_{\mathrm{s}}$ & hot plate spatial (lateral) temperature variation $(\mathrm{K})$ \\
\hline$\Delta L$ & change in the average thickness of the specimen pair in Eq. (E-20) $(\mathrm{mm})$ \\
\hline$\Delta L_{\mathrm{gb}}$ & length correction of gage block in Eq. (D-5) (mm) \\
\hline$\Delta L_{\mathrm{q}}$ & change in length of fused-quartz rod due to thermal expansion/contraction (mm) \\
\hline$\Delta m_{\mathrm{c}}$ & $\begin{array}{l}\text { change in thickness of the thermometry cold plate due to thermal expansion/con- } \\
\text { traction }(\mathrm{mm})\end{array}$ \\
\hline$\Delta m_{\mathrm{h}}$ & change in thickness of hot plate due to thermal expansion/contraction (mm) \\
\hline$\Delta Q$ & $\begin{array}{l}\text { change in meter-plate heater power due to imbalance condition expressed in Eq. (E-7) } \\
\text { (W) }\end{array}$ \\
\hline$\Delta t$ & elapsed time in Eq. (4) (s) \\
\hline$\Delta T$ & $\begin{array}{l}\text { surface-to-surface temperature difference across guarded-hot-plate test specimen } \\
(\mathrm{K}), \Delta T=\left(T_{h}-T_{c}\right)\end{array}$ \\
\hline$\Delta T_{\mathrm{av}}$ & average temperature difference in Eq. (18) (K) \\
\hline$\Delta T_{\text {gap }}$ & temperature difference across the guard gap in Fig. $17(\mathrm{~K})$ \\
\hline$\Delta T_{\mathrm{HPCG}}$ & temperature difference across the hot plate connection guard (W) \\
\hline$\Delta T_{\mathrm{mp}}$ & change in meter plate temperature from room conditions $(\mathrm{K})$ \\
\hline$\rho$ & bulk density $\left(\mathrm{kg} \cdot \mathrm{m}^{-3}\right)$ \\
\hline$\rho_{\text {av }}$ & average in-situ bulk density of a specimen pair $\left(\mathrm{kg} \cdot \mathrm{m}^{-3}\right)$ \\
\hline$\rho p$ & bulk density of insulation panel in Eq. $(10)\left(\mathrm{kg} \cdot \mathrm{m}^{-3}\right)$ \\
\hline$\rho_{\mathrm{s}}$ & bulk density of guarded-hot-plate test specimen in Eq. (1) and Eq. (16) $\left(\mathrm{kg} \cdot \mathrm{m}^{-3}\right)$ \\
\hline$\lambda$ & thermal conductivity $\left(\mathrm{W} \cdot \mathrm{m}^{-1} \cdot \mathrm{K}^{-1}\right)$ \\
\hline$\lambda_{0}$ & baseline (balanced) case for imbalance model in Eq. $(\mathrm{E}-7)\left(\mathrm{W} \cdot \mathrm{m}^{-1} \cdot \mathrm{K}^{-1}\right)$ \\
\hline$\lambda_{a}$ or $k_{a}$ & apparent thermal conductivity $\left(\mathrm{W} \cdot \mathrm{m}^{-1} \cdot \mathrm{K}^{-1}\right)$ \\
\hline$\lambda \exp$ & experimental thermal conductivity in Eq. $(18)\left(\mathrm{W} \cdot \mathrm{m}^{-1} \cdot \mathrm{K}^{-1}\right)$ \\
\hline$\lambda_{\text {pred }}$ & predicted thermal conductivity for imbalance model in Eq. $(\mathrm{E}-7)\left(\mathrm{W} \cdot \mathrm{m}^{-1} \cdot \mathrm{K}^{-1}\right)$ \\
\hline$\lambda_{\mathrm{Ni}}$ & thermal conductivity of nickel in Eq. $(\mathrm{E}-15)\left(\mathrm{W} \cdot \mathrm{m}^{-1} \cdot \mathrm{K}^{-1}\right)$ \\
\hline
\end{tabular}




\section{Additional subscripts}

1 denotes inboard cold plate/specimen relative to the vertical vacuum baseplate

2 denotes outboard cold plate/specimen relative to the vertical vacuum baseplate av denotes average value for a quantity associated with the specimen pair

A denotes Type A standard uncertainty evaluation

B denotes Type B standard uncertainty evaluation

$\mathrm{Ni}$ denotes nickel or nickel 201 alloy

Additional superscript

- denotes sample mean

$\wedge \quad$ denotes predicted 


\section{Introduction}

The National Institute of Standards and Technology (NIST) issues Standard Reference Materials $^{\circledR}$ (SRMs) ${ }^{1}$ for insulating materials having certified value assignments for thermal conductivity or thermal resistance. Thermal insulation SRMs are intended specifically for application in standardized steady-state methods employing test apparatus with experimental arrangements either having flat plates or conditioning chambers, or both [1-3]. These primary standards support metrology and traceability for insulation testing communities in industry, academia, and government as an integral component of their quality assurance systems. In the United States, these SRMs can also assist insulation manufacturers in complying with federal requirements for labeling and advertising of home insulation commonly known as the U.S. Federal Trade Commission R-value Rule [4].

The thermal transmission properties of insulating SRMs are characterized as functions of bulk density, mean temperature, and, for SRM 1450e, atmospheric air pressure. Since it is impractical to measure the thermal conductivity of every specimen, the characterization is realized by batch certification. The benefit of batch certification is production of a large quantity of units that are economical and available on demand for several years. A minor disadvantage is that the uncertainty statement contains a component, usually small, due to the material lot variability. The measurement plan involves a statistically based sampling strategy for selecting specimens from the candidate material lot for testing in a guardedhot-plate apparatus. The analysis of the thermal conductivity data of the sample sub-lot is used for certification of the SRM lot.

Value assignments for NIST thermal insulation SRMs are developed by means of the guardedhot-plate apparatus [1]. The instrument is an absolute method since the resultant thermal transmission properties are determined directly from basic measurements of electrical power, temperature, length, and area. The measurement technique establishes steady-state heat flow through flat homogeneous slabs - the surfaces of which are in contact with adjoining parallel boundaries (i.e., plates) maintained at constant temperatures. By accurately monitoring the plate separation, temperature difference, and knowing the geometric shape factor for the heat flow, the steady-state heat transmission properties of the specimen are determined using Fourier's law of heat conduction. Influence quantities such as ambient temperature, plate clamping pressure, and plate emittance, among others, are controlled during the measurement.

This report provides supplemental documentation for the SRM 1450e Certificate on the following topics:

- overview and historical background;

- standard terminology for reference materials, thermal insulation, and measurement uncertainty;

- certification project plan;

- measurement methods for the bulk density and thermal conductivity;

- uncertainty analysis; and,

- certification.

${ }^{1}$ The term "Standard Reference Material" and the diamond-shaped logo which contains the term "SRM," are registered with the United States Patent and Trademark Office. 


\section{Overview}

The renewal process for SRM 1450e involves three major phases (Fig. 1): 1) material fabrication and acquisition; 2) batch certification by a NIST technical laboratory; and, 3) distribution by the NIST Office of Reference Materials (ORM).

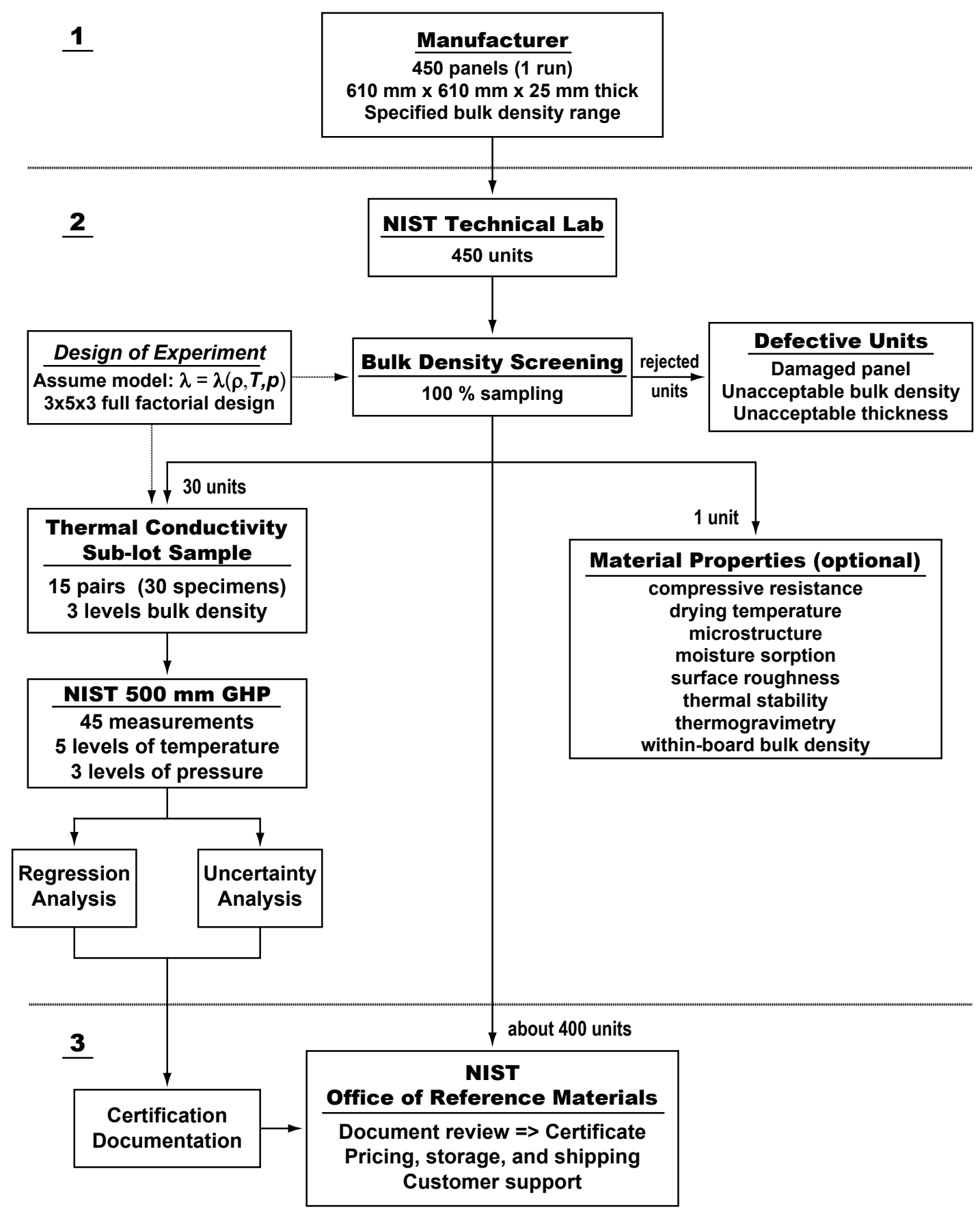

Fig. 1. Production of SRM 1450e. 


\subsection{Development and Production}

In Phase 1, the NIST technical laboratory, as part of its planning and research, assesses the needs and priorities of U.S. industry with regard to thermal insulation reference materials. Based on industry input, the laboratory prepares the technical requirements for procurement of the insulating material. Acquisition is accomplished via a contract with an approved vendor. Execution of Phase 1 generally requires one year from initiation to completion.

For Phase 2, the technical lab proceeds with production and certification of the renewal after delivery of the material. Execution of the steps below to measure the properties for certification typically requires two years.

1) First and foremost, development of a statistically justified sampling and measurement plan;

2) Measurements of bulk density for homogeneity screening of the material lot (100\% sampling);

a. rejection of anomalous and/or damaged panels (i.e., units);

b. selection of a stratified sub-sample of 15 pairs of specimens containing low (5 pairs), mid (5 pairs), and high (5 pairs) bulk density strata;

3) Thermal conductivity measurements of a statistical sub-sample using the NIST $500 \mathrm{~mm}$ guarded-hot-plate apparatus; and,

4) Analysis of data leading to batch certification.

Phase 3, undertaken by the NIST Office of Reference Materials (ORM), encompasses all final administrative functions including document review and approval, pricing, storage, shipping, publicity, and customer support. The production costs of the renewal are recovered, under current Congressional authorization, through the sale of the SRM to end users.

Figure 1 also depicts an optional compilation of supplemental material properties that have been previously investigated by NIST researchers for various lots of 1450 materials [5]. The primary purpose of these investigations is to determine what, if any, are the effects of other (secondary) factors on the certified properties of thermal conductivity and thermal resistance. In contrast to a NIST Certified Value (Sec. 3), these investigations provide informative data of interest and are noted as such when included in the certificate. Standard Reference Material 1450e does not incorporate any of the supplemental measurements depicted in Fig. 1 and, thus, does not include NIST Information Values.

\subsection{Historical Progress}

Standard Reference Material 1450e, like previous 1450 lots, is a semi-rigid, high-density molded fibrous-glass board commercially manufactured from a single run. Table 1 reviews the chronology of the 1450 Series and includes information for year acquired, year issued, bulk density, temperature, references on the technical development (where available), and laboratory facility for each SRM. When an SRM lot is exhausted, the renewal (i.e., replacement lot) retains the original number designation and a lower-case letter (a, b, c, etc.) is appended to denote the new lot. Revisions to the certificates due to modifications, corrections, or other changes are noted on the Certificate Revision History and, in this report, are denoted by a Roman numeral (I, II, etc.). 
The SRM approach for thermal insulating materials was recommended in 1977 by a working group [6] under ASTM Subcommittee C16.30 on Thermal Measurement as part of a larger mission to establish a national accreditation program for thermal insulation. In response, NIST (formerly the National Bureau of Standards ${ }^{2}$ (NBS)) established SRM 1450 in 1978 using materials obtained previously for an internal NBS calibration program.

Table 1. Chronology of SRM 1450, Fibrous Glass Board.

\begin{tabular}{|c|c|c|c|c|c|c|}
\hline SRM & $\begin{array}{c}\text { Year } \\
\text { acquired }\end{array}$ & $\begin{array}{l}\text { Year } \\
\text { issued }\end{array}$ & $\begin{array}{c}\text { Bulk } \\
\text { density } \\
\left(\mathrm{kg} \cdot \mathrm{m}^{-3}\right)\end{array}$ & $\begin{array}{c}\text { Temperature } \\
\text { (K) }\end{array}$ & Ref. & $\begin{array}{l}\text { NIST } \\
\text { facility }\end{array}$ \\
\hline 1450 & 1961 & $1978^{\mathrm{a}}$ & 100 to 180 & 255 to 330 & [7-8] & $\mathrm{b}$ \\
\hline $1450 \mathrm{a}$ & 1958 & $1979^{\mathrm{a}}$ & 60 to 140 & 255 to 330 & [7-8] & b \\
\hline $1450 \mathrm{~b}(\mathrm{I})$ & 1981 & 1982 & 110 to 150 & 260 to 330 & -- & $\mathrm{b}$ \\
\hline $1450 \mathrm{~b}(\mathrm{II})$ & 1980, 1981 & 1985 & 110 to 150 & 100 to 330 & [9] & $\mathrm{b}, \mathrm{c}, \mathrm{d}$ \\
\hline $1450 \mathrm{c}(\mathrm{I})$ & 1996 & 1997 & 150 to 165 & 280 to 340 & [10] & $\mathrm{e}$ \\
\hline $1450 \mathrm{c}(\mathrm{II})$ & 1996 & 2010 & 150 to 165 & 280 to 340 & --- & e \\
\hline $1450 \mathrm{~d}$ & 2009 & 2011 & 114 to 124 & 280 to 340 & {$[11]$} & $\mathrm{e}$ \\
\hline $1450 \mathrm{e}$ & 2017 & 2020 & 110 to 154 & 280 to 360 & & $f$ \\
\hline
\end{tabular}

${ }^{\mathrm{a}}$ Issued initially under an internal NBS calibration program.

${ }^{\mathrm{b}}$ NBS $200 \mathrm{~mm}$ square guarded-hot-plate apparatus, Gaithersburg, Maryland.

${ }^{c}$ NBS $300 \mathrm{~mm}$ diameter guarded-hot-plate apparatus, Gaithersburg, Maryland.

${ }^{d}$ NBS 200 mm diameter guarded-hot-plate apparatus, Boulder, Colorado.

${ }^{\mathrm{e}}$ NIST $1016 \mathrm{~mm}$ diameter guarded-hot-plate apparatus, Gaithersburg, Maryland.

${ }^{\mathrm{f}}$ NIST $500 \mathrm{~mm}$ diameter guarded-hot-plate apparatus, Gaithersburg, Maryland.

Table 1 footnotes identify the five guarded-hot-plate facilities utilized for the thermal characterization of 1450 and ensuing renewals. The renewal for $1450 \mathrm{~b}$ was cooperatively characterized by aggregating data from the NBS Center for Chemical Engineering in Boulder, Colorado and the NBS Center for Building Technology in Gaithersburg, Maryland. In $1982,1450 \mathrm{~b}(\mathrm{I})$ was issued with certified values over a limited temperature range and informational values below $255 \mathrm{~K}$. After low-temperature measurements were conducted at Boulder, Colorado, NBS re-issued 1450b(II) with certified values from $100 \mathrm{~K}$ to $330 \mathrm{~K}$. Standard Reference Material 1450c(I) was initially issued in 1997 and was re-issued in 2010 with revised certification values for thermal resistance (1450c(II)).

Although the SRM approach for insulation materials was established in 1978, NBS initiated a formal calibration program [7] for thermal insulation in 1958. The program provided customers with individual calibration measurements of high-density molded fibrous glass insulation board. From 1958 to 1978, NBS provided over 300 pairs [8] of calibrated reference specimens selected from one of four lots of fibrous-glass board, designated by the year of their acquisition $(1958,1959,1961$, and 1970) using the NBS $200 \mathrm{~mm}$ guardedhot-plate apparatus located in Gaithersburg, Maryland. In 1978, the remaining supply of boards was used to establish SRMs 1450 and 1450a [8]. Due to limited stockpiles, 1450 and 1450a were rapidly depleted and two new lots were acquired in 1980 and 1981 for the development of SRM 1450b [9].

\footnotetext{
${ }^{2}$ In 1901, Congress established the National Bureau of Standards (NBS) to support industry, commerce, scientific institutions, and all branches of government. In 1988, as part of the Omnibus Trade and Competitiveness Act, the name was changed to the National Institute of Standards and Technology (NIST) to reflect a broader mission for the agency. For historical accuracy, this report will use, where appropriate, NBS for events prior to 1988.
} 
In 1995, the NIST Standard Reference Materials Program (SRMP) requested that the Building and Fire Research Laboratory initiate a research program to replenish $1450 \mathrm{~b}$ with a new SRM lot, designated 1450c. Because 1450b had been characterized in the early 1980s, a questionnaire to re-assess requirements for a new SRM was disseminated to the user community. Based on the survey responses, NIST procured a new material lot of molded fibrous-glass insulation boards [10] having a nominal bulk density of $160 \mathrm{~kg} \cdot \mathrm{m}^{-3}$ $\left(10 \mathrm{lb} \cdot \mathrm{ft}^{-3}\right)$. In contrast to previous 1450 lots, the procedures for acquisition, testing, and production of $1450 \mathrm{c}$ were modified as described below.

- 130 molded fibrous-glass boards $(1220 \mathrm{~mm}$ by $1220 \mathrm{~mm})$ from a single production run were acquired [10]. After completion of the thermal characterization, the units were cut by NIST SRMP to their final dimensions of $610 \mathrm{~mm} 610 \mathrm{~mm}$.

- Under guidance from the NIST Statistical Engineering Division, a balanced experimental design for temperature and bulk density was developed and implemented for batch certification of the material lot [10].

- Additional measurements and statistical analyses were carried out to assess not only the between-board but also within-board variability for thickness and bulk density.

The planning and research phase for renewal of SRM 1450d began in 2007 when NIST acquired and evaluated two replacement candidates [12]. Additional technical information and requirements were obtained from SRM customers and from an ASTM C16.30 Reference Materials Task Group. Based on this response, the following characteristics for $1450 \mathrm{~d}$ were established [11].

- The nominal bulk density for $1450 \mathrm{~d}$ was specified to be $128 \mathrm{~kg} \cdot \mathrm{m}^{-3}\left(8 \mathrm{lb} \cdot \mathrm{ft}^{-3}\right)$, congruent with the $1450 \mathrm{~b}$ version.

- A single production run of 450 units was stipulated and the vendor was required to trim the boards to a final panel size of $610 \mathrm{~mm}$ by $610 \mathrm{~mm}$ ( 24 in. by $24 \mathrm{in}$.).

- The 1450d experimental design was modified to individually certify the bulk density of each unit, necessitating $100 \%$ sampling of the panels and assigning a unique identification number from 001 to 450 to each panel.

The planning phase for the renewal of SRM 1450e began in 2016 and the characteristics, based on 1450d, were established and summarized below. Details of the certification project design are explained in Sec. 4.

- The nominal bulk density for $1450 \mathrm{e}$ was the same as $1450 \mathrm{~d}, 128 \mathrm{~kg} \cdot \mathrm{m}^{-3}\left(8 \mathrm{lb} \cdot \mathrm{ft}^{-3}\right)$.

- A single production run of 450 units was stipulated and the vendor was required to trim the boards to a final panel size of $610 \mathrm{~mm}$ by $610 \mathrm{~mm}$ ( $24 \mathrm{in}$. by $24 \mathrm{in}$.). For $100 \%$ sampling of the panels, NIST assigned a unique identification number from 500 to 949 to individual panels (differentiating the $1450 \mathrm{e}$ lot from the $1450 \mathrm{~d}$ numbering sequence).

- In an effort to extend the upper temperature certification, the thermal characterization was increased from $340 \mathrm{~K}$ to $360 \mathrm{~K}$ (Table 1). The technical approach for SRM 1450e also considered the effect of gas pressure on the thermal conductivity over a restricted range from $60 \mathrm{kPa}$ to $100 \mathrm{kPa}$. 


\section{Terms and Definitions}

\subsection{Reference Materials}

Section 3.1 provides definitions for reference materials, excerpted verbatim, from Refs. [13-14]. Additional SRM definitions are available at https://www.nist.gov/srm/srm-definitions.

Reference Material (RM): material, sufficiently homogeneous and stable with respect to one or more specified properties, which has been established to be fit for its intended use in a measurement process [14].

NOTE 1 RM is a generic term.

NOTE 2 Properties can be quantitative or qualitative, e.g. identity of substances or species.

NOTE 3 Uses may include the calibration of a measurement system, assessment of a measurement procedure, assigning values to other materials, and quality control.

NOTE 4 ISO/IEC Guide 99:2007 has an analogous definition (5.13), but restricts the term "measurement" to apply to quantitative values. However, Note 3 of ISO/IEC Guide 99:2007, 5.13 (VIM) specifically includes qualitative properties, called "nominal properties".

Certified Reference Material (CRM): Reference material (RM) characterized by a metrologically valid procedure for one or more specified properties, accompanied by an RM certificate that provides the value of the specified property, its associated uncertainty, and a statement of metrological traceability [14].

NOTE 1 The concept of value includes a nominal property or a qualitative attribute such as identity or sequence. Uncertainties for such attributes may be expressed as probabilities or levels of confidence.

NOTE 2 Metrologically valid procedures for the production and certification of RMs are given in, among others, ISO Guides 34 and 35.

NOTE 3 ISO Guide 31 gives guidance on the contents of RM certificates.

NOTE 4 ISO/IEC Guide 99:2007 has an analogous definition (5.14).

NIST Standard Reference Material ${ }^{\circledR}$ (SRM): A CRM issued by NIST that also meets additional NIST-specified certification criteria and is issued with a certificate or certificates of analysis that reports the results of its characterizations and provides information regarding the appropriate use(s) of the material [13]. NOTE: An SRM is prepared and used for three main purposes: (1) to help develop accurate methods of analysis; (2) to calibrate measurement systems used to facilitate exchange of goods, institute quality control, determine performance characteristics, or measure a property at the state-of-the-art limit; and (3) to ensure the long-term adequacy and integrity of measurement quality assurance programs. The terms "Standard Reference Material" and the diamond-shaped logo which contains the term "SRM," are registered with the United States Patent and Trademark Office.

NIST Certified Value: A value reported on an SRM certificate or certificate of analysis for which NIST has the highest confidence in its accuracy in that all known or suspected sources of bias have been fully investigated or accounted for by NIST [13]. 


\subsection{Thermal Insulation}

Section 3.2 provides terms, symbols, definitions, and units pertaining to properties and measurements of thermal insulating materials, excerpted verbatim, from Refs. [1] and [15].

apparent thermal conductivity, $\lambda_{a}$ or $k_{a}$ : a thermal conductivity assigned to a material that exhibits thermal transmission by several modes of heat transfer resulting in property variation with specimen thickness, or surface emittance $\left(S I\right.$ units: $\left(\mathrm{W} / \mathrm{m}^{2}\right) /(\mathrm{K} / \mathrm{m})=$ $\left.\mathrm{W} \cdot \mathrm{m}^{-1} \cdot \mathrm{K}^{-1}\right)[15]$.

NOTE 1 Thermal conductivity and resistivity are normally considered to be intrinsic or specific properties of materials and, as such, should be independent of thickness. When nonconductive modes of heat transfer are present within the specimen (radiation, free convection) this may not be the case. To indicate the possible presence of these phenomena (for example, thickness effect) the modifier "apparent" is used, as in apparent thermal conductivity.

NOTE 2 Test data using the "apparent" modifier must be quoted only for the conditions of the measurement. Values of thermal conductance and thermal resistance calculated from apparent thermal conductivity or resistivity, are valid only for the same conditions.

density, $\rho$ : the mass per unit volume of material. (SI units: $\left.\mathrm{kg} \cdot \mathrm{m}^{-3}\right)$ [15].

NOTE 1 The metered section density, $\rho_{\mathrm{m}}$, or the specimen density, $\rho_{\mathrm{s}}$ where metered section area density cannot be obtained, are to be reported as the average of the two pieces (excerpted from Ref. [1]). The equation for specimen density is the following:

$$
\rho_{\mathrm{s}}=\frac{m_{\mathrm{s}}}{A_{\mathrm{s}} \times L}
$$

where:

$m_{\mathrm{s}}=$ mass of the specimen $(\mathrm{kg})$,

$A_{\mathrm{s}}=$ area of the specimen $\left(\mathrm{m}^{2}\right)$, and

$L=$ specimen thickness $(\mathrm{m})$.

heat flow; heat flow rate, $Q$ : the quantity of heat transferred to or from a system in unit time (W) [15].

NOTE 1 see heat flux for the areal dependence.

NOTE 2 This definition is different from that given in some textbooks, which may use $\dot{Q}$ or $\dot{q}$ to represent heat flow rate. The ISO definition uses $\Phi$.

heat flux, $q$ : the heat flow rate through a surface of unit area perpendicular to the direction of heat flow $\left(\mathrm{W} \cdot \mathrm{m}^{-2}\right)[15]$.

fibrous glass: a synthetic vitreous fiber insulation made by melting predominantly silica sand and other inorganic materials, and then physically forming the melt into fibers [15].

NOTE 1 Commonly referred to as fiber glass.

NOTE 2 To form an insulation product, there are often other materials applied to the fibrous glass such as binders, oils, etc.

thermal conductivity, $\lambda$ : the time rate of steady state heat flow through a unit area of a homogeneous material induced by a unit temperature gradient in a direction perpendicular to that unit area $\left(S I\right.$ units: $\left.\left(\mathrm{W} / \mathrm{m}^{2}\right) /(\mathrm{K} / \mathrm{m})=\mathrm{W} \cdot \mathrm{m}^{-1} \cdot \mathrm{K}^{-1}\right)[15]$.

NOTE 1 Thermal conductivity testing is usually done in one of two apparatus/specimen geometries: flat-slab specimens with parallel heat flux lines, or cylindrical specimens 
with radial heat flux lines. The operational definition of thermal conductivity for flat-slab specimens is given as follows:

$$
\lambda=\frac{Q L}{A \Delta T}
$$

where:

$Q=$ heat flow rate,

$A=$ area through which $Q$ passes, and

$L=$ thickness of the flat-slab specimen across which the temperature difference $\Delta T$ exists

The $\Delta T / L$ ratio approximates the temperature gradient.

thermal resistance, $R$ : the quantity determined by the temperature difference, at steady state, between two defined surfaces of a material or construction that induces a unit heat flow rate through a unit area.

$$
R=\frac{\Delta T}{q}=\frac{L}{\lambda}
$$

A resistance $(R)$ associated with a material shall be specified as a material $R$. A resistance $(R)$ associated with a system or construction shall be specified as a system $R$ ( $R$ in SI units: $\mathrm{K} /\left(\mathrm{W} / \mathrm{m}^{2}\right)=\mathrm{K} \cdot \mathrm{m}^{2} \cdot \mathrm{W}^{-1}[15]$

NOTE 1 Thermal resistance and thermal conductance are multiplicative reciprocals.

thermal transmission properties: those properties of a material or system that define the ability of a material or system to transfer heat such as thermal resistance and thermal conductivity, among others [1].

semi-rigid board insulation: qualitative property associated with the degree of suppleness (i.e., flexibility), particularly related to the geometrical dimensions and bulk density of the board.

\subsection{Uncertainty}

Section 3.3 provides definitions pertaining to measurement uncertainty, excerpted verbatim, from Refs. [16-17].

combined standard uncertainty, $\boldsymbol{u}_{\mathrm{c}}$ : standard uncertainty of the result of a measurement when that result is obtained from the values of a number of other quantities, equal to the positive square root of a sum of terms, the terms being the variances or covariances of these other quantities weighted according to how the measurement result varies with changes in these quantities.

coverage factor, $\boldsymbol{k}$ : numerical factor used as a multiplier of the combined standard uncertainty in order to obtain an expanded uncertainty.

NOTE 1 A coverage factor, $k$, is typically in the range 2 to 3.

expanded uncertainty, $\boldsymbol{U}$ : quantity defining an interval about the result of a measurement that may be expected to encompass a large fraction of the distribution of values that could be reasonably attributed to the measurand.

standard uncertainty, $\boldsymbol{u}_{i}:$ uncertainty of the result of a measurement expressed as standard deviation. 
Type A evaluation (of uncertainty): method of evaluation of uncertainty by the statistical analysis of a series of observations

Type B evaluation (of uncertainty): method of evaluation of uncertainty by means other than the statistical analysis of a series of observations

\section{Certification Project Design}

Section 4 describes the project plan for certification of SRM 1450e beginning with the project definition and scope for intended use. Descriptions of the material, fabrication, and manufacturer controls are presented. The material preparation at NIST covers inspection, storage, and conditioning as part of the overall sampling plan. Lastly, the measurement methods for the homogeneity analysis, certification measurements, and uncertainty evaluation are described.

\subsection{Project Definition and Scope for Intended Use}

The certification project is defined as follows.

The preparation of thermal insulation SRM $1450 \mathrm{e}\left(128 \mathrm{~kg} \cdot \mathrm{m}^{-3}\right)$ for thermal conductivity and thermal resistance measurements with expanded uncertainties $(k=2)$ associated with the certified values of less than or equal to $2 \%$ over a mean temperature range of $280 \mathrm{~K}$ to $360 \mathrm{~K}$ and an atmospheric pressure range of $60 \mathrm{kPa}$ to $100 \mathrm{kPa}$.

Standard Reference Material 1450e is intended for use as a proven check for the guardedhot-plate apparatus [1], or other absolute thermal conductivity apparatus, and for calibration of a heat-flow-meter apparatus [2] over the temperatures $280 \mathrm{~K}$ to $360 \mathrm{~K}$ and barometric pressures from $60 \mathrm{kPa}$ to $101.3 \mathrm{kPa}$ (sea-level pressure). This report cannot exclude the use of SRM 1450e for other purposes, but the user is cautioned that other applications are not necessarily covered by the SRM 1450 e Certificate or by this report. Additional usage issues are covered in Sec. 8 and in the SRM 1450e Certificate (under Instructions for Handling, Storage, And Use).

\subsection{Material}

The material is manufactured in board form consisting of discontinuous glass fibers bonded by a thermosetting resin, typically a phenolic binder formulation. The organic binder restricts the upper temperature of the material to $473 \mathrm{~K}$ [10]. Recent 1450 certificates, however, advise a precautionary upper value of $380 \mathrm{~K}$.

\subsubsection{Fabrication}

The material lot was fabricated by Quiet Core Incorporated over a three-day period in $\mathrm{Au}-$ gust 2017 at their manufacturing facility in Bethlehem, Pennsylvania. Raw material consisting of uncured fibrous-glass insulation, nominally $20 \mathrm{~kg} \cdot \mathrm{m}^{-3}$, was cut, compiled in multiple layers (i.e., pelts) between two metal platens, and molded into boards under pressure and heat. The thickness and bulk density of a board was controlled by the construction and number of pelts in a board. The glass fiber lay for an assembly is characteristically parallel to the long dimensions of the sheet (i.e., perpendicular to the direction of heat flow in application). After removal from the mold, the sheet was cooled and trimmed to finished panels each having a nominal size of $610 \mathrm{~mm}$ by $610 \mathrm{~mm}$.

The technical information for the physical properties of the finished material lot is summarized below: 
- production run time period: 3 days (August 14-16, 2017)

- target bulk density: $\quad 128 \mathrm{~kg} \cdot \mathrm{m}^{-3} \pm 10 \%$

- target thickness: $\quad 25.4 \mathrm{~mm}$

- trimmed panel size: $\quad 610 \mathrm{~mm} \times 610 \mathrm{~mm}$

- approximate mold size : $1321 \mathrm{~mm} \times 2540 \mathrm{~mm}(52 \mathrm{in} . \times 100 \mathrm{in}$.)

- number of molded sheets: 57

- number of panels per sheet: 8

- number of panels: $\quad 450$ (from one lot of material)

- panel color: amber

The number of requested panels was determined based on the number of units required to provide a 10-year inventory for the NIST Office of Reference Materials, plus 30 panels necessary for the thermal characterization of the candidate reference material (Fig. 1).

\subsubsection{Production Control}

The manufacturer implemented the following controls during the production of the material lot.

- Prior to fabrication, incoming uncured rolls having the same nominal density were selected at random and the gram mass per unit area sampled at six pre-determined locations. The mass average and range were computed and checked against required nominal values and range limits for acceptance.

- During the fabrication process, the molded sheets were monitored at regular intervals by control charting measured data for the thickness, mass, and density.

- The control limits for the thickness average and range were determined for a subgroup of four measurements taken from each panel location within a sheet ( 8 panels $\times 4$ measurements per panel $=32$ measurements per sheet). The control limits for the thickness average and range were compared against a specified thickness of $25.4 \mathrm{~mm}$ and range of $0.8 \mathrm{~mm}$, respectively.

- The control limits for the mass and density were determined for each of the panels measured. The control limits for the density average and range were compared against the specified density of $128 \mathrm{~kg} \cdot \mathrm{m}^{-3}$ and tolerance of $\pm 10 \%$.

- During the fabrication process, the individual sheets were inspected visually for any obvious material defects. After the cutting process, the panels were stacked and crated for protection during transport.

\subsection{Delivery, Inspection, and Storage}

The 450 finished panels, comprising the lot of material, were delivered to NIST in August, 2017. An inspection of each panel by NIST personnel revealed that 15 panels were substantially damaged and, later, removed from the lot (Sec. 5.3.6). During the review, an identification number from 500 to 949 was sequentially assigned to each panel, permanently marked in black on one edge with a spray-paint template. The material lot was stored for several months in a laboratory workspace at ambient conditions.

\subsection{Measurement Methods}

The bulk density study required $100 \%$ sampling of the lot of material. The results of the study were used to select a stratified sub-sample for the thermal characterization of the reference material. 


\subsubsection{Sampling Procedure}

The 450 panels were randomly divided into nine groups of 50 panels. Each group of 50 panels was processed through a three-day measurement procedure outlined below.

- Day 1: Convection oven, $100^{\circ} \mathrm{C}$

- The group of 50 panels was placed in a convection oven and heat treated in air at $100{ }^{\circ} \mathrm{C}$ for approximately $19 \mathrm{~h}$.

- Day 2: Mass measurements, $23{ }^{\circ} \mathrm{C}$

- Each panel was removed from the oven and weighed nine times every $20 \mathrm{~s}$ over three minutes at ambient conditions of $23{ }^{\circ} \mathrm{C}$ to establish a mass time history.

- The completion of mass measurements for a group of 50 panels typically required $3.3 \mathrm{~h}$.

- Day 3: Dimensional measurements, $24^{\circ} \mathrm{C}$

- After weighing, the group of 50 panels was placed (in a different randomization sequence order) in another laboratory at ambient conditions of $24{ }^{\circ} \mathrm{C}$ for approximately $21 \mathrm{~h}$.

- The lateral dimensions (length and width) of each panel were measured by one operator and the thickness dimensions of each panel were measured concurrently by another operator.

- The completion of lateral and thickness measurements of a group of 50 panels typically required $1.9 \mathrm{~h}$ and $2.7 \mathrm{~h}$, respectively.

The entire measurement process for all nine groups of 50 panels (450 panels in total) required 36 days.

\subsubsection{Bulk Density}

The bulk density, which is defined in Sec. 3.2, was determined for each finished panel from established gravimetric and dimensional measurement procedures that are documented in Sec. 5. The objective of the bulk density study was to assess the homogeneity of the lot, that is, variability between insulation panels (i.e., material variability), thereby providing empirical data for the following:

- quantitative ranking of the material lot by bulk density;

- the upper and lower bulk density limits of the material lot; and,

- detection of any anomalous thermal insulation panels for possible exclusion.

\subsubsection{Thermal Characterization}

The steady-state thermal transmission measurements (i.e., thermal conductivity) were determined in accordance with ASTM Test Method C 177 [1] using the NIST $500 \mathrm{~mm}$ guarded-hot-plate apparatus [18]. In contrast to the $100 \%$ sampling process for the homogeneity study, the thermal conductivity of SRM 1450e was batch certified. Sub-sampling of the insulation material lot was based on the demonstrated approach taken for the development of the previous version, SRM 1450d [11]. The SRM 1450e lot was sub-sampled at three levels of bulk density (low, mid, and high). Quantitative values for these rankings were defined using the results of the homogeneity study (Sec. 5.3). Detailed procedures of the thermal conductivity study and subsequent analysis of data are documented in Sec. 6 and Sec. 7, respectively. 


\section{Bulk Density Study}

This section describes the mass and dimensional measurements, graphical analyses, and tabulated results for mass, panel area, thickness, and bulk density for the insulation panels.

\subsection{Mass Measurements}

The mass of an insulation panel was determined by the gravimetric method. The measurement station consisted of:

- digital weighing balance (32.1 kg range, $0.0001 \mathrm{~kg}$ resolution);

- foot switch for manual event activation; and,

- RS-232 serial interface for the digital balance and a desktop computer.

Following the sampling procedure in 4.4.1, 50 panels were placed in a large convection oven and conditioned at $100{ }^{\circ} \mathrm{C}$ for approximately $19 \mathrm{~h}$. Each panel was removed and weighed as a function of elapsed time $(\Delta t)$. The start time was synchronized with the specimen removal by means of a foot switch and the mass data, in kilograms, were repeatedly acquired from the digital balance every $20 \mathrm{~s}$ for $180 \mathrm{~s}$ using a computer program.

By measuring the panel mass at equal time intervals and establishing a mass history, the initial mass $\left(m_{0}\right)$ for each panel at time zero $\left(t_{0}\right)$ is determined by regression analysis, thus correcting for the small mass change with time. The mass data were fitted to Eq. (4) using three different computer analysis programs, cross-checked for complete consistency of results.

$$
m(t)=m_{0}+a(\Delta t)
$$

Appendix B provides a graphical analysis of the mass measurements for all 450 insulation panels (500 through 949) and summarizes regression values for $m_{0}$ for each panel.

\subsection{Dimensional Measurements}

After completion of the mass measurements, the 50 panels were placed in a laboratory at ambient conditions of $24{ }^{\circ} \mathrm{C}$ for $21 \mathrm{~h}$. The length, width, and thickness measurements of each group of 50 insulation panels were performed concurrently by two operators under ambient conditions of approximately $24{ }^{\circ} \mathrm{C}$ and $10 \%$ to $30 \%$ relative humidity. The dimensional measurements were derived from basic length measurements using electronic height gages with digital readouts. The datum plane was defined by a large granite surface plate. A touch probe, providing a consistent contact force, was brought in contact with a polished workpiece placed on the insulation panel. The acquired length value, in millimeters, was transferred to a desktop computer by a USB interface cable and recorded in an electronic spreadsheet.

\subsubsection{Lateral Panel Dimensions - Length and Width}

Figure 2 illustrates the essential features of the measurement station for the lateral measurements of a panel, consisting of the following instrumentation:

- $\quad$ granite surface plate (1.2 m by $1.8 \mathrm{~m}$, unilateral flatness tolerance of $0.018 \mathrm{~mm}$ );

- $\quad$ electronic height gage with digital readout (635 $\mathrm{mm}$ range, $0.01 \mathrm{~mm}$ resolution);

- $\quad$ bi-directional touch probe (3 mm diameter carbide ball contact point, $0.4 \mathrm{~N}$ measuring force); and, 
- $\quad$ statistical process control (SPC) data output cable with converter tool to USB communication cable for connection to a desktop computer.

The insulation panel was placed on the granite surface plate in a vertical position and clamped securely between an aluminum sheet and a right-angle support fixture (Fig. 2a). The fixture consisted of an aluminum jig plate $(13 \mathrm{~mm}$ thick by $560 \mathrm{~mm}$ by $560 \mathrm{~mm}$ ) attached to two right angles $(200 \mathrm{~mm}$ by $125 \mathrm{~mm})$. The right angles were precision ground square to within $0.051 \mathrm{~mm}$ (per $150 \mathrm{~mm}$ ) and parallel to within $0.006 \mathrm{~mm}$ (per $150 \mathrm{~mm}$ ). The touch probe measurements were carried out with a round polished gage block as the workpiece in contact with the insulation panel.

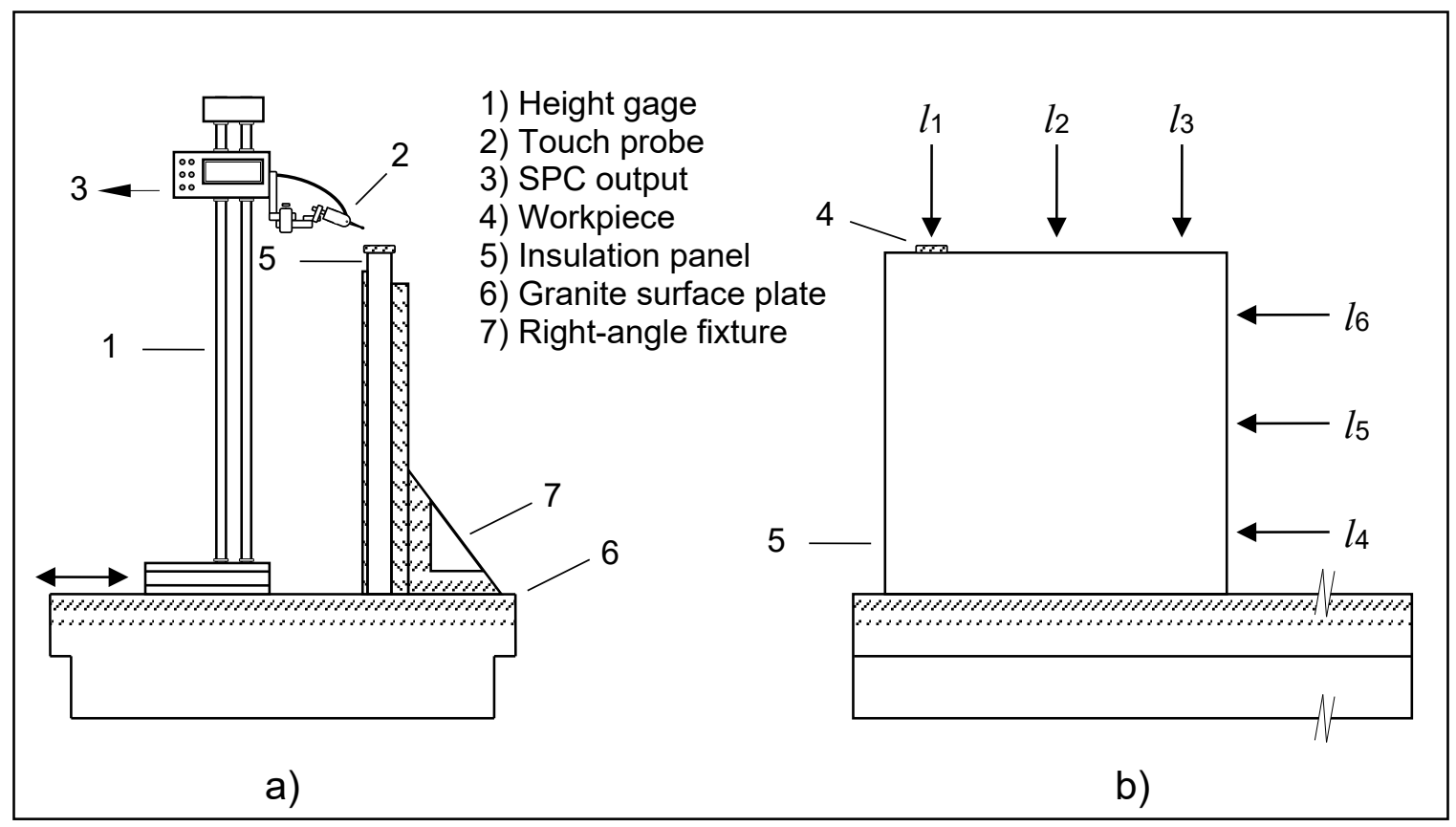

Fig. 2. a) Side view shows height gage and right-angle fixture with insulation panel clamped between the aluminum jig plate and aluminum sheet. b) Front view shows panel length measurements at locations $l_{1}, l_{2}, l_{3}, l_{4}, l_{5}$, and $l_{6}$ (clamp fixture and height gage are not shown).

Prior to measuring each panel, a zero-reference plane for the workpiece was established, and the measurement process was checked, at the beginning and end of the process, using a $609.6 \mathrm{~mm}$ gage standard consisting of two $304.8 \mathrm{~mm}$ (12 in.) gage blocks wrung together. The linear dimensions $l_{1}, l_{2}$, and $l_{3}$ in Fig. 2 were obtained by moving the height gage along the surface plate and contacting the workpiece at each location. Afterwards, the panel was unclamped, rotated $90^{\circ}$ clockwise, and re-clamped to measure $l_{4}, l_{5}$, and $l_{6}$. Pilot testing indicated that data acquired from the two middle locations, $l_{2}$ and $l_{5}$, were sufficient for the determination of bulk density. As a check, however, one panel from each group was selected, at random, for measurements at all locations $\left(l_{1}, l_{2}, l_{3}, l_{4}, l_{5}\right.$, and $\left.l_{6}\right)$.

For nine panels (IDs 542, 571, 619, 641, 684, 755, 759, 879, and 903), the area of the panel $A_{p}$ was computed from Eq. (5). 


$$
A_{\mathrm{p}}=\left(\frac{l_{1}+l_{2}+l_{3}}{3}\right) \times\left(\frac{l_{4}+l_{5}+l_{6}}{3}\right)
$$

The areas $\left(A_{\mathrm{p}}\right)$ of the other panels were computed from Eq. (6).

$$
A_{\mathrm{p}}=l_{2} \times l_{5}
$$

\subsubsection{Thickness}

Figure 3 illustrates the essential features of the measurement station for the thickness measurements of a panel. The measurement station was the same in function as the station for lateral dimensions except a different electronic height gage $(330 \mathrm{~mm}$ range, $0.01 \mathrm{~mm}$ resolution), desktop computer, and connection cable were used. The insulation panel was placed horizontally on the granite surface plate (Fig. 3a). The thickness measurement locations ( $L_{1}, L_{2}, L_{3}, L_{4}, L_{5}, L_{6}, L_{7}$, and $L_{8}$ ), each representing the geometric center of a $203 \mathrm{~mm}$ by $203 \mathrm{~mm}$ subdivision, are shown in Fig. 3b. The thickness and lateral dimensional measurements were conducted concurrently by two operators.

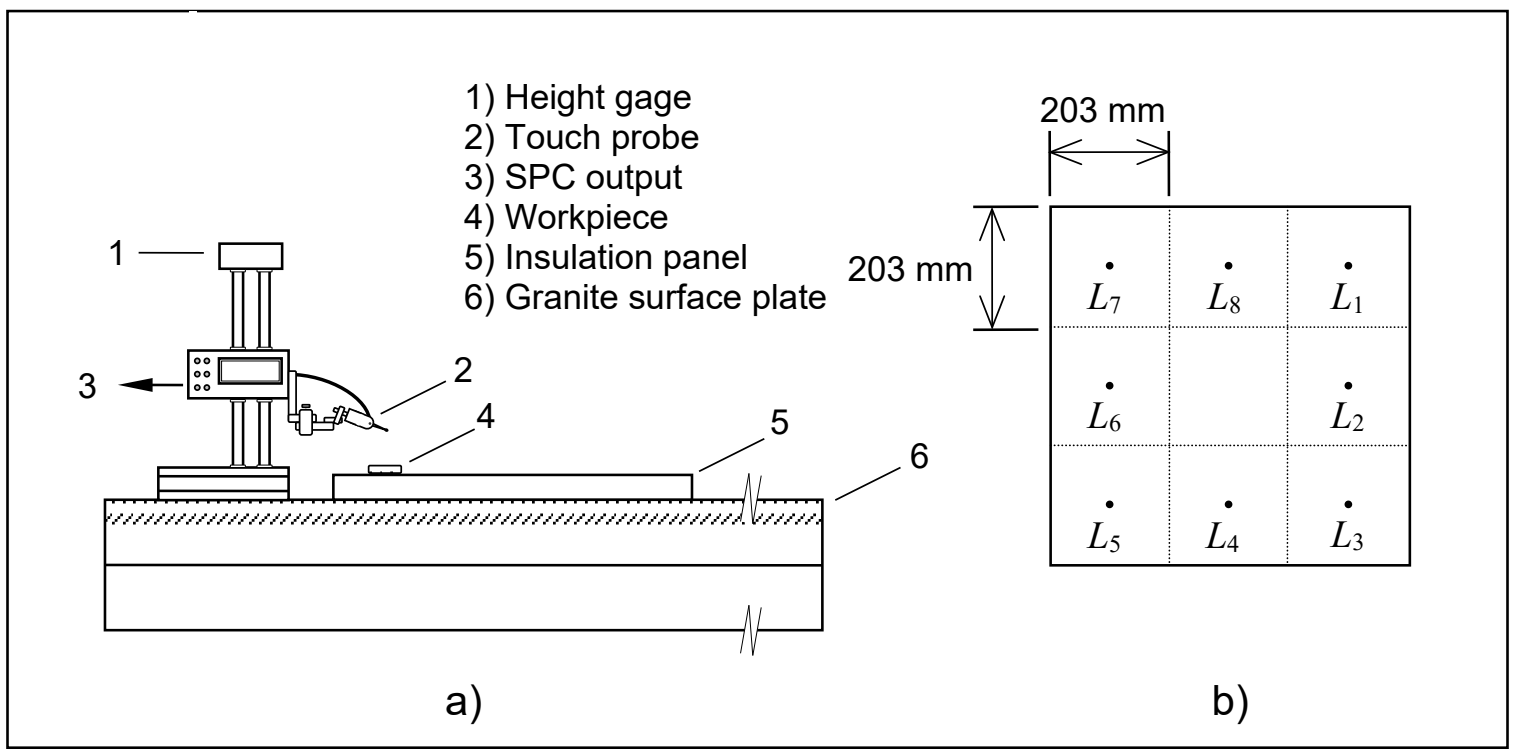

Fig. 3. a) Front view shows $305 \mathrm{~mm}$ height gage and insulation panel, with workpiece, on granite surface plate. b) Top view shows the eight measurement locations ( $L_{1}$ through $\left.L_{8}\right)$ each in the geometric center of a $203 \mathrm{~mm}$ by $203 \mathrm{~mm}$ subdivision of the insulation panel.

Prior to measuring each panel, a zero-reference plane for the workpiece was established, and the measurement process was checked, at the beginning and end of the process, using a $25.4 \mathrm{~mm}$ (1 in.) gage block. For the thickness dimensions, the height gage was stationary, and the panel re-positioned so that the touch probe contacted the workpiece at each measurement location. Based on previous testing for $1450 \mathrm{~d}$ [11], thickness measurements from four locations were sufficient for determination of the bulk density. For each group, onehalf of the panels were measured at the corners $\left(L_{1}, L_{3}, L_{5}\right.$, and $\left.L_{7}\right)$ and the other half, at the mid-centers $\left(L_{2}, L_{4}, L_{6}\right.$, and $\left.L_{8}\right)$. The pattern was sequentially alternated from panel to 
panel. As a check, one panel from each group was selected, at random, for measurements at locations $L_{1}$ through $L_{8}$.

For nine panels (IDs: 542, 571, 619, 641, 684, 755, 759, 879, and 903), the mean thickness of the panel was computed from Eq. (7). The thicknesses of the other panels were computed using either Eq. (8) or Eq. (9).

$$
\begin{gathered}
\bar{L}_{\mathrm{p}}=\left(L_{1}+L_{2}+L_{3}+L_{4}+L_{5}+L_{6}+L_{7}+L_{8}\right) / 8 \\
\bar{L}_{\mathrm{p}}=\left(L_{1}+L_{3}+L_{5}+L_{7}\right) / 4 \\
\bar{L}_{\mathrm{p}}=\left(L_{2}+L_{4}+L_{6}+L_{8}\right) / 4
\end{gathered}
$$

Appendix C provides a graphical analysis of the thickness measurements for all 450 insulation panels.

\subsection{Homogeneity Assessment}

The bulk density for a panel $\left(\rho_{\mathrm{p}}\right)$ was determined from the gravimetric and dimensional measurements of the panel using Eq. (10)

$$
\rho_{\mathrm{p}}=\frac{m_{0}}{A_{\mathrm{p}} \times \bar{L}_{\mathrm{p}}}
$$

where $m_{0}$ is the mass of the panel $(\mathrm{kg})$ from Eq. (4); $A_{p}$ is the area of the panel $\left(\mathrm{m}^{2}\right)$ from Eq. (5) or Eq. (6); and, $\overline{L_{\mathrm{p}}}$ is the average panel thickness (m) from either Eq. (7), Eq. (8), or Eq. (9). The mass and dimensional measurements for the 450 panels (acquired in nine groups of 50 panels) were conducted over 36 days from February 28, 2018 to March 19, 2018. The following aggregate data were collected for the 450 panels.

- 4050 mass measurements ( 9 observations per panel $\times 450$ panels)

- 936 lateral panel dimensions $(2$ observations per panel $\times 441$ panels +6 per panel $\times 9$ panels)

- 1836 thickness dimensions (4 observations per panel $\times 441$ panels +8 per panel $\times$ 9 panels)

\subsubsection{Tabulated Results}

Table 2 summarizes the physical properties of Panel IDs 500 to 949 (450 panels) and includes the quantities: mass $\left(m_{0}\right)$, length $\left(l_{2}\right)$, width $\left(l_{5}\right)$, area $\left(A_{\mathrm{s}}\right)$, thickness $\left(\overline{L_{\mathrm{p}}}\right)$, and bulk density $\left(\rho_{\mathrm{p}}\right)$. For the nine panels on which three measurements for length and width were acquired, the value for $l_{2}$ and $l_{5}$ in Table 2 represent the averages of the three measurements. The values of bulk density presented were rounded to the nearest whole number for certification purposes. 
Table 2. Physical properties of SRM 1450e units (450 panels).

\begin{tabular}{|c|c|c|c|c|c|c|}
\hline $\begin{array}{c}\text { Panel } \\
\text { ID }\end{array}$ & $\begin{array}{c}\text { Mass } \\
\text { (kg) }\end{array}$ & $\begin{array}{c}\text { Length } \\
(\mathrm{mm})\end{array}$ & $\begin{array}{c}\text { Width } \\
\text { (mm) }\end{array}$ & $\begin{array}{c}\text { Area } \\
\left(\mathbf{m}^{2}\right)\end{array}$ & $\begin{array}{c}\text { Thickness } \\
\text { (mm) }\end{array}$ & $\begin{array}{c}\text { Bulk density } \\
\left(\mathrm{kg} \cdot \mathrm{m}^{-3}\right)\end{array}$ \\
\hline 500 & 1.2143 & 613.13 & 610.71 & 0.37445 & 25.17 & 129 \\
\hline 501 & 1.2838 & 608.41 & 610.94 & 0.37170 & 25.19 & 137 \\
\hline 502 & 1.3111 & 612.95 & 610.76 & 0.37437 & 25.05 & 140 \\
\hline 503 & 1.1666 & 610.38 & 608.70 & 0.37154 & 25.24 & 124 \\
\hline 504 & 1.0958 & 613.25 & 610.88 & 0.37462 & 25.14 & 116 \\
\hline 505 & 1.2171 & 608.40 & 610.65 & 0.37152 & 25.13 & 130 \\
\hline 506 & 1.2291 & 608.21 & 610.50 & 0.37131 & 25.31 & 131 \\
\hline 507 & 1.2628 & 613.31 & 610.53 & 0.37444 & 25.14 & 134 \\
\hline 508 & 1.1923 & 610.40 & 608.84 & 0.37164 & 25.08 & 128 \\
\hline 509 & 1.2015 & 610.47 & 612.99 & 0.37421 & 25.24 & 127 \\
\hline 510 & 1.2211 & 610.41 & 608.64 & 0.37152 & 25.40 & 129 \\
\hline 511 & 1.1531 & 610.49 & 612.76 & 0.37408 & 25.17 & 122 \\
\hline 512 & 1.1970 & 608.87 & 610.63 & 0.37179 & 25.51 & 126 \\
\hline 513 & 1.0791 & 613.35 & 610.70 & 0.37457 & 25.21 & 114 \\
\hline 514 & 1.2159 & 608.10 & 609.68 & 0.37075 & 25.26 & 130 \\
\hline 515 & 1.1350 & 614.05 & 610.22 & 0.37471 & 25.14 & 120 \\
\hline 516 & 1.2576 & 609.09 & 609.59 & 0.37130 & 25.23 & 134 \\
\hline 517 & 1.1212 & 611.33 & 609.56 & 0.37264 & 25.04 & 120 \\
\hline 518 & 1.1508 & 609.31 & 610.08 & 0.37173 & 25.25 & 123 \\
\hline 519 & 1.2049 & 610.64 & 609.95 & 0.37246 & 25.35 & 128 \\
\hline 520 & 1.2437 & 609.37 & 609.50 & 0.37141 & 25.30 & 132 \\
\hline 521 & 1.0972 & 610.94 & 609.41 & 0.37231 & 25.18 & 117 \\
\hline 522 & 1.2695 & 610.03 & 609.42 & 0.37176 & 25.56 & 134 \\
\hline 523 & 1.0877 & 610.76 & 610.06 & 0.37260 & 25.42 & 115 \\
\hline 524 & 1.2054 & 609.57 & 609.25 & 0.37138 & 25.12 & 129 \\
\hline 525 & 1.0901 & 609.96 & 610.91 & 0.37263 & 25.03 & 117 \\
\hline 526 & 1.1965 & 609.78 & 610.36 & 0.37219 & 25.56 & 126 \\
\hline 527 & 1.1155 & 611.46 & 609.81 & 0.37287 & 25.16 & 119 \\
\hline 528 & 1.0631 & 610.43 & 610.78 & 0.37284 & 25.24 & 113 \\
\hline 529 & 1.2522 & 609.70 & 610.21 & 0.37205 & 25.28 & 133 \\
\hline 530 & 1.2509 & 609.94 & 609.77 & 0.37192 & 25.45 & 132 \\
\hline 531 & 1.1953 & 610.69 & 609.22 & 0.37205 & 25.14 & 128 \\
\hline 532 & 1.0986 & 609.52 & 609.87 & 0.37173 & 25.25 & 117 \\
\hline 533 & 1.2520 & 610.17 & 610.28 & 0.37238 & 25.46 & 132 \\
\hline 534 & 1.1147 & 608.86 & 610.84 & 0.37192 & 25.06 & 120 \\
\hline 535 & 1.2390 & 610.26 & 610.07 & 0.37230 & 25.47 & 131 \\
\hline 536 & 1.0709 & 609.76 & 610.00 & 0.37195 & 25.16 & 114 \\
\hline 537 & 1.2196 & 609.76 & 609.54 & 0.37167 & 25.13 & 131 \\
\hline 538 & 1.0815 & 609.69 & 609.90 & 0.37185 & 25.26 & 115 \\
\hline 539 & 1.0983 & 609.86 & 609.90 & 0.37195 & 25.28 & 117 \\
\hline 540 & 1.1965 & 609.33 & 609.94 & 0.37166 & 25.47 & 126 \\
\hline 541 & 1.1839 & 609.23 & 610.53 & 0.37195 & 25.66 & 124 \\
\hline 542 & 1.1642 & 609.55 & 610.59 & 0.37219 & 25.22 & 124 \\
\hline 543 & 1.2263 & 609.68 & 609.73 & 0.37174 & 25.08 & 132 \\
\hline 544 & 1.2321 & 610.12 & 609.74 & 0.37202 & 25.38 & 130 \\
\hline 545 & 1.0898 & 609.60 & 609.74 & 0.37170 & 25.33 & 116 \\
\hline 546 & 1.2595 & 609.45 & 609.92 & 0.37172 & 25.70 & 132 \\
\hline 547 & 1.2432 & 609.68 & 609.53 & 0.37162 & 25.44 & 131 \\
\hline 548 & 1.0909 & 610.17 & 609.80 & 0.37208 & 25.10 & 117 \\
\hline 549 & 1.1618 & 609.96 & 609.86 & 0.37199 & 25.18 & 124 \\
\hline 550 & 1.1441 & 610.98 & 608.44 & 0.37175 & 25.02 & 123 \\
\hline 551 & 1.1306 & 611.24 & 613.59 & 0.37505 & 25.10 & 120 \\
\hline
\end{tabular}




\begin{tabular}{|c|c|c|c|c|c|c|}
\hline $\begin{array}{c}\text { Panel } \\
\text { ID }\end{array}$ & $\begin{array}{c}\text { Mass } \\
\text { (kg) }\end{array}$ & $\begin{array}{c}\text { Length } \\
(\mathrm{mm})\end{array}$ & $\begin{array}{l}\text { Width } \\
\text { (mm) }\end{array}$ & $\begin{array}{l}\text { Area } \\
\left(\mathbf{m}^{2}\right)\end{array}$ & $\begin{array}{c}\text { Thickness } \\
\text { (mm) }\end{array}$ & $\begin{array}{c}\text { Bulk density } \\
\left(\mathbf{k g} \cdot \mathrm{m}^{-3}\right)\end{array}$ \\
\hline 552 & 1.1481 & 608.67 & 610.59 & 0.37165 & 25.25 & 122 \\
\hline 553 & 1.1913 & 613.16 & 610.74 & 0.37448 & 25.38 & 125 \\
\hline 554 & 1.0954 & 610.72 & 608.70 & 0.37175 & 25.36 & 116 \\
\hline 555 & 1.0810 & 610.19 & 613.08 & 0.37410 & 25.27 & 114 \\
\hline 556 & 1.1959 & 611.24 & 608.93 & 0.37220 & 25.10 & 128 \\
\hline 557 & 1.1077 & 611.02 & 612.99 & 0.37455 & 25.03 & 118 \\
\hline 558 & 1.1311 & 610.68 & 608.57 & 0.37164 & 25.08 & 121 \\
\hline 559 & 1.2140 & 610.40 & 613.30 & 0.37436 & 25.17 & 129 \\
\hline 560 & 1.1908 & 610.72 & 608.57 & 0.37167 & 25.56 & 125 \\
\hline 561 & 1.1269 & 610.60 & 612.82 & 0.37419 & 25.30 & 119 \\
\hline 562 & 1.1860 & 611.15 & 608.71 & 0.37201 & 25.47 & 125 \\
\hline 563 & 1.1067 & 613.10 & 610.92 & 0.37456 & 25.21 & 117 \\
\hline 564 & 1.2095 & 611.15 & 608.21 & 0.37171 & 25.03 & 130 \\
\hline 565 & 1.1710 & 610.26 & 613.78 & 0.37457 & 25.14 & 124 \\
\hline 566 & 1.2270 & 609.45 & 610.31 & 0.37195 & 25.15 & 131 \\
\hline 567 & 1.0811 & 609.17 & 609.91 & 0.37154 & 25.12 & 116 \\
\hline 568 & 1.2395 & 609.33 & 608.97 & 0.37106 & 25.14 & 133 \\
\hline 569 & 1.1797 & 609.07 & 611.35 & 0.37236 & 25.04 & 127 \\
\hline 570 & 1.0837 & 609.96 & 610.27 & 0.37224 & 25.05 & 116 \\
\hline 571 & 1.0499 & 609.94 & 609.39 & 0.37169 & 25.22 & 112 \\
\hline 572 & 1.1072 & 609.02 & 609.66 & 0.37130 & 25.00 & 119 \\
\hline 573 & 1.1919 & 609.15 & 610.82 & 0.37208 & 25.04 & 128 \\
\hline 574 & 1.1038 & 609.96 & 610.32 & 0.37227 & 25.18 & 118 \\
\hline 575 & 1.2340 & 610.07 & 609.40 & 0.37178 & 25.30 & 131 \\
\hline 576 & 1.2042 & 609.48 & 609.04 & 0.37120 & 25.12 & 129 \\
\hline 577 & 1.1363 & 609.14 & 611.48 & 0.37248 & 25.03 & 122 \\
\hline 578 & 1.2629 & 609.87 & 609.28 & 0.37158 & 25.22 & 135 \\
\hline 579 & 1.1390 & 609.53 & 610.84 & 0.37233 & 25.05 & 122 \\
\hline 580 & 1.1113 & 609.39 & 610.07 & 0.37177 & 25.31 & 118 \\
\hline 581 & 1.2331 & 610.29 & 610.15 & 0.37237 & 25.43 & 130 \\
\hline 582 & 1.2621 & 609.53 & 609.33 & 0.37141 & 25.39 & 134 \\
\hline 583 & 1.1200 & 609.33 & 610.64 & 0.37208 & 25.22 & 119 \\
\hline 584 & 1.2206 & 609.44 & 610.17 & 0.37186 & 25.39 & 129 \\
\hline 585 & 1.1042 & 609.48 & 610.37 & 0.37201 & 24.99 & 119 \\
\hline 586 & 1.2757 & 609.64 & 609.68 & 0.37169 & 25.27 & 136 \\
\hline 587 & 1.1068 & 610.29 & 610.06 & 0.37231 & 25.08 & 119 \\
\hline 588 & 1.1941 & 609.33 & 609.50 & 0.37139 & 25.32 & 127 \\
\hline 589 & 1.2431 & 609.86 & 609.52 & 0.37172 & 25.28 & 132 \\
\hline 590 & 1.1189 & 609.58 & 610.72 & 0.37228 & 25.13 & 120 \\
\hline 591 & 1.1318 & 609.68 & 610.79 & 0.37239 & 25.21 & 121 \\
\hline 592 & 1.1063 & 610.20 & 610.15 & 0.37231 & 25.24 & 118 \\
\hline 593 & 1.1944 & 609.97 & 609.74 & 0.37192 & 25.55 & 126 \\
\hline 594 & 1.2049 & 611.24 & 609.46 & 0.37253 & 25.16 & 129 \\
\hline 595 & 1.1196 & 609.70 & 609.71 & 0.37174 & 25.16 & 120 \\
\hline 596 & 1.2328 & 610.01 & 608.52 & 0.37120 & 25.35 & 131 \\
\hline 597 & 1.0667 & 610.00 & 611.22 & 0.37284 & 25.06 & 114 \\
\hline 598 & 1.1132 & 609.71 & 609.88 & 0.37185 & 24.95 & 120 \\
\hline 599 & 1.2325 & 610.63 & 609.90 & 0.37242 & 25.09 & 132 \\
\hline 600 & 1.1839 & 611.34 & 609.39 & 0.37254 & 25.36 & 125 \\
\hline 601 & 1.1245 & 610.93 & 612.76 & 0.37435 & 25.26 & 119 \\
\hline 602 & 1.0834 & 610.97 & 609.01 & 0.37209 & 25.15 & 116 \\
\hline 603 & 1.2356 & 611.07 & 613.20 & 0.37471 & 25.23 & 131 \\
\hline 604 & 1.2163 & 613.85 & 610.70 & 0.37488 & 25.41 & 128 \\
\hline 605 & 1.1009 & 608.27 & 611.07 & 0.37170 & 25.24 & 117 \\
\hline
\end{tabular}




\begin{tabular}{|c|c|c|c|c|c|c|}
\hline $\begin{array}{l}\text { Panel } \\
\text { ID }\end{array}$ & $\begin{array}{c}\text { Mass } \\
\text { (kg) }\end{array}$ & $\begin{array}{c}\text { Length } \\
(\mathrm{mm})\end{array}$ & $\begin{array}{l}\text { Width } \\
\text { (mm) }\end{array}$ & $\begin{array}{l}\text { Area } \\
\left(\mathbf{m}^{2}\right)\end{array}$ & $\begin{array}{c}\text { Thickness } \\
\text { (mm) }\end{array}$ & $\begin{array}{c}\text { Bulk density } \\
\left(\mathbf{k g} \cdot \mathrm{m}^{-3}\right)\end{array}$ \\
\hline 606 & 1.1269 & 608.93 & 611.00 & 0.37206 & 25.00 & 121 \\
\hline 607 & 1.1974 & 612.96 & 610.90 & 0.37446 & 25.15 & 127 \\
\hline 608 & 1.1333 & 611.06 & 613.32 & 0.37478 & 25.27 & 120 \\
\hline 609 & 1.2127 & 610.56 & 608.74 & 0.37167 & 25.56 & 128 \\
\hline 610 & 1.1830 & 610.61 & 608.77 & 0.37172 & 25.27 & 126 \\
\hline 611 & 1.0681 & 610.64 & 612.64 & 0.37410 & 25.22 & 113 \\
\hline 612 & 1.2048 & 609.42 & 610.70 & 0.37217 & 25.11 & 129 \\
\hline 613 & 1.1222 & 612.42 & 610.99 & 0.37418 & 25.12 & 119 \\
\hline 614 & 1.0838 & 609.01 & 610.67 & 0.37190 & 24.93 & 117 \\
\hline 615 & 1.2133 & 612.92 & 610.77 & 0.37435 & 25.07 & 129 \\
\hline 616 & 1.0739 & 610.04 & 609.65 & 0.37191 & 24.91 & 116 \\
\hline 617 & 1.2220 & 609.97 & 610.12 & 0.37216 & 25.19 & 130 \\
\hline 618 & 1.2166 & 609.64 & 609.29 & 0.37145 & 25.21 & 130 \\
\hline 619 & 1.1462 & 609.58 & 610.86 & 0.37237 & 25.04 & 123 \\
\hline 620 & 1.1967 & 610.14 & 609.77 & 0.37205 & 25.30 & 127 \\
\hline 621 & 1.1995 & 609.98 & 609.85 & 0.37200 & 25.44 & 127 \\
\hline 622 & 1.2408 & 609.50 & 609.70 & 0.37161 & 25.26 & 132 \\
\hline 623 & 1.1873 & 609.63 & 610.61 & 0.37225 & 25.18 & 127 \\
\hline 624 & 1.2334 & 609.82 & 609.78 & 0.37186 & 25.32 & 131 \\
\hline 625 & 1.0681 & 610.18 & 609.89 & 0.37214 & 25.23 & 114 \\
\hline 626 & 1.2083 & 610.31 & 610.12 & 0.37236 & 25.50 & 127 \\
\hline 627 & 1.2090 & 609.84 & 610.01 & 0.37201 & 25.28 & 129 \\
\hline 628 & 1.2655 & 609.58 & 610.11 & 0.37191 & 25.42 & 134 \\
\hline 629 & 1.1139 & 609.96 & 609.98 & 0.37206 & 25.16 & 119 \\
\hline 630 & 1.1798 & 609.99 & 609.71 & 0.37192 & 25.65 & 124 \\
\hline 631 & 1.1458 & 610.11 & 610.22 & 0.37230 & 25.41 & 121 \\
\hline 632 & 1.1690 & 609.32 & 609.65 & 0.37147 & 25.07 & 126 \\
\hline 633 & 1.1131 & 608.58 & 610.69 & 0.37165 & 25.16 & 119 \\
\hline 634 & 1.1969 & 609.24 & 609.94 & 0.37160 & 25.16 & 128 \\
\hline 635 & 1.1516 & 608.89 & 610.49 & 0.37172 & 25.13 & 123 \\
\hline 636 & 1.2124 & 609.66 & 609.98 & 0.37188 & 25.26 & 129 \\
\hline 637 & 1.1165 & 609.57 & 610.52 & 0.37216 & 25.06 & 120 \\
\hline 638 & 1.2292 & 611.30 & 610.13 & 0.37297 & 25.16 & 131 \\
\hline 639 & 1.0821 & 609.74 & 609.74 & 0.37178 & 25.02 & 116 \\
\hline 640 & 1.1022 & 609.58 & 610.72 & 0.37228 & 25.12 & 118 \\
\hline 641 & 1.2236 & 609.94 & 609.65 & 0.37185 & 25.09 & 131 \\
\hline 642 & 1.1348 & 610.81 & 609.94 & 0.37256 & 24.99 & 122 \\
\hline 643 & 1.2552 & 610.43 & 609.73 & 0.37220 & 25.47 & 132 \\
\hline 644 & 1.1348 & 610.77 & 609.99 & 0.37256 & 25.22 & 121 \\
\hline 645 & 1.1900 & 609.85 & 610.07 & 0.37205 & 25.10 & 127 \\
\hline 646 & 1.1848 & 610.00 & 610.19 & 0.37222 & 25.35 & 126 \\
\hline 647 & 1.0461 & 609.94 & 609.35 & 0.37167 & 25.15 & 112 \\
\hline 648 & 1.1125 & 609.93 & 609.74 & 0.37190 & 25.05 & 119 \\
\hline 649 & 1.2090 & 609.81 & 610.44 & 0.37225 & 25.13 & 129 \\
\hline 650 & 1.0931 & 609.17 & 610.78 & 0.37207 & 25.07 & 117 \\
\hline 651 & 1.2037 & 612.86 & 610.89 & 0.37439 & 25.27 & 127 \\
\hline 652 & 1.2684 & 608.49 & 611.24 & 0.37193 & 25.60 & 133 \\
\hline 653 & 1.1543 & 611.71 & 613.62 & 0.37536 & 25.42 & 121 \\
\hline 654 & 1.0428 & 611.08 & 609.73 & 0.37259 & 25.24 & 111 \\
\hline 655 & 1.2361 & 612.65 & 611.56 & 0.37467 & 25.34 & 130 \\
\hline 656 & 1.2216 & 612.92 & 610.89 & 0.37443 & 25.63 & 127 \\
\hline 657 & 1.1126 & 609.00 & 611.14 & 0.37218 & 25.06 & 119 \\
\hline 658 & 1.2353 & 610.82 & 612.66 & 0.37423 & 25.53 & 129 \\
\hline 659 & 1.1370 & 609.19 & 610.79 & 0.37209 & 25.03 & 122 \\
\hline
\end{tabular}




\begin{tabular}{|c|c|c|c|c|c|c|}
\hline $\begin{array}{l}\text { Panel } \\
\text { ID }\end{array}$ & $\begin{array}{l}\text { Mass } \\
\text { (kg) }\end{array}$ & $\begin{array}{c}\text { Length } \\
(\mathrm{mm})\end{array}$ & $\begin{array}{l}\text { Width } \\
\text { (mm) }\end{array}$ & $\begin{array}{c}\text { Area } \\
\left(\mathbf{m}^{2}\right)\end{array}$ & $\begin{array}{c}\text { Thickness } \\
\text { (mm) }\end{array}$ & $\begin{array}{c}\text { Bulk density } \\
\left(\mathbf{k g} \cdot \mathrm{m}^{-3}\right)\end{array}$ \\
\hline 660 & 1.2473 & 610.23 & 609.15 & 0.37172 & 25.29 & 133 \\
\hline 661 & 1.0686 & 610.61 & 612.56 & 0.37404 & 24.95 & 114 \\
\hline 662 & 1.0688 & 607.78 & 610.70 & 0.37117 & 25.10 & 115 \\
\hline 663 & 1.2894 & 614.05 & 610.96 & 0.37516 & 25.28 & 136 \\
\hline 664 & 1.0987 & 608.90 & 611.06 & 0.37207 & 25.35 & 116 \\
\hline 665 & 1.2091 & 613.26 & 611.08 & 0.37475 & 25.77 & 125 \\
\hline 666 & 1.1794 & 609.37 & 610.01 & 0.37172 & 25.43 & 125 \\
\hline 667 & 1.0792 & 610.03 & 609.83 & 0.37202 & 25.29 & 115 \\
\hline 668 & 1.2438 & 609.04 & 610.05 & 0.37155 & 25.58 & 131 \\
\hline 669 & 1.1472 & 610.65 & 610.02 & 0.37251 & 25.34 & 122 \\
\hline 670 & 1.1958 & 609.27 & 609.34 & 0.37125 & 25.01 & 129 \\
\hline 671 & 1.1507 & 609.01 & 611.28 & 0.37228 & 25.06 & 123 \\
\hline 672 & 1.2397 & 609.98 & 609.54 & 0.37181 & 25.42 & 131 \\
\hline 673 & 1.1142 & 609.77 & 610.34 & 0.37217 & 25.24 & 119 \\
\hline 674 & 1.1842 & 609.51 & 609.19 & 0.37131 & 25.08 & 127 \\
\hline 675 & 1.0994 & 610.76 & 609.02 & 0.37197 & 25.21 & 117 \\
\hline 676 & 1.1190 & 609.44 & 611.94 & 0.37294 & 25.10 & 120 \\
\hline 677 & 1.2038 & 609.60 & 609.51 & 0.37156 & 25.09 & 129 \\
\hline 678 & 1.1237 & 610.41 & 609.71 & 0.37217 & 25.29 & 119 \\
\hline 679 & 1.2187 & 610.39 & 611.05 & 0.37298 & 25.36 & 129 \\
\hline 680 & 1.2901 & 609.66 & 610.29 & 0.37207 & 25.39 & 137 \\
\hline 681 & 1.1362 & 610.83 & 609.65 & 0.37239 & 25.15 & 121 \\
\hline 682 & 1.1780 & 609.82 & 609.63 & 0.37177 & 25.62 & 124 \\
\hline 683 & 1.0627 & 609.99 & 610.06 & 0.37213 & 25.34 & 113 \\
\hline 684 & 1.2352 & 609.99 & 609.23 & 0.37162 & 25.52 & 130 \\
\hline 685 & 1.0946 & 609.85 & 610.81 & 0.37250 & 25.21 & 117 \\
\hline 686 & 1.2398 & 609.65 & 610.21 & 0.37202 & 25.76 & 129 \\
\hline 687 & 1.1251 & 610.29 & 609.96 & 0.37225 & 25.26 & 120 \\
\hline 688 & 1.2351 & 610.14 & 609.74 & 0.37203 & 25.36 & 131 \\
\hline 689 & 1.0795 & 610.78 & 610.06 & 0.37261 & 25.17 & 115 \\
\hline 690 & 1.2155 & 609.67 & 610.19 & 0.37202 & 25.58 & 128 \\
\hline 691 & 1.0785 & 610.18 & 610.96 & 0.37280 & 25.31 & 114 \\
\hline 692 & 1.2003 & 610.21 & 610.05 & 0.37226 & 25.63 & 126 \\
\hline 693 & 1.1143 & 609.14 & 609.69 & 0.37139 & 25.40 & 118 \\
\hline 694 & 1.1163 & 610.18 & 609.96 & 0.37219 & 25.63 & 117 \\
\hline 695 & 1.2005 & 609.59 & 609.96 & 0.37183 & 25.91 & 125 \\
\hline 696 & 1.2528 & 610.13 & 609.89 & 0.37211 & 25.49 & 132 \\
\hline 697 & 1.1939 & 609.70 & 609.72 & 0.37175 & 25.26 & 127 \\
\hline 698 & 1.1148 & 609.87 & 609.57 & 0.37176 & 25.28 & 119 \\
\hline 699 & 1.1536 & 609.01 & 610.45 & 0.37177 & 25.17 & 123 \\
\hline 700 & 1.2091 & 610.61 & 608.81 & 0.37175 & 24.98 & 130 \\
\hline 701 & 1.1737 & 610.18 & 612.74 & 0.37388 & 24.98 & 126 \\
\hline 702 & 1.0573 & 608.92 & 611.20 & 0.37217 & 25.00 & 114 \\
\hline 703 & 1.1211 & 612.54 & 610.47 & 0.37394 & 25.01 & 120 \\
\hline 704 & 1.1226 & 609.01 & 610.44 & 0.37176 & 24.99 & 121 \\
\hline 705 & 1.1127 & 612.29 & 610.22 & 0.37363 & 25.13 & 119 \\
\hline 706 & 1.1145 & 611.99 & 610.96 & 0.37390 & 25.39 & 117 \\
\hline 707 & 1.0425 & 610.86 & 609.07 & 0.37206 & 25.48 & 110 \\
\hline 708 & 1.1264 & 612.27 & 610.71 & 0.37392 & 25.43 & 118 \\
\hline 709 & 1.1179 & 610.24 & 609.28 & 0.37181 & 25.19 & 119 \\
\hline 710 & 1.1557 & 610.53 & 608.81 & 0.37170 & 25.02 & 124 \\
\hline 711 & 1.1174 & 610.60 & 612.99 & 0.37429 & 25.13 & 119 \\
\hline 712 & 1.2048 & 610.28 & 608.83 & 0.37156 & 24.94 & 130 \\
\hline 713 & 1.2851 & 609.89 & 612.99 & 0.37386 & 24.98 & 138 \\
\hline
\end{tabular}




\begin{tabular}{|c|c|c|c|c|c|c|}
\hline $\begin{array}{l}\text { Panel } \\
\text { ID }\end{array}$ & $\begin{array}{c}\text { Mass } \\
\text { (kg) }\end{array}$ & $\begin{array}{c}\text { Length } \\
\text { (mm) }\end{array}$ & $\begin{array}{l}\text { Width } \\
\text { (mm) }\end{array}$ & $\begin{array}{c}\text { Area } \\
\left(\mathbf{m}^{2}\right)\end{array}$ & $\begin{array}{c}\text { Thickness } \\
\text { (mm) }\end{array}$ & $\begin{array}{c}\text { Bulk density } \\
\left(\mathbf{k g} \cdot \mathrm{m}^{-3}\right)\end{array}$ \\
\hline 714 & 1.0779 & 610.17 & 608.56 & 0.37133 & 25.32 & 115 \\
\hline 715 & 1.1336 & 610.00 & 612.85 & 0.37384 & 25.06 & 121 \\
\hline 716 & 1.3193 & 610.30 & 608.75 & 0.37152 & 24.99 & 142 \\
\hline 717 & 1.2909 & 610.14 & 613.07 & 0.37406 & 24.94 & 138 \\
\hline 718 & 1.2011 & 610.58 & 609.13 & 0.37192 & 25.52 & 127 \\
\hline 719 & 1.2355 & 609.67 & 612.26 & 0.37328 & 25.30 & 131 \\
\hline 720 & 1.3767 & 609.95 & 608.83 & 0.37136 & 25.33 & 146 \\
\hline 721 & 1.3284 & 609.99 & 612.38 & 0.37355 & 25.35 & 140 \\
\hline 722 & 1.3607 & 610.40 & 609.15 & 0.37183 & 25.21 & 145 \\
\hline 723 & 1.3262 & 609.84 & 613.73 & 0.37428 & 25.14 & 141 \\
\hline 724 & 1.2809 & 610.81 & 608.49 & 0.37167 & 25.13 & 137 \\
\hline 725 & 1.2735 & 612.97 & 610.21 & 0.37404 & 24.96 & 136 \\
\hline 726 & 1.2297 & 610.46 & 608.83 & 0.37167 & 25.46 & 130 \\
\hline 727 & 1.2821 & 610.19 & 612.60 & 0.37380 & 25.27 & 136 \\
\hline 728 & 1.3980 & 610.10 & 609.27 & 0.37172 & 25.12 & 150 \\
\hline 729 & 1.3592 & 609.99 & 611.97 & 0.37330 & 25.30 & 144 \\
\hline 730 & 1.2834 & 610.55 & 608.93 & 0.37178 & 24.93 & 138 \\
\hline 731 & 1.3623 & 609.78 & 613.46 & 0.37408 & 25.08 & 145 \\
\hline 732 & 1.2800 & 610.60 & 608.54 & 0.37158 & 25.09 & 137 \\
\hline 733 & 1.2888 & 610.02 & 613.31 & 0.37413 & 25.08 & 137 \\
\hline 734 & 1.2475 & 610.20 & 608.76 & 0.37147 & 24.97 & 134 \\
\hline 735 & 1.2737 & 610.49 & 613.74 & 0.37468 & 25.12 & 135 \\
\hline 736 & 1.1874 & 610.26 & 608.85 & 0.37156 & 24.93 & 128 \\
\hline 737 & 1.2705 & 610.22 & 614.47 & 0.37496 & 25.05 & 135 \\
\hline 738 & 1.0391 & 610.59 & 608.77 & 0.37171 & 25.30 & 111 \\
\hline 739 & 1.0890 & 609.96 & 612.85 & 0.37381 & 25.18 & 116 \\
\hline 740 & 1.2216 & 610.43 & 608.24 & 0.37129 & 25.11 & 131 \\
\hline 741 & 1.2260 & 610.44 & 614.17 & 0.37491 & 25.26 & 129 \\
\hline 742 & 1.2465 & 608.49 & 610.16 & 0.37128 & 25.04 & 134 \\
\hline 743 & 1.3513 & 610.09 & 612.69 & 0.37380 & 25.44 & 142 \\
\hline 744 & 1.2295 & 608.93 & 610.30 & 0.37163 & 25.08 & 132 \\
\hline 745 & 1.2321 & 613.39 & 610.29 & 0.37435 & 25.04 & 131 \\
\hline 746 & 1.2026 & 611.00 & 608.91 & 0.37204 & 25.41 & 127 \\
\hline 747 & 1.1931 & 610.98 & 612.68 & 0.37434 & 25.23 & 126 \\
\hline 748 & 1.2373 & 610.78 & 608.87 & 0.37189 & 25.18 & 132 \\
\hline 749 & 1.2021 & 610.67 & 612.56 & 0.37407 & 25.26 & 127 \\
\hline 750 & 1.1349 & 613.45 & 610.48 & 0.37450 & 25.04 & 121 \\
\hline 751 & 1.0192 & 609.97 & 613.12 & 0.37399 & 25.03 & 109 \\
\hline 752 & 1.1031 & 610.04 & 609.24 & 0.37166 & 25.24 & 118 \\
\hline 753 & 1.1877 & 611.67 & 609.91 & 0.37306 & 25.43 & 125 \\
\hline 754 & 1.1816 & 610.14 & 609.00 & 0.37158 & 25.21 & 126 \\
\hline 755 & 1.1721 & 612.25 & 610.34 & 0.37368 & 25.22 & 124 \\
\hline 756 & 1.1368 & 608.72 & 611.12 & 0.37200 & 25.09 & 122 \\
\hline 757 & 1.1510 & 612.53 & 610.41 & 0.37389 & 24.99 & 123 \\
\hline 758 & 1.2298 & 609.24 & 612.05 & 0.37289 & 24.99 & 132 \\
\hline 759 & 1.2094 & 610.90 & 612.55 & 0.37420 & 24.94 & 130 \\
\hline 760 & 1.1261 & 609.99 & 609.19 & 0.37160 & 24.96 & 121 \\
\hline 761 & 1.1938 & 610.03 & 611.81 & 0.37322 & 25.20 & 127 \\
\hline 762 & 1.1065 & 610.25 & 608.50 & 0.37134 & 24.89 & 120 \\
\hline 763 & 1.2032 & 610.54 & 612.93 & 0.37422 & 24.94 & 129 \\
\hline 764 & 1.1914 & 609.04 & 610.10 & 0.37158 & 24.89 & 129 \\
\hline 765 & 1.1415 & 610.88 & 612.35 & 0.37407 & 25.10 & 122 \\
\hline 766 & 1.1561 & 609.17 & 610.67 & 0.37200 & 24.99 & 124 \\
\hline 767 & 1.2363 & 609.96 & 612.90 & 0.37384 & 24.97 & 132 \\
\hline
\end{tabular}




\begin{tabular}{|c|c|c|c|c|c|c|}
\hline $\begin{array}{l}\text { Panel } \\
\text { ID }\end{array}$ & $\begin{array}{c}\text { Mass } \\
\text { (kg) }\end{array}$ & $\begin{array}{c}\text { Length } \\
\text { (mm) }\end{array}$ & $\begin{array}{l}\text { Width } \\
\text { (mm) }\end{array}$ & $\begin{array}{c}\text { Area } \\
\left(\mathbf{m}^{2}\right)\end{array}$ & $\begin{array}{c}\text { Thickness } \\
\text { (mm) }\end{array}$ & $\begin{array}{c}\text { Bulk density } \\
\left(\mathbf{k g} \cdot \mathrm{m}^{-3}\right)\end{array}$ \\
\hline 768 & 1.1888 & 610.83 & 613.29 & 0.37462 & 25.06 & 127 \\
\hline 769 & 1.1913 & 610.23 & 608.55 & 0.37136 & 25.02 & 128 \\
\hline 770 & 1.2015 & 610.17 & 608.21 & 0.37111 & 25.04 & 129 \\
\hline 771 & 1.2200 & 610.06 & 613.60 & 0.37433 & 25.03 & 130 \\
\hline 772 & 1.2281 & 610.35 & 611.95 & 0.37350 & 25.29 & 130 \\
\hline 773 & 1.2879 & 609.80 & 609.32 & 0.37156 & 25.09 & 138 \\
\hline 774 & 1.2150 & 610.27 & 608.99 & 0.37165 & 25.34 & 129 \\
\hline 775 & 1.2229 & 610.17 & 612.51 & 0.37374 & 25.12 & 130 \\
\hline 776 & 1.1051 & 610.04 & 608.33 & 0.37111 & 25.00 & 119 \\
\hline 777 & 1.1106 & 610.79 & 613.94 & 0.37499 & 25.25 & 117 \\
\hline 778 & 1.2303 & 610.17 & 607.53 & 0.37070 & 25.00 & 133 \\
\hline 779 & 1.2564 & 610.78 & 615.06 & 0.37567 & 25.05 & 134 \\
\hline 780 & 1.0343 & 608.68 & 610.21 & 0.37142 & 25.26 & 110 \\
\hline 781 & 1.0574 & 612.48 & 610.06 & 0.37365 & 25.10 & 113 \\
\hline 782 & 1.2108 & 608.81 & 610.19 & 0.37149 & 25.19 & 129 \\
\hline 783 & 1.2908 & 613.42 & 610.21 & 0.37432 & 25.15 & 137 \\
\hline 784 & 1.2445 & 608.90 & 610.58 & 0.37178 & 25.10 & 133 \\
\hline 785 & 1.2980 & 612.51 & 610.09 & 0.37369 & 25.16 & 138 \\
\hline 786 & 1.2133 & 608.58 & 610.65 & 0.37163 & 25.15 & 130 \\
\hline 787 & 1.2394 & 612.98 & 610.41 & 0.37417 & 25.09 & 132 \\
\hline 788 & 1.2022 & 609.50 & 610.78 & 0.37227 & 25.37 & 127 \\
\hline 789 & 1.1870 & 611.86 & 610.48 & 0.37353 & 25.32 & 126 \\
\hline 790 & 1.3524 & 609.06 & 610.37 & 0.37175 & 25.35 & 144 \\
\hline 791 & 1.3348 & 612.43 & 611.22 & 0.37433 & 25.46 & 140 \\
\hline 792 & 1.2958 & 610.88 & 609.04 & 0.37205 & 25.44 & 137 \\
\hline 793 & 1.2516 & 610.61 & 612.45 & 0.37397 & 25.29 & 132 \\
\hline 794 & 1.3047 & 610.45 & 608.85 & 0.37167 & 25.15 & 140 \\
\hline 795 & 1.3238 & 610.57 & 613.51 & 0.37459 & 25.18 & 140 \\
\hline 796 & 1.2453 & 610.29 & 608.86 & 0.37158 & 25.14 & 133 \\
\hline 797 & 1.3166 & 610.43 & 612.83 & 0.37409 & 25.38 & 139 \\
\hline 798 & 1.2845 & 610.48 & 608.88 & 0.37171 & 25.20 & 137 \\
\hline 799 & 1.2752 & 610.20 & 612.96 & 0.37403 & 25.15 & 136 \\
\hline 800 & 1.2899 & 612.53 & 610.18 & 0.37375 & 25.22 & 137 \\
\hline 801 & 1.3899 & 610.06 & 609.10 & 0.37159 & 25.30 & 148 \\
\hline 802 & 1.2870 & 610.42 & 608.82 & 0.37164 & 25.10 & 138 \\
\hline 803 & 1.2950 & 612.39 & 609.89 & 0.37349 & 25.14 & 138 \\
\hline 804 & 1.2792 & 610.24 & 608.79 & 0.37151 & 25.35 & 136 \\
\hline 805 & 1.3505 & 612.14 & 610.17 & 0.37351 & 25.90 & 140 \\
\hline 806 & 1.2853 & 610.46 & 608.94 & 0.37173 & 25.16 & 137 \\
\hline 807 & 1.3453 & 610.39 & 612.82 & 0.37406 & 25.32 & 142 \\
\hline 808 & 1.3367 & 608.69 & 610.38 & 0.37153 & 25.24 & 143 \\
\hline 809 & 1.3542 & 610.18 & 612.62 & 0.37381 & 25.06 & 145 \\
\hline 810 & 1.4003 & 607.84 & 610.52 & 0.37110 & 25.94 & 145 \\
\hline 811 & 1.1939 & 610.09 & 609.10 & 0.37161 & 25.01 & 128 \\
\hline 812 & 1.2989 & 610.80 & 614.00 & 0.37503 & 25.11 & 138 \\
\hline 813 & 1.1945 & 612.65 & 610.13 & 0.37380 & 25.04 & 128 \\
\hline 814 & 1.1711 & 612.27 & 610.22 & 0.37362 & 25.11 & 125 \\
\hline 815 & 1.0955 & 609.20 & 609.99 & 0.37161 & 25.14 & 117 \\
\hline 816 & 1.1274 & 612.35 & 610.44 & 0.37380 & 25.11 & 120 \\
\hline 817 & 1.0940 & 609.08 & 610.12 & 0.37161 & 25.05 & 118 \\
\hline 818 & 1.3089 & 608.42 & 610.38 & 0.37137 & 25.02 & 141 \\
\hline 819 & 1.2944 & 612.92 & 609.98 & 0.37387 & 25.06 & 138 \\
\hline 820 & 1.2559 & 608.33 & 610.30 & 0.37126 & 25.14 & 135 \\
\hline 821 & 1.2649 & 612.88 & 610.28 & 0.37403 & 24.95 & 136 \\
\hline
\end{tabular}




\begin{tabular}{|c|c|c|c|c|c|c|}
\hline $\begin{array}{l}\text { Panel } \\
\text { ID }\end{array}$ & $\begin{array}{c}\text { Mass } \\
\text { (kg) }\end{array}$ & $\begin{array}{c}\text { Length } \\
(\mathrm{mm})\end{array}$ & $\begin{array}{l}\text { Width } \\
\text { (mm) }\end{array}$ & $\begin{array}{c}\text { Area } \\
\left(\mathbf{m}^{2}\right)\end{array}$ & $\begin{array}{c}\text { Thickness } \\
\text { (mm) }\end{array}$ & $\begin{array}{c}\text { Bulk density } \\
\left(\mathrm{kg} \cdot \mathrm{m}^{-3}\right)\end{array}$ \\
\hline 822 & 1.3512 & 612.97 & 610.12 & 0.37399 & 25.27 & 143 \\
\hline 823 & 1.2054 & 608.81 & 610.32 & 0.37157 & 25.34 & 128 \\
\hline 824 & 1.2529 & 612.08 & 610.10 & 0.37343 & 25.18 & 133 \\
\hline 825 & 1.3781 & 608.51 & 609.66 & 0.37098 & 25.23 & 147 \\
\hline 826 & 1.3418 & 610.01 & 609.05 & 0.37153 & 25.14 & 144 \\
\hline 827 & 1.2697 & 610.44 & 612.16 & 0.37369 & 25.26 & 135 \\
\hline 828 & 1.3427 & 609.98 & 608.57 & 0.37122 & 25.09 & 144 \\
\hline 829 & 1.3096 & 610.49 & 612.88 & 0.37416 & 25.09 & 140 \\
\hline 830 & 1.2117 & 608.81 & 610.84 & 0.37189 & 25.38 & 128 \\
\hline 831 & 1.2701 & 612.31 & 609.80 & 0.37339 & 25.32 & 134 \\
\hline 832 & 1.3045 & 609.07 & 610.27 & 0.37170 & 25.12 & 140 \\
\hline 833 & 1.2640 & 612.47 & 610.02 & 0.37362 & 25.09 & 135 \\
\hline 834 & 1.2637 & 613.49 & 610.52 & 0.37455 & 25.17 & 134 \\
\hline 835 & 1.1826 & 610.53 & 608.12 & 0.37128 & 25.37 & 126 \\
\hline 836 & 1.3120 & 612.89 & 610.44 & 0.37413 & 24.96 & 140 \\
\hline 837 & 1.2818 & 610.38 & 608.69 & 0.37153 & 25.09 & 138 \\
\hline 838 & 1.2634 & 608.47 & 610.16 & 0.37126 & 25.02 & 136 \\
\hline 839 & 1.2320 & 612.80 & 610.04 & 0.37383 & 25.30 & 130 \\
\hline 840 & 1.2474 & 610.48 & 612.74 & 0.37407 & 25.26 & 132 \\
\hline 841 & 1.2663 & 608.28 & 610.21 & 0.37118 & 25.15 & 136 \\
\hline 842 & 1.2642 & 608.46 & 610.51 & 0.37147 & 25.21 & 135 \\
\hline 843 & 1.3231 & 610.21 & 612.72 & 0.37389 & 25.13 & 141 \\
\hline 844 & 1.2549 & 610.58 & 608.79 & 0.37172 & 24.92 & 135 \\
\hline 845 & 1.2709 & 610.39 & 609.14 & 0.37181 & 25.05 & 136 \\
\hline 846 & 1.2566 & 609.10 & 610.12 & 0.37162 & 25.14 & 134 \\
\hline 847 & 1.3084 & 610.45 & 612.68 & 0.37401 & 25.01 & 140 \\
\hline 848 & 1.2754 & 611.29 & 610.42 & 0.37314 & 25.28 & 135 \\
\hline 849 & 1.2886 & 612.77 & 611.73 & 0.37485 & 25.04 & 137 \\
\hline 850 & 1.1986 & 609.91 & 608.93 & 0.37139 & 25.12 & 128 \\
\hline 851 & 1.2540 & 612.17 & 610.27 & 0.37359 & 25.36 & 132 \\
\hline 852 & 1.1572 & 609.84 & 608.82 & 0.37128 & 25.42 & 123 \\
\hline 853 & 1.1283 & 612.01 & 610.08 & 0.37338 & 25.10 & 120 \\
\hline 854 & 1.2418 & 608.81 & 610.19 & 0.37149 & 25.09 & 133 \\
\hline 855 & 1.2963 & 610.40 & 612.52 & 0.37388 & 25.09 & 138 \\
\hline 856 & 1.2013 & 609.08 & 610.20 & 0.37166 & 25.24 & 128 \\
\hline 857 & 1.2644 & 610.44 & 612.30 & 0.37377 & 25.37 & 133 \\
\hline 858 & 1.3213 & 609.98 & 608.91 & 0.37142 & 25.23 & 141 \\
\hline 859 & 1.3770 & 612.42 & 610.47 & 0.37386 & 25.39 & 145 \\
\hline 860 & 1.2756 & 610.14 & 608.10 & 0.37103 & 25.44 & 135 \\
\hline 861 & 1.2280 & 612.96 & 609.83 & 0.37380 & 25.29 & 130 \\
\hline 862 & 1.0286 & 610.58 & 609.05 & 0.37187 & 25.15 & 110 \\
\hline 863 & 1.1286 & 608.73 & 610.42 & 0.37158 & 25.16 & 121 \\
\hline 864 & 1.1171 & 612.84 & 610.38 & 0.37407 & 25.00 & 119 \\
\hline 865 & 1.0910 & 608.82 & 610.45 & 0.37165 & 24.99 & 117 \\
\hline 866 & 1.1855 & 608.89 & 609.91 & 0.37137 & 25.28 & 126 \\
\hline 867 & 1.1416 & 612.46 & 610.20 & 0.37372 & 25.01 & 122 \\
\hline 868 & 1.2851 & 612.96 & 610.48 & 0.37420 & 25.03 & 137 \\
\hline 869 & 1.2729 & 608.70 & 610.09 & 0.37136 & 25.08 & 137 \\
\hline 870 & 1.2275 & 608.94 & 610.24 & 0.37160 & 24.89 & 133 \\
\hline 871 & 1.2473 & 612.65 & 610.27 & 0.37388 & 24.94 & 134 \\
\hline 872 & 1.3339 & 609.06 & 609.80 & 0.37141 & 25.06 & 143 \\
\hline 873 & 1.3321 & 612.06 & 610.00 & 0.37336 & 25.17 & 142 \\
\hline 874 & 1.2848 & 608.91 & 610.06 & 0.37147 & 25.30 & 137 \\
\hline 875 & 1.2625 & 612.24 & 610.36 & 0.37369 & 25.05 & 135 \\
\hline
\end{tabular}




\begin{tabular}{|c|c|c|c|c|c|c|}
\hline $\begin{array}{l}\text { Panel } \\
\text { ID }\end{array}$ & $\begin{array}{c}\text { Mass } \\
\text { (kg) }\end{array}$ & $\begin{array}{c}\text { Length } \\
\text { (mm) }\end{array}$ & $\begin{array}{l}\text { Width } \\
\text { (mm) }\end{array}$ & $\begin{array}{c}\text { Area } \\
\left(\mathbf{m}^{2}\right)\end{array}$ & $\begin{array}{c}\text { Thickness } \\
\text { (mm) }\end{array}$ & $\begin{array}{c}\text { Bulk density } \\
\left(\mathrm{kg}^{\prime} \cdot \mathrm{m}^{-3}\right)\end{array}$ \\
\hline 876 & 1.2221 & 610.84 & 608.79 & 0.37187 & 25.29 & 130 \\
\hline 877 & 1.2248 & 609.84 & 612.54 & 0.37355 & 25.21 & 130 \\
\hline 878 & 1.3193 & 610.28 & 609.26 & 0.37182 & 25.08 & 141 \\
\hline 879 & 1.2783 & 611.02 & 612.73 & 0.37439 & 25.27 & 135 \\
\hline 880 & 1.2573 & 608.68 & 609.94 & 0.37126 & 24.96 & 136 \\
\hline 881 & 1.2818 & 613.57 & 610.22 & 0.37441 & 25.10 & 136 \\
\hline 882 & 1.2651 & 609.85 & 610.24 & 0.37216 & 25.19 & 135 \\
\hline 883 & 1.2899 & 612.46 & 610.01 & 0.37361 & 25.07 & 138 \\
\hline 884 & 1.3084 & 613.53 & 610.29 & 0.37443 & 25.01 & 140 \\
\hline 885 & 1.2040 & 608.50 & 610.35 & 0.37140 & 24.97 & 130 \\
\hline 886 & 1.2444 & 607.97 & 610.04 & 0.37089 & 25.09 & 134 \\
\hline 887 & 1.2800 & 613.76 & 610.46 & 0.37468 & 24.96 & 137 \\
\hline 888 & 1.0696 & 610.14 & 607.81 & 0.37085 & 25.20 & 114 \\
\hline 889 & 1.1423 & 610.28 & 613.14 & 0.37419 & 25.16 & 121 \\
\hline 890 & 1.2725 & 610.02 & 608.46 & 0.37117 & 25.03 & 137 \\
\hline 891 & 1.2792 & 610.40 & 612.80 & 0.37405 & 25.22 & 136 \\
\hline 892 & 1.2252 & 613.22 & 610.85 & 0.37459 & 25.13 & 130 \\
\hline 893 & 1.2924 & 609.19 & 610.66 & 0.37201 & 25.01 & 139 \\
\hline 894 & 1.2903 & 612.81 & 610.96 & 0.37440 & 25.07 & 137 \\
\hline 895 & 1.2758 & 611.65 & 608.97 & 0.37248 & 25.11 & 136 \\
\hline 896 & 1.2493 & 610.92 & 612.52 & 0.37420 & 25.42 & 131 \\
\hline 897 & 1.2487 & 610.55 & 609.37 & 0.37205 & 25.24 & 133 \\
\hline 898 & 1.2564 & 610.56 & 612.62 & 0.37404 & 25.35 & 133 \\
\hline 899 & 1.2515 & 610.24 & 609.15 & 0.37173 & 25.03 & 134 \\
\hline 900 & 1.2305 & 608.68 & 610.35 & 0.37151 & 25.08 & 132 \\
\hline 901 & 1.2677 & 609.95 & 609.09 & 0.37151 & 25.12 & 136 \\
\hline 902 & 1.2202 & 612.10 & 610.28 & 0.37355 & 25.35 & 129 \\
\hline 903 & 1.2468 & 610.09 & 608.83 & 0.37144 & 25.10 & 134 \\
\hline 904 & 1.3496 & 612.19 & 610.26 & 0.37360 & 25.15 & 144 \\
\hline 905 & 1.2547 & 610.42 & 608.98 & 0.37173 & 25.09 & 135 \\
\hline 906 & 1.3728 & 612.37 & 610.44 & 0.37382 & 25.17 & 146 \\
\hline 907 & 1.2670 & 610.34 & 608.82 & 0.37159 & 25.19 & 135 \\
\hline 908 & 1.2836 & 610.10 & 608.69 & 0.37136 & 25.34 & 136 \\
\hline 909 & 1.3282 & 612.53 & 610.28 & 0.37382 & 25.54 & 139 \\
\hline 910 & 1.2517 & 610.17 & 608.49 & 0.37128 & 25.44 & 133 \\
\hline 911 & 1.1908 & 610.38 & 613.69 & 0.37458 & 25.16 & 126 \\
\hline 912 & 1.1459 & 610.70 & 612.50 & 0.37405 & 25.13 & 122 \\
\hline 913 & 1.1798 & 612.48 & 610.35 & 0.37383 & 25.03 & 126 \\
\hline 914 & 1.2010 & 608.86 & 610.30 & 0.37159 & 25.19 & 128 \\
\hline 915 & 1.1716 & 610.67 & 612.45 & 0.37401 & 25.08 & 125 \\
\hline 916 & 1.1999 & 610.45 & 611.96 & 0.37357 & 25.32 & 127 \\
\hline 917 & 1.1939 & 610.57 & 609.05 & 0.37187 & 25.50 & 126 \\
\hline 918 & 1.1892 & 611.74 & 610.29 & 0.37334 & 25.29 & 126 \\
\hline 919 & 1.3409 & 610.06 & 609.13 & 0.37161 & 25.26 & 143 \\
\hline 920 & 1.2255 & 611.90 & 610.51 & 0.37357 & 25.36 & 129 \\
\hline 921 & 1.2762 & 608.97 & 610.26 & 0.37163 & 25.15 & 137 \\
\hline 922 & 1.2639 & 608.52 & 610.02 & 0.37121 & 25.25 & 135 \\
\hline 923 & 1.2104 & 610.58 & 612.78 & 0.37415 & 25.34 & 128 \\
\hline 924 & 1.1051 & 608.96 & 609.82 & 0.37136 & 25.31 & 118 \\
\hline 925 & 1.2767 & 610.41 & 612.38 & 0.37380 & 26.42 & 129 \\
\hline 926 & 1.2763 & 610.69 & 612.11 & 0.37381 & 25.31 & 135 \\
\hline 927 & 1.2131 & 612.48 & 610.41 & 0.37386 & 25.19 & 129 \\
\hline 928 & 1.2186 & 612.61 & 610.43 & 0.37396 & 25.19 & 129 \\
\hline 929 & 1.3198 & 608.76 & 611.28 & 0.37212 & 25.38 & 140 \\
\hline
\end{tabular}




\begin{tabular}{ccccccc}
\hline $\begin{array}{c}\text { Panel } \\
\text { ID }\end{array}$ & $\begin{array}{c}\text { Mass } \\
(\mathbf{k g})\end{array}$ & $\begin{array}{c}\text { Length } \\
(\mathbf{m m})\end{array}$ & $\begin{array}{c}\text { Width } \\
(\mathbf{m m})\end{array}$ & $\begin{array}{c}\text { Area } \\
\left(\mathbf{m}^{\mathbf{2}}\right)\end{array}$ & $\begin{array}{c}\text { Thickness } \\
(\mathbf{m m})\end{array}$ & $\begin{array}{c}\text { Bulk density } \\
\left(\mathbf{k g} \cdot \mathbf{m}^{-3}\right)\end{array}$ \\
\hline 930 & 1.3328 & 612.63 & 610.88 & 0.37424 & 25.32 & 141 \\
931 & 1.2586 & 608.75 & 610.22 & 0.37147 & 25.37 & 134 \\
932 & 1.2841 & 613.18 & 611.19 & 0.37477 & 25.30 & 135 \\
933 & 1.2448 & 610.15 & 608.99 & 0.37158 & 25.05 & 134 \\
934 & 1.1353 & 608.85 & 610.15 & 0.37149 & 25.29 & 121 \\
935 & 1.2008 & 610.30 & 612.70 & 0.37393 & 25.17 & 128 \\
936 & 1.2372 & 608.99 & 610.06 & 0.37152 & 25.25 & 132 \\
937 & 1.2058 & 612.69 & 610.77 & 0.37421 & 25.24 & 128 \\
938 & 1.1966 & 610.19 & 609.00 & 0.37161 & 25.40 & 127 \\
939 & 1.2365 & 608.50 & 610.21 & 0.37131 & 25.02 & 133 \\
940 & 1.2506 & 608.81 & 610.07 & 0.37142 & 25.13 & 134 \\
941 & 1.2717 & 610.66 & 612.14 & 0.37381 & 25.20 & 135 \\
942 & 1.2540 & 609.00 & 610.00 & 0.37149 & 25.20 & 134 \\
943 & 1.2197 & 610.46 & 612.06 & 0.37364 & 25.24 & 129 \\
944 & 1.3372 & 610.14 & 608.18 & 0.37108 & 25.75 & 140 \\
945 & 1.2320 & 608.89 & 610.08 & 0.37147 & 25.19 & 132 \\
946 & 1.1883 & 612.91 & 610.56 & 0.37422 & 25.08 & 127 \\
947 & 1.2586 & 608.98 & 610.47 & 0.37176 & 25.35 & 134 \\
948 & 1.1452 & 610.50 & 612.83 & 0.37413 & 25.19 & 122 \\
949 & 1.2661 & 613.53 & 610.57 & 0.37460 & 25.15 & 134 \\
\hline
\end{tabular}

\subsubsection{Graphical Analyses}

The quantities in Table 2 - mass, length, width, area, thickness, and bulk density - were subjected to a four step graphical analysis to investigate the homogeneity of the material lot (i.e., between-panel results). For each set of data, the graphical analysis verified the underlying assumptions [19] of an ideal measurement process: a) stability, that is, fixed location and variation, b) randomness, and c) normality. It should be noted that initial diagnostic checks, using similar graphical data analyses (not presented), were applied to each group (50 panels) of data immediately after measurement completion to verify that measurement process was in control.

Figures 4 through 9 illustrate the four step graphical analysis [20] for panel mass $\left(m_{0}\right)$, length $\left(l_{2}\right)$, width $\left(l_{5}\right)$, area $\left(A_{\mathrm{p}}\right)$, thickness $\left(L_{\mathrm{p}}\right)$, and bulk density $\left(\rho_{\mathrm{p}}\right)$, respectively, for the 450 panels. Each figure consists of 4 plots: a) run-sequence plot; b) lag plot; c) histogram; and d) normality plot. The four-step method was applied for verification of the four characteristics indicating statistical control of a process.

1) Run sequence plot plots values in the order obtained versus a sequence surrogate index $\left(x_{i}\right.$ versus $\left.i\right)$ and checks for systematic and random changes.

2) Lag plot plots adjacent values ( $x_{i}$ versus $x_{i-1}$ ) and also checks for randomness (specifically, lack of autocorrelation).

3) A histogram of values $\left(x_{i}\right)$ checks the frequency distribution.

4) Normal probability plot of values (of $x_{i}$ ) checks the normality assumption. 

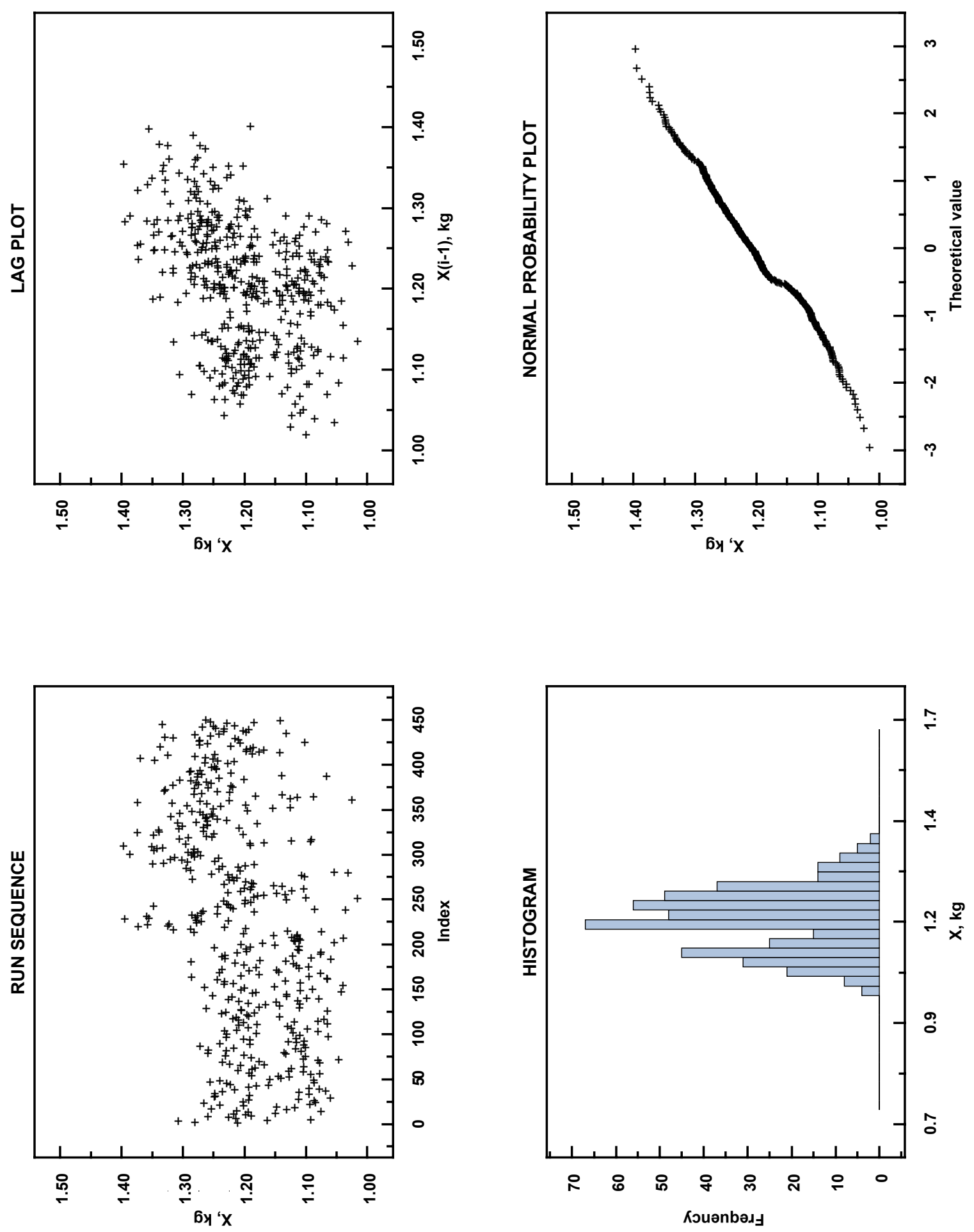

Fig. 4. a) Graphical analysis of panel mass $(n=450)$ : (a) run sequence plot, (b) lag plot, (c) histogram, (d) normal probability plot (normality index). Summary statistics: mean = $1.2059 \mathrm{~kg}$, standard deviation $=0.0784 \mathrm{~kg}$, range $=0.3811 \mathrm{~kg}$. 

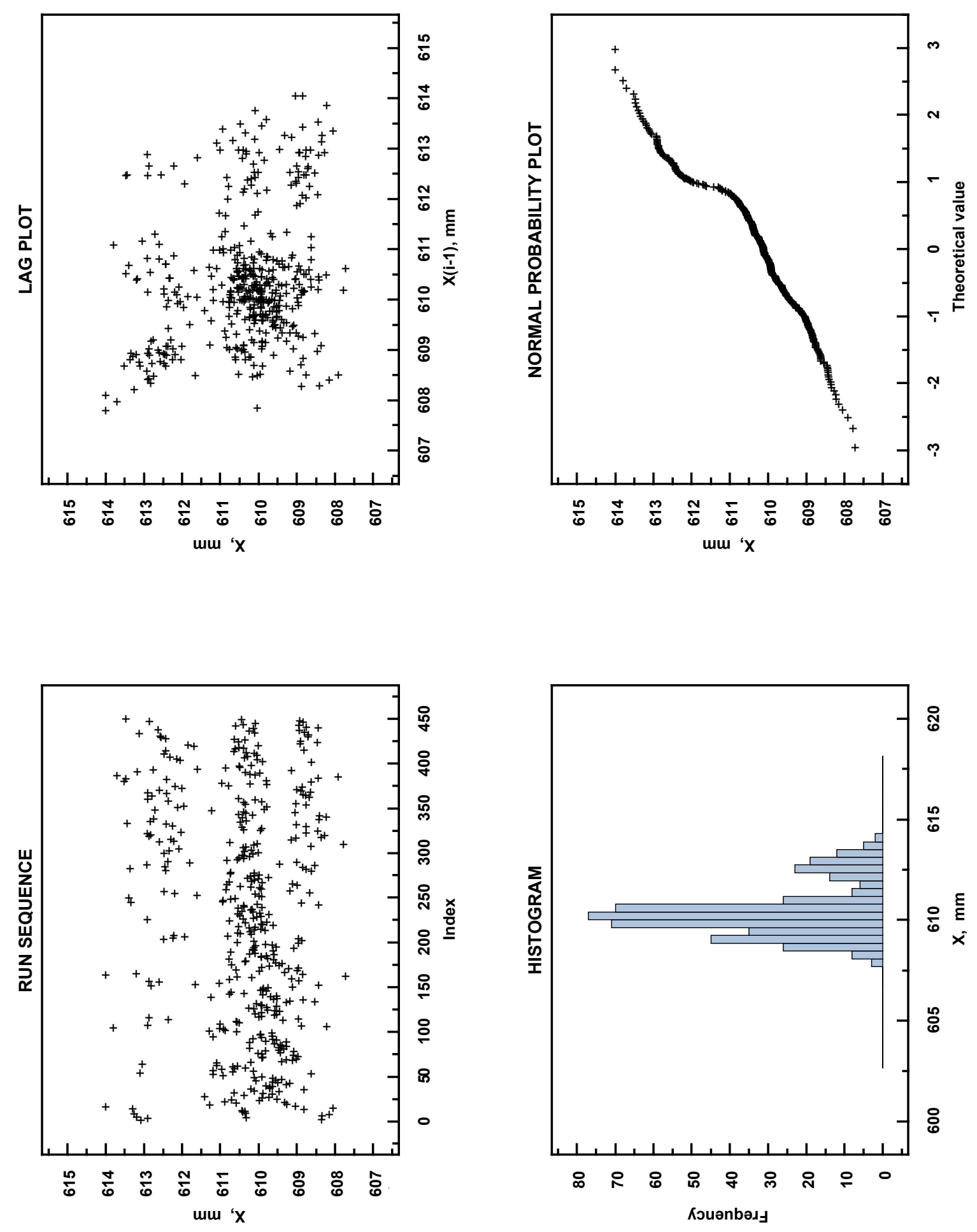

Fig. 5. a) Graphical analysis of panel length $(n=450)$ : (a) run sequence plot, (b) lag plot, (c) histogram, (d) normal probability plot (normality index). Summary statistics: mean = $610.40 \mathrm{~mm}$, standard deviation $=1.30 \mathrm{~mm}$, range $=6.27 \mathrm{~mm}$. 

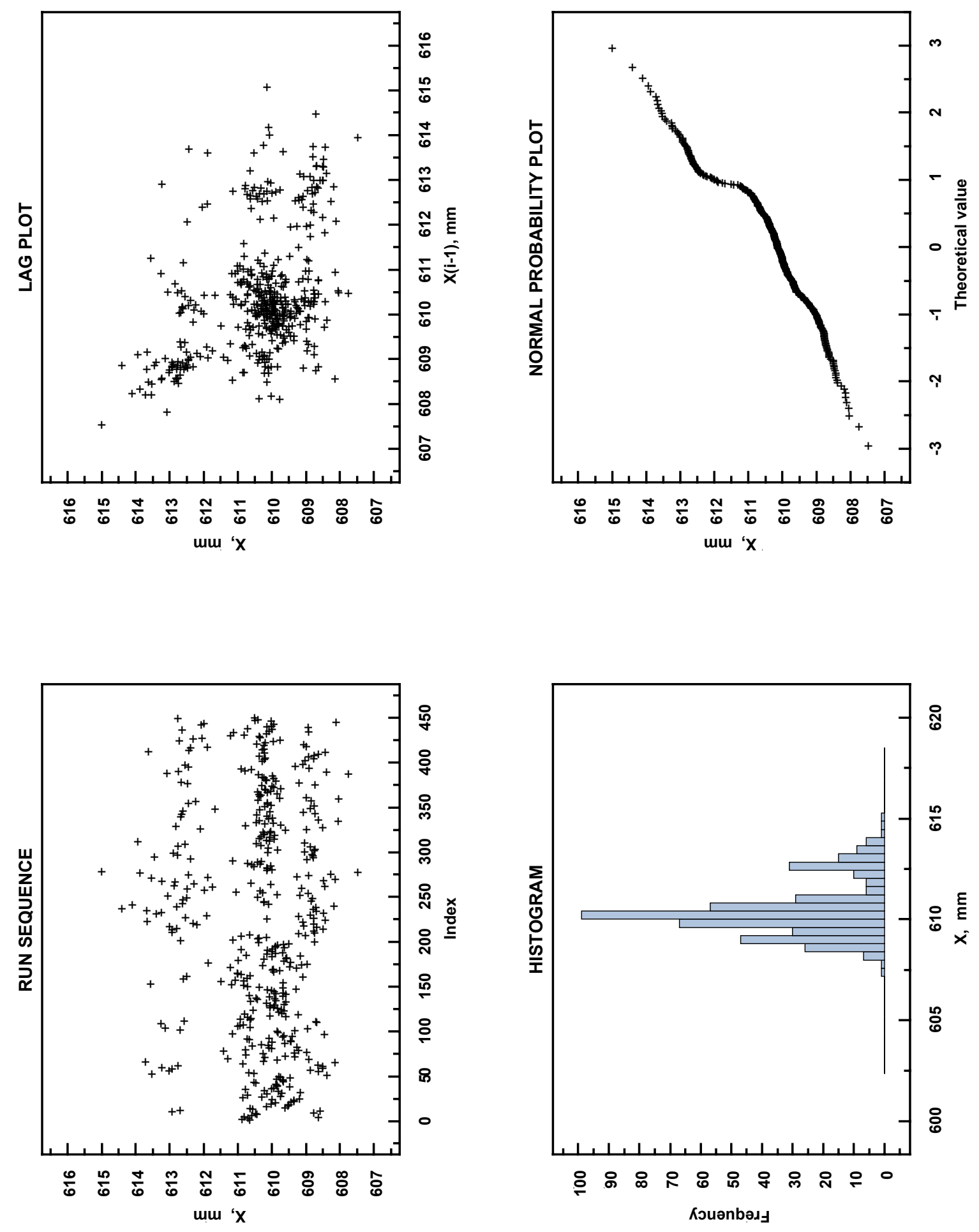

Fig. 6. a) Graphical analysis of panel width $(n=450)$ : (a) run sequence plot, (b) lag plot, (c) histogram, (d) normal probability plot (normality index). Summary statistics: mean = $610.42 \mathrm{~mm}$, standard deviation $=1.35 \mathrm{~mm}$, range $=7.53 \mathrm{~mm}$. 

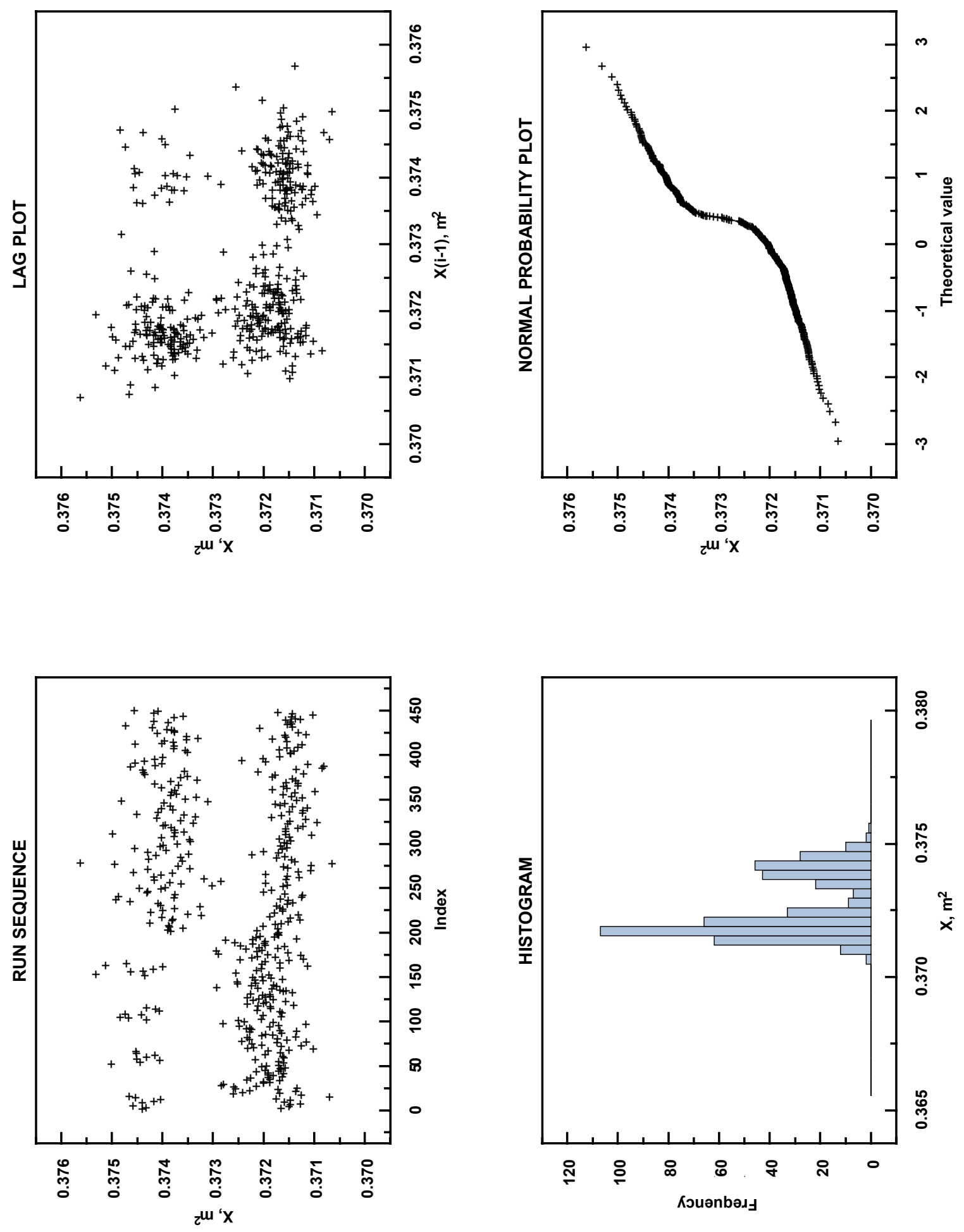

Fig. 7. a) Graphical analysis of panel area $(n=450)$ : (a) run sequence plot, (b) lag plot, (c) histogram, (d) normal probability plot (normality index). Summary statistics: mean = $0.37260 \mathrm{~m}^{2}$, standard deviation $=0.00118 \mathrm{~m}^{2}$, range $=0.00497 \mathrm{~m}^{2}$. 

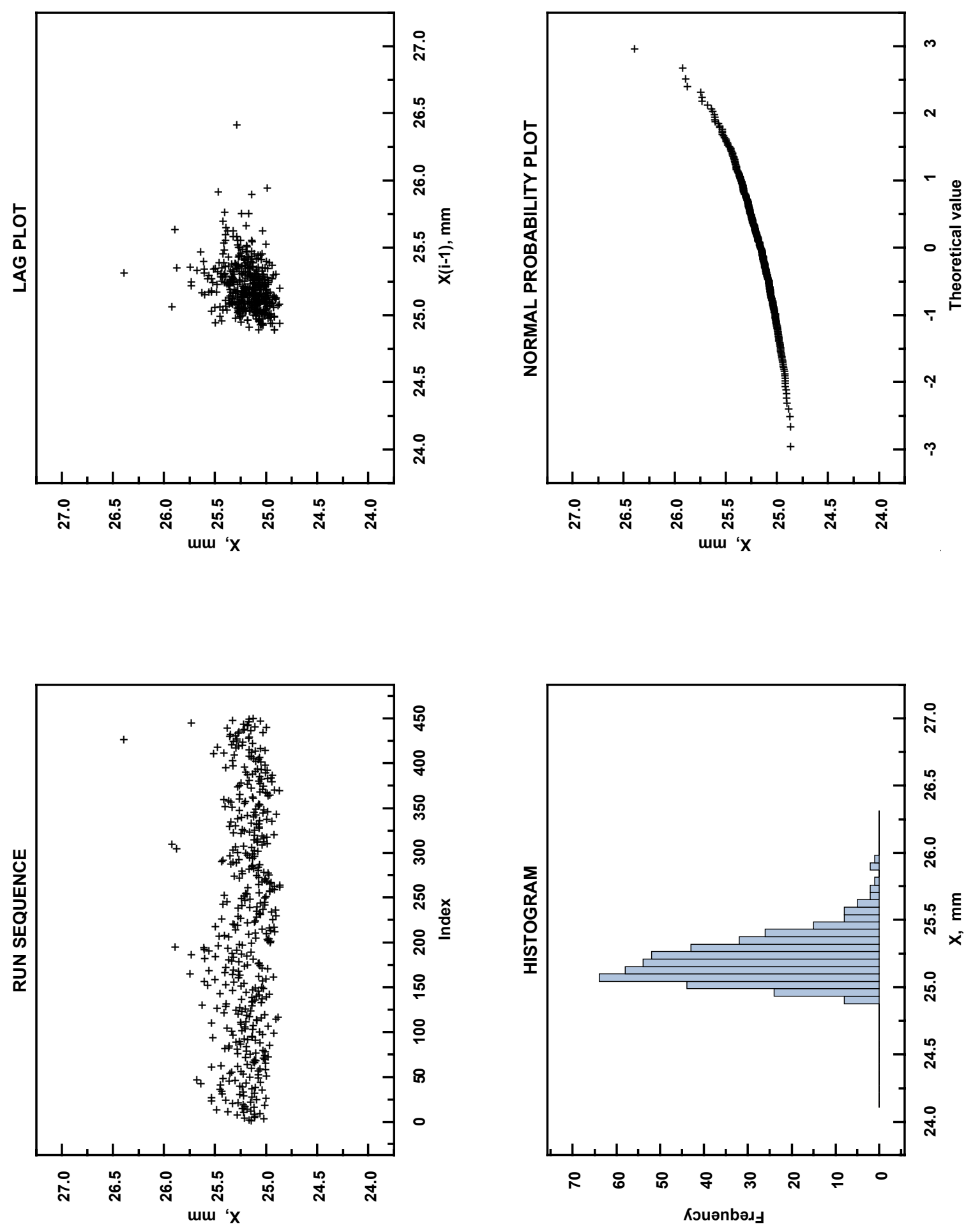

Fig. 8. a) Graphical analysis of panel thickness $(n=450)$ : (a) run sequence plot, (b) lag plot, (c) histogram, (d) normal probability plot (normality index). Summary statistics: mean $=25.21 \mathrm{~mm}$, standard deviation $=0.18 \mathrm{~mm}$, range $=1.53 \mathrm{~mm}$. 

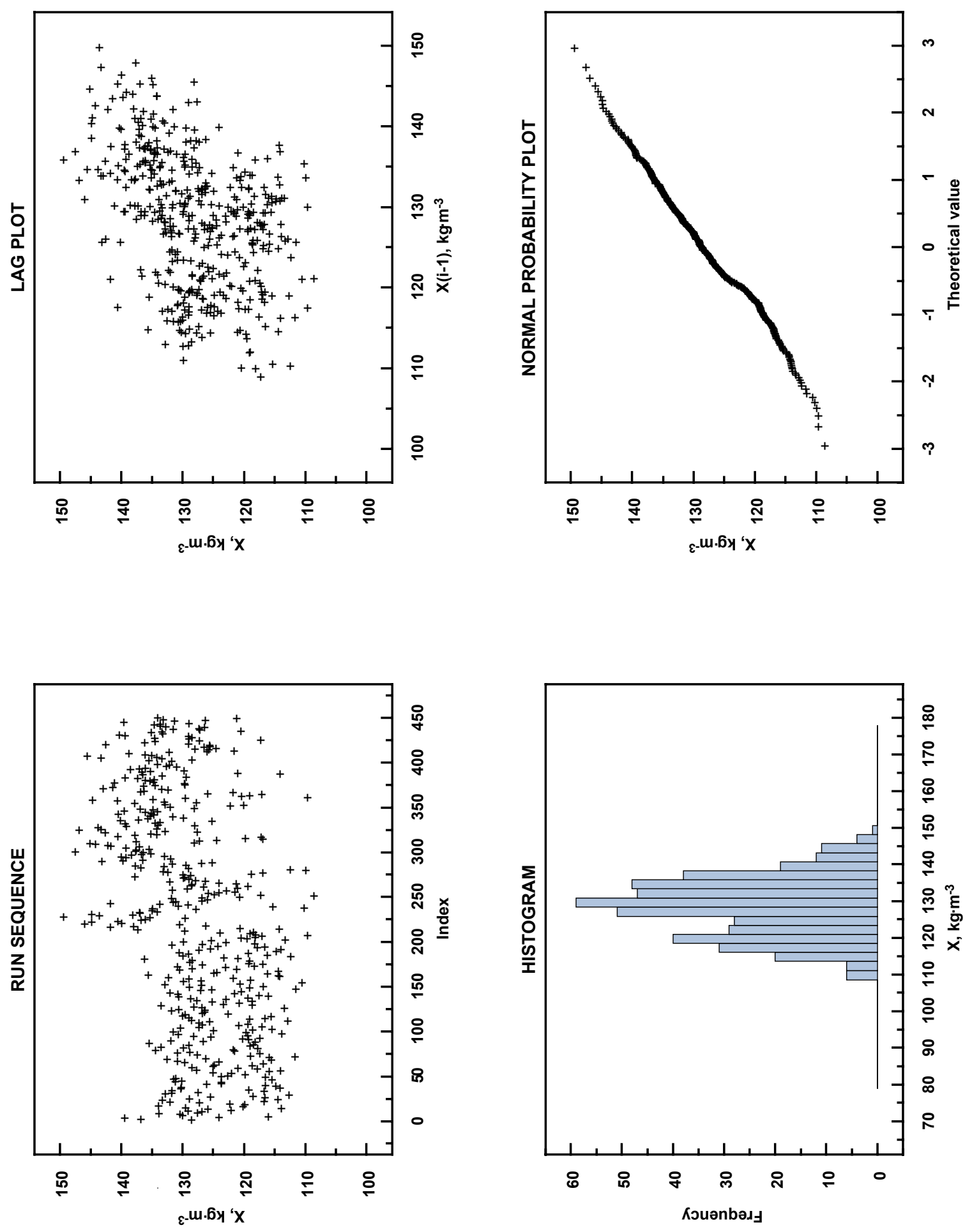

Fig. 9. a) Graphical analysis of panel bulk density ( $n=450)$ : (a) run sequence plot, (b) lag plot, (c) histogram, (d) normal probability plot (normality index). Summary statistics: mean $=128.4 \mathrm{~kg} \cdot \mathrm{m}^{-3}$, standard deviation $=8.2 \mathrm{~kg} \cdot \mathrm{m}^{-3}$, range $=40.9 \mathrm{~kg} \cdot \mathrm{m}^{-3}$. 
Diagnostic plots of the forms shown in Fig. 4 through 9, the so-called 4-plots, and in Appendix B and Appendix $\mathrm{C}$, were done throughout the data logging stages of the experiment to check the integrity of the data as the data were being taken, to check for outlying points or entire outlying samples, and to check that values of $m_{0}, l_{2}, l_{5}, A_{\mathrm{p}}, \overline{L_{\mathrm{p}}}$, and the resultant $\rho_{p}$ were within their anticipated ranges.

\subsubsection{Panel Mass $\left(m_{0}\right)$}

In Fig. $4\left(m_{0}\right)$, there is indication of bimodality, that is, two underlying populations of masses. This quality is evident in the histogram (directly visible), the normal probability plot (two line segments with comparable slopes but different intercepts conjoined in a single plot), and the run sequence plot (high/low excursions from the mean values). The normal (Gaussian) probability plot is compatible with a normality assumption for the data, with the possible exception of just a few of the tail (extreme end) points, which are routinely observed with empirical data. The most probable source of variation in panel mass is from the manufacturing process itself.

\subsubsection{Panel Length and Width $\left(l_{2}\right.$ and $\left.l_{5}\right)$}

In Fig. 5 and Fig. 6 ( $l_{2}$ and $l_{5}$, respectively), there are suggestions of multimodality, that is, two or more underlying populations of lengths and widths, respectively. This quality is evident in the histograms (directly visible), the normal probability plots (multiple line segments with comparable slopes but different intercepts conjoined in a single plot), and the run sequence plots (high/low excursions from the mean values). The presence of multi-modes is almost certainly due simply to the fact that the panels are not quite square, so that pairs of sides do not match exactly in length. The lag sequence plots are not suggestive of any autocorrelation, or systematic departure from randomness.

\subsubsection{Panel Area $\left(A_{\mathrm{p}}\right)$}

In Fig. $7\left(A_{\mathrm{p}}\right)$, both the histogram and normal probability plots are strongly suggestive of underlying bimodality, viz. two underlying populations. However, the difference in the histogram peaks of approximately $0.5 \%$ is not considered significant. While not suggestive of autocorrelation, the patterned heavy overstrike in the lag plot is apparent.

\subsubsection{Panel Thickness $\left(L_{p}\right)$}

In Fig. $8\left(L_{\mathrm{p}}\right)$, the histogram and normal probability plots are well-behaved, with the exception of some obvious outlying tail observations (common with empirical data, as mentioned in Sec. 5.3.2.1 for Fig. 4). The flywheel appearance of the lag plot is attributable to only a small subset of the overall set of measurements and is not indicative of systematic behavior. The obvious, approximately contiguous, high-lying and low-lying points in the run sequence plot may be the cause of these linear excursions from the random mass at the center of the lag plot.

\subsubsection{Panel Bulk Density $\left(\rho_{p}\right)$}

In Fig. $9\left(\rho_{\mathrm{p}}\right)$, the plots are well-behaved, meaning that the measurement process for $\rho_{\mathrm{p}}$ was in statistical control. It is interesting to note that much of the bi-modality present in the mass and area plots (Fig.4 and Fig. 7, respectively) does not appear in the density plots due, in part, to stronger contributions from thickness (Fig. 8). 


\subsubsection{Summary Statistics}

Table 3 provides summary statistics for mass, length, width, area, thickness, and bulk density of the 450 panels. Overall, the mean values for length and width are within acceptable limits. A few panels that have linear dimensions greater than $613 \mathrm{~mm}$ (Figs. 5 and 6) could necessitate further trimming by the customer for installation in a heat-flow-meter apparatus [2]. The mean thickness of $25.21 \mathrm{~mm}$ is very near the target of $25.4 \mathrm{~mm}$ and the mean bulk density of $128.4 \mathrm{~kg} \cdot \mathrm{m}^{-3}$ is nearly the same as the target density of $128 \mathrm{~kg} \cdot \mathrm{m}^{-3}$. The small standard deviation for thickness $(0.18 \mathrm{~mm})$ indicates that most of the panels are near the mean thickness. Unfortunately, the large range $(1.53 \mathrm{~mm})$ indicates that some of the panels are unacceptably thin or thick, as discussed in Sec. 5.3.4. The exceptionally large range for bulk density $\left(40.9 \mathrm{~kg} \cdot \mathrm{m}^{-3}\right)$ is more than three times larger than the requested tolerance of $12.8 \mathrm{~kg} \cdot \mathrm{m}^{-3}(10 \%)$ in Sec. 4.2.1.

Table 3. Summary statistics for the SRM 1450e production run (450 panels)

\begin{tabular}{lcrrrrr}
\hline \multicolumn{1}{c}{ Statistic } & $\begin{array}{c}\text { Mass } \\
(\mathbf{k g})\end{array}$ & $\begin{array}{c}\text { Length } \\
(\mathbf{m m})\end{array}$ & $\begin{array}{c}\text { Width } \\
(\mathbf{m m})\end{array}$ & $\begin{array}{c}\text { Area } \\
\left(\mathbf{m}^{2}\right)\end{array}$ & $\begin{array}{c}\text { Thickness } \\
(\mathbf{m m})\end{array}$ & $\begin{array}{c}\text { Bulk density } \\
\left(\mathbf{k g}^{-3} \mathbf{m}^{-3}\right)\end{array}$ \\
\hline Mean & 1.2059 & 610.4 & 610.4 & 0.37260 & 25.21 & 128.4 \\
Std. dev. $(s)$ & 0.0784 & 1.3 & 1.3 & 0.00118 & 0.18 & 8.2 \\
Range & 0.3811 & 6.3 & 7.5 & 0.00497 & 1.53 & 40.9 \\
Minimum & 1.0192 & 607.8 & 607.5 & 0.37070 & 24.89 & 108.9 \\
Maximum & 1.4003 & 614.1 & 615.1 & 0.37567 & 26.42 & 149.8 \\
\hline Rel. std. dev. (\%) & $6.5 \%$ & $0.2 \%$ & $0.2 \%$ & $0.3 \%$ & $0.7 \%$ & $6.4 \%$ \\
\hline
\end{tabular}

\subsubsection{Between- and Within-Panel Thickness Variations}

Figures 10a and $10 \mathrm{~b}$ plot the individual panel thickness mean and standard deviation, respectively, for the 450 panels. Each plot is rank ordered from lowest to highest value (indexed from 1 to 450).

\subsubsection{Between-Panel Variation}

Figure 10a shows graphically that the mean panel thickness ranges from $24.89 \mathrm{~mm}$ to $26.42 \mathrm{~mm}$. There are five panels outside the upper limit equal to the grand mean plus three times the standard deviation $(+3 s)$. These five panels $(665,695,805,810$, and 925) were removed from the material lot. There are no panels outside the lower limit equal to the grand mean minus three times the standard deviation $(-3 s)$.

\subsubsection{Within-Panel Variation}

Figure $10 \mathrm{~b}$ plots the standard deviation of the thickness measurements for each panel indicating the range of panel thickness variation. The individual panel variation ranges from $0.02 \mathrm{~mm}$ to approximately $1.6 \mathrm{~mm}$. From Fig. 10b, an upper limit cutoff of $0.55 \mathrm{~mm}$ was selected to remove the extreme outlying data points. The eleven panels outside this limit $(546,560,656,658,665,753,805,810,857,910$, and 925) were removed from the material lot. Four of the panels $(665,805,810$, and 925$)$ were previously identified for removal due to unacceptable thickness (Sec. 5.3.4.1). For most of the data, the variation is less than $0.35 \mathrm{~mm}$, or about $1 \%$ of the grand mean panel thickness given in Table 3 . 

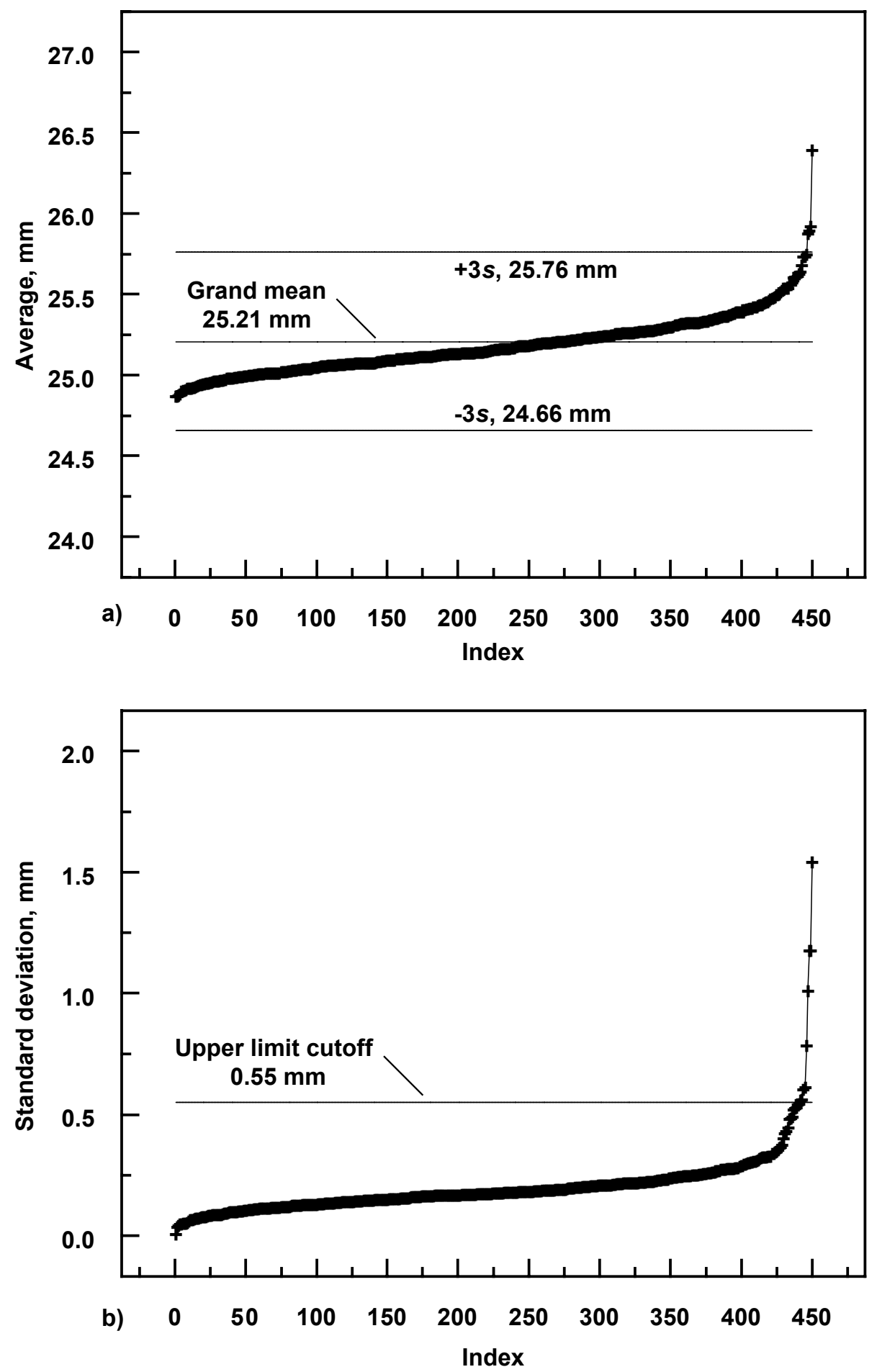

Fig. 10. a) Graphical analysis of between-panel thickness variation represented by the means of the individual panel thickness measurements. Panels outside the control limits of three times the standard deviation $( \pm 3 s$, where $s$ equals $0.18 \mathrm{~mm}$ from Table 3$)$ were removed. b) Graphical analysis of within-panel thickness variation represented by the standard deviations of the individual panel thickness measurements. The upper limit cutoff of $0.55 \mathrm{~mm}$ was selected arbitrarily. 


\subsubsection{Between-Panel Bulk Density Variations}

Figure 11 plots the individual panel bulk density for all 450 panels, rank ordered from lowest to highest value.

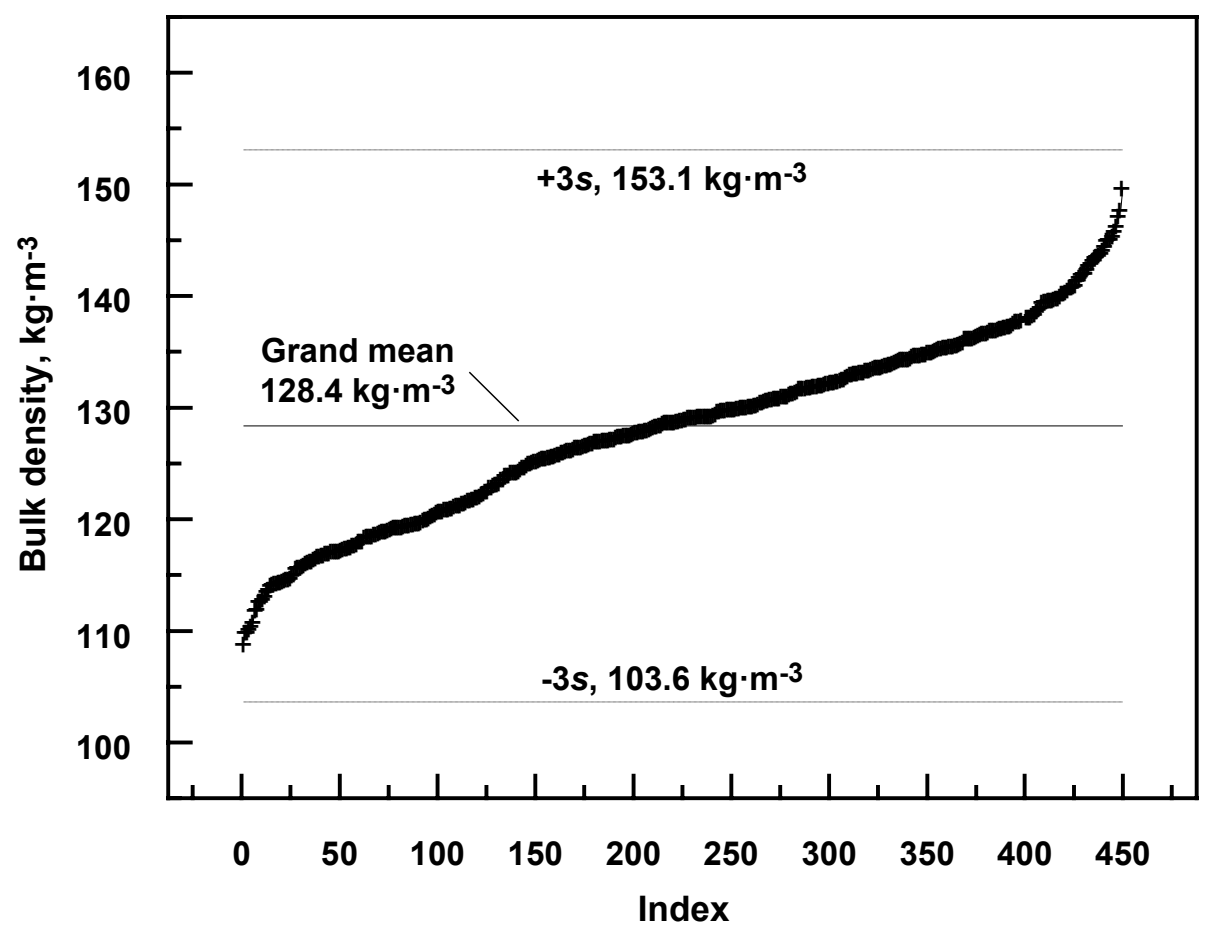

Fig. 11. Graphical analysis of between-panel bulk density variation.

\subsubsection{Rejected Panels}

There were 27 panels rejected from the material lot for the reasons stated below. The excluded panels represented $6 \%$ (27 of 450) of the material lot (423 panels were accepted, or $94 \%)$.

- Unacceptable thickness (1.1\%): 665, 695, 805, 810, and 925

- Unacceptable thickness variation (1.6\%): 546, 560, 656, 658, 753, 857, 910

- Material defect (1.8\%): 547, 574, 686, 699, 764, 819, 895, 944

- Damaged during shipping (1.6 \%): 674, 741, 742, 744, 745, 849, 949

\subsection{Uncertainty Assessment Panel Density}

Substituting Eq. (6) for the area term $\left(A_{\mathrm{p}}\right)$ in Eq. (1) and utilizing the terminology described for measured mass and thickness yields Eq. (11).

$$
\rho_{\mathrm{p}}=\frac{m_{0}}{l_{2} \times l_{5} \times L_{\mathrm{p}}}
$$

For the simple multiplicative expression in Eq. (11), the relative uncertainties associated with each component are combined in quadrature. 


$$
u_{c, \mathrm{r}}\left(\rho_{\mathrm{p}}\right)=\frac{u_{c}\left(\rho_{\mathrm{p}}\right)}{\rho_{\mathrm{p}}}=\sqrt{\left(\frac{u\left(m_{0}\right)}{m_{0}}\right)^{2}+\left(\frac{u\left(l_{2}\right)}{l_{2}}\right)^{2}+\left(\frac{u\left(l_{5}\right)}{l_{5}}\right)^{2}+\left(\frac{u\left(L_{\mathrm{p}}\right)}{L_{\mathrm{p}}}\right)^{2}}
$$

Substituting the standard uncertainties for $m_{0}, l_{2}, l_{5}$, and, $L_{\mathrm{p}}$ derived in Appendix D and the minimum quantity estimates from Table 3 yields the following relative uncertainty estimate for bulk density.

$$
u_{c, \mathrm{r}}\left(\rho_{\mathrm{p}}\right)=\sqrt{\left(\frac{0.000397}{1.0192}\right)^{2}+\left(\frac{0.315}{607.8}\right)^{2}+\left(\frac{0.315}{607.5}\right)^{2}+\left(\frac{0.186}{24.89}\right)^{2}}=0.00752
$$

The relative expanded uncertainty, $U_{\mathrm{r}}(\rho)$, is defined for a coverage factor of $k=2$ in Eq. (14).

$$
U_{\mathrm{r}}\left(\rho_{\mathrm{p}}\right)=k u_{\mathrm{c}, \mathrm{r}}=2 u_{\mathrm{c}, \mathrm{r}}\left(\rho_{\mathrm{p}}\right)=0.015
$$

Expressed as a percent $(\times 100), U_{\mathrm{r}}\left(\rho_{\mathrm{p}}\right)$ is equal to $1.5 \%$.

\subsection{Bulk Density Metrological Traceability}

Table 4 summarizes the calibration information for the electronic balance, gage blocks, and surface plate used to carry out the bulk density measurements. The calibration uncertainties were included in the extended uncertainty analysis (Appendix D). Internal checks (Items 2, 5 , and 6) were conducted by the operators during the measurement process. The check of the Mettler balance (Item 2) was conducted before and after the mass measurements of each group of 50 panels. The digital height gages (Items 5 and 6) were checked before and after

\begin{tabular}{|c|c|c|c|c|c|}
\hline \multirow[b]{2}{*}{ Item } & \multirow{2}{*}{$\begin{array}{l}\text { Equipment } \\
\text { Calibrated }\end{array}$} & \multirow{2}{*}{$\begin{array}{l}\text { Description } \\
\text { of standard }\end{array}$} & \multicolumn{3}{|c|}{ Calibration } \\
\hline & & & Organization & Date & Cert. Number \\
\hline 1 & $\begin{array}{l}\text { Mettler balance } \\
\text { SG32001DL }\end{array}$ & $\begin{array}{l}\text { Weight set } 632 \\
\text { traceable to NIST }\end{array}$ & Mettler Toledo & 2017 & $\begin{array}{l}020218-133- \\
032317\end{array}$ \\
\hline 2 & Mettler balance check & $\begin{array}{l}1 \mathrm{~kg} \text { and } 500 \mathrm{~g} \\
\text { masses }\end{array}$ & 732.03 & & \\
\hline 3 & 1 in. gage block EBW1 & $\begin{array}{l}\text { Standards of the } \\
\text { United States }\end{array}$ & NIST & 2018 & 290351-18 \\
\hline 4 & $\begin{array}{l}12 \text { in. gage blocks } \\
\text { L4M041 \& L4M042 }\end{array}$ & $\begin{array}{l}\text { Standards of the } \\
\text { United States }\end{array}$ & NIST & 2018 & 290351-18 \\
\hline 5 & $\begin{array}{l}\text { Mitutoyo } 0 \text { to } 300 \mathrm{~mm} \\
\text { height gage } 192-670-10\end{array}$ & 1 in. gage block & 732.03 & & \\
\hline 6 & $\begin{array}{l}\text { Mitutoyo } 0 \text { to } 600 \mathrm{~mm} \\
\text { height gage } 192-672-10\end{array}$ & 24 in. gage block & 732.03 & & \\
\hline 7 & Starrett surface plate & Traceable to NIST & LTI Metrology & 2017 & $\begin{array}{l}\text { NIS001-10- } \\
41425-1\end{array}$ \\
\hline 8 & $\begin{array}{l}\text { Troemner E/B weight set } \\
4000010240\end{array}$ & $\begin{array}{l}\text { Reference masses } \\
\text { traceable to NIST } \\
(684 / 289871-17)\end{array}$ & Troemner LLC & 2017 & $967451-1$ \\
\hline
\end{tabular}
the dimensional measurements of each group of 50 panels.

Table 4. Calibration information for the bulk density measurements. 


\section{Thermal Conductivity Study}

This section describes the experimental design, specimens, guarded-hot-plate measurements, and determinations of thermal conductivity.

\subsection{Experimental Design}

The experimental design for the determination of thermal conductivity $(\lambda)$ was based on the assumed model for bulk density $(\rho)$, temperature $\left(T_{m}\right)$, and air pressure $(p)$ given in Eq. (15).

$$
\lambda=(\rho, T, p)=a_{0}+a_{1} \rho+a_{2} T_{m}+a_{3} p
$$

where $\rho$ is the bulk density of the $500 \mathrm{~mm}$ diameter specimen (discussed in Sec. 6.2.4), $T_{m}$, is the mean temperature, and $p$ is the atmospheric pressure. The settings selected for each variable in Eq. (15) are given below:

- $\rho 3$ levels (low, mid, and high);

- $T_{m} 5$ levels $(280 \mathrm{~K}, 300 \mathrm{~K}, 320 \mathrm{~K}, 340 \mathrm{~K}, 360 \mathrm{~K})$; and,

- $\quad 3$ levels $(60 \mathrm{kPa}, 80 \mathrm{kPa}, 100 \mathrm{kPa})$.

\subsection{Specimens}

For thermal characterization, a stratified density sample of 30 panels was selected from the lot of 450 panels (Table 2), excluding the rejected panels in Sec. 5.3.6. Because bulk density is a material property of a panel, this factor cannot be set as precisely as the other factors - temperature $\left(T_{m}\right)$ and pressure $(p)$.

\subsubsection{Bulk Density Settings}

The bulk densities of the 450 panels in Table 2 were ranked from lowest to highest and the following panels were selected.

- Low range: $107 \mathrm{~kg} \cdot \mathrm{m}^{-3}$ to $114 \mathrm{~kg} \cdot \mathrm{m}^{-3}$

ID: $751,707,862,780,738,654,647,571,683$, and 781 (10 panels having the smallest bulk density)

- Mid-range: $126 \mathrm{~kg} \cdot \mathrm{m}^{-3}$ to $133 \mathrm{~kg} \cdot \mathrm{m}^{-3}$

ID: $634,856,736,769,914,830,811,850,627$, and 594 (10 panels having a bulk density near the lot average)

- High range: $144 \mathrm{~kg} \cdot \mathrm{m}^{-3}$ to $152 \mathrm{~kg} \cdot \mathrm{m}^{-3}$

ID: $729,828,809,859,722,731,906,720,825$, and 801 (10 panels having the largest bulk density)

\subsubsection{Preparation}

The specimens were hand-cut into $500 \mathrm{~mm}$ diameter discs for testing in the NIST $500 \mathrm{~mm}$ Guarded-Hot-Plate Apparatus using a sharp blade and a metal cutting template manufactured by the NIST Instrument Shop (Fig. 12). Each $500 \mathrm{~mm}$ diameter specimen was labeled with the same 3-digit identification number assigned to the panel (Table 2).

\subsubsection{Conditioning}

The $500 \mathrm{~mm}$ diameter specimens were placed in a large test chamber (Fig. 13) and were conditioned at $100{ }^{\circ} \mathrm{C}$ for $17.5 \mathrm{~h}$. 


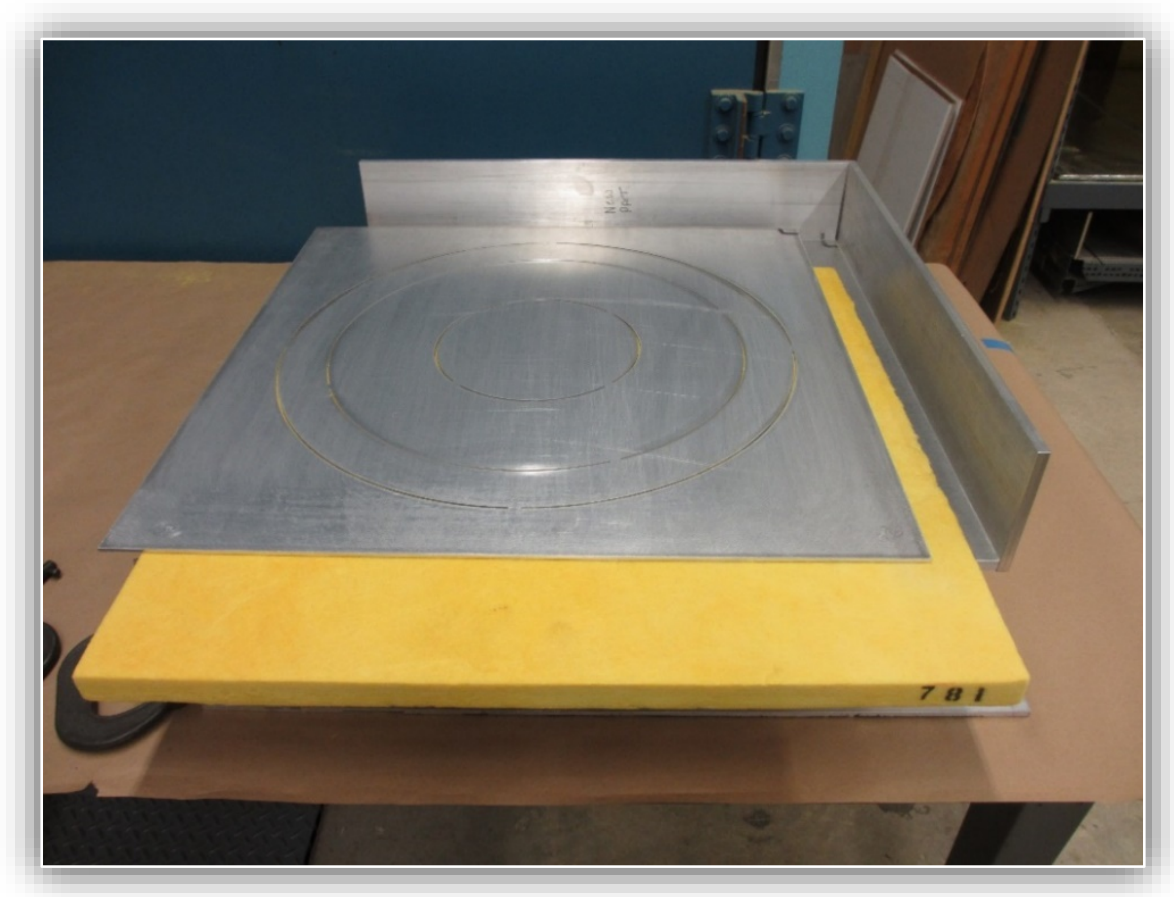

Fig. 12. Panel 781 placed in metal cutting template.

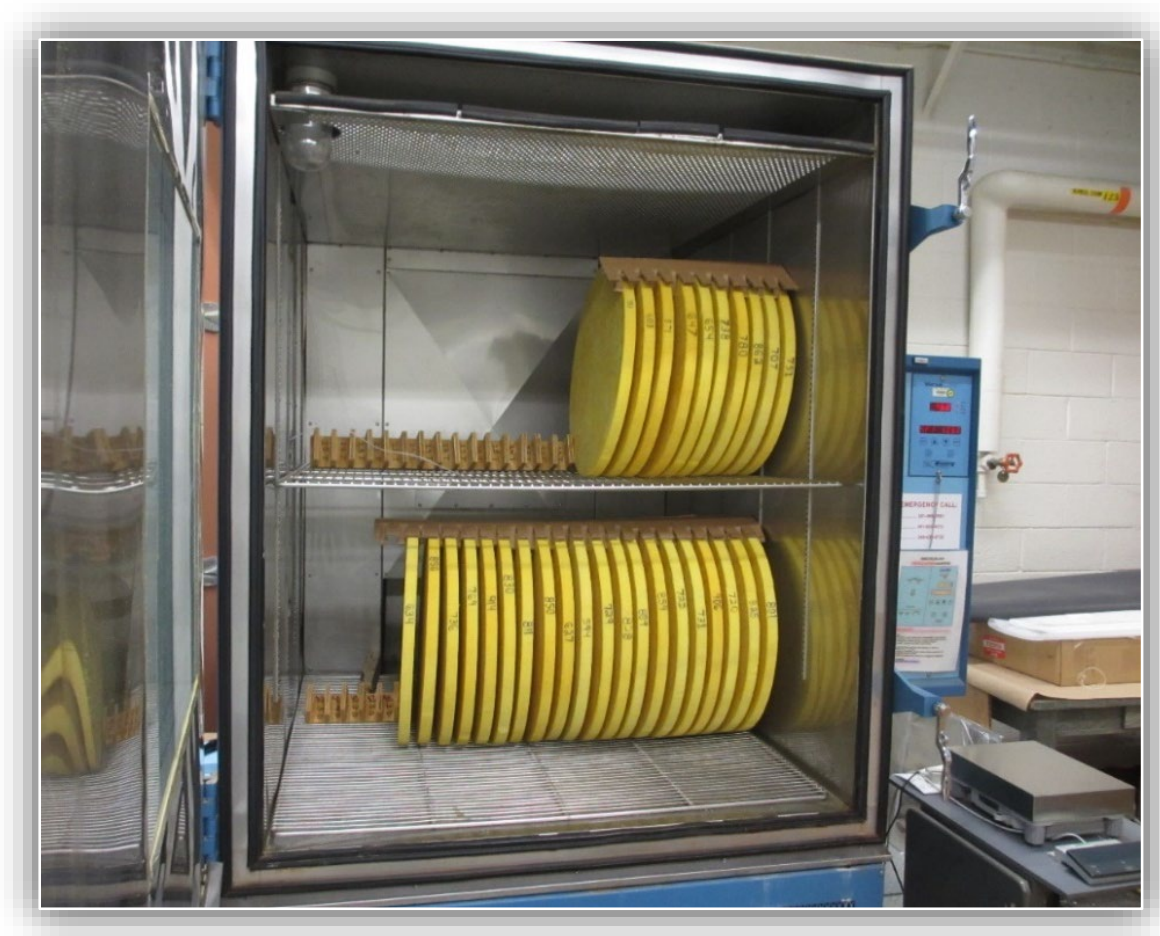

Fig. 13. Test specimens (500 $\mathrm{mm}$ diameter) in a large conditioning chamber.

\subsubsection{Selection}

The bulk densities of the 30 specimens were determined to corroborate the preceding results obtained for the panels (Table 2). The measurements of mass $\left(m_{0}\right)$ and thickness $(L)$, 
with minor modifications, were conducted as described in Sec. 5.1 and Sec. 5.2, respectively. The specimen diameters $\left(\bar{d}_{\mathrm{s}}\right)$ were obtained from the average of two measurements using a precision steel rule having a resolution of $0.05 \mathrm{~cm}$. The bulk densities of the round test specimens were computed from Eq. (16).

$$
\rho_{\mathrm{s}}=\frac{m_{0}}{\pi\left(\frac{\bar{d}_{\mathrm{s}}}{2}\right)^{2} \times L_{\mathrm{s}}}
$$

The bulk densities for the 30 test specimens are ranked from low to high and summarized in Table 5. The last column yields the 15 pairs of test specimens.

Table 5. Ranked bulk densities of the 30 test specimens.

\begin{tabular}{|c|c|c|c|c|c|c|c|}
\hline & Mass & Thickness & SD & Diameter & Area & Density & \\
\hline ID & (kg) & $(\mathbf{m m})$ & $(\mathbf{m m})$ & (cm) & & & \\
\hline 707 & 0.5431 & 25.5250 & 0.1215 & 50.200 & 0.19792 & 107.50 & \\
\hline 751 & 0.5354 & 25.1225 & 0.0900 & 50.175 & 0.19773 & 107.78 & 1 \\
\hline 780 & 0.5465 & 25.3750 & 0.1271 & 50.350 & 0.19911 & 108.17 & $?$ \\
\hline 862 & 0.5457 & 25.2200 & 0.1329 & 50.300 & 0.19871 & 108.89 & 2 \\
\hline 571 & 0.5523 & 25.2925 & 0.0793 & 50.350 & 0.19911 & 109.67 & \\
\hline 654 & 0.5505 & 25.2550 & 0.0785 & 50.300 & 0.19871 & 109.69 & 3 \\
\hline 738 & 0.5546 & 25.3400 & 0.1294 & 50.375 & 0.19931 & 109.82 & \\
\hline 683 & 0.5556 & 25.3975 & 0.0939 & 50.325 & 0.19891 & 109.98 & 4 \\
\hline 781 & 0.5685 & 25.1350 & 0.0858 & 50.350 & 0.19911 & 113.60 & \\
\hline 647 & 0.5696 & 25.1900 & 0.0852 & 50.250 & 0.19832 & 114.02 & 5 \\
\hline 736 & 0.6278 & 24.9950 & 0.1261 & 50.350 & 0.19911 & 126.15 & \\
\hline 914 & 0.6334 & 25.2250 & 0.1443 & 50.325 & 0.19891 & 126.23 & 0 \\
\hline 850 & 0.6389 & 25.2525 & 0.1266 & 50.350 & 0.19911 & 127.06 & \\
\hline 634 & 0.6388 & 25.1750 & 0.1453 & 50.400 & 0.19950 & 127.19 & I \\
\hline 594 & 0.6429 & 25.2000 & 0.1530 & 50.350 & 0.19911 & 128.13 & \\
\hline 769 & 0.6404 & 25.1050 & 0.1797 & 50.325 & 0.19891 & 128.25 & 0 \\
\hline 830 & 0.6526 & 25.4900 & 0.1042 & 50.300 & 0.19871 & 128.85 & 0 \\
\hline 811 & 0.6469 & 25.1700 & 0.1759 & 50.225 & 0.19812 & 129.72 & $y$ \\
\hline 856 & 0.6544 & 25.2750 & 0.2138 & 50.350 & 0.19911 & 130.04 & \\
\hline 627 & 0.6699 & 25.3900 & 0.0716 & 50.300 & 0.19871 & 132.79 & 10 \\
\hline 809 & 0.7198 & 25.1775 & 0.1247 & 50.350 & 0.19911 & 143.59 & \\
\hline 828 & 0.7196 & 25.1225 & 0.1666 & 50.375 & 0.19931 & 143.71 & \\
\hline 729 & 0.7301 & 25.4500 & 0.1581 & 50.400 & 0.19950 & 143.79 & \\
\hline 859 & 0.7294 & 25.4775 & 0.1212 & 50.325 & 0.19891 & 143.92 & 12 \\
\hline 722 & 0.7326 & 25.2450 & 0.1741 & 50.275 & 0.19852 & 146.18 & \\
\hline 731 & 0.7361 & 25.2350 & 0.1399 & 50.350 & 0.19911 & 146.50 & 3 \\
\hline 720 & 0.7509 & 25.4100 & 0.1296 & 50.350 & 0.19911 & 148.41 & 14 \\
\hline 906 & 0.7518 & 25.2550 & 0.1756 & 50.200 & 0.19792 & 150.40 & 14 \\
\hline 825 & 0.7624 & 25.2850 & 0.1041 & 50.375 & 0.19931 & 151.29 & \\
\hline 801 & 0.7679 & 25.4275 & 0.2777 & 50.275 & 0.19852 & 152.14 & \\
\hline
\end{tabular}


The percent differences $(\delta \rho)$ between the panels $\left(\rho_{\mathrm{p}}\right)$ and $500 \mathrm{~mm}$ diameter specimens $\left(\rho_{\mathrm{s}}\right)$ were computed from Eq. (17).

$$
\delta \rho=\frac{\rho_{\mathrm{p}}-\rho_{\mathrm{s}}}{\rho_{\mathrm{p}}} \times 100
$$

Figure 14 plots values of $\delta \rho$ for the 30 specimens ranked from low to high within each subrange of bulk density. The changes for individual specimens ranged from $-3.3 \%$ to $+2.4 \%$ indicating a small within-panel density variation. However, on average, each group of ten specimens (corresponding to low-, mid-, and high- $\rho$ ) changed by only $\pm 1 \%$.

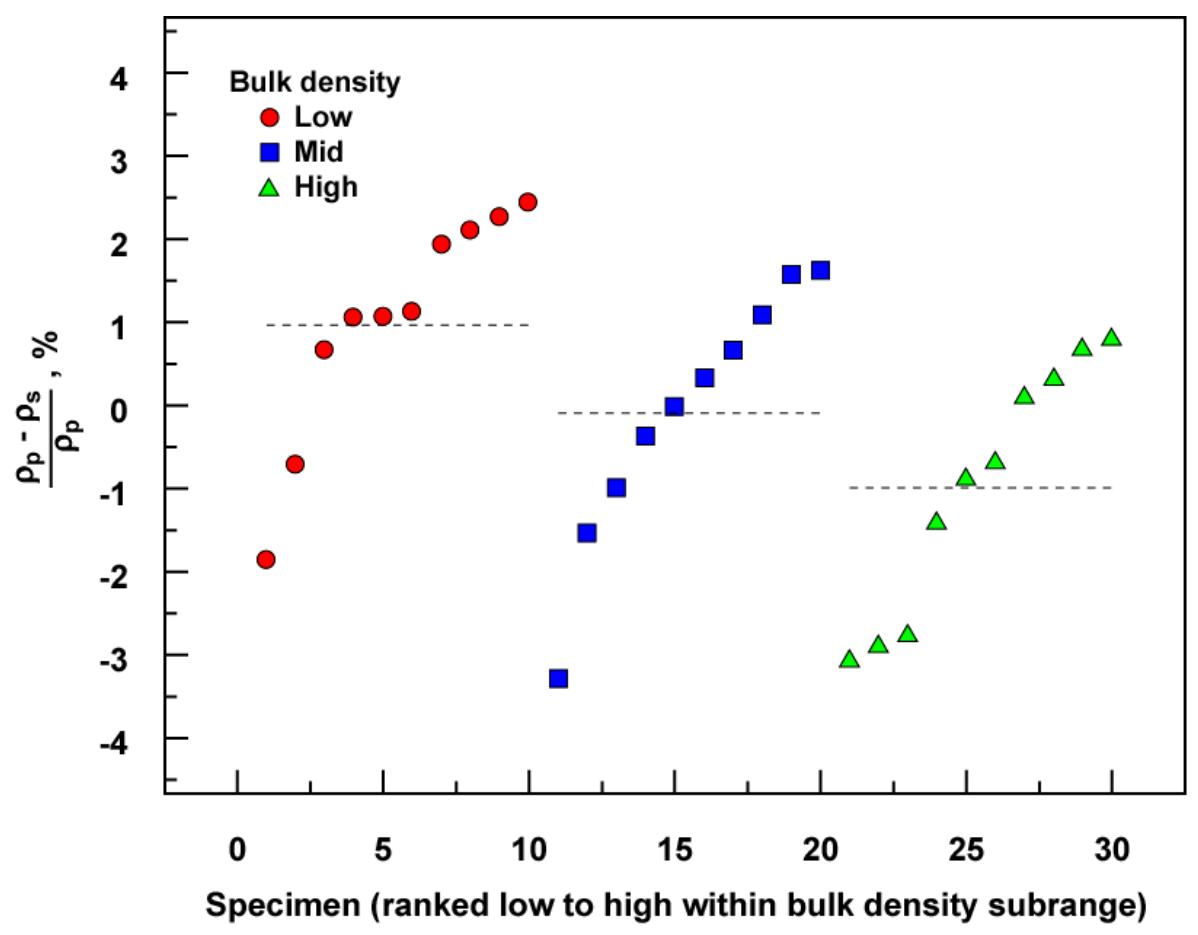

Fig. 14. Percent change in bulk density for the $500 \mathrm{~mm}$ diameter specimens.

\subsection{Model Inputs}

This section describes the final settings for the input parameters ( $\rho, T_{m}$, and $p$ ) in Eq. (15).

\subsubsection{Temperature and Bulk Density}

Based on recent renewals of 1450 [5], temperature and bulk density, in that order, are the main factors affecting $\lambda$. Figure 15 plots the full factorial design for the three levels of $\rho$ from Table 5 and the five (settable) levels of $T_{m}$ (based on material and equipment limitations). This design checks the adequacy of Eq. (15) and also allows checking for the necessity of quadratic terms for both $\rho$ and $T_{m}$. Each set of two data points, identified by their assigned IDs, represents a pair of specimens from Table 5. The benefit of testing a unique pair of specimens at each combined level of temperature and density is that independent information is obtained at each such level. The experimental design given in Fig. 15 is balanced in the sense that an equivalent amount of information is obtained at each setting of the independent variables. If either extra information had been obtained at some of the 
settings, or worse, critical information omitted at one setting, the design would be unbalanced, and the resulting statistical analysis would suffer.

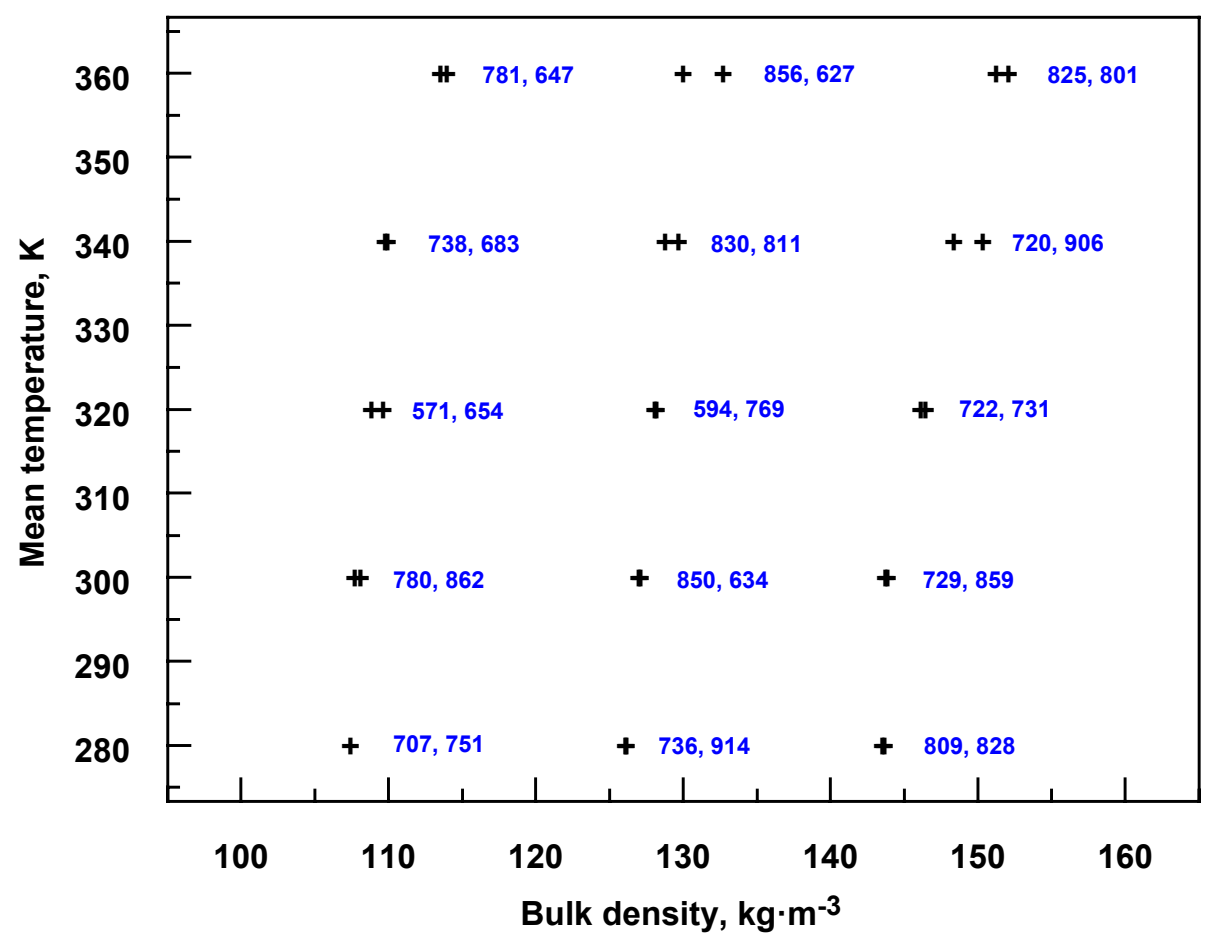

Fig. 15. Model inputs for mean temperature and bulk density.

\subsubsection{Atmospheric Pressure}

Previous NIST thermal conductivity data [21-22] for SRMs 1450b and 1450c revealed a gas pressure dependency for fibrous-glass board, particularly below $20 \mathrm{kPa}$. For SRM $1450 \mathrm{e}$, the effect of gas pressure dependency at higher settings was reassessed to support thermal conductivity measurements at national metrology laboratories in the Inter-American Metrology System (SIM). SIM currently has 34 members and the elevations of these laboratory facilities range from sea level to nearly 4000 m (IBMETRO, La Paz, Bolivia).

Figure 16 plots the pressure for the NACA standard (lower) atmosphere [23] from an altitude of $0 \mathrm{~m}$ to $6000 \mathrm{~m}$. The range of interest for the SIM national metrology institutes is sea-level, essentially $0 \mathrm{~m}$, to $4000 \mathrm{~m}$ corresponding to an atmospheric pressure range of $101.3 \mathrm{kPa}$ to $61.6 \mathrm{kPa}$ [23]. Based on the results of Fig. 16, three pressure levels of $60 \mathrm{kPa}$, $80 \mathrm{kPa}$, and $100 \mathrm{kPa}$ were selected for input to Eq. (15). Because of practical test limitations, these levels were not input independently to the model in Eq. (15). Rather, the three pressure levels of $60 \mathrm{kPa}, 80 \mathrm{kPa}$, and $100 \mathrm{kPa}$ were randomly input for each $(T, \rho)$ data point in Fig. 15. 


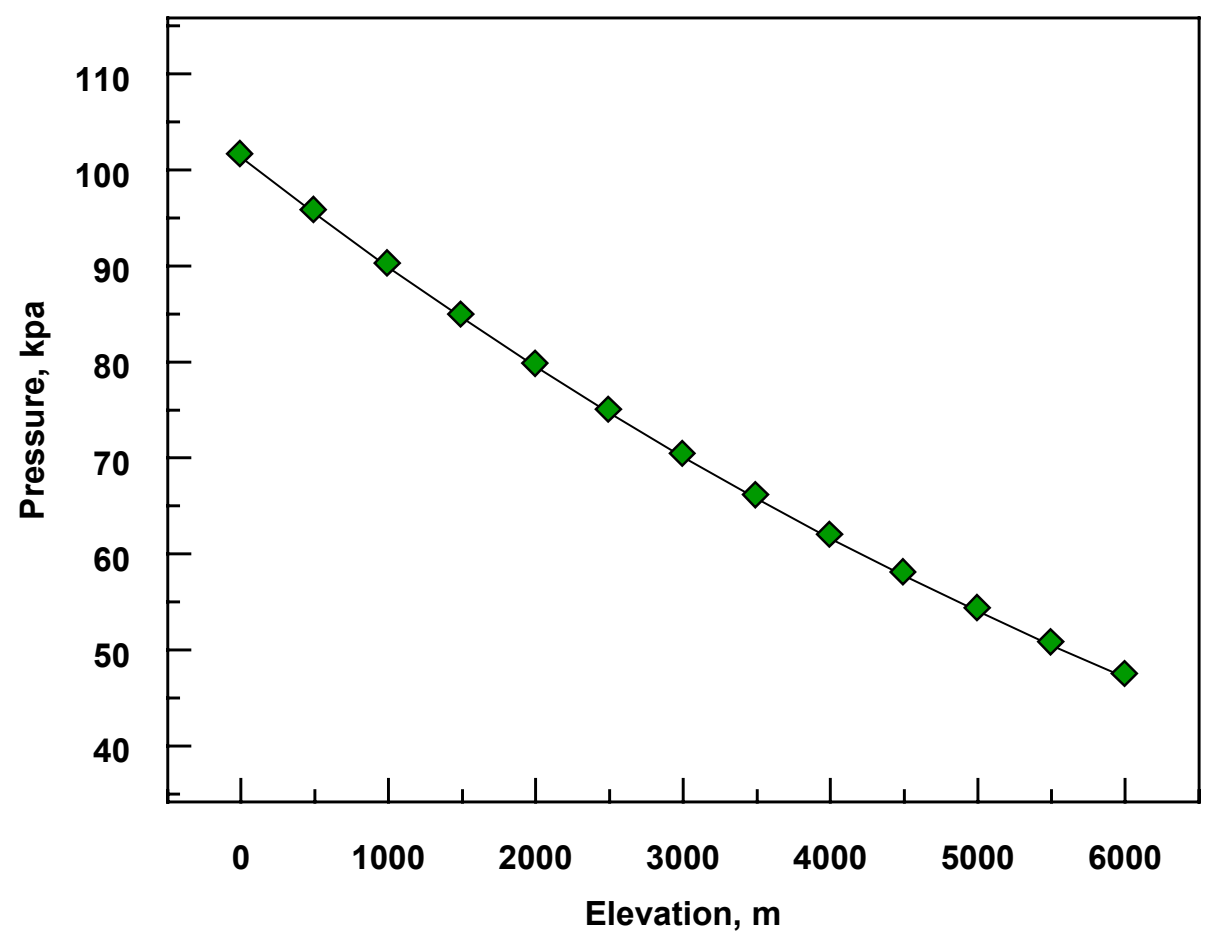

Fig. 16. Atmospheric pressure as a function of elevation (NACA standard [23]).

\subsubsection{Supplementary Quantities}

Other measurement quantities that were considered "nuisance" or influence parameters were either fixed at specified levels during testing in the guarded-hot-plate apparatus or recorded. The following parameters were fixed, or varied (slightly) with temperature, during the test.

- The direction of heat flow across the thickness of the specimens was fixed in the horizontal direction for the double-sided mode of operation.

- The temperature difference $(\Delta T)$ across the specimen was fixed at $25 \mathrm{~K}$ and followed standard practice for selecting test temperatures [24].

- The clamping pressure $\left(p_{\mathrm{a}}\right)$ on the specimens was manually applied at a nominal value of $500 \mathrm{~Pa}$ for all tests.

- The average temperature ( $\left.T_{\mathrm{eg}}\right)$ of the primary edge guards (inboard and outboard) were controlled to within $0.1 \mathrm{~K}$, or less, of the mean temperature $\left(T_{m}\right)$.

- The supply air to the chamber was maintained at a dewpoint of $213 \mathrm{~K}\left(-60^{\circ} \mathrm{C}\right)$, or less, by a purge gas generator supplied by NIST compressed air. In general, however, the supply airline was manually closed during testing.

\subsection{Test Arrangement and Settings}

Table 6 re-ranks the specimens listed in Table 5 by input temperature $\left(T_{m}\right)$ and by bulk density $\left(\rho_{\mathrm{s}}\right)$ within each temperature setting. Each specimen pair was tested at three randomized levels of pressure $(p)$. The second column assigns a randomized test sequence for the guarded-hot-plate measurements. The test sequence outlined in Table 6 involved a total of $45(=3 \times 5 \times 3)$ runs. 
Table 6. Random test sequence and settings for the 15 pairs of test specimens.

\begin{tabular}{|c|c|c|c|c|c|c|c|}
\hline Index & $\begin{array}{c}\text { Test } \\
\text { Sequence }\end{array}$ & $\begin{array}{l}\text { Specimen } \\
\text { ID }\end{array}$ & $\begin{array}{c}\rho_{\mathrm{s}} \\
\left(\mathrm{kg} \cdot \mathrm{m}^{-3}\right)\end{array}$ & $\begin{array}{l}T_{m} \\
(\mathbf{K})\end{array}$ & $\begin{array}{c}p_{1} \\
(\mathrm{kPa})\end{array}$ & $\begin{array}{c}p_{2} \\
(\mathrm{kPa})\end{array}$ & $\begin{array}{c}p_{3} \\
(\mathbf{k P a})\end{array}$ \\
\hline 1 & 1 & $\begin{array}{l}707 \\
751\end{array}$ & $\begin{array}{l}107.50 \\
107.78\end{array}$ & 280 & 100 & 80 & 60 \\
\hline 2 & 3 & $\begin{array}{l}736 \\
914\end{array}$ & $\begin{array}{l}126.15 \\
126.23\end{array}$ & 280 & 80 & 100 & 60 \\
\hline 3 & 2 & $\begin{array}{l}809 \\
828\end{array}$ & $\begin{array}{l}143.59 \\
143.71\end{array}$ & 280 & 80 & 60 & 100 \\
\hline 4 & 6 & $\begin{array}{l}780 \\
862\end{array}$ & $\begin{array}{l}108.17 \\
108.89\end{array}$ & 300 & 60 & 100 & 80 \\
\hline 5 & 10 & $\begin{array}{l}850 \\
634\end{array}$ & $\begin{array}{l}127.06 \\
127.19\end{array}$ & 300 & 100 & 80 & 60 \\
\hline 6 & 7 & $\begin{array}{l}729 \\
859 \\
\end{array}$ & $\begin{array}{l}143.79 \\
143.92 \\
\end{array}$ & 300 & 80 & 100 & 60 \\
\hline 7 & 8 & $\begin{array}{l}571 \\
654\end{array}$ & $\begin{array}{l}109.67 \\
109.69\end{array}$ & 320 & 100 & 60 & 80 \\
\hline 8 & 9 & $\begin{array}{l}594 \\
769\end{array}$ & $\begin{array}{l}128.13 \\
128.25\end{array}$ & 320 & 100 & 80 & 60 \\
\hline 9 & 4 & $\begin{array}{l}722 \\
731\end{array}$ & $\begin{array}{l}146.18 \\
146.50\end{array}$ & 320 & 80 & 100 & 60 \\
\hline 10 & 14 & $\begin{array}{l}738 \\
683\end{array}$ & $\begin{array}{l}109.82 \\
109.98\end{array}$ & 340 & 60 & 80 & 100 \\
\hline 11 & 5 & $\begin{array}{l}830 \\
811\end{array}$ & $\begin{array}{l}128.85 \\
129.72\end{array}$ & 340 & 100 & 80 & 60 \\
\hline 12 & 13 & $\begin{array}{l}720 \\
906\end{array}$ & $\begin{array}{l}148.41 \\
150.40\end{array}$ & 340 & 60 & 80 & 100 \\
\hline 13 & 15 & $\begin{array}{l}781 \\
647\end{array}$ & $\begin{array}{l}113.60 \\
114.02\end{array}$ & 360 & 80 & 60 & 100 \\
\hline 14 & 12 & $\begin{array}{l}856 \\
627\end{array}$ & $\begin{array}{l}130.04 \\
132.79\end{array}$ & 360 & 100 & 80 & 60 \\
\hline 15 & 11 & $\begin{array}{l}825 \\
801\end{array}$ & $\begin{array}{l}151.29 \\
152.14\end{array}$ & 360 & 60 & 80 & 100 \\
\hline
\end{tabular}

\subsection{Guarded-Hot-Plate Method}

Figure 17 illustrates the main components of a guarded-hot-plate apparatus designed for horizontal heat flow through the specimens. The typical arrangement utilizes parallel flat plates as constant temperature heat sources and sinks in contact with the surfaces of homogeneous specimens to establish a steady-state heat flux across the thickness dimension of the specimen. The central heating element of the apparatus (e.g., meter plate) is encompassed by a primary guard designed to promote one dimensional heat flow $(Q)$ perpendicular to the plate surface in the central volume of the adjoining test specimens. The physical 
separation between the meter plate and guard plate components is designated the guard gap, or gap for short, and consists of an airspace.

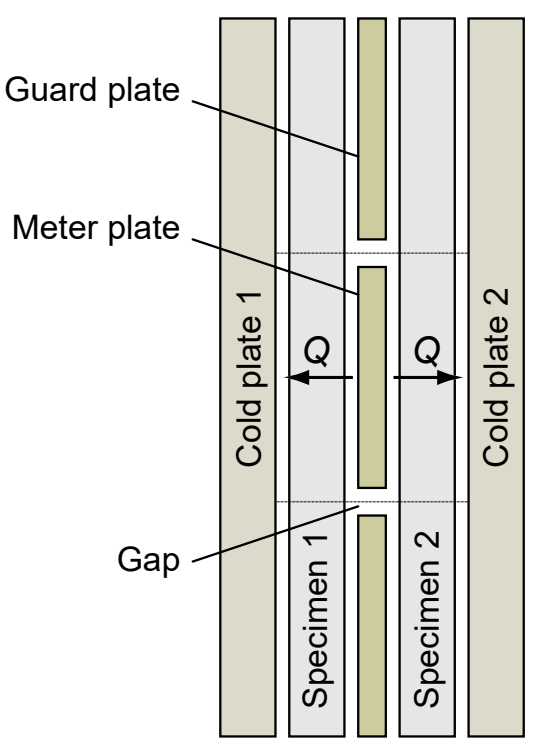

Fig. 17. Schematic illustration of a guarded-hot-plate apparatus (vertical plates) with a specimen pair installed. The numbers " 1 " and " 2 " refer to inboard and outboard locations relative to the hot plate.

The double-sided mode requires that the cold plates operate at the same temperature; thus, the heat flow $Q$ represents the measurement for the pair of specimens (Fig. 17). The guard plate is independently operated at the same temperature as the hot plate to minimize lateral heat flows. The governing equation for the guarded-hot-plate method employs an algebraic form of the Fourier heat conduction equation slightly modified from the definition given in Eq. (2) in Sec. 3.2. The thermal transmission calculations, based on heat flux measurements from the guarded-hot-plate apparatus, are implemented in accordance with Eq. (18) for double-sided operation.

$$
\lambda_{\text {exp }}=\frac{Q L_{\mathrm{av}}}{2 A \Delta T_{\mathrm{av}}}
$$

The terms $L_{\mathrm{av}}$ and $\Delta T_{\mathrm{av}}$ in Eq. (18) represent the average values associated with the pair of specimens 1 and 2 in Fig. 17. The $2 A$ term in Eq. (18) represents heat flow through two surfaces of the metered area. Values of $\lambda_{\exp }$ are reported at the mean specimen temperature, $T_{m}$, given by Eq. (19).

$$
T_{m}=\frac{T_{h}+T_{c}}{2}=\frac{T_{h}+\left(T_{c 1}+T_{c 2}\right) / 2}{2}
$$

The thermal transmission properties of heat insulators determined from standard test methods typically include multiple mechanisms of heat transfer, including conduction, radiation, and possibly convection. For that reason, some experimentalists will include the adjective "apparent" when describing the thermal conductivity of insulating materials (Sec. 3.2). However, for brevity, the term thermal conductivity will be used in this report. 


\subsection{NIST Guarded-Hot-Plate Facility}

Figure 18 shows the NIST $500 \mathrm{~mm}$ diameter guarded-hot-plate apparatus (with the edge of an outboard SRM 1450e specimen visible) and the vacuum bell jar. Under operation, the specimen pair, plates, guards, and peripheral equipment are enclosed by the vacuum bell jar. The plates are commercially pure nickel and the working surfaces have been treated with a black ceramic coating to have a surface total emittance of 0.8 . The surfaces in contact with the specimens' metering area are flat to within $0.1 \mathrm{~mm}$. The hot plate and cold plates are suspended from overhead rails and translate in the horizontal direction during installation of the specimen pair. A clamping force is transmitted axially to each cold plate by manual application, and an in-line load cell measures the applied loading (i.e., clamping pressure) during the test. The apparatus is described by Zarr et al. [18].

The hot plate is a monolithic assembly, $16.0 \mathrm{~mm}$ thick, consisting of a meter plate $200 \mathrm{~mm}$ in diameter and a co-planar, concentric guard plate $500 \mathrm{~mm}$ in diameter. The circular gap separating the meter plate and guard plate is $0.92 \mathrm{~mm}$ wide at the plate surface. The crosssectional profile of the gap is diamond shaped to minimize lateral heat flow [18]. The temperature difference across the gap is measured by combining the outputs from two Type $\mathrm{K}$ twelve-junction thermopiles. Each thermopile is embedded on opposing surfaces of the hot plate.

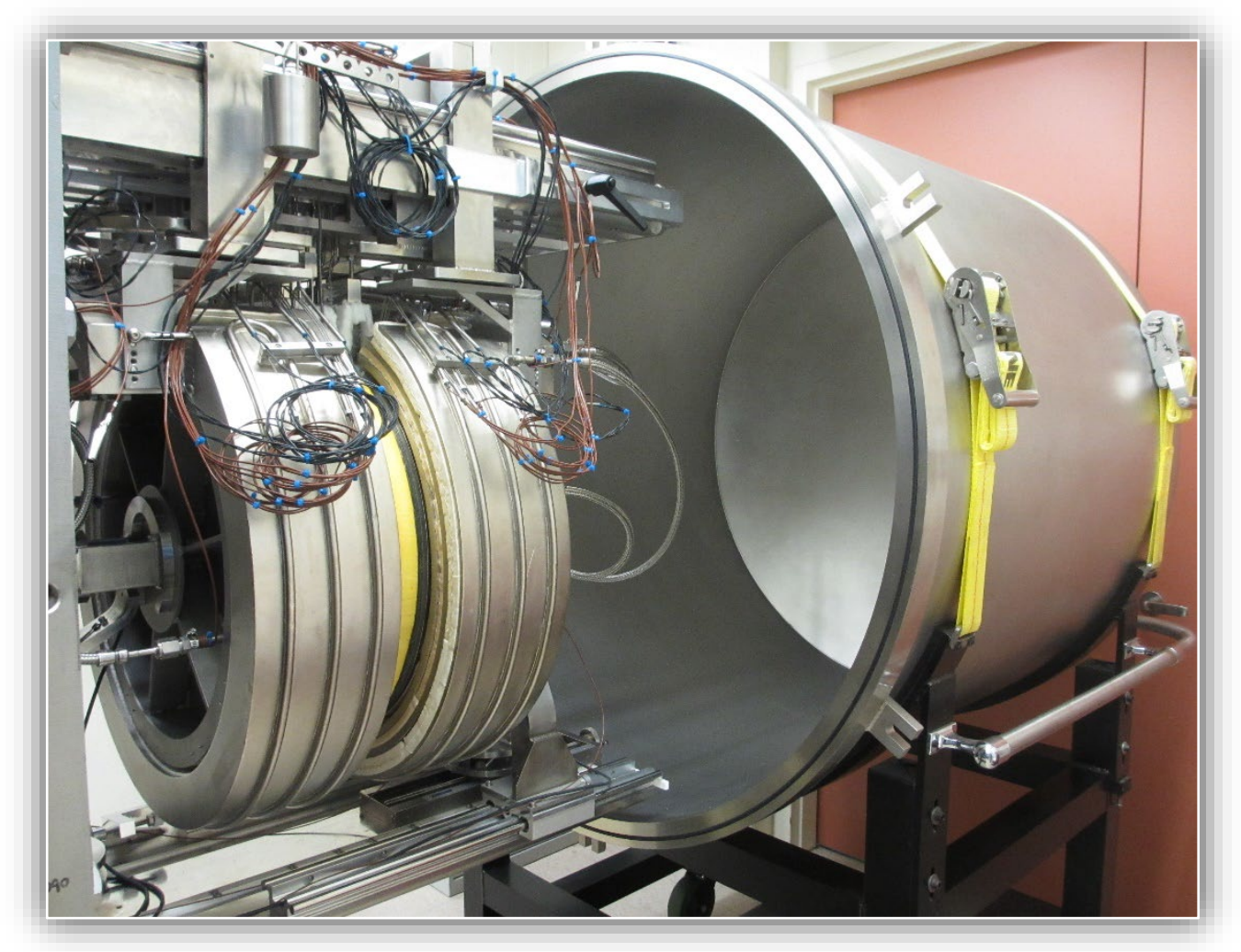

Fig. 18. NIST $500 \mathrm{~mm}$ diameter guarded-hot-plate apparatus: plates and edge guard (foreground), vacuum bell jar (background). The edge guards are partially separated revealing an amber SRM 1450e insulation specimen. 
The metal-sheathed heaters for the hot plate are $3.2 \mathrm{~mm}$ in diameter and were custom manufactured using an internal bifilar design of nickel wires butt welded to gold (99.99\% nominal purity) wire leads. The heaters were formed such that the nickel-gold weld terminations were within $3 \mathrm{~mm}$ (or less) of the plate edge and the 2-to-4 wire transition of the meter-plate heater was within $1 \mathrm{~mm}$ of the centerline of the guard gap. After forming, the heaters were vacuum brazed in serpentine patterns at the midplane of the plate [18]. The electrical resistance of the meter-plate heater at room temperature is approximately $3.3 \Omega$.

Each cold plate system, shown schematically in Fig. 17 as a single layer, is in fact a multilayered assembly consisting of the following components: thermometry plate; woven glass fabric; heater plate; microporous insulation; coolant plate; rigid alumina insulation; and, water-cooled back plate. Active cooling of each cold plate system was accomplished by circulation of a chilled liquid through the coolant plate (described in Sec. 6.6.1). Temperature control of the thermometry plate was provided by the adjoining heater plate.

The primary temperature sensors installed in each plate for the determination of $T_{h}, T_{c 1}$, and $T_{c 2}$ in Eq. (19) are long-stem standard platinum resistance thermometers (SPRTs). The sensors have a 4-wire sensing element located within the first $50 \mathrm{~mm}$ of the sheath tip. The SPRT is placed in a well that is brazed at the midplane of the plate so that the sensing region resides in the geometric center of the plate. To check temperature uniformity of a plate, six Type $\mathrm{N}$ metal sheathed thermocouples, $1.6 \mathrm{~mm}$ in diameter, were brazed in the surface of each plate at the locations described in Appendix E (E1.2).

\subsubsection{Heating and Cooling Equipment}

There are 16 separate heating circuits for controlling the temperatures of the apparatus components. Table 7 summarizes their (On/Off) status for each heater (items 1 through 16) at each mean temperature setting used during the development of SRM 1450e. The meter plate and cold plate heaters are items 1,5 , and 6 , respectively. The primary guard (plate) heater for the meter plate is item 2. The remaining active heaters (items 3, 4, 9, 10, 11 through 16) function as secondary guards. The subscripts (1) and (2) in Table 7 refer to inboard and outboard components depicted in Fig. 17. The inactive guard heaters (items $3,7,8,13$, and 14) were not required for the temperature range of interest for thermal characterization of SRM 1450e. All active electrical heaters were energized by DC power supplies that were under proportional-integral-derivative (PID) computer control during testing [22].

There are four separate active cooling arrangements for the apparatus - specifically, the inboard and outboard coolant and water-jacket systems (items 17 through 20 in Table 7). The temperature for each system was maintained by a designated refrigerated circulation bath. At $280 \mathrm{~K}$, low-temperature chillers, circulating ethanol, were installed. At other temperatures, the chillers were replaced by refrigerated baths circulating a mixture of ethanol and distilled water (volume fraction of $50 \%$ ). For all tests, the water jackets were operated with distilled water at a baseline temperature of $20{ }^{\circ} \mathrm{C}$. All external thermal surfaces of the apparatus were protected by these constant-temperature water-jacket systems (Fig. 18). Table 8 summarizes the bath setpoints, in ${ }^{\circ} \mathrm{C}$, for below- and near-ambient operation at each mean temperature setting used during the thermal characterization of SRM $1450 \mathrm{e}$. 
Table 7. Status of heating and cooling equipment.

\begin{tabular}{|c|c|c|c|c|c|c|}
\hline Item & Description & $280 \mathrm{~K}$ & $300 \mathrm{~K}$ & $320 \mathrm{~K}$ & $340 \mathrm{~K}$ & $360 \mathrm{~K}$ \\
\hline 1 & Meter plate & On & On & On & On & On \\
\hline 2 & Guard plate & On & On & On & On & On \\
\hline 3 & Hot plate rim & Off & Off & Off & Off & Off \\
\hline 4 & Hot plate connection & On & On & On & On & On \\
\hline 5 & Cold plate $_{1}$ & On & On & On & On & On \\
\hline 6 & Cold plate 2 & On & On & On & On & On \\
\hline 7 & Cold plate 1 rim & Off & Off & Off & Off & Off \\
\hline 8 & Cold plate 2 rim & Off & Off & Off & Off & Off \\
\hline 9 & Cold plate 1 connection & On & On & On & On & On \\
\hline 10 & Cold plate 2 connection & On & On & On & On & On \\
\hline 11 & Edge guard & On & On & On & On & On \\
\hline 12 & Edge guard & On & On & On & On & On \\
\hline 13 & Edge guard ${ }_{1}$ auxiliary & Off & Off & Off & Off & Off \\
\hline 14 & Edge guard 2 auxiliary & Off & Off & Off & Off & Off \\
\hline 15 & Edge guard $\operatorname{arch}$ & On & On & On & On & On \\
\hline 16 & Edge guard 2 arch & On & On & On & On & On \\
\hline 17 & Coolant bath 1 & $\mathrm{a}$ & $\mathrm{b}$ & b & $\mathrm{b}$ & $\mathrm{b}$ \\
\hline 18 & Coolant bath 2 & a & b & $\mathrm{b}$ & $\mathrm{b}$ & b \\
\hline 19 & Water jacket 1 & On & On & On & On & On \\
\hline 20 & Water jacket2 2 & On & On & On & On & On \\
\hline 21 & Mass flow controller & Off & Off & Off & Off & Off \\
\hline
\end{tabular}

Table 8. Bath temperature setpoints.

\begin{tabular}{|c|c|c|c|c|c|c|}
\hline Item & Description & $280 \mathrm{~K}$ & $300 \mathrm{~K}$ & $320 \mathrm{~K}$ & $340 \mathrm{~K}$ & $360 \mathrm{~K}$ \\
\hline 17 & Coolant bath 1 & $-30^{\circ} \mathrm{C}$ & $-5^{\circ} \mathrm{C}$ & $15^{\circ} \mathrm{C}$ & $20^{\circ} \mathrm{C}$ & $20^{\circ} \mathrm{C}$ \\
\hline 18 & Coolant bath 2 & $-30^{\circ} \mathrm{C}$ & $-5^{\circ} \mathrm{C}$ & $15^{\circ} \mathrm{C}$ & $20^{\circ} \mathrm{C}$ & $20^{\circ} \mathrm{C}$ \\
\hline 19 & Water jacket ${ }_{1}$ & $20^{\circ} \mathrm{C}$ & $20^{\circ} \mathrm{C}$ & $20^{\circ} \mathrm{C}$ & $20^{\circ} \mathrm{C}$ & $20^{\circ} \mathrm{C}$ \\
\hline 20 & Water jacket $_{2}$ & $20^{\circ} \mathrm{C}$ & $20^{\circ} \mathrm{C}$ & $20^{\circ} \mathrm{C}$ & $20^{\circ} \mathrm{C}$ & $20^{\circ} \mathrm{C}$ \\
\hline
\end{tabular}

\subsubsection{Vacuum Equipment}

Atmospheric pressure control at $60 \mathrm{kPa}, 80 \mathrm{kPa}$, and $100 \mathrm{kPa}$ was achieved with a small diaphragm pump, vacuum controller, and vacuum gauge with an air admittance solenoid valve. The equipment is not shown in Fig. 18 but is described by Zarr and Thomas [22].

\subsubsection{Specimen Installation and Operation}

Each pair of test specimens was installed in the NIST $500 \mathrm{~mm}$ guarded-hot-plate apparatus at, or near, room conditions following a standard operating procedure. Before installation, the datum for the thickness display (Heidenhain ND 231B) was set with a fixture of $25.4 \mathrm{~mm}$ (1 in.) diameter precision spheres under an applied loading of $133 \mathrm{~N}$ to $178 \mathrm{~N}$ ( 30 $\mathrm{lb}_{\mathrm{f}}$ to $40 \mathrm{lb}_{\mathrm{f}}$ ). The specimen pair was installed under the same range of applied loading. 
After enclosing the apparatus with the vacuum bell jar, the cooling, vacuum, and heating equipment were energized (in that order). Computer control of the apparatus was accomplished using a visual graphical programming language. The test data (including $T_{h}, T_{c}, L$, and $Q$ ) were collected each minute during a $4 \mathrm{~h}$ steady-state period ( $n=240$ observations per parameter) using a computer-controlled data acquisition system [22].

\subsection{Guarded-Hot-Plate Measurements}

The guarded-hot-plate measurements for production of SRM 1450e commenced on February 25, 2019 and concluded on May 8, 2019. The test facility was shut down for a sitewide maintenance outage from April 10 to April 16, 2019. A check standard consisting of a pair of SRM 1450d specimens $(107,155)$ was utilized at the beginning, end, and between Tests \#3 and \#4 (Table 6) to check the operation of the apparatus as testing progressed. At the conclusion of the production run, specimens 594 and 769 (from Table 6) were selected for subsequent validation measurements from $280 \mathrm{~K}$ to $360 \mathrm{~K}$.

\subsubsection{Data Summary (Tabular Format)}

Table 9 summarizes the main experimental results - specimen information, input estimates, and the output estimate for measured thermal conductivity $\left(\lambda_{\exp }\right)$ - for the 15 specimen pairs specified in the experimental design (Table 6). The rows of data in Table 9 are grouped by $T_{m}$ from $280 \mathrm{~K}$ to $360 \mathrm{~K}$ and, within each level of $T_{m}$, the average specimen densities $\left(\rho_{\text {av }}\right)$ are arranged from lowest to highest value. Within each level of $\rho_{a v}$, the data are ranked by air pressure $(p)$ from $60 \mathrm{kPa}$ to $100 \mathrm{kPa}$.

The subscript notations (1) and (2) for ID in Table 9 denote the inboard and outboard specimen, respectively; where inboard refers to the specimen location nearest to the vertical vacuum baseplate of the apparatus. The bulk density $\rho_{\mathrm{av}}$ is the average of $\rho_{1}$ and $\rho_{2}$ for the specimen pair (ID 1 and $\mathrm{ID}_{2}$ ) under test. The heat flux, $q$, is equal to the heat flow rate $(Q)$ divided by the metering area $(A)$. Estimates for $A$ were corrected for thermal expansion effects of the meter-plate radius (Appendix E). The output estimates for $\lambda$ include an extra digit to reduce rounding errors.

During testing, the specimens were compressed slightly under load, thereby decreasing the in-situ specimen thickness $(L)$ and increasing the bulk density. The densities $\left(\rho_{\mathrm{s}}\right)$ in Table 7 were adjusted by Eq. (20).

$$
\rho=\rho_{\mathrm{s}}\left(\frac{L_{\mathrm{s}}}{L}\right)
$$

where $\rho$ is the in-situ bulk density during testing and $L_{\mathrm{s}}$ was the specimen thickness as determined on the granite surface plate (Sec. 4.3). No adjustments were made for changes in the specimen lateral surface area or mass. Values of $\rho$ increased from $0.7 \%$ to $1.5 \%$. 
Table 9. SRM 1450e sub-sample thermal conductivity data.

\begin{tabular}{|c|c|c|c|c|c|c|c|c|}
\hline ID $_{1}$ & ID $_{2}$ & $\begin{array}{c}\rho_{\mathrm{av}} \\
\left(\mathrm{kg} \cdot \mathrm{m}^{-3}\right)\end{array}$ & $\begin{array}{l}T_{m} \\
(\mathbf{K})\end{array}$ & $\begin{array}{l}\Delta T_{\text {av }} \\
(\mathbf{K})\end{array}$ & $\begin{array}{c}p \\
\text { (kPa) }\end{array}$ & $\begin{array}{l}L_{\text {av }} \\
(\mathrm{m})\end{array}$ & $\begin{array}{c}q \\
\left(\mathbf{W} \cdot \mathbf{m}^{-2}\right)\end{array}$ & $\begin{array}{c}\lambda_{\exp } \\
\left(\mathbf{W} \cdot \mathbf{m}^{-1} \cdot \mathbf{K}^{-1}\right)\end{array}$ \\
\hline 707 & 751 & 110.0 & 280.001 & 25.002 & 59.8 & 0.02496 & 60.98 & 0.03044 \\
\hline 707 & 751 & 110.0 & 280.002 & 25.000 & 80.0 & 0.02497 & 61.08 & 0.03050 \\
\hline 707 & 751 & 110.0 & 280.005 & 25.003 & 100.7 & 0.02497 & 61.16 & 0.03053 \\
\hline 736 & 914 & 128.4 & 280.001 & 24.999 & 59.9 & 0.02485 & 61.61 & 0.03062 \\
\hline 736 & 914 & 128.4 & 280.001 & 25.000 & 80.0 & 0.02485 & 61.74 & 0.03069 \\
\hline 736 & 914 & 128.4 & 280.001 & 25.001 & 100.0 & 0.02485 & 61.80 & 0.03071 \\
\hline 809 & 828 & 146.1 & 280.001 & 25.001 & 59.9 & 0.02488 & 62.84 & 0.03127 \\
\hline 809 & 828 & 146.1 & 280.002 & 25.001 & 80.0 & 0.02488 & 62.96 & 0.03133 \\
\hline 809 & 828 & 146.3 & 280.001 & 25.000 & 100.3 & 0.02486 & 63.04 & 0.03135 \\
\hline 780 & 862 & 110.8 & 300.000 & 25.000 & 60.1 & 0.02496 & 65.04 & 0.03247 \\
\hline 780 & 862 & 110.9 & 300.000 & 24.999 & 80.0 & 0.02494 & 65.10 & 0.03248 \\
\hline 780 & 862 & 110.9 & 300.000 & 25.001 & 100.0 & 0.02495 & 65.14 & 0.03250 \\
\hline 634 & 850 & 129.0 & 300.000 & 25.000 & 59.9 & 0.02501 & 65.85 & 0.03293 \\
\hline 634 & 850 & 129.0 & 300.000 & 24.999 & 80.0 & 0.02501 & 65.92 & 0.03297 \\
\hline 634 & 850 & 129.0 & 300.000 & 24.999 & 99.9 & 0.02501 & 65.96 & 0.03299 \\
\hline 729 & 859 & 146.3 & 300.000 & 25.001 & 59.9 & 0.02520 & 66.38 & 0.03346 \\
\hline 729 & 859 & 146.2 & 300.003 & 25.007 & 79.9 & 0.02521 & 66.54 & 0.03354 \\
\hline 729 & 859 & 146.3 & 300.001 & 25.001 & 99.9 & 0.02520 & 66.54 & 0.03354 \\
\hline 571 & 654 & 112.1 & 319.999 & 24.996 & 59.9 & 0.02490 & 69.93 & 0.03482 \\
\hline 571 & 654 & 112.2 & 320.000 & 25.000 & 80.0 & 0.02489 & 69.97 & 0.03482 \\
\hline 571 & 654 & 112.1 & 320.003 & 25.005 & 99.8 & 0.02490 & 69.99 & 0.03484 \\
\hline 594 & 769 & 129.9 & 320.000 & 25.000 & 59.9 & 0.02498 & 70.06 & 0.03501 \\
\hline 594 & 769 & 129.9 & 320.000 & 25.000 & 80.0 & 0.02498 & 70.11 & 0.03503 \\
\hline 594 & 769 & 129.9 & 320.001 & 25.003 & 99.9 & 0.02499 & 70.14 & 0.03504 \\
\hline 722 & 731 & 149.1 & 320.000 & 24.999 & 59.9 & 0.02492 & 71.05 & 0.03542 \\
\hline 722 & 731 & 149.1 & 320.003 & 25.003 & 80.0 & 0.02493 & 71.17 & 0.03548 \\
\hline 722 & 731 & 149.1 & 320.000 & 25.000 & 99.0 & 0.02492 & 71.16 & 0.03547 \\
\hline 683 & 738 & 111.9 & 340.000 & 25.000 & 59.8 & 0.02512 & 73.80 & 0.03708 \\
\hline 683 & 738 & 111.9 & 340.000 & 25.000 & 79.9 & 0.02511 & 73.76 & 0.03705 \\
\hline 683 & 738 & 111.9 & 340.000 & 25.000 & 99.9 & 0.02510 & 73.74 & 0.03702 \\
\hline 811 & 830 & 131.7 & 340.000 & 24.999 & 59.9 & 0.02503 & 74.14 & 0.03711 \\
\hline 811 & 830 & 131.7 & 340.000 & 24.999 & 80.0 & 0.02502 & 74.16 & 0.03711 \\
\hline 811 & 830 & 131.7 & 340.001 & 25.003 & 99.9 & 0.02503 & 74.13 & 0.03710 \\
\hline 720 & 906 & 151.4 & 340.000 & 25.000 & 59.9 & 0.02516 & 75.03 & 0.03775 \\
\hline 720 & 906 & 151.5 & 340.001 & 25.001 & 80.0 & 0.02515 & 75.05 & 0.03774 \\
\hline 720 & 906 & 151.5 & 340.001 & 25.003 & 99.8 & 0.02515 & 75.02 & 0.03772 \\
\hline 647 & 781 & 116.0 & 360.000 & 25.000 & 60.0 & 0.02489 & 78.84 & 0.03925 \\
\hline 647 & 781 & 116.0 & 360.000 & 24.999 & 80.0 & 0.02489 & 78.75 & 0.03920 \\
\hline 647 & 781 & 116.0 & 360.001 & 25.001 & 100.0 & 0.02489 & 78.63 & 0.03913 \\
\hline 627 & 856 & 133.3 & 360.000 & 25.000 & 59.9 & 0.02515 & 79.32 & 0.03990 \\
\hline 627 & 856 & 133.3 & 360.000 & 25.000 & 80.0 & 0.02515 & 79.29 & 0.03988 \\
\hline 627 & 856 & 133.3 & 360.000 & 25.000 & 100.1 & 0.02515 & 79.23 & 0.03986 \\
\hline 801 & 825 & 154.4 & 360.000 & 25.000 & 59.9 & 0.02509 & 79.40 & 0.03984 \\
\hline 801 & 825 & 154.4 & 360.001 & 25.001 & 80.0 & 0.02508 & 79.36 & 0.03980 \\
\hline 801 & 825 & 154.5 & 360.001 & 25.002 & 99.5 & 0.02507 & 79.22 & 0.03972 \\
\hline
\end{tabular}




\subsubsection{Secondary Factors}

Table 10 summarizes test data for seven important secondary factors that were either fixed or merely monitored during the test. The order of presentation is the same as that in Table 9 . The factors include the specimen clamping pressure $\left(p_{\mathrm{a}}\right)$, primary guard temperature difference $\left(\Delta T_{\text {gap }}\right)$, secondary edge guard temperatures $\left(T_{\mathrm{eg} 1}, T_{\mathrm{eg} 2}\right)$, chamber air temperature $\left(T_{\mathrm{a}}\right)$, and water jacket temperatures $\left(T_{\mathrm{WJ} 1}, T_{\mathrm{WJ} 2}\right)$ at their respective plate inlets. The data for these quantities are examined below.

The clamping pressure $\left(p_{\mathrm{a}}\right)$ was manually set at the beginning of each test (Sec. 6.6.3) by the operator. The average value of $p_{\mathrm{a}}$ was $0.526 \mathrm{kPa}$ but, unfortunately, as evident in Table 10 , the values ranged from $0.47 \mathrm{kPa}$ to $0.60 \mathrm{kPa}$, or about $25 \%$ due to changes in mean

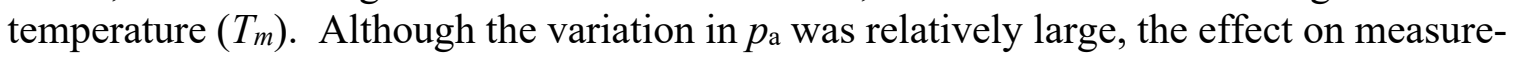
ments of $\lambda$ was expected to be small.

A major factor affecting the measurement of $\lambda$ is the temperature difference across the guard gap $\left(\Delta T_{\text {gap }}\right)$, determined by two 12-junction Type $\mathrm{K}$ thermopiles arranged in a circumferential zig-zag pattern across the guard gap. Ideally, $\Delta T_{\text {gap }}$ is maintained at, or near, zero kelvin to minimize detrimental lateral heat flows that would affect the measurement of the specimen heat flow $(Q)$. A previous sensitivity study [25] for a pair of SRM 1450d specimens $(\Delta T$ of $25 \mathrm{~K})$ showed that an imbalance of $\Delta T_{\text {gap }}$ equal to $\pm 250 \mathrm{mK}$ affected the measurement of $\lambda$ by $\pm 5 \%$. The absolute values of $\Delta T_{\text {gap }}$ in Table 10 are on the order of $0.7 \mathrm{mK}$, or less, except for one test where $\Delta T_{\text {gap }}$ was approximately $1.4 \mathrm{mK}$.

The temperatures of the inboard and outboard edge guards ( $T_{\mathrm{eg} 1}, T_{\mathrm{eg} 2}$, respectively) were determined from the averages of six Type $\mathrm{N}$ thermocouples brazed in the inner ring of each guard system. Comparison of the edge guard temperatures in Table 10 with the mean temperatures $\left(T_{m}\right)$ in Table 9 shows that the differences were $10 \mathrm{mK}$, or less. The sensitivity study [25] showed that an imbalance in $T_{\text {eg1 }}$ and $T_{\text {eg2 }}$ of $\pm 2 \mathrm{~K}$ from $T_{m}$ had a negligible effect on measured values of $\lambda$.

The water jacket temperatures $\left(T_{\mathrm{WJ} 1}, T_{\mathrm{WJ} 2}\right)$ were measured by Type $\mathrm{T}$ thermocouples wrapped around the inlet piping to the cold plate system. As evident in Table 10, $T_{\mathrm{WJ}}$ and

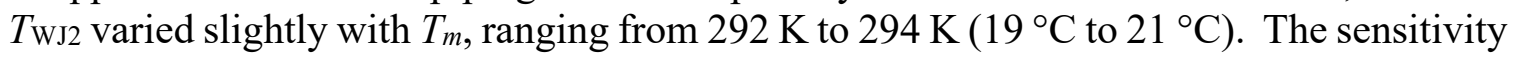
study [25] showed that an imbalance in $T_{\mathrm{WJ} 1}$ and $T_{\mathrm{WJ} 2}$ of $\pm 2 \mathrm{~K}$ from $T_{m}$ had a negligible effect on measured values of $\lambda$.

The ambient chamber air temperature $\left(T_{\mathrm{a}}\right)$ was uncontrolled and determined from the average of six Type $\mathrm{T}$ thermocouples placed at carefully chosen locations inside the vacuum bell jar. Table 10 shows that $T_{\mathrm{a}}$ ranged from $290.9 \mathrm{~K}$ to $301.5 \mathrm{~K}$ (difference of $10.6 \mathrm{~K}$ ) for values of $T_{m}$ from $280 \mathrm{~K}$ to $360 \mathrm{~K}$. However, because $T_{\text {eg1 }}$ and $T_{\text {eg2 }}$ were maintained within a few millikelvin of $T_{m}$, the effect of $T_{\mathrm{a}}$ on measurements of $\lambda$ was expected to be small. 
Table 10. SRM 1450e sub-sample secondary test factors.

\begin{tabular}{|c|c|c|c|c|c|c|c|c|}
\hline ID $_{1}$ & $\mathrm{ID}_{2}$ & $\begin{array}{c}p_{\mathrm{a}} \\
(\mathbf{k P a})\end{array}$ & $\begin{array}{c}\Delta T_{\text {gap }} \\
(\mathrm{K})\end{array}$ & $\begin{array}{l}T_{\text {eg1 }} \\
(\mathrm{K})\end{array}$ & $\begin{array}{l}T_{\text {eg2 }} \\
\text { (K) }\end{array}$ & $\begin{array}{c}T_{\mathrm{a}} \\
(\mathbf{K})\end{array}$ & $\begin{array}{c}T_{\mathrm{WJ1}} \\
(\mathbf{K})\end{array}$ & $\begin{array}{c}T_{\mathrm{WJ} 2} \\
(\mathbf{K})\end{array}$ \\
\hline 707 & 751 & 0.55 & 0.00004 & 280.00 & 280.00 & 290.9 & 292.4 & 293.2 \\
\hline 707 & 751 & 0.58 & 0.00004 & 280.00 & 280.00 & 291.5 & 292.4 & 293.3 \\
\hline 707 & 751 & 0.58 & -0.00036 & 280.01 & 280.00 & 290.9 & 292.4 & 293.2 \\
\hline 736 & 914 & 0.48 & 0.00005 & 280.00 & 280.00 & 292.7 & 292.9 & 293.4 \\
\hline 736 & 914 & 0.48 & 0.00004 & 280.00 & 280.00 & 291.0 & 292.8 & 293.3 \\
\hline 736 & 914 & 0.48 & -0.00002 & 280.00 & 280.00 & 292.1 & 292.9 & 293.3 \\
\hline 809 & 828 & 0.49 & 0.00005 & 280.00 & 280.00 & 291.1 & 292.4 & 293.3 \\
\hline 809 & 828 & 0.50 & 0.00004 & 280.00 & 280.00 & 291.1 & 292.4 & 293.2 \\
\hline 809 & 828 & 0.48 & 0.00015 & 280.00 & 280.00 & 291.0 & 292.8 & 293.2 \\
\hline 780 & 862 & 0.55 & -0.00002 & 300.00 & 300.00 & 295.2 & 293.0 & 293.4 \\
\hline 780 & 862 & 0.55 & 0.00000 & 300.00 & 300.00 & 295.4 & 293.0 & 293.4 \\
\hline 780 & 862 & 0.55 & -0.00008 & 300.00 & 300.00 & 295.0 & 293.0 & 293.4 \\
\hline 634 & 850 & 0.50 & 0.00000 & 300.00 & 300.00 & 295.2 & 293.0 & 293.4 \\
\hline 634 & 850 & 0.50 & -0.00001 & 300.00 & 300.00 & 295.1 & 293.0 & 293.4 \\
\hline 634 & 850 & 0.51 & 0.00006 & 300.00 & 300.00 & 294.9 & 293.0 & 293.4 \\
\hline 729 & 859 & 0.54 & 0.00000 & 300.00 & 300.00 & 295.0 & 293.0 & 293.4 \\
\hline 729 & 859 & 0.55 & -0.00013 & 300.00 & 300.00 & 294.8 & 293.0 & 293.4 \\
\hline 729 & 859 & 0.55 & -0.00005 & 300.00 & 300.00 & 295.0 & 293.0 & 293.4 \\
\hline 571 & 654 & 0.55 & 0.00015 & 320.00 & 320.00 & 297.9 & 293.1 & 293.5 \\
\hline 571 & 654 & 0.55 & -0.00001 & 320.00 & 320.00 & 298.3 & 293.2 & 293.5 \\
\hline 571 & 654 & 0.55 & 0.00037 & 320.00 & 320.00 & 298.0 & 293.1 & 293.5 \\
\hline 594 & 769 & 0.50 & 0.00000 & 320.00 & 320.00 & 298.3 & 293.2 & 293.5 \\
\hline 594 & 769 & 0.51 & 0.00002 & 320.00 & 320.00 & 298.3 & 293.2 & 293.5 \\
\hline 594 & 769 & 0.51 & 0.00016 & 320.00 & 320.00 & 298.1 & 293.1 & 293.5 \\
\hline 722 & 731 & 0.58 & 0.00002 & 320.00 & 320.00 & 298.7 & 293.2 & 293.6 \\
\hline 722 & 731 & 0.60 & 0.00144 & 320.00 & 320.00 & 297.8 & 293.1 & 293.5 \\
\hline 722 & 731 & 0.59 & 0.00002 & 320.00 & 320.00 & 298.3 & 293.2 & 293.6 \\
\hline 683 & 738 & 0.49 & 0.00001 & 340.00 & 340.00 & 298.2 & 293.1 & 293.5 \\
\hline 683 & 738 & 0.50 & -0.00001 & 340.00 & 340.00 & 298.4 & 293.1 & 293.5 \\
\hline 683 & 738 & 0.51 & -0.00004 & 340.00 & 340.00 & 298.7 & 293.1 & 293.5 \\
\hline 811 & 830 & 0.53 & 0.00003 & 340.00 & 340.00 & 299.7 & 293.2 & 293.6 \\
\hline 811 & 830 & 0.54 & 0.00004 & 340.00 & 340.00 & 300.0 & 293.2 & 293.6 \\
\hline 811 & 830 & 0.54 & 0.00053 & 340.00 & 340.00 & 300.0 & 293.2 & 293.6 \\
\hline 720 & 906 & 0.47 & 0.00033 & 340.00 & 340.00 & 299.8 & 293.2 & 293.6 \\
\hline 720 & 906 & 0.47 & -0.00005 & 340.00 & 340.00 & 300.0 & 293.2 & 293.6 \\
\hline 720 & 906 & 0.48 & 0.00010 & 340.00 & 340.00 & 298.9 & 293.1 & 293.5 \\
\hline 647 & 781 & 0.51 & 0.00003 & 360.00 & 360.00 & 299.1 & 293.1 & 293.5 \\
\hline 647 & 781 & 0.52 & 0.00037 & 360.00 & 360.01 & 299.6 & 293.1 & 293.6 \\
\hline 647 & 781 & 0.51 & -0.00010 & 360.00 & 360.00 & 299.8 & 293.1 & 293.6 \\
\hline 627 & 856 & 0.52 & 0.00001 & 360.00 & 360.00 & 301.0 & 293.2 & 293.6 \\
\hline 627 & 856 & 0.53 & 0.00001 & 360.00 & 360.00 & 301.3 & 293.2 & 293.7 \\
\hline 627 & 856 & 0.53 & -0.00001 & 360.00 & 359.99 & 301.5 & 293.3 & 293.7 \\
\hline 801 & 825 & 0.54 & 0.00066 & 360.00 & 360.00 & 300.5 & 293.2 & 293.6 \\
\hline 801 & 825 & 0.55 & -0.00007 & 360.00 & 360.00 & 301.1 & 293.2 & 293.7 \\
\hline 801 & 825 & 0.55 & 0.00005 & 360.00 & 360.00 & 301.5 & 293.3 & 293.7 \\
\hline
\end{tabular}




\subsection{Check Standard Data}

Table 11 summarizes the thermal conductivity measurement data for the SRM 1450d check standard $(107,155)$ described in Sec. 6.7. The average bulk density ( $\left.\rho_{\text {av }}\right)$ for the specimen pair was $120 \mathrm{~kg} \cdot \mathrm{m}^{-3}$.

Table 11. Thermal conductivity data for SRM 1450d check standard.

\begin{tabular}{cccccc}
\hline Date & $\begin{array}{c}\boldsymbol{T}_{\boldsymbol{m}} \\
(\mathbf{K})\end{array}$ & $\begin{array}{c}\Delta \boldsymbol{T}_{\text {av }} \\
(\mathbf{K})\end{array}$ & $\begin{array}{c}\boldsymbol{p} \\
(\mathbf{k P a})\end{array}$ & $\begin{array}{c}\boldsymbol{L}_{\text {av }} \\
(\mathbf{m})\end{array}$ & $\begin{array}{c}\boldsymbol{\lambda}_{\exp } \\
\left(\mathbf{W} \cdot \mathbf{m}^{-1} \cdot \mathbf{K}^{-1}\right)\end{array}$ \\
\hline 25 Feb 2019 & 300.00 & 25.01 & 100.2 & 0.02583 & 0.03248 \\
12 Mar 2019 & 300.00 & 25.01 & 100.0 & 0.02596 & 0.03256 \\
13 Mar 2019 & 300.01 & 25.01 & 99.4 & 0.02595 & 0.03253 \\
12 May 2019 & 300.00 & 25.00 & 99.9 & 0.02593 & 0.03253 \\
\hline
\end{tabular}

The mean value for $\lambda$ exp in Table 11 is $0.03252 \mathrm{~W} \cdot \mathrm{m}^{-1} \cdot \mathrm{K}^{-1}$ and the relative range (maximum value minus the minimum value divided by the mean) is $0.22 \%$ indicating the that the measurement process was in a state of statistical control during the production run for SRM 1450e.

\section{Analysis and Uncertainty Evaluation}

Section 7 presents a graphical analysis of the thermal conductivity data for the SRM 1450e production run, final model determination, assessment of measurement uncertainties, and information on metrological traceability.

\subsection{Data Screening (Graphical Analysis)}

Figures 19, 20, and 21 plot values of $\lambda_{\exp }$ from Table 9 as a function of the input variables $\rho, T_{m}$, and $p$, respectively, for the design model given in Eq. (15). In each plot, the individual data points are plotted as filled circle, square, and triangle symbols (without error bars for clarity) corresponding to the three main levels selected for bulk density. For Figs. 19 and 21, the five levels of $T_{m}$ from $280 \mathrm{~K}, 300 \mathrm{~K}, 320 \mathrm{~K}, 340 \mathrm{~K}$, and $360 \mathrm{~K}$ are given for each profile.

The limits of the $y$-axis for each plot have been purposely fixed for a straightforward comparison of the effect of each input variable on the response variable $\lambda$ exp. A cursory review of the three plots strongly suggests that, in the range of $\rho_{\mathrm{s}}, T_{m}$, and $p$ covered for the 450 specimens comprising the current SRM, $T_{m}$, followed by $\rho$ have the greatest effect on $\lambda$. The effect of $p$, for the range from $60 \mathrm{kPa}$ to $100 \mathrm{kPa}$ appears insignificant. 


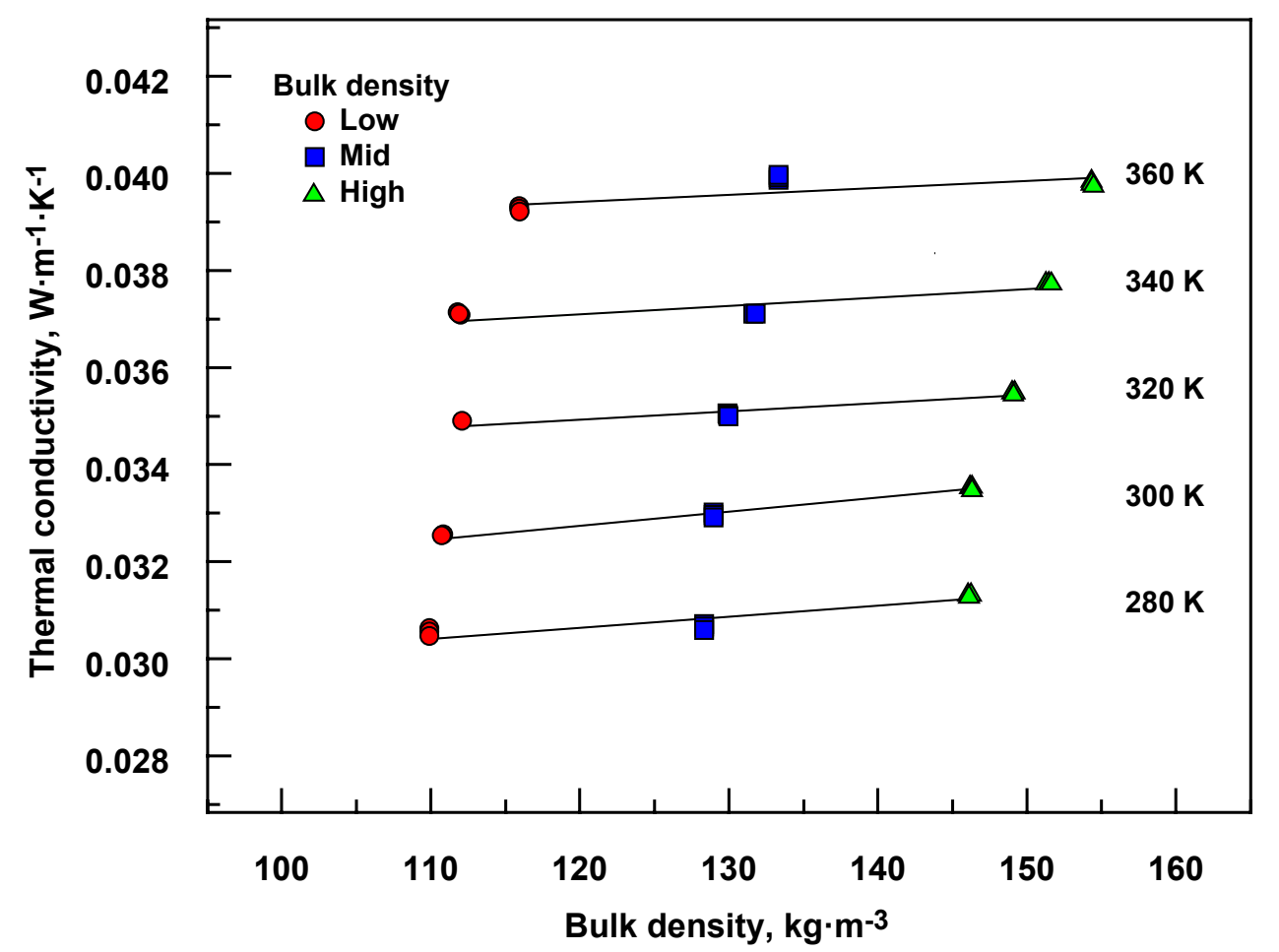

Fig. 19. Scatter plot of $\lambda_{\exp }$ versus $\rho$.

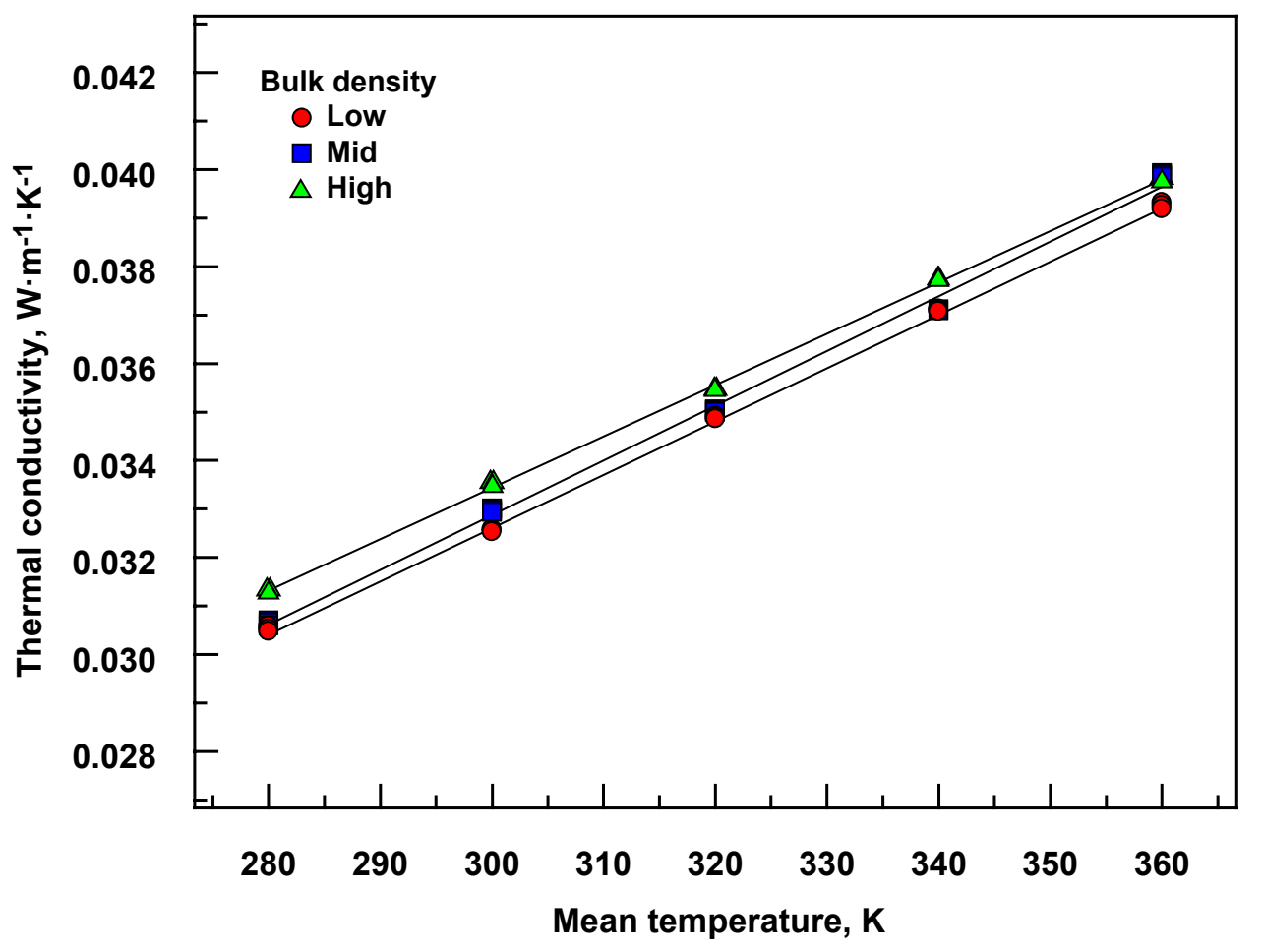

Fig. 20. Scatter plot of $\lambda_{\exp }$ versus $T_{m}$. 


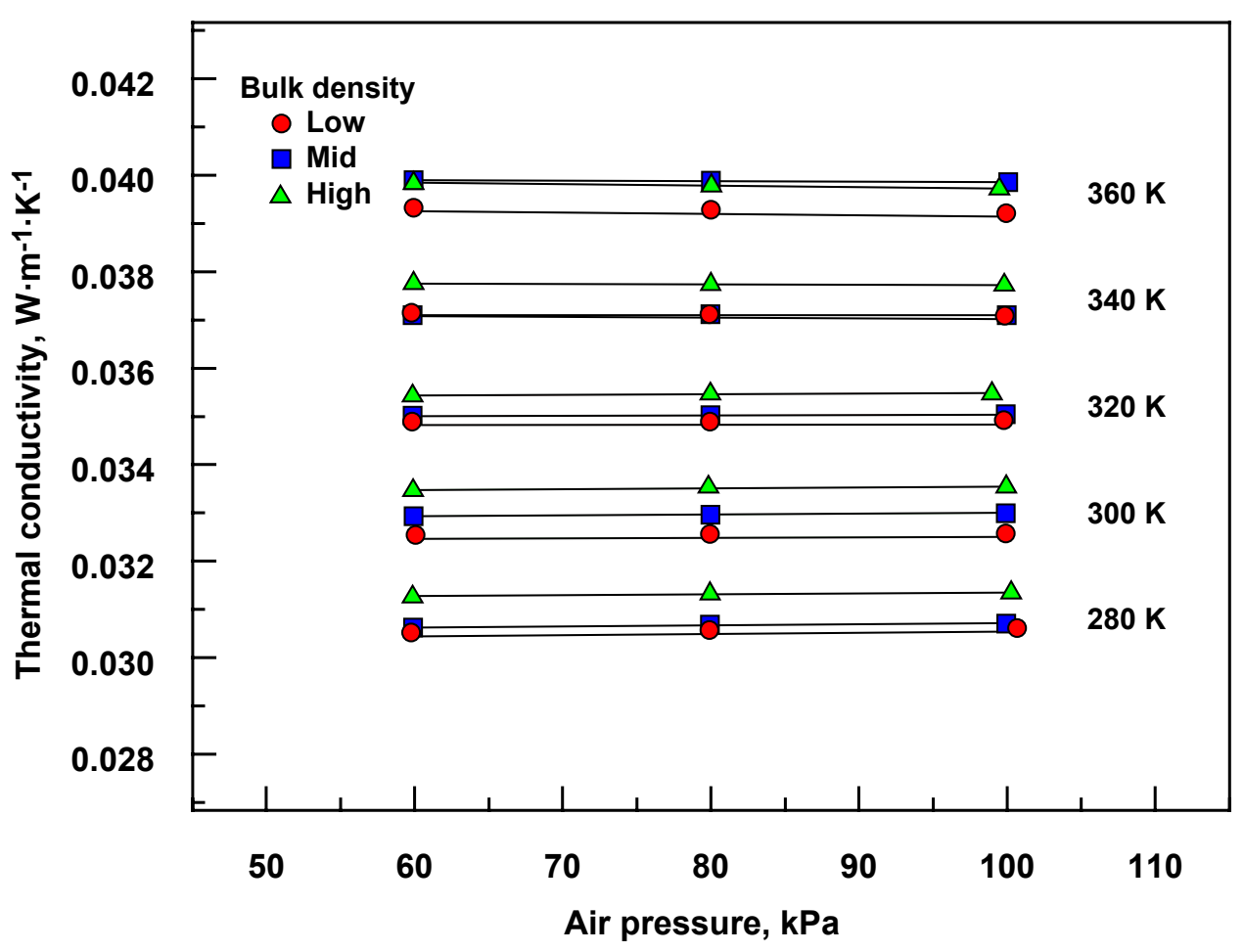

Fig. 21. Scatter plot of $\lambda_{\exp }$ versus $p$.

Table 12 summarizes the slopes of the lines shown in Fig. 19 and their corresponding $t$ values. For the five profiles (from $280 \mathrm{~K}$ to $360 \mathrm{~K}$ ), the slopes are statistically significant $(|t| \geq 2)$ at $95 \%$ confidence.

Table 12. Summary of linear profiles for $\lambda_{\exp }$ versus $\rho$ (Fig. 19).

\begin{tabular}{ccc}
\hline $\begin{array}{r}\boldsymbol{T}_{\boldsymbol{m}} \\
(\mathbf{K})\end{array}$ & $\begin{array}{c}\text { Slope } \\
\left(\mathbf{W} \cdot \mathbf{m}^{\mathbf{2}} \cdot \mathbf{K}^{-1} \cdot \mathbf{k g}^{-\mathbf{1}}\right)\end{array}$ & $\begin{array}{c}\boldsymbol{t} \text {-value } \\
(\mathbf{d i m e n s i o n l e s s})\end{array}$ \\
\hline 280 & $2.274 \times 10^{-5}$ & 7.6 \\
300 & $2.905 \times 10^{-5}$ & 31.4 \\
320 & $1.702 \times 10^{-5}$ & 13.1 \\
340 & $1.745 \times 10^{-5}$ & 5.5 \\
360 & $1.460 \times 10^{-5}$ & 3.0 \\
\hline
\end{tabular}

Table 13 summarizes the slopes of the lines shown in Fig. 20 and their corresponding $t$ values. For the three profiles (low-, mid-, and high- $\rho$ ), the slopes are statistically significant $(|t| \geq 2)$ at $95 \%$ confidence.

Table 13. Summary of linear profiles for $\lambda_{\exp }$ versus $T_{m}$ (Fig. 20).

\begin{tabular}{ccc}
\hline $\boldsymbol{\rho}$-level & $\begin{array}{c}\text { Slope } \\
\left(\mathbf{W} \cdot \mathbf{m}^{-1} \cdot \mathbf{K}^{-2}\right)\end{array}$ & $\begin{array}{c}\boldsymbol{t} \text {-value } \\
(\mathbf{d i m e n s i o n l e s s )}\end{array}$ \\
\hline Low & $1.099 \times 10^{-4}$ & 146 \\
Mid & $1.128 \times 10^{-4}$ & 64 \\
High & $1.058 \times 10^{-4}$ & 150 \\
\hline
\end{tabular}


Table 14 summarizes the slopes of the lines shown in Fig. 21 and their corresponding $t$ values. In general, the slopes are small, one to two orders of magnitude smaller than the regression coefficients for bulk density (Table 12). Four of the profiles (shaded rows) are statistically indistinguishable from zero $(|t| \leq 2)$ at $95 \%$ confidence. It is interesting to note that the slopes are positive from $280 \mathrm{~K}$ to $320 \mathrm{~K}$ and negative from $340 \mathrm{~K}$ to $360 \mathrm{~K}$. The reason for the change in sign is not known at present.

Table 14. Summary of linear profiles for $\lambda_{\exp }$ versus $p$ (Fig. 21).

\begin{tabular}{cccc}
\hline $\begin{array}{c}\boldsymbol{T}_{\boldsymbol{m}} \\
(\mathbf{K})\end{array}$ & $\boldsymbol{\rho}$-level & $\begin{array}{c}\text { Slope } \\
\left(\mathbf{W} \cdot \mathbf{m}^{-\mathbf{1}} \cdot \mathbf{K}^{-\mathbf{1}} \mathbf{k} \mathbf{k P a}^{-\mathbf{1}}\right)\end{array}$ & $\begin{array}{c}\boldsymbol{t} \text {-value } \\
(\text { dimensionless })\end{array}$ \\
\hline 280 & Low & $23.5 \times 10^{-7}$ & 7.6 \\
280 & Mid & $22.2 \times 10^{-7}$ & 3.8 \\
280 & High & $19.5 \times 10^{-7}$ & 2.6 \\
\hline 300 & Low & $8.33 \times 10^{-7}$ & 5.9 \\
300 & Mid & $15.7 \times 10^{-7}$ & 8.4 \\
300 & High & $20.2 \times 10^{-7}$ & 1.5 \\
\hline 320 & Low & $3.85 \times 10^{-7}$ & 1.4 \\
320 & Mid & $8.97 \times 10^{-7}$ & 10.0 \\
320 & High & $13.8 \times 10^{-7}$ & 1.3 \\
\hline 340 & Low & $-13.7 \times 10^{-7}$ & -21.2 \\
340 & Mid & $-2.32 \times 10^{-7}$ & -1.2 \\
340 & High & $-6.89 \times 10^{-7}$ & -3.1 \\
\hline 360 & Low & $-29.8 \times 10^{-7}$ & -9.9 \\
360 & Mid & $-11.2 \times 10^{-7}$ & -19.4 \\
360 & High & $-29.6 \times 10^{-7}$ & -4.0 \\
\hline
\end{tabular}

\subsection{Final Model}

Equation (21) gives the final model for SRM 1450e

$$
\hat{\lambda}=-1.9731 \times 10^{-3}+1.9923 \times 10^{-5} \rho+1.0792 \times 10^{-4} T_{m}
$$

where $\hat{\lambda}$ is the predicted thermal conductivity $\left(\mathrm{W} \cdot \mathrm{m}^{-1} \cdot \mathrm{K}^{-1}\right), \rho$ is the bulk density $\left(\mathrm{kg} \cdot \mathrm{m}^{-3}\right)$, and $T_{m}$ is mean temperature $(\mathrm{K})$. The residual standard deviation of the fit was $0.000158 \mathrm{~W} \cdot \mathrm{m}^{-1} \cdot \mathrm{K}^{-1}$. The last digit of each regression coefficient in Eq. (21) is provided to reduce rounding errors. The pressure term in the design model (Eq. (15)) was determined not to be significant and was excluded from the final model. However, based on the empirical data, certified values of $\lambda$ are valid for barometric pressures from $60 \mathrm{kPa}$ to $101.3 \mathrm{kPa}$ (sea-level pressure).

Figures 22 and 23 plot the deviations $\left(\lambda_{\exp }-\hat{\lambda}\right) / \hat{\lambda}$ in $\%$ versus $\rho$ and $T_{m}$, respectively. As before, the data are color coded as shown in the legends. An additional temperature legend is included for Fig. 22. The deviations for both plots are randomly and interchangeably scattered (i.e., no discernible pattern) around zero. 


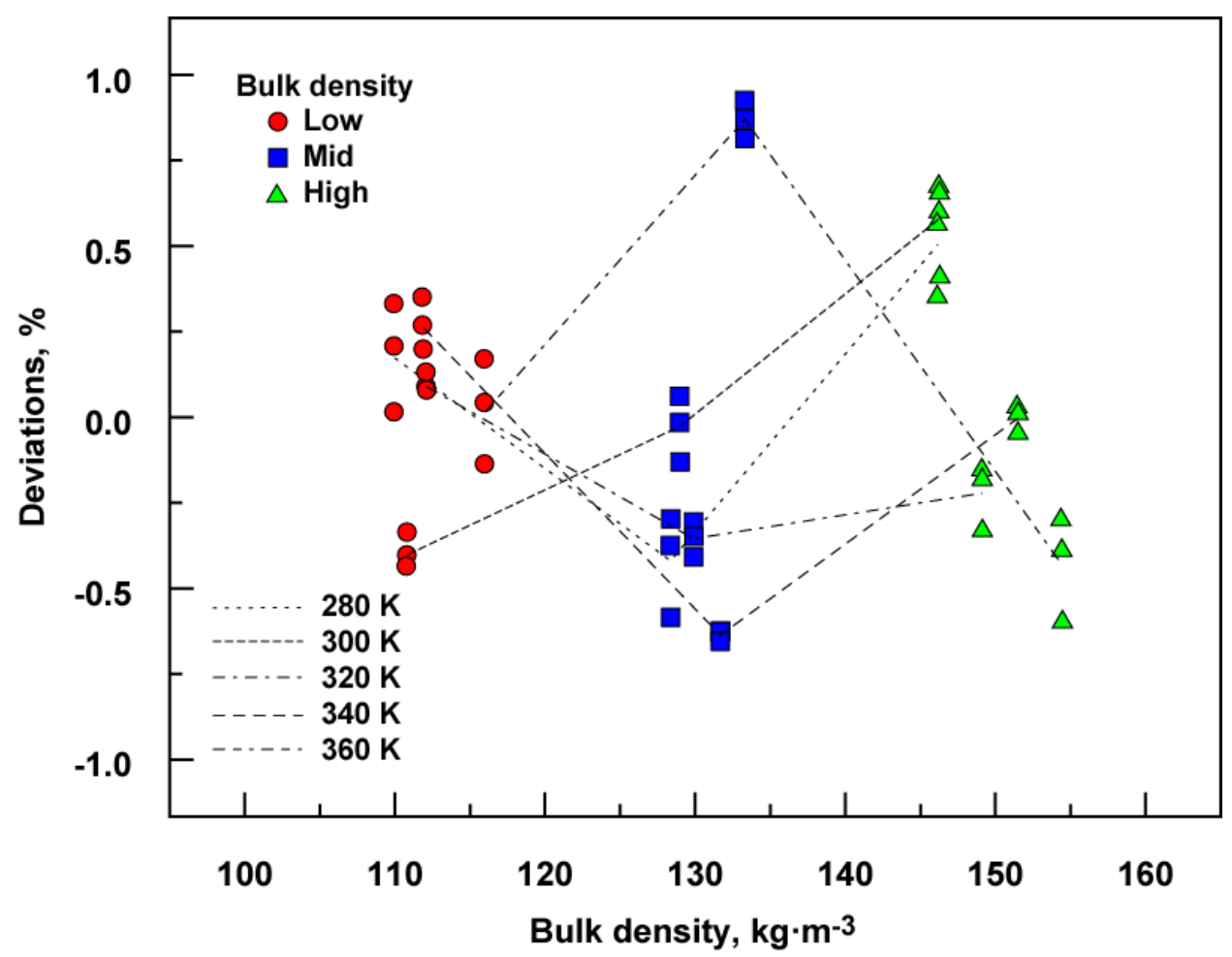

Fig. 22. Graphical analysis of deviations (in \%) for the fit given in Eq. (21).

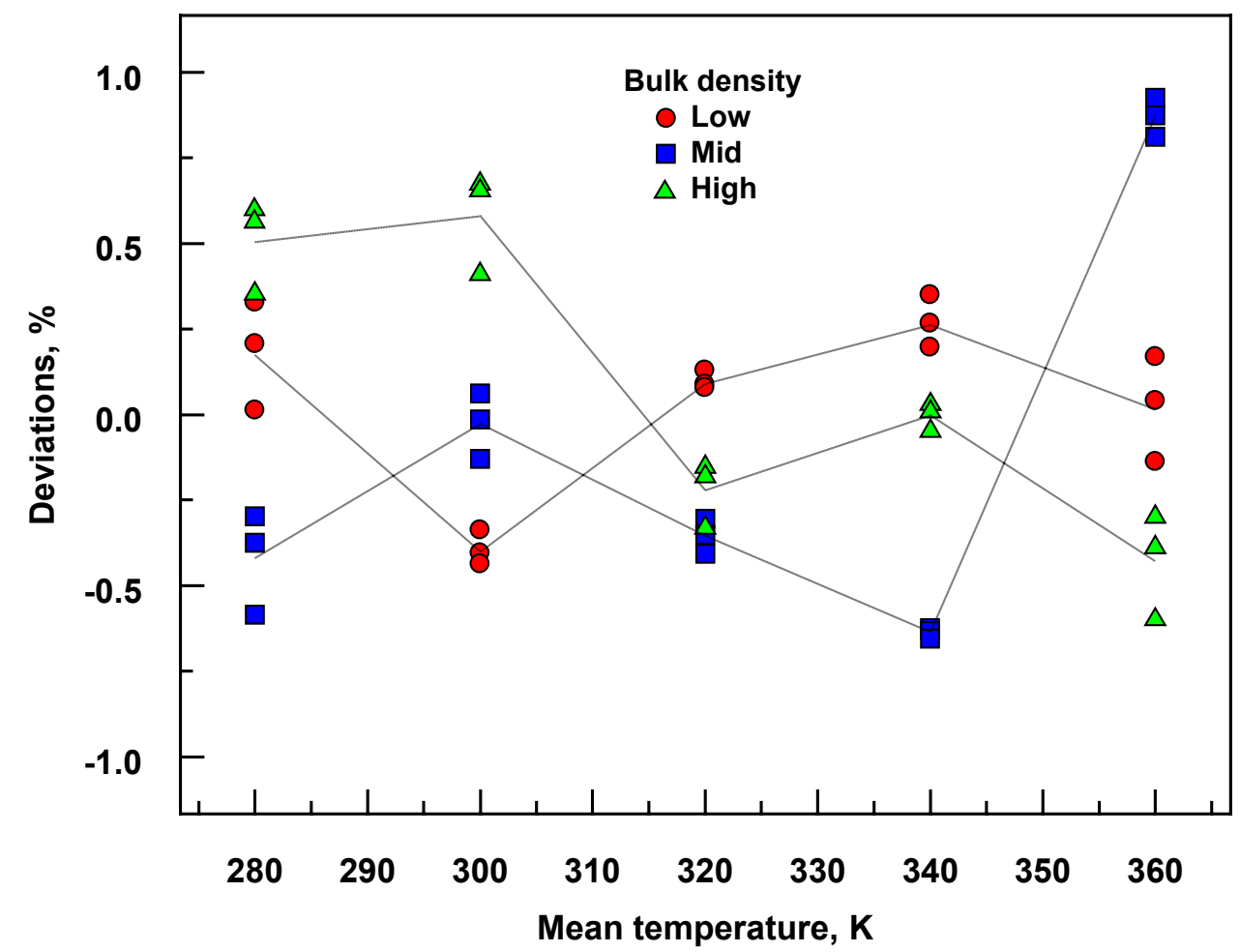

Fig. 23. Graphical analysis of deviations (in \%) for the fit given in Eq. (21). 


\subsection{Model Validation}

In addition to checking the model deviations as was done in Figs. 22 and 23, the final model given in Eq. (21) for SRM 1450e was validated by comparison with an independent set of thermal conductivity data. A series of supplemental thermal conductivity measurements were conducted for specimen pair $(594,769)$ having a bulk density of $130 \mathrm{~kg} \cdot \mathrm{m}^{-3}$. These measurements were conducted sequentially from June 4, 2019 to June 12, 2019 at multiple temperatures from $280 \mathrm{~K}$ to $360 \mathrm{~K}$ without removing the specimens from the guarded-hotplate apparatus. Figure 24 plots the thermal conductivity data (diamond symbols) and the fitted line for the thermal conductivity data (Eq. (21)) versus mean temperature. It is observed that all the supplemental points in Fig. 24 fall very close to the final model given in Eq. (21).

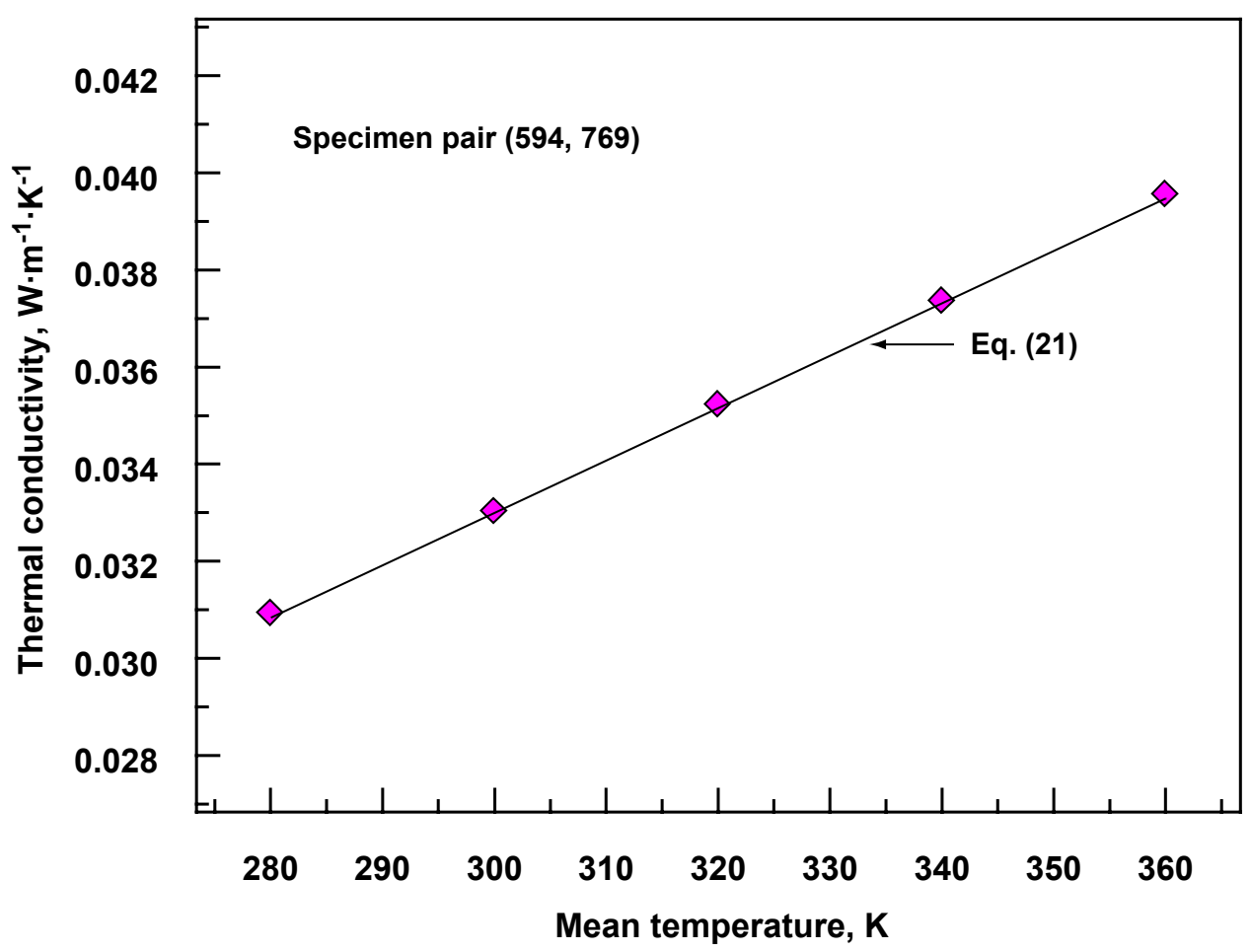

Fig. 24. Re-measured thermal conductivity versus mean temperature for specimen pair $(594,769)$. The solid line represents the fitted model given in Eq. $(21), \rho=130 \mathrm{~kg} \cdot \mathrm{m}^{-3}$.

\subsection{Thermal Conductivity Uncertainty Assessment}

For the multiplicative expression in Eq. (2), the relative combined standard uncertainty in $\lambda$ can be expressed as the relative uncertainties associated with each factor combined in quadrature.

$$
u_{\mathrm{c}, \mathrm{r}}(\lambda)=\frac{u_{\mathrm{c}}(\lambda)}{\lambda}=\sqrt{\left(\frac{u(Q)}{Q}\right)^{2}+\left(\frac{u(\Delta T)}{\Delta T}\right)^{2}+\left(\frac{u(L)}{L}\right)^{2}+\left(\frac{u(A)}{A}\right)^{2}}
$$


The standard uncertainties and input quantities in Eq. (22) are derived in Appendix E. Table 15 summarizes the relative contributory, combined $(k=1)$, and expanded uncertainties $(k=2)$ for thermal conductivity as a function of mean temperature.

Table 15. Thermal conductivity uncertainty budget.

\begin{tabular}{ccccccc}
\hline $\boldsymbol{T}_{\boldsymbol{m}}$ & $\begin{array}{c}\boldsymbol{u}_{\mathrm{c}, \mathbf{r}}(\boldsymbol{Q}) \\
(\mathbf{K})\end{array}$ & $\begin{array}{c}\boldsymbol{u}_{\mathrm{c}, \mathrm{r}}(\boldsymbol{\Delta} \boldsymbol{T}) \\
(\mathbf{\%})\end{array}$ & $\begin{array}{c}\boldsymbol{u}_{\mathrm{c}, \mathrm{r}}(\boldsymbol{L}) \\
\mathbf{( \% )}\end{array}$ & $\begin{array}{c}\boldsymbol{u}_{\mathrm{c}, \mathrm{r}}(\boldsymbol{A}) \\
\mathbf{( \% )}\end{array}$ & $\begin{array}{c}\boldsymbol{u}_{\mathrm{c}, \mathbf{r}}(\boldsymbol{\lambda}) \\
\mathbf{( \% )}\end{array}$ & $\begin{array}{c}\boldsymbol{U}_{\mathbf{r}}(\boldsymbol{\lambda}) \\
(\boldsymbol{\%})\end{array}$ \\
\hline 280 & 0.11 & 0.19 & 0.24 & 0.03 & 0.33 & 0.66 \\
300 & 0.10 & 0.07 & 0.23 & 0.03 & 0.26 & 0.53 \\
320 & 0.10 & 0.26 & 0.24 & 0.03 & 0.37 & 0.74 \\
340 & 0.11 & 0.25 & 0.24 & 0.03 & 0.36 & 0.72 \\
360 & 0.13 & 0.41 & 0.24 & 0.03 & 0.49 & 0.98 \\
\hline
\end{tabular}

From Table 15, the maximum value of $0.98 \%$ (at $360 \mathrm{~K}$ ) was selected as a conservative estimate for the expanded uncertainty for thermal conductivity measurement. Rounded for convenience and expressed as a percent, $U_{\mathrm{r}}(\lambda)$ is equal to $1.0 \%$. The major contributory uncertainties for SRM 1450e are due to the empirical determinations for specimen temperature difference $\left(\Delta T_{\mathrm{av}}\right)$ and thickness $\left(L_{\mathrm{av}}\right)$. These findings are consistent with results from a previous guarded-hot-plate uncertainty analysis [26].

\subsection{Thermal Conductivity Metrological Traceability}

Table 16 summarizes the calibration information for the guarded-hot-plate equipment. The uncertainties due to calibration of the artifacts and equipment were included in the extended uncertainty analysis described in Appendix E.

Table 16. Calibration information for the thermal conductivity measurements.

\begin{tabular}{|c|c|c|c|c|c|}
\hline \multirow[b]{2}{*}{ Item } & \multirow{2}{*}{$\begin{array}{l}\text { Equipment } \\
\text { Calibrated }\end{array}$} & \multirow{2}{*}{$\begin{array}{l}\text { Description } \\
\text { of standard }\end{array}$} & \multicolumn{3}{|c|}{ Calibration } \\
\hline & & & Organization & Date & Cert. Number \\
\hline 1 & $\begin{array}{l}\text { Otto Wolff Model N85-7a7, } \\
\text { S/N: } 5350\end{array}$ & $\begin{array}{l}\text { Standards of the } \\
\text { United States }\end{array}$ & NIST & 2018 & $291216-18$ \\
\hline 2 & $\begin{array}{l}\text { Agilent 3458A, } \\
\text { S/N: US28029523 }\end{array}$ & see Certificate & $\begin{array}{l}\text { Keysight Tech- } \\
\text { nologies }\end{array}$ & 2018 & $1-9836320191-1$ \\
\hline 3 & $\begin{array}{l}\text { Rosemont Aerospace } \\
163 \mathrm{CE}\end{array}$ & $\begin{array}{l}\text { Standards of the } \\
\text { United States }\end{array}$ & NIST & 2000 & $262640-00$ \\
\hline 4 & $\begin{array}{l}\text { MicroK 800, S/N: 08-P050 } \\
\text { ITL28502/1 }\end{array}$ & see Certificate & $\begin{array}{c}\text { Isothermal Tech- } \\
\text { nology }\end{array}$ & 2008 & 08-07-68 \\
\hline 5 & $\begin{array}{l}\text { Tinsley Model 5685-A, } \\
\text { S/N: } 274591\end{array}$ & $\begin{array}{l}\text { Standards of the } \\
\text { United States }\end{array}$ & NIST & 2018 & $291216-18$ \\
\hline 6 & $\begin{array}{l}\text { ARI T-11N-39.3BN9B } \\
\text { Type N TC, Tag: Start }\end{array}$ & $\begin{array}{l}\text { By comparison } \\
\text { w/SPRT }\end{array}$ & NIST & 2002 & 267520D \\
\hline 7 & $\begin{array}{l}\text { ARI T-11N-39.3BN9B } \\
\text { Type N TC, Tag: Middle }\end{array}$ & $\begin{array}{l}\text { By comparison } \\
\text { w/SPRT }\end{array}$ & NIST & 2002 & 267520D \\
\hline 8 & $\begin{array}{l}\text { ARI T-11N-39.3BN9B } \\
\text { Type N TC, Tag: End }\end{array}$ & $\begin{array}{l}\text { By comparison } \\
\text { w/SPRT }\end{array}$ & NIST & 2002 & $267520 \mathrm{D}$ \\
\hline 9 & $\begin{array}{l}\text { Bal-tec }^{\mathrm{TM}}, \text { Grade 25, } 25.4 \\
\text { mm balls }\end{array}$ & $\begin{array}{l}\text { Standards of the } \\
\text { United States }\end{array}$ & NIST & 2018 & $18-732-3079$ \\
\hline 10 & Fused-silica & SRM 739 & NIST & & \\
\hline
\end{tabular}




\begin{tabular}{|c|c|c|c|c|c|}
\hline 11 & $\begin{array}{l}\text { Heidenhain MT12, } \\
\text { S/N: 10315800D }\end{array}$ & $\begin{array}{l}\text { Inspection Certifi- } \\
\text { cate }\end{array}$ & Heidenhain & 2001 & $243602-01$ \\
\hline 12 & $\begin{array}{l}\text { Heidenhain MT12, } \\
\text { S/N: 10315803D }\end{array}$ & $\begin{array}{l}\text { Inspection Certifi- } \\
\text { cate }\end{array}$ & Heidenhain & 2001 & $243602-01$ \\
\hline 13 & $\begin{array}{l}\text { Heidenhain ND231B, } \\
\text { S/N: 9387273-A3 }\end{array}$ & $\begin{array}{l}\text { Bal-tec }{ }^{\mathrm{TM}} \text {, Grade } 25, \\
25.4 \mathrm{~mm} \text { balls }\end{array}$ & 732.03 & & \\
\hline 14 & Hot plate diameters & $\begin{array}{l}\text { Standards of the } \\
\text { United States }\end{array}$ & NIST & 2006 & $274749-07$ \\
\hline 15 & $\begin{array}{l}\text { Transducer Techniques } \\
\text { Load Cell } 119216\end{array}$ & $\begin{array}{l}\text { Standards of the } \\
\text { United States }\end{array}$ & NIST & 2007 & $274030-06$ \\
\hline 16 & $\begin{array}{l}\text { Nor-Cal CDG091-100 } \\
\text { w/APC-001, s/n:215008 }\end{array}$ & $\begin{array}{l}\text { Standards of the } \\
\text { United States }\end{array}$ & NIST & 2006 & $283622-06$ \\
\hline
\end{tabular}

\section{Certification}

Section 8 presents summary information on the properties of interest, values and uncertainty, statement of metrological traceability, and instructions for use for Standard Reference Material 1450e. This information is intended to provide supplementary documentation for the SRM 1450e Certificate.

\subsection{Properties of Interest}

Standard Reference Material 1450e is a high-density molded fibrous glass board certified for bulk density, $\rho$, and thermal conductivity, $\lambda$. Each SRM unit consists of a square panel of fine-glass fibers and phenolic binder molded into a semi-rigid board. The nominal dimensions of a unit are $610 \mathrm{~mm}$ by $610 \mathrm{~mm}$ by $25.2 \mathrm{~mm}$ (Table 3) and the bulk density ranges from $110 \mathrm{~kg} \cdot \mathrm{m}^{-3}$ to $154 \mathrm{~kg} \cdot \mathrm{m}^{-3}$ (Table 9).

\subsection{Values and Uncertainties}

Each unit of SRM 1450e is individually certified for bulk density, $\rho$ (Table 3), and batch certified for thermal conductivity with Eq. (23):

$$
\hat{\lambda}=-1.9731 \times 10^{-3}+1.9923 \times 10^{-5} \rho+1.0792 \times 10^{-4} T_{m}
$$

where $\hat{\lambda}$ is the predicted thermal conductivity $\left(\mathrm{W} \cdot \mathrm{m}^{-1} \cdot \mathrm{K}^{-1}\right), \rho$ is the bulk density $\left(\mathrm{kg} \cdot \mathrm{m}^{-3}\right)$, and $T_{m}$ is the mean specimen temperature (K). Equation (23) is certified to be valid for $\rho$ from $110 \mathrm{~kg} \cdot \mathrm{m}^{-3}$ to $154 \mathrm{~kg} \cdot \mathrm{m}^{-3}$, specimen $\Delta T$ of $25 \mathrm{~K}, T_{m}$ from $280 \mathrm{~K}$ to $360 \mathrm{~K}$, and $p$ from $60 \mathrm{kPa}$ to $101.3 \mathrm{kPa}$ (sea-level pressure). The expanded uncertainty for $\lambda$ values from Eq. (23) is $1 \%$ with a coverage factor of approximately $k=2$.

\subsection{Statement of Metrological Traceability}

The input quantities for the determination of bulk density and thermal conductivity are metrologically traceable to working references maintained at NIST as described in Sec. 5.5 and Sec. 7.4, respectively.

\subsection{Instructions for Use}

Standard Reference Material 1450e is intended for use as a proven check for the guardedhot-plate apparatus (or other absolute thermal conductivity apparatus) and for calibration 
of a heat-flow-meter apparatus over the temperature range of $280 \mathrm{~K}$ to $360 \mathrm{~K}$ and barometric pressures from $60 \mathrm{kPa}$ to $101.3 \mathrm{kPa}$ (sea-level pressure). NIST cannot exclude the use of SRM 1450e for other purposes, but the user is cautioned that other purposes are not sanctioned by the SRM 1450e Certificate.

\subsubsection{Storage}

For protection and identification, it is recommended that the reference material be stored in the original packaging in a clean, dry environment at temperatures between $15^{\circ} \mathrm{C}$ and $30{ }^{\circ} \mathrm{C}$.

\subsubsection{Preparation and Conditioning Before Measurement}

Prior to the thermal conductivity measurement, the reference material should be conditioned in laboratory conditions of $20^{\circ} \mathrm{C}$ to $25^{\circ} \mathrm{C}$ and from $40 \% \mathrm{RH}$ to $65 \% \mathrm{RH}$ until the mass of the unit is stable (i.e., two successive measurements within $24 \mathrm{~h}$ are less than $1 \%[1])$.

\subsubsection{Thermal Conductivity Measurement}

Thermal conductivity measurements should be conducted in accordance with the appropriate ASTM Test Method C 177 [1], C 518 [2], or another similar international standard.

\subsubsection{Guidelines and Precautions}

The following guidelines and precautions are provided for the user.

- Stacking: Certified values of thermal conductivity are valid for a single unit and are invalid for stacked units.

- Slicing: Certified values of thermal conductivity are invalid for a unit where the thickness of the material has been modified by slicing.

- Cutting: It is possible to cut the reference material unit into smaller pieces. It is imperative to verify that bulk density of each piece is within the certified range of bulk density (Sec. 8.2).

- Compression: The SRM unit should not be compressed more than $10 \%$ of original thickness.

- Upper Temperature Limit: The upper temperature limit for this reference material is limited to the decomposition point of the binder, approximately $473 \mathrm{~K}\left(200{ }^{\circ} \mathrm{C}\right)$ [10]. As a precaution, this reference material should not be heated above $380 \mathrm{~K}$ $\left(107^{\circ} \mathrm{C}\right)$. It should be noted that oven drying, as opposed to desiccant drying, can remove other volatiles and potentially affect chemical or physical properties of the material.

- Lower Temperature Limit: A lower temperature limit for SRM 1450e has not been established but, in principle, there is no known lower limit.

- Atmospheric Pressure: The effect due to changes in barometric pressure from $60 \mathrm{kPa}$ to $101.3 \mathrm{kPa}$ (sea-level pressure) is negligible for this material. 


\section{Acknowledgments}

The authors appreciate the assistance provided by Jeffrey Cregger and Matthew Spencer in conducting the mass and dimensional measurements for bulk density.

\section{References}

[1] ASTM International (2019) C177-19 - Test Method for Steady-State Heat Flux Measurements and Thermal Transmission Properties by Means of the GuardedHot-Plate Apparatus (ASTM International, West Conshohocken, Pennsylvania).

[2] ASTM International (2019) C518-17 - Test Method for Steady-State Thermal Transmission Properties by Means of the Heat Flow Meter Apparatus (ASTM International, West Conshohocken, Pennsylvania).

[3] ASTM International (2019) C1363-11 - Test Method for Thermal Performance of Building Materials and Envelope Assemblies by Means of a Hot Box Apparatus (ASTM International, West Conshohocken, Pennsylvania).

[4] Federal Trade Commission (2019) R-value Rule 16 CFR Part 460 - Labeling and Advertising of Home Insulation (Electronic Code of Federal Regulations). https://www.ecfr.gov

[5] Zarr RR, Heckert NA, and Leigh SD (2014) Retrospective Analysis of NIST Standard Reference Material 1450, Fibrous Glass Board, for Thermal Insulation Measurements. J. Res. Natl. Inst. Stand. Technol 119: 296-370. http://dx.doi.org/10.6028/jres.119.012

[6] ASTM Subcommittee C16.30 (1978) Reference Materials for Insulation Measurement Comparisons. Thermal Transmission Measurements of Insulation, ASTM STP 660, ed Tye RP (ASTM International, West Conshohocken, Pennsylvania), pp 7-29.

[7] NBS (1959) Research Highlights of the National Bureau of Standards: Annual Report, Fiscal Year 1959. Miscellaneous Publication 229, p 88.

[8] Siu MCI (1980) Fibrous Glass Board as a Standard Reference Material for Thermal Resistance Measurement Systems. Thermal Insulation Performance, ASTM STP 718, eds McElroy DL and Tye RP, pp 343-360.

[9] Hust JG (1985) Standard Reference Materials: Glass Fiberboard SRM for Thermal Resistance. National Institute of Standards and Technology, NBS Special Publication 260-98.

[10] Zarr RR (1997) Standard Reference Materials: Glass Fiberboard, SRM 1450c, for Thermal Resistance from $280 \mathrm{~K}$ to $340 \mathrm{~K}$. National Institute of Standards and Technology, NIST Special Publication 260-130.

[11] Zarr RR, Harris AC, Roller JF, Leigh SL (2011) Standard Reference Materials: SRM 1450d, Fibrous-Glass Board, for Thermal Conductivity from $280 \mathrm{~K}$ to $340 \mathrm{~K}$. National Institute of Standards and Technology, NIST Special Publication 260-173.

[12] Zarr RR, Leber, DD (2010) Evaluation of Thermal Insulation Materials for NIST SRM 1450d, Fibrous-Glass Board. Thermal Conductivity 30, ed Gaal DS, Gall PS (DEStech Publications, Inc., Lancaster, Pennsylvania), 386-392.

[13] May W, Parris R, Beck C, Fassett J, Greenberg R, Guenther F, Kramer G, Wise S, Gills T, Colbert J, Gettings R, MacDonald B (2000) Standard Reference Materials ${ }^{\circledR}$ : Definitions of Terms and Modes Used at NIST for Value-Assignment of Reference 
Materials for Chemical Measurements. National Institute of Standards and Technology, NIST Special Publication 260-136.

[14] International Organization for Standardization (2015) ISO Guide 30:2015 - Reference materials - Selected terms and definitions (International Organization for Standardization, Geneva, Switzerland).

[15] ASTM International (2019) C 168-19 - Standard Terminology Relating to Thermal Insulation Annual Book of ASTM Standards (ASTM International, West Conshohocken, Pennsylvania).

[16] International Bureau of Weights and Measures (2010) JCGM 100:2008 - Evaluation of measurement data - Guide to the expression of uncertainty in measurement (Joint Committee for Guides in Metrology, International Bureau of Weights and Measures, Paris, France). https://www.bipm.org/utils/common/documents/jcgm/JCGM_100_2008_E.pdf

[17] Taylor, BN, Kuyatt CE (1994) Guidelines for Evaluating and Expressing the Uncertainty of NIST Measurement Results. U.S. Department of Commerce, Washington, D.C. NIST Technical Note 1297. https://nvlpubs.nist.gov/nistpubs/Legacy/TN/nbstechnicalnote1297.pdf

[18] Zarr RR, Flynn DR, Hettenhouser JW, Brandenburg NJ, Healy WM (2006) Fabrication of a guarded-hot-plate apparatus for use over an extended temperature range and in a controlled gas environment. Thermal Conductivity 28, ed Dinwiddie RB, White MA, McElroy DL (DEStech Publications Inc. Lancaster, Pennsylvania), pp. 235-245.

[19] National Institute of Standards and Technology (2012) NIST/SEMATECH e-Handbook of Statistical Methods. https:/www.itl.nist.gov/div898/handbook/eda/section2/eda21.htm

[20] National Institute of Standards and Technology (2012) NIST/SEMATECH e-Handbook of Statistical Methods. https://www.itl.nist.gov/div898/handbook/eda/section2/eda23.htm

[21] Smith DR, Hust JG (1983) Effective Thermal Conductivity of Glass-Fiber Board and Blanket Standard Reference Materials. Thermal Conductivity 17, ed Hust JG (Plenum, New York, New York), pp. 483-496.

[22] Zarr RR, Thomas WC (2013) Initial measurement results of the NIST $500 \mathrm{~mm}$ guarded-hot-plate apparatus under automated temperature and pressure control. Thermal Conductivity 31, ed Kiss LI, St-Georges L (DEStech Publications Inc. Lancaster, Pennsylvania), pp. 195-204.

[23] List RJ (1966) Smithsonian Meteorological Tables (Smithsonian Institution), 6th Ed., p. 267.

[24] ASTM International (2019) C1058/C1058M-10(Reapproved 2015) - Practice for Selecting Temperatures for Evaluating and Reporting Thermal Properties of Thermal Insulation (ASTM International, West Conshohocken, Pennsylvania).

[25] Zarr RR, Filliben JJ (2016) Sensitivity analysis for a guarded-hot-plate apparatus: A methodology based on orthogonal experiment designs. Journal of Testing and Evaluation 44(1): 102-127. 
[26] Zarr RR (2010) Assessment of Uncertainties for the NIST 1016 mm Guarded-HotPlate Apparatus: Extended Analysis for Low-Density Fibrous-Glass Thermal Insulation. J. Res. Natl. Inst. Stand. Technol., 115(1), 23-59. http://dx.doi.org/10.6028/jres.115.004

[27] Miller V (2002) Recommended guide for determining and reporting uncertainties for balances and scales. National Institute of Standards and Technology, Gaithersburg, Maryland, NISTIR 6919. https://www.nist.gov/system/files/documents/2017/04/28/NISTIR6919.pdf

[28] Doiron T, Stoup J (1997) Uncertainty and dimensional calibrations. J. Res. Natl. Inst. Stand. Technol., 102(6): 647-676. http://dx.doi.org/10.6028/jres.102.044

[29] Flynn DR (2005) Design of a $500 \mathrm{~mm}$ Guarded Hot Plate Apparatus for Measuring Thermal Transmission Properties of Insulations from 90 to $900 \mathrm{~K}$ : Phase II. NIST GCR 05-881, pp. 101-102.

[30] Kollie TG (1977) Measurement of the thermal-expansion coefficient of nickel from 300 to $1000 \mathrm{~K}$ and determination of the power-law constants near the Curie temperature. Physical Review B, 16(11): 4872-4881.

[31] SRM 739 Fused Silica Thermal Expansion; National Institute of Standards and Technology; U.S. Department of Commerce: Gaithersburg, MD (27 December 1991). 
Appendix A

\section{Appendix A: Change Log}

No revisions (April 2020). 


\section{Appendix B}

Appendix B: Mass Plots (Panel ID: 500 through 949)
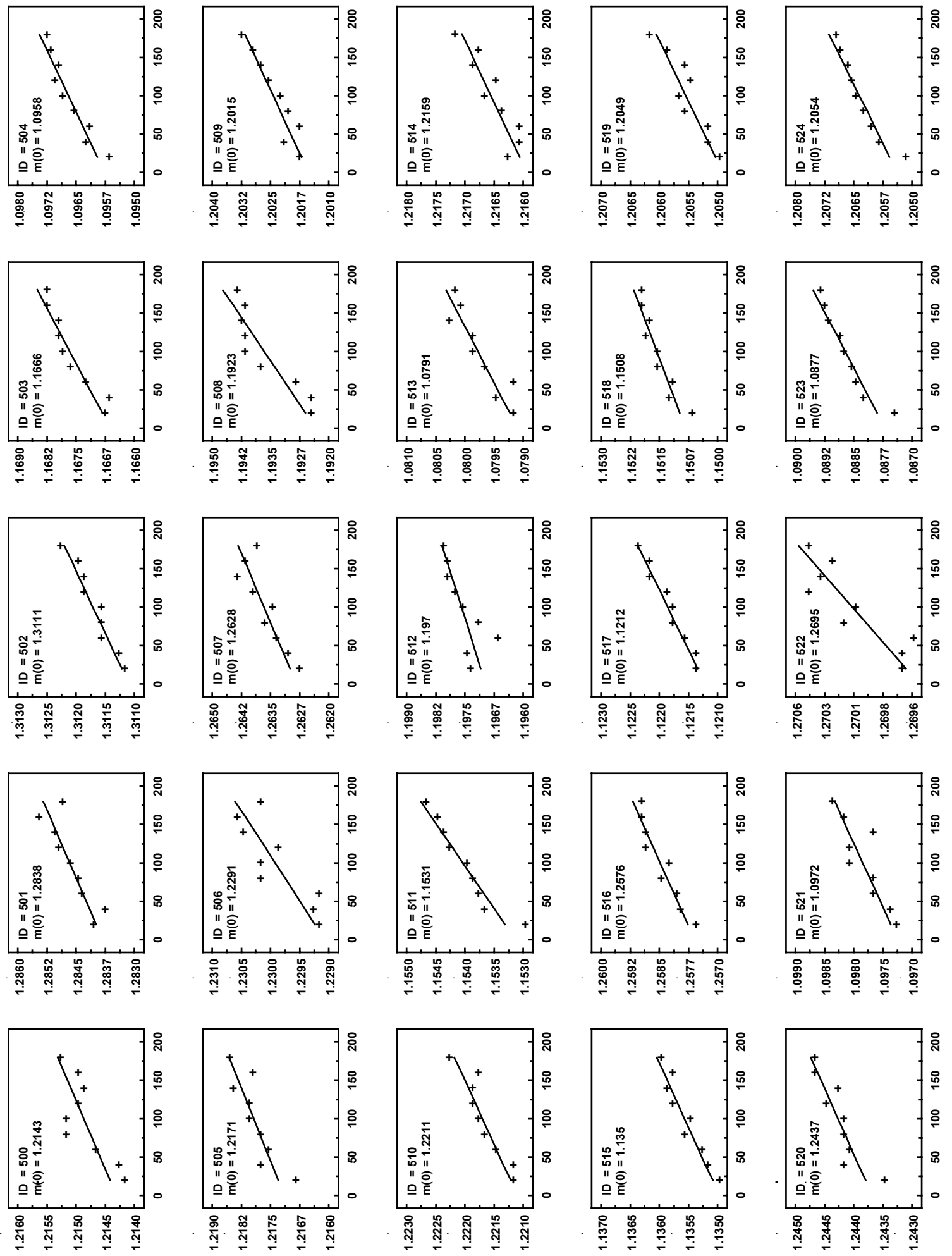

Fig. 25. Panel ID=500-524: Multiple mass observations (in kilograms) as a function of elapsed time (in seconds) for insulation panels 500 through 524. Linear fit for data (shown as solid line) was back-extrapolated to elapsed time zero $\left(t_{0}\right)$ to determine $m_{0}$ for each panel. 


\section{Appendix B}
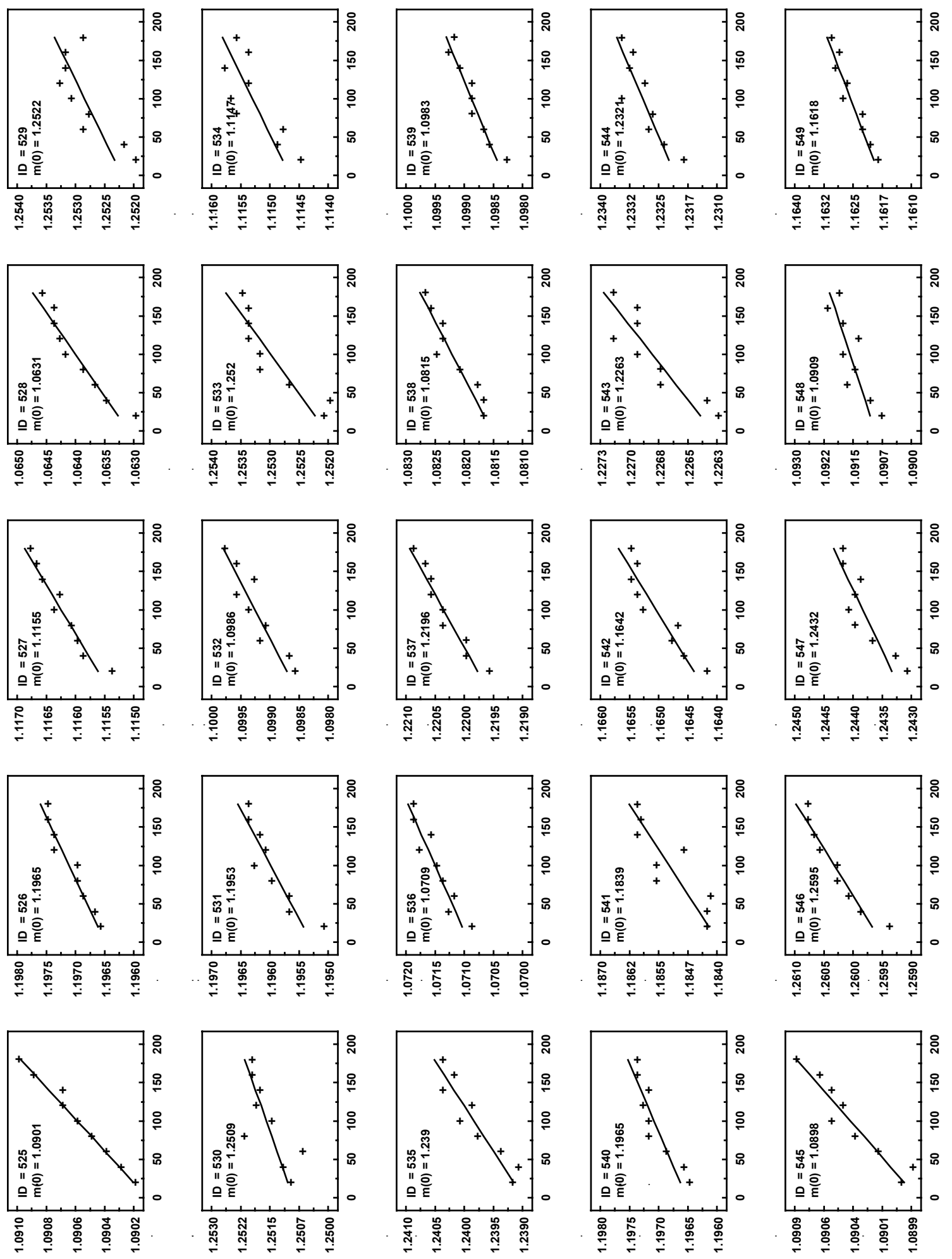

Fig. 26. Panel ID=525-549: Multiple mass observations (in kilograms) as a function of elapsed time (in seconds) for insulation panels 525 through 549. Linear fit for data (shown as solid line) was back-extrapolated to elapsed time zero $\left(t_{0}\right)$ to determine $m_{0}$ for each panel. 


\section{Appendix B}
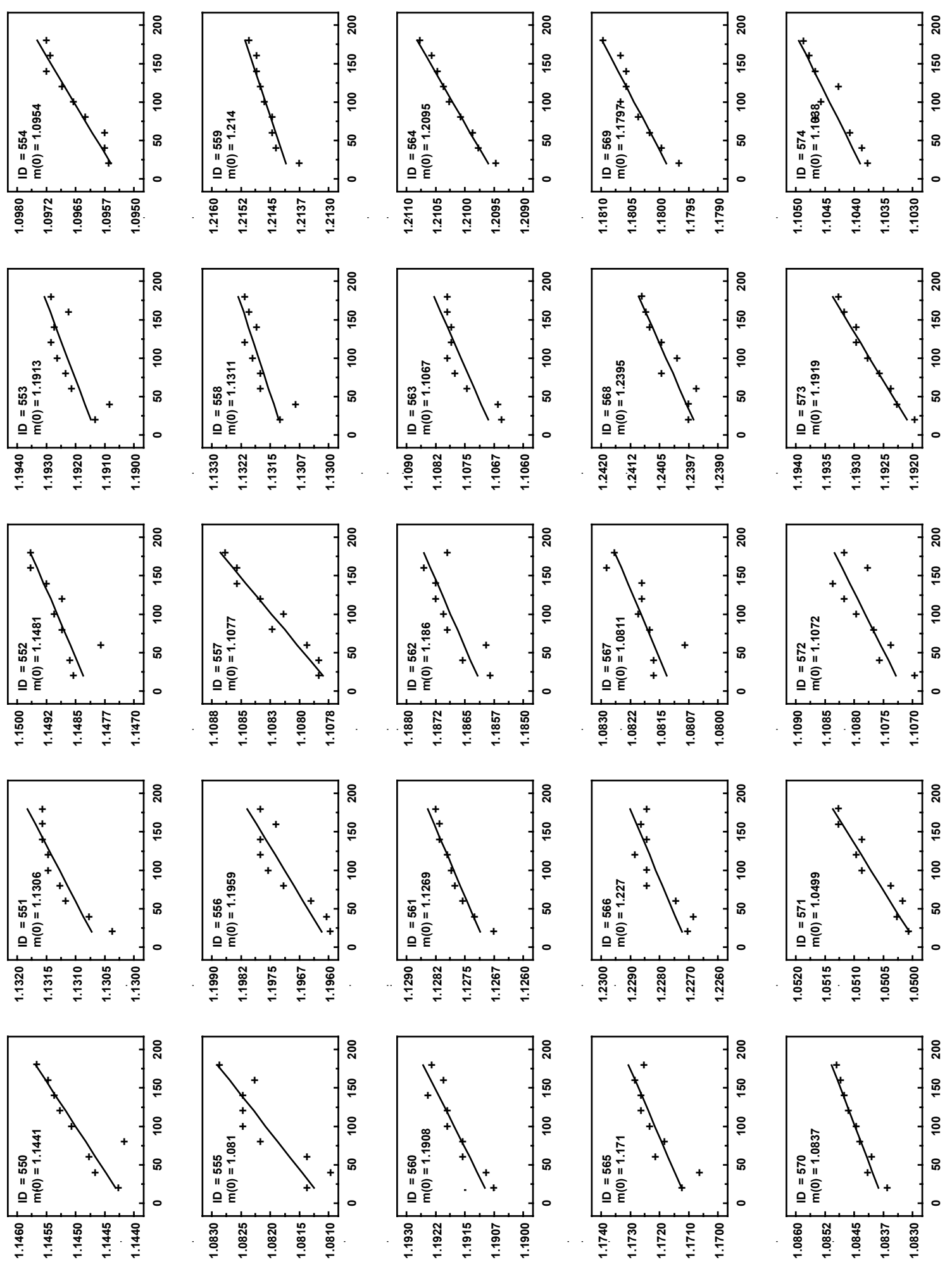

Fig. 27. Panel ID=550-574: Multiple mass observations (in kilograms) as a function of elapsed time (in seconds) for insulation panels 550 through 574. Linear fit for data (shown as solid line) was back-extrapolated to elapsed time zero $\left(t_{0}\right)$ to determine $m_{0}$ for each panel. 


\section{Appendix B}
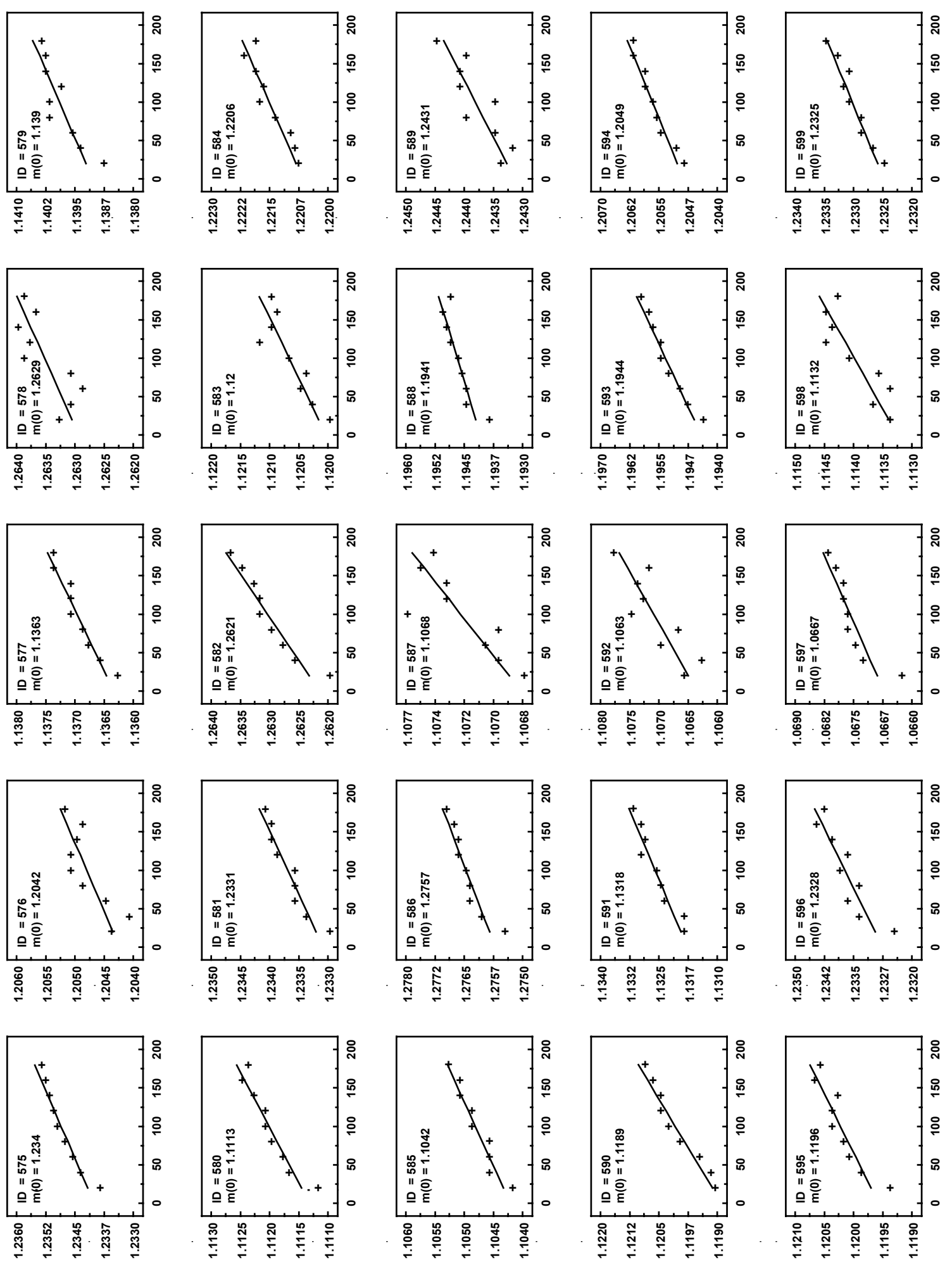

Fig. 28. Panel ID=575-599: Multiple mass observations (in kilograms) as a function of elapsed time (in seconds) for insulation panels 575 through 599. Linear fit for data (shown as solid line) was back-extrapolated to elapsed time zero $\left(t_{0}\right)$ to determine $m_{0}$ for each panel. 


\section{Appendix B}
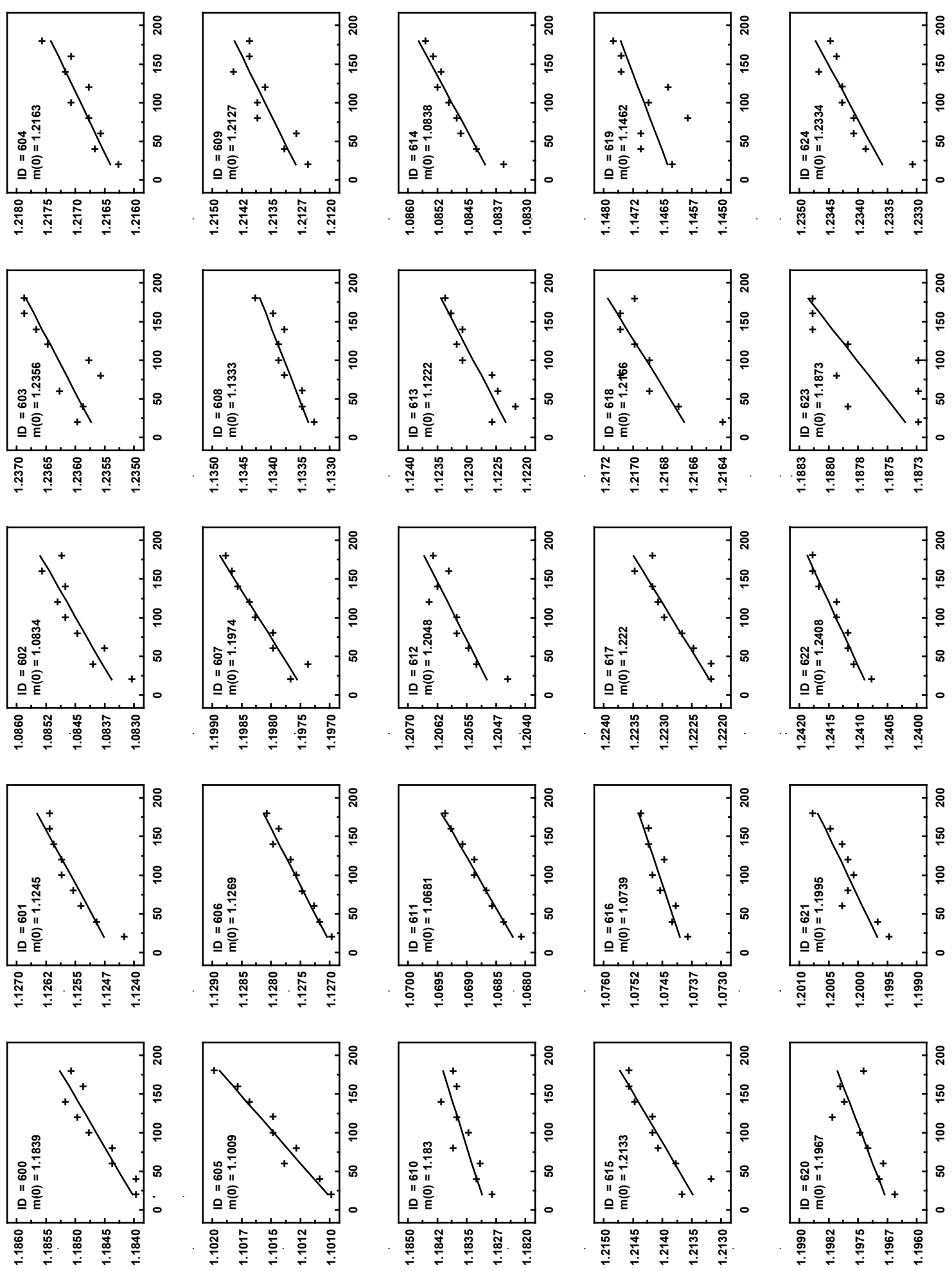

Fig. 29. Panel ID $=600-624$ : Multiple mass observations (in kilograms) as a function of elapsed time (in seconds) for insulation panels 600 through 624. Linear fit for data (shown as solid line) was back-extrapolated to elapsed time zero $\left(t_{0}\right)$ to determine $m_{0}$ for each panel. 


\section{Appendix B}
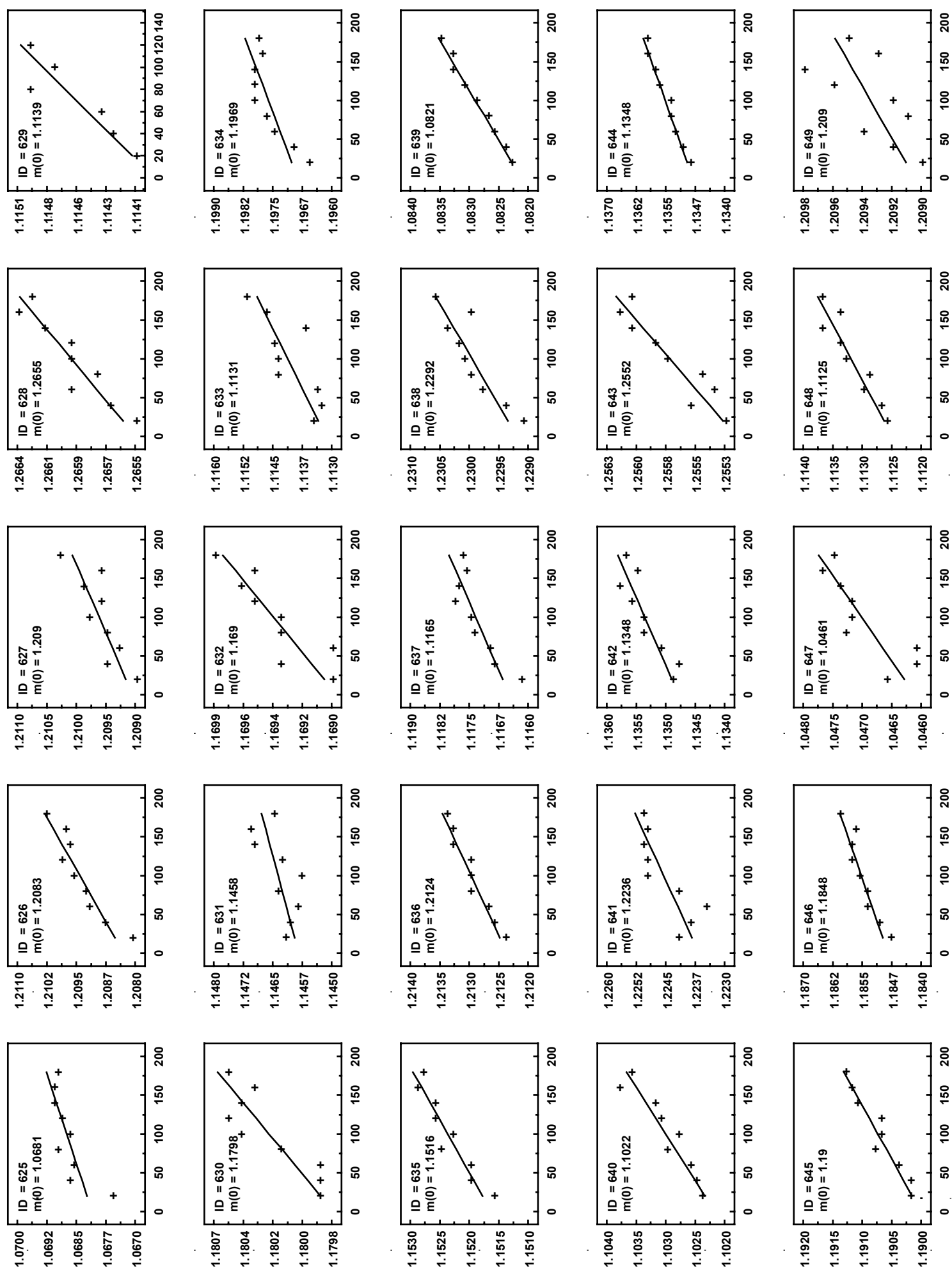

Fig. 30. Panel $I D=625-649$ : Multiple mass observations (in kilograms) as a function of elapsed time (in seconds) for insulation panels 625 through 649. Linear fit for data (shown as solid line) was back-extrapolated to elapsed time zero $\left(t_{0}\right)$ to determine $m_{0}$ for each panel. Note that only 6 observations are included for panel 629 due to an interruption in the measurement process. 
Appendix B
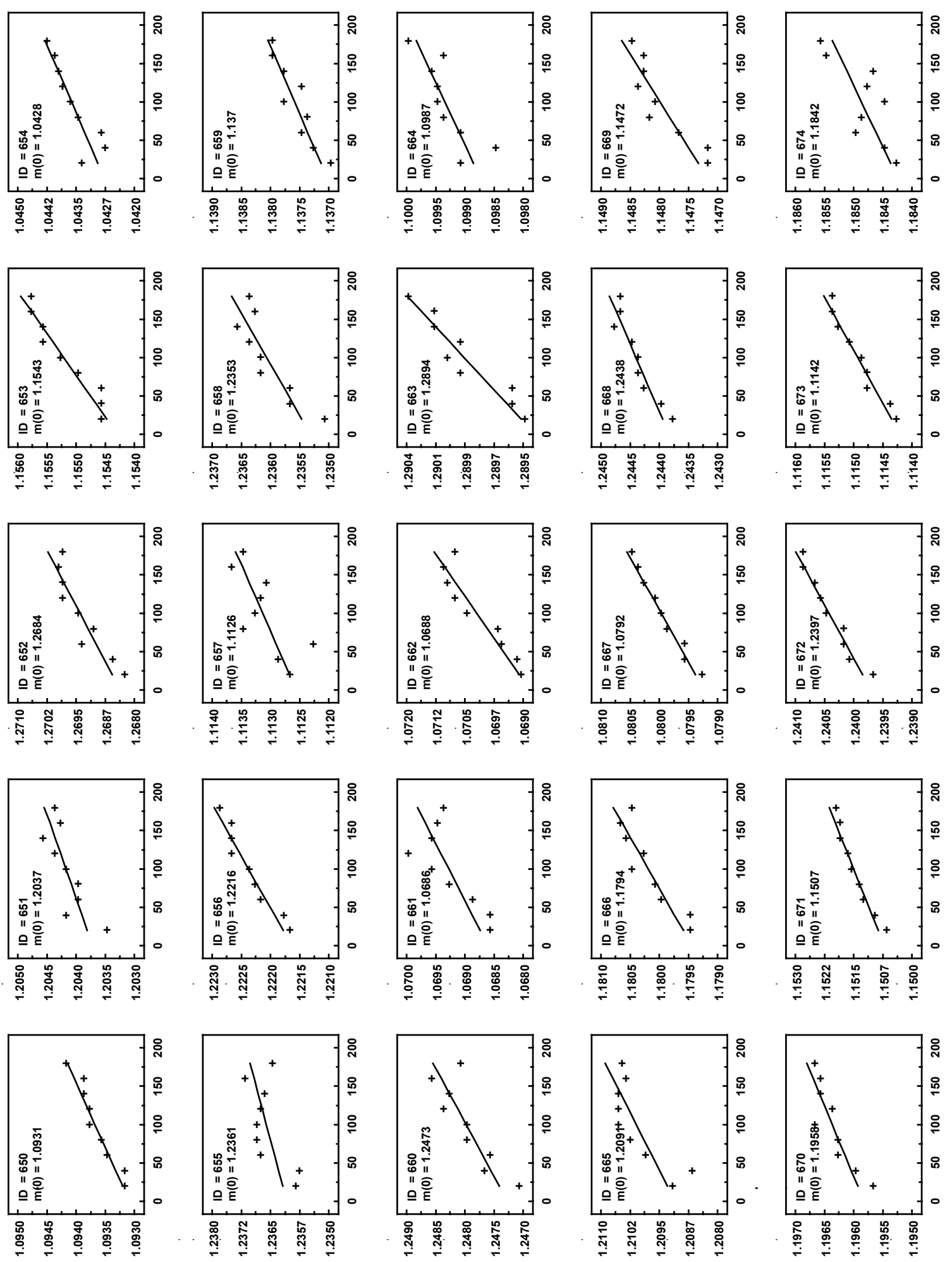

Fig. 31. Panel ID=650-674: Multiple mass observations (in kilograms) as a function of elapsed time (in seconds) for insulation panels 650 through 674. Linear fit for data (shown as solid line) was back-extrapolated to elapsed time zero $\left(t_{0}\right)$ to determine $m_{0}$ for each panel. 
Appendix B
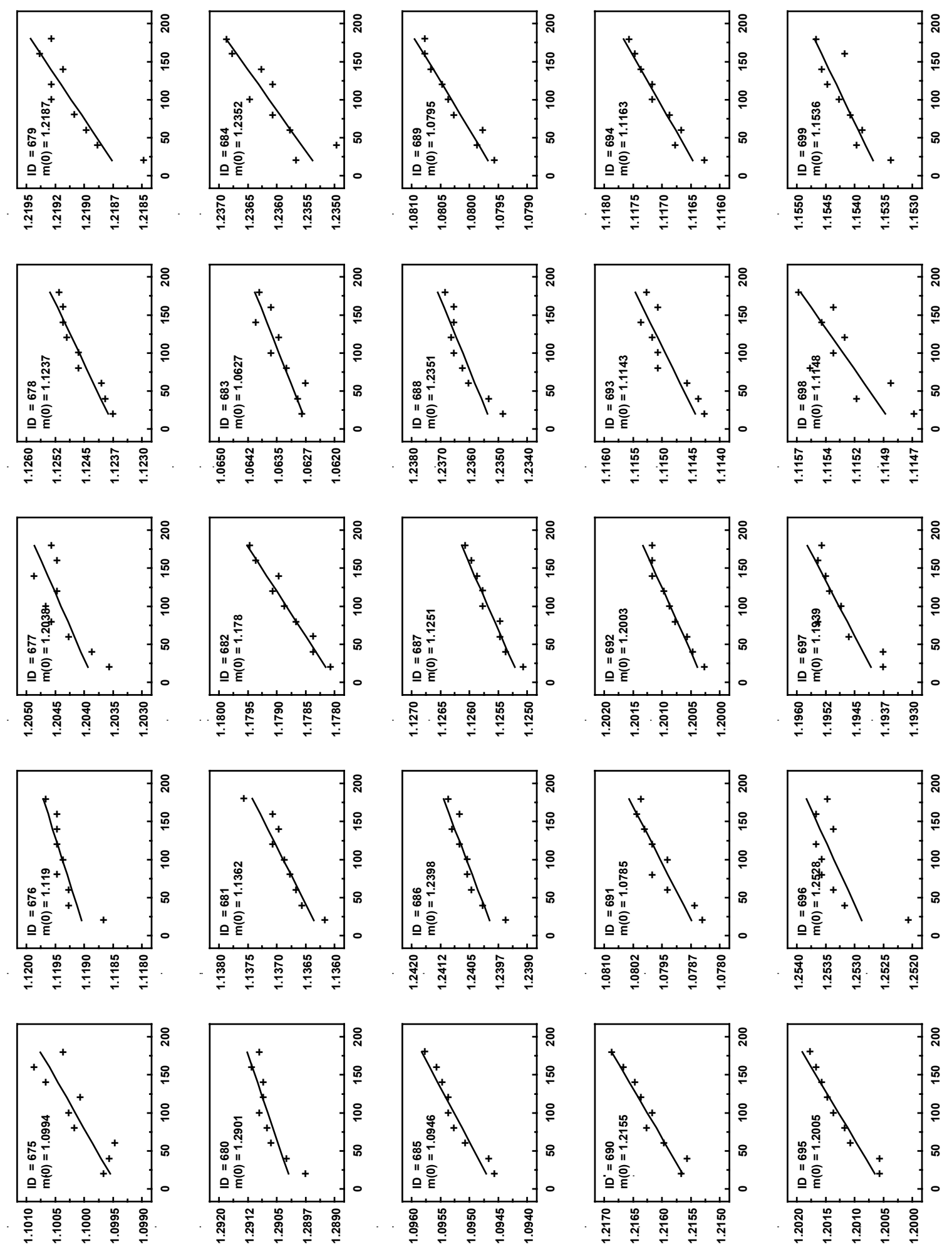

Fig. 32. Panel ID $=675-699$ : Multiple mass observations (in kilograms) as a function of elapsed time (in seconds) for insulation panels 675 through 699. Linear fit for data (shown as solid line) was back-extrapolated to elapsed time zero $\left(t_{0}\right)$ to determine $m_{0}$ for each panel. 


\section{Appendix B}
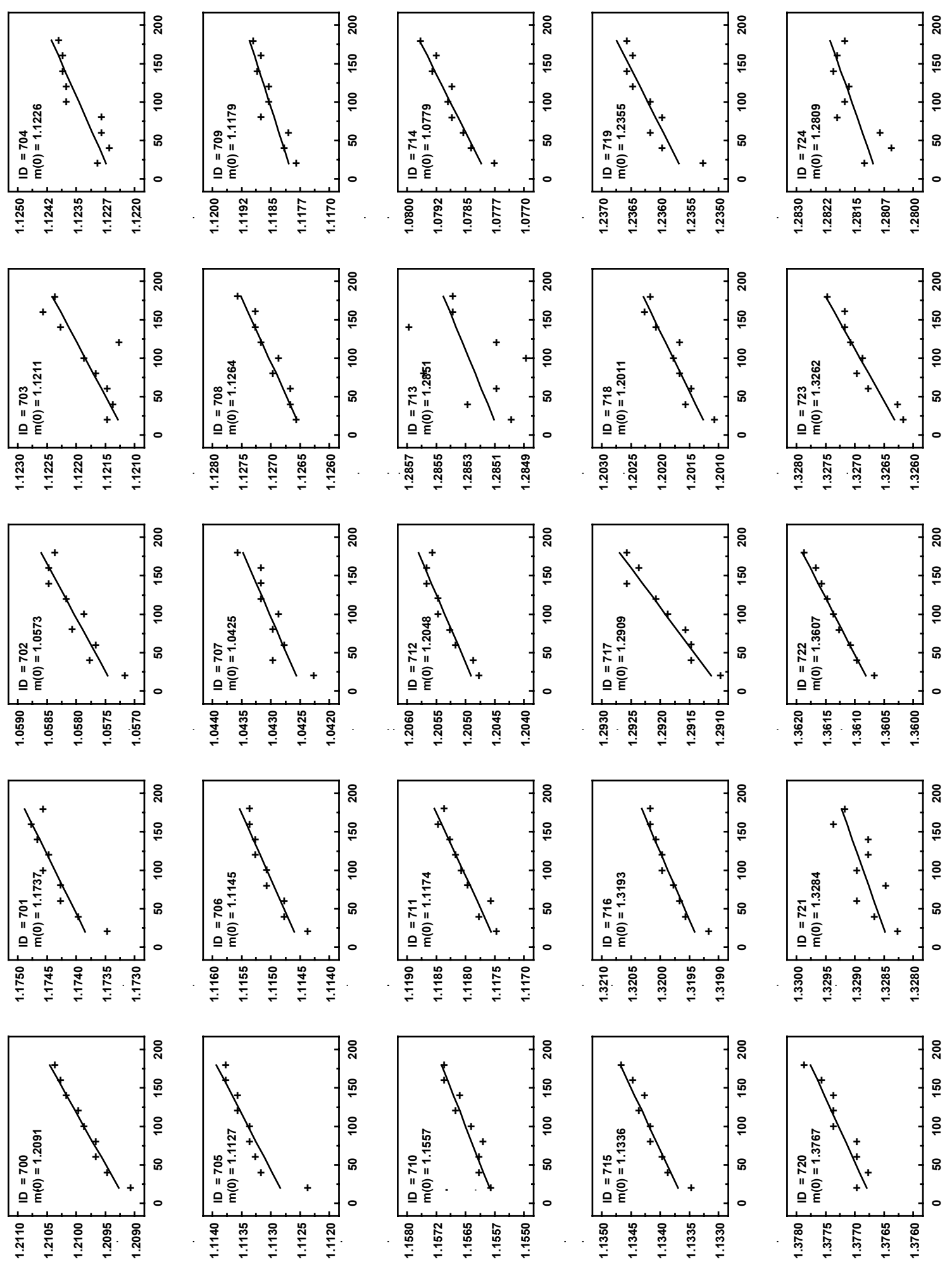

Fig. 33. Panel ID=700-724: Multiple mass observations (in kilograms) as a function of elapsed time (in seconds) for insulation panels 700 through 724. Linear fit for data (shown as solid line) was back-extrapolated to elapsed time zero $\left(t_{0}\right)$ to determine $m_{0}$ for each panel. 


\section{Appendix B}
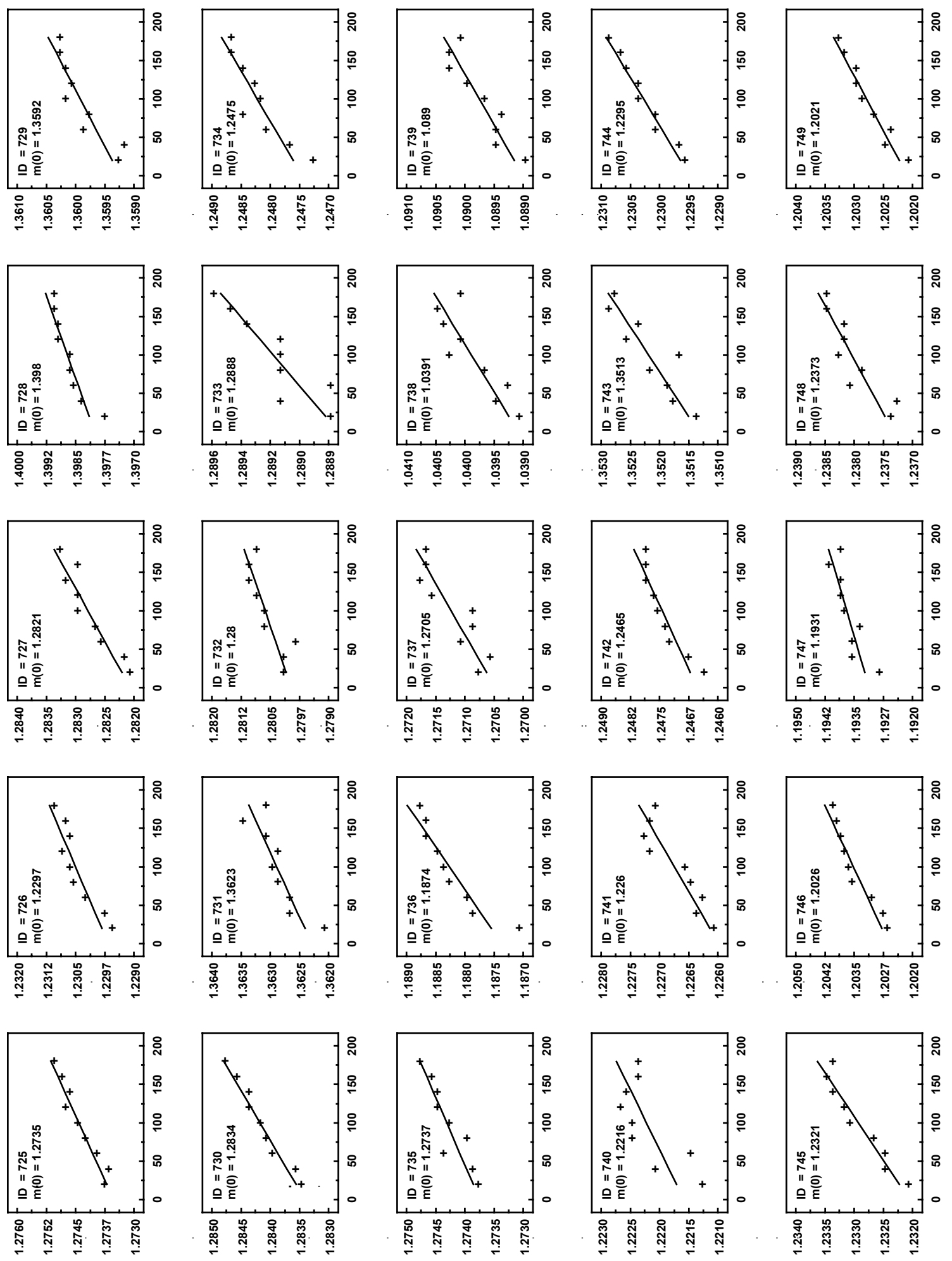

Fig. 34. Panel ID=725-749: Multiple mass observations (in kilograms) as a function of elapsed time (in seconds) for insulation panels 725 through 749. Linear fit for data (shown as solid line) was back-extrapolated to elapsed time zero $\left(t_{0}\right)$ to determine $m_{0}$ for each panel. 


\section{Appendix B}
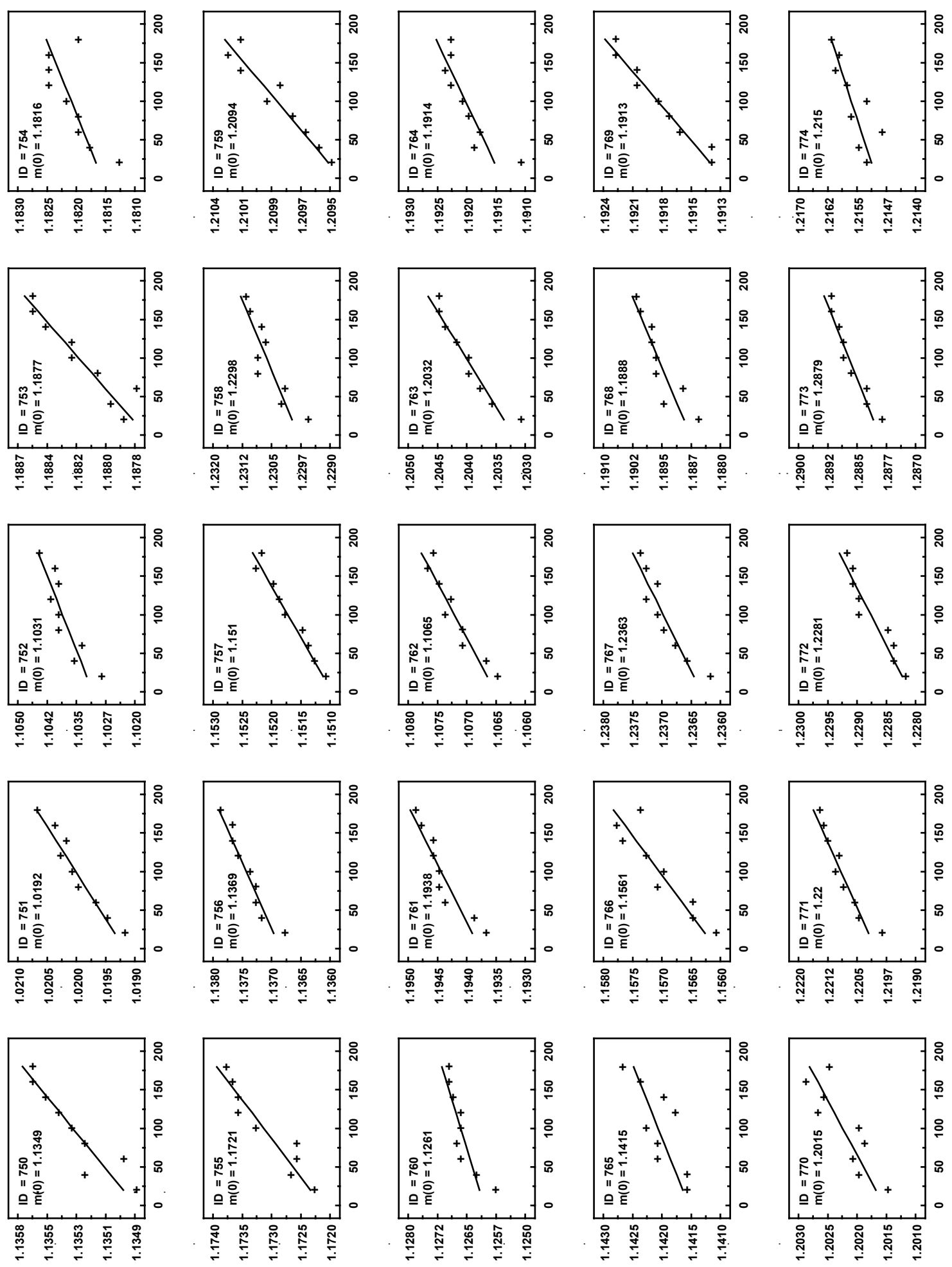

Fig. 35. Panel ID=750-774: Multiple mass observations (in kilograms) as a function of elapsed time (in seconds) for insulation panels 750 through 774. Linear fit for data (shown as solid line) was back-extrapolated to elapsed time zero $\left(t_{0}\right)$ to determine $m_{0}$ for each panel. 


\section{Appendix B}
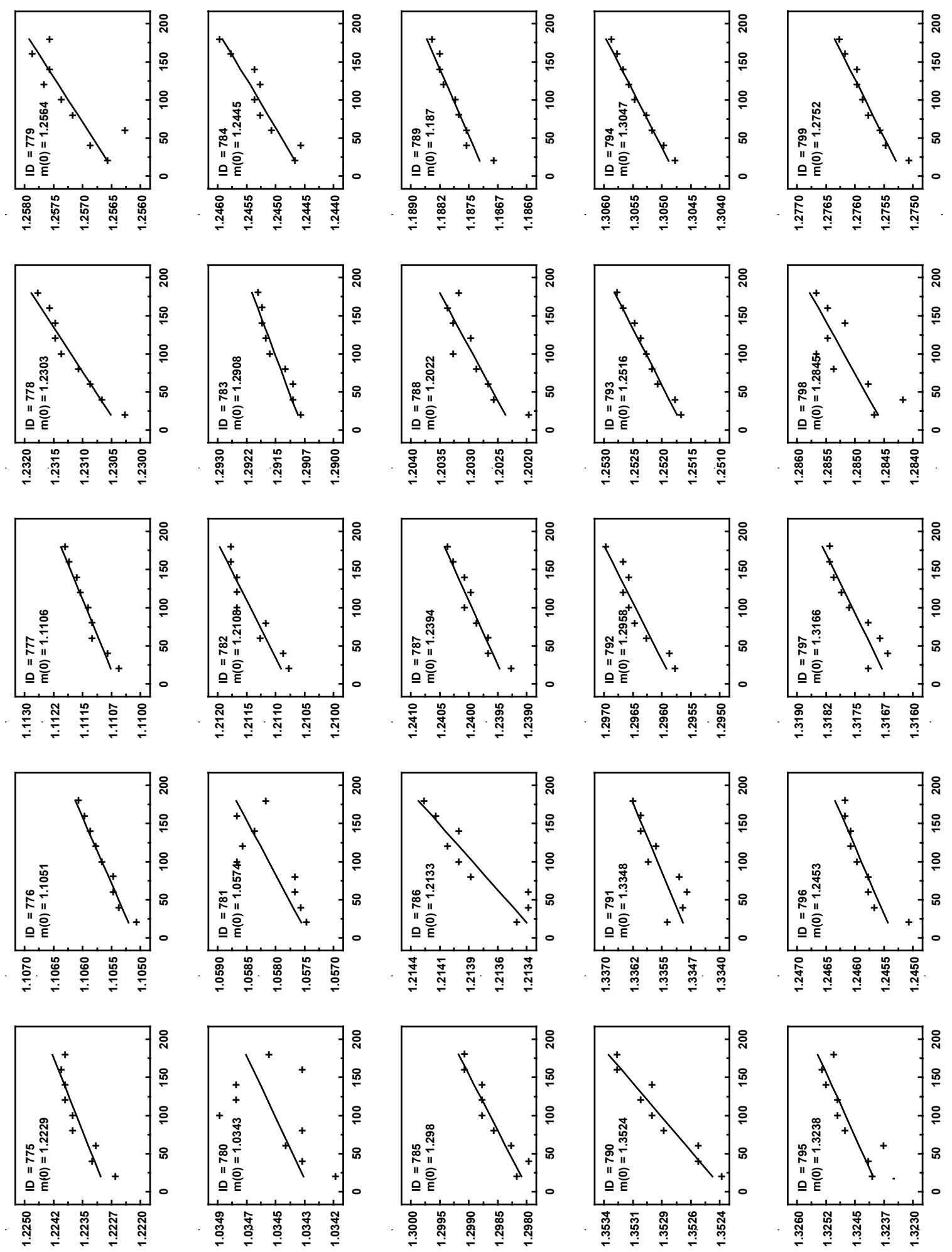

Fig. 36. Panel ID=775-799: Multiple mass observations (in kilograms) as a function of elapsed time (in seconds) for insulation panels 775 through 799. Linear fit for data (shown as solid line) was back-extrapolated to elapsed time zero $\left(t_{0}\right)$ to determine $m_{0}$ for each panel. 


\section{Appendix B}
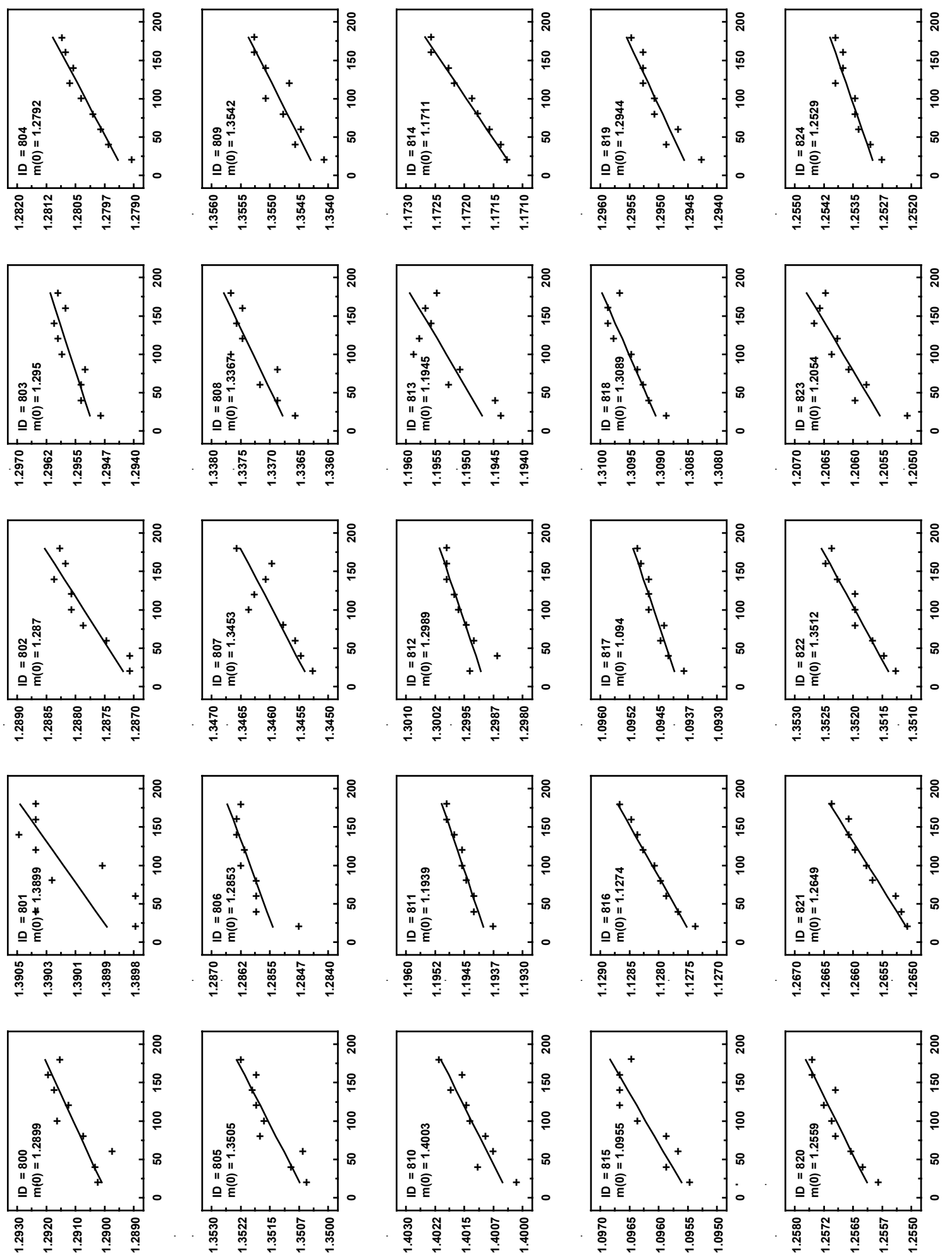

Fig. 37. Panel ID=800-824: Multiple mass observations (in kilograms) as a function of elapsed time (in seconds) for insulation panels 800 through 824. Linear fit for data (shown as solid line) was back-extrapolated to elapsed time zero $\left(t_{0}\right)$ to determine $m_{0}$ for each panel. 


\section{Appendix B}
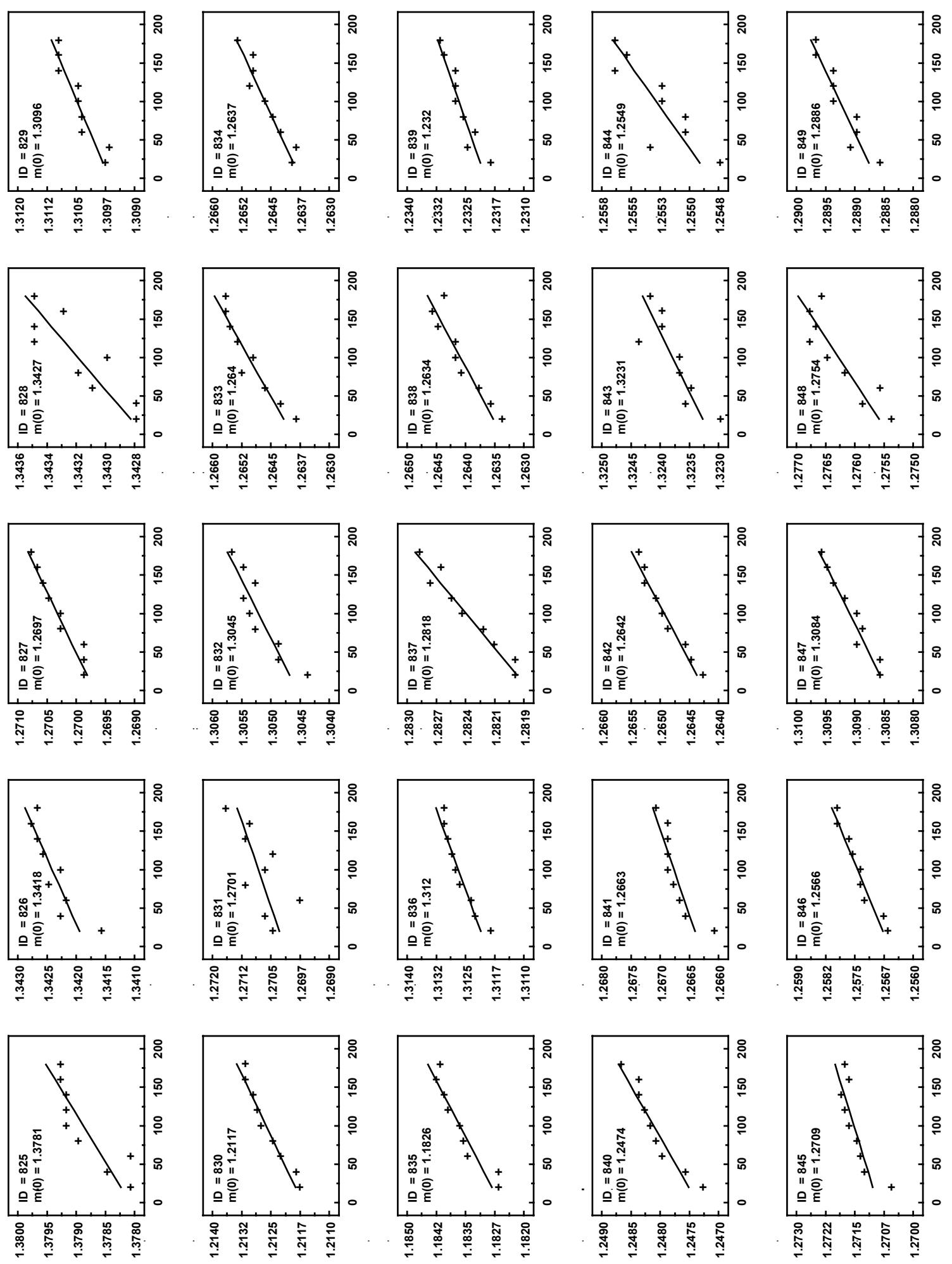

Fig. 38. Panel ID=825-849: Multiple mass observations (in kilograms) as a function of elapsed time (in seconds) for insulation panels 825 through 849. Linear fit for data (shown as solid line) was back-extrapolated to elapsed time zero $\left(t_{0}\right)$ to determine $m_{0}$ for each panel. 


\section{Appendix B}
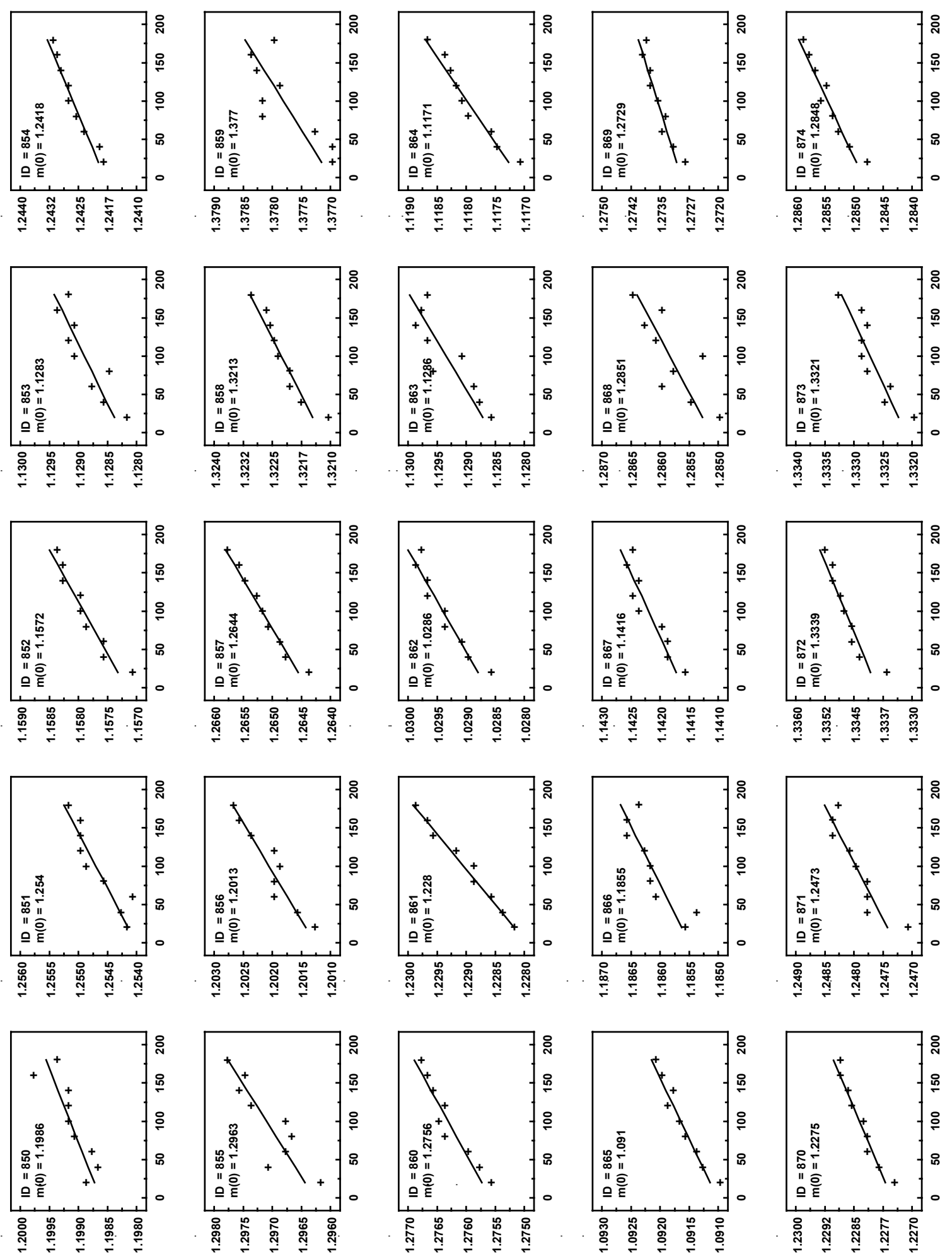

Fig. 39. Panel $I D=850-874$ : Multiple mass observations (in kilograms) as a function of elapsed time (in seconds) for insulation panels 850 through 874. Linear fit for data (shown as solid line) was back-extrapolated to elapsed time zero $\left(t_{0}\right)$ to determine $m_{0}$ for each panel. 


\section{Appendix B}
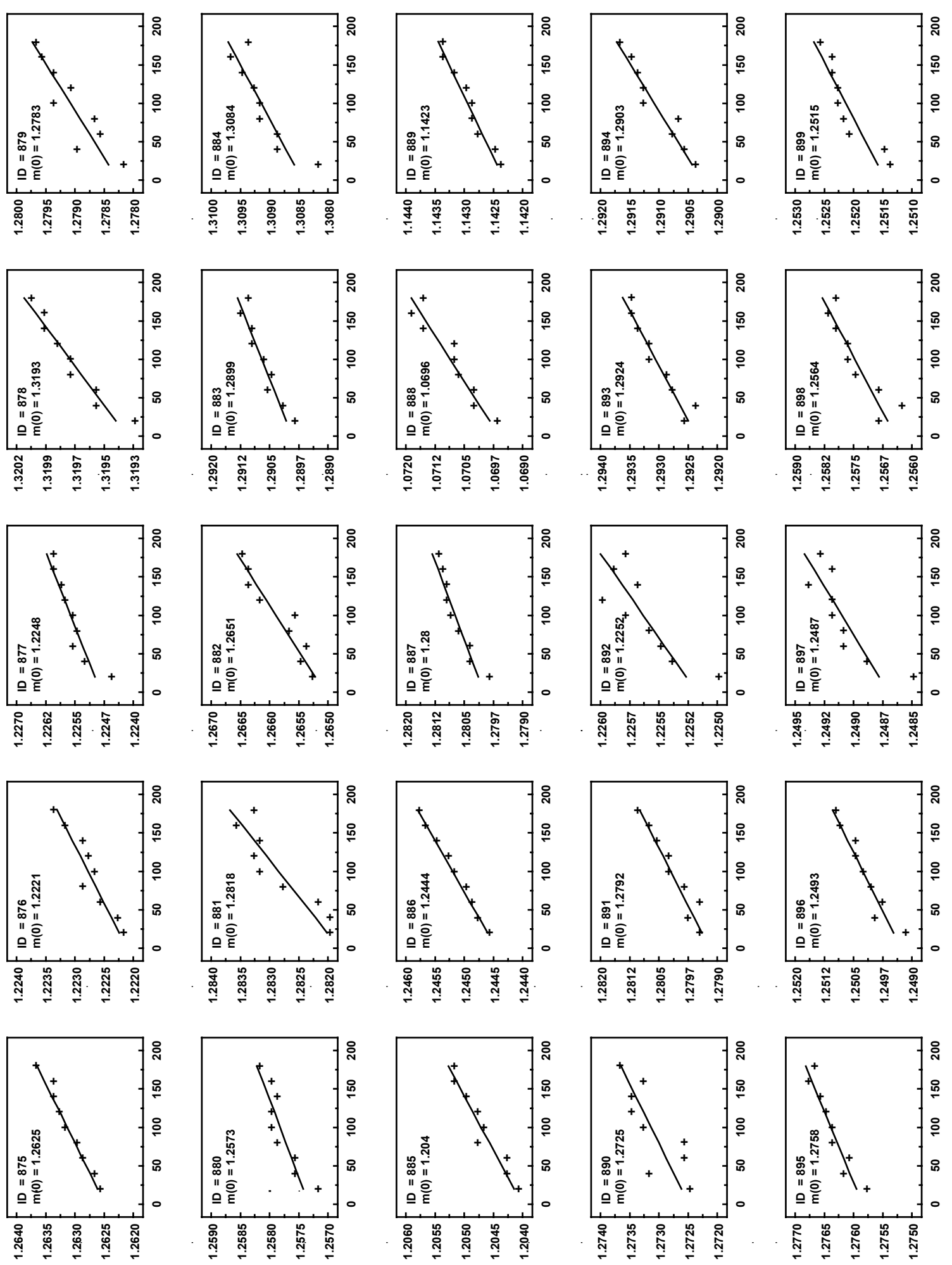

Fig. 40. Panel ID=875-899: Multiple mass observations (in kilograms) as a function of elapsed time (in seconds) for insulation panels 875 through 899. Linear fit for data (shown as solid line) was back-extrapolated to elapsed time zero $\left(t_{0}\right)$ to determine $m_{0}$ for each panel. 


\section{Appendix B}
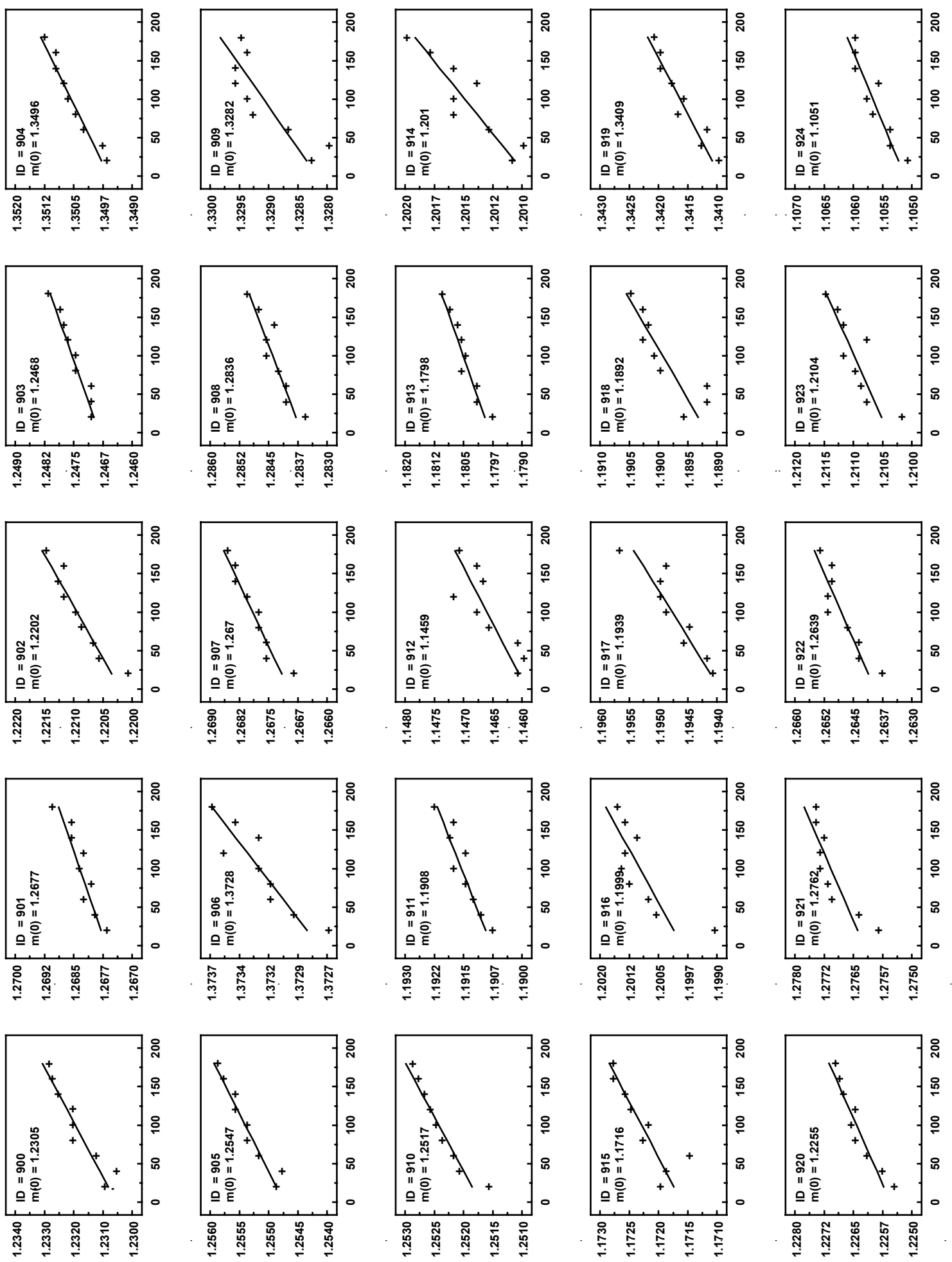

Fig. 41. Panel ID=900-924: Multiple mass observations (in kilograms) as a function of elapsed time (in seconds) for insulation panels 900 through 924. Linear fit for data (shown as solid line) was back-extrapolated to elapsed time zero $\left(t_{0}\right)$ to determine $m_{0}$ for each panel. 
Appendix B
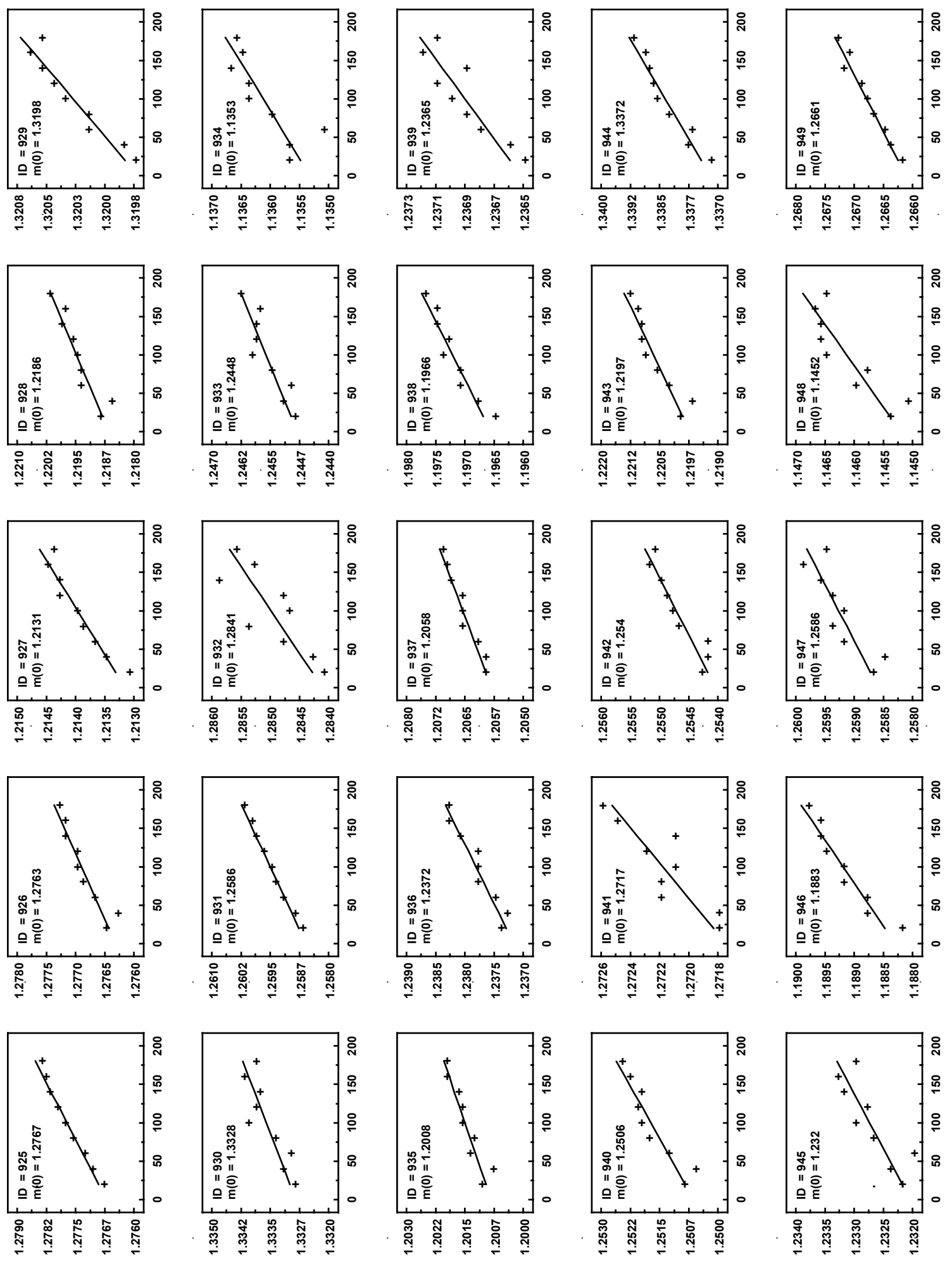

Fig. 42. Panel ID=925-949: Multiple mass observations (in kilograms) as a function of elapsed time (in seconds) for insulation panels 925 through 949. Linear fit for data (shown as solid line) was back-extrapolated to elapsed time zero $\left(t_{0}\right)$ to determine $m_{0}$ for each panel. 


\section{Appendix C: Thickness Plots (Panel ID: 500 through 949)}
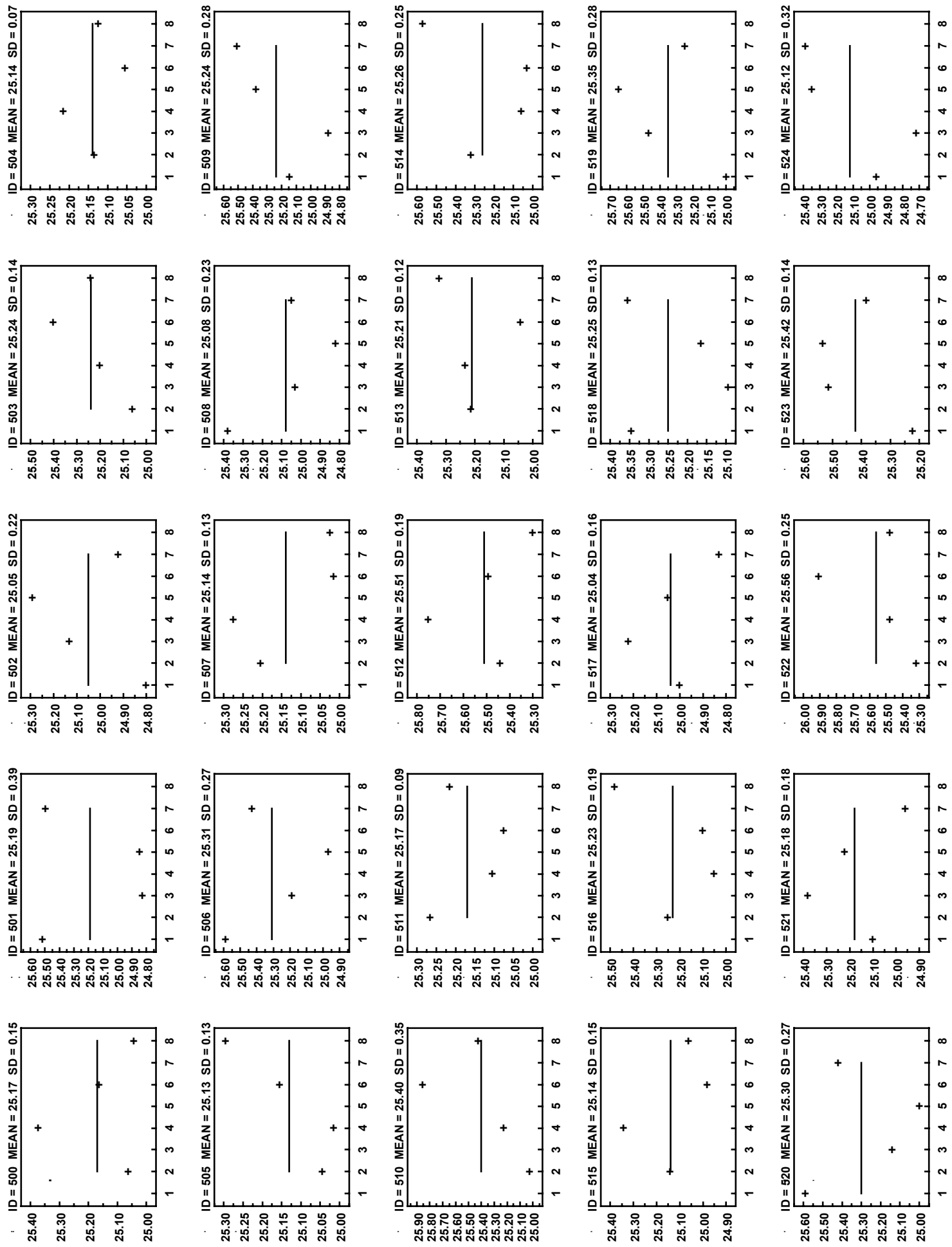

Fig. 43. Panel $I D=500-524$ : Thickness measurements (in millimeters) at locations 1 through 8 (Fig. 3) for insulation panels 500 through 524. Mean is shown as solid line (with numerical values for mean and standard deviation (SD) in the title of each frame). 
Appendix C
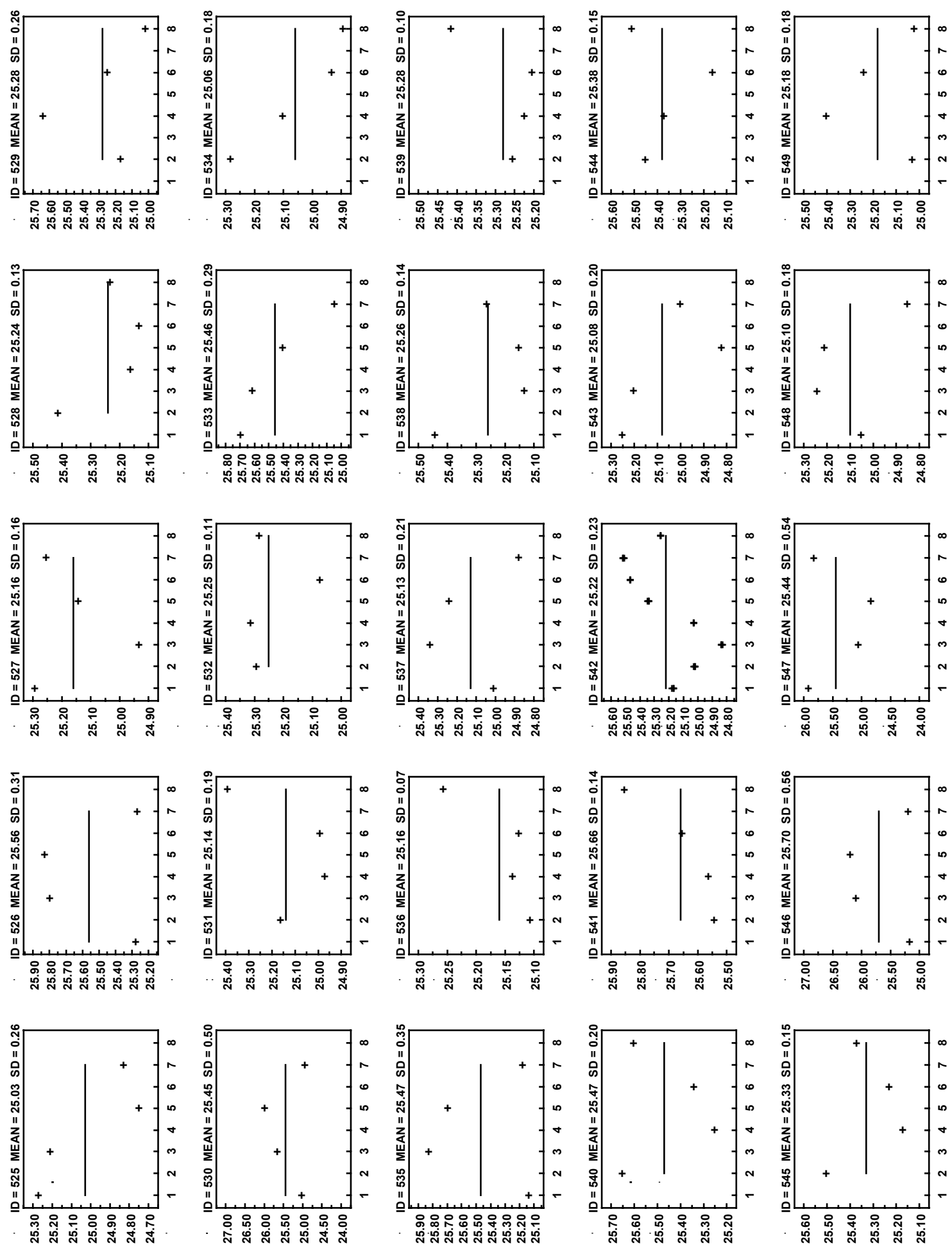

Fig. 44. Panel ID $=525-549$ : Thickness measurements (in millimeters) at locations 1 through 8 (Fig. 3) for insulation panels 525 through 549. Mean is shown as solid line (with numerical values for mean and standard deviation (SD) in the title of each frame). 
Appendix C
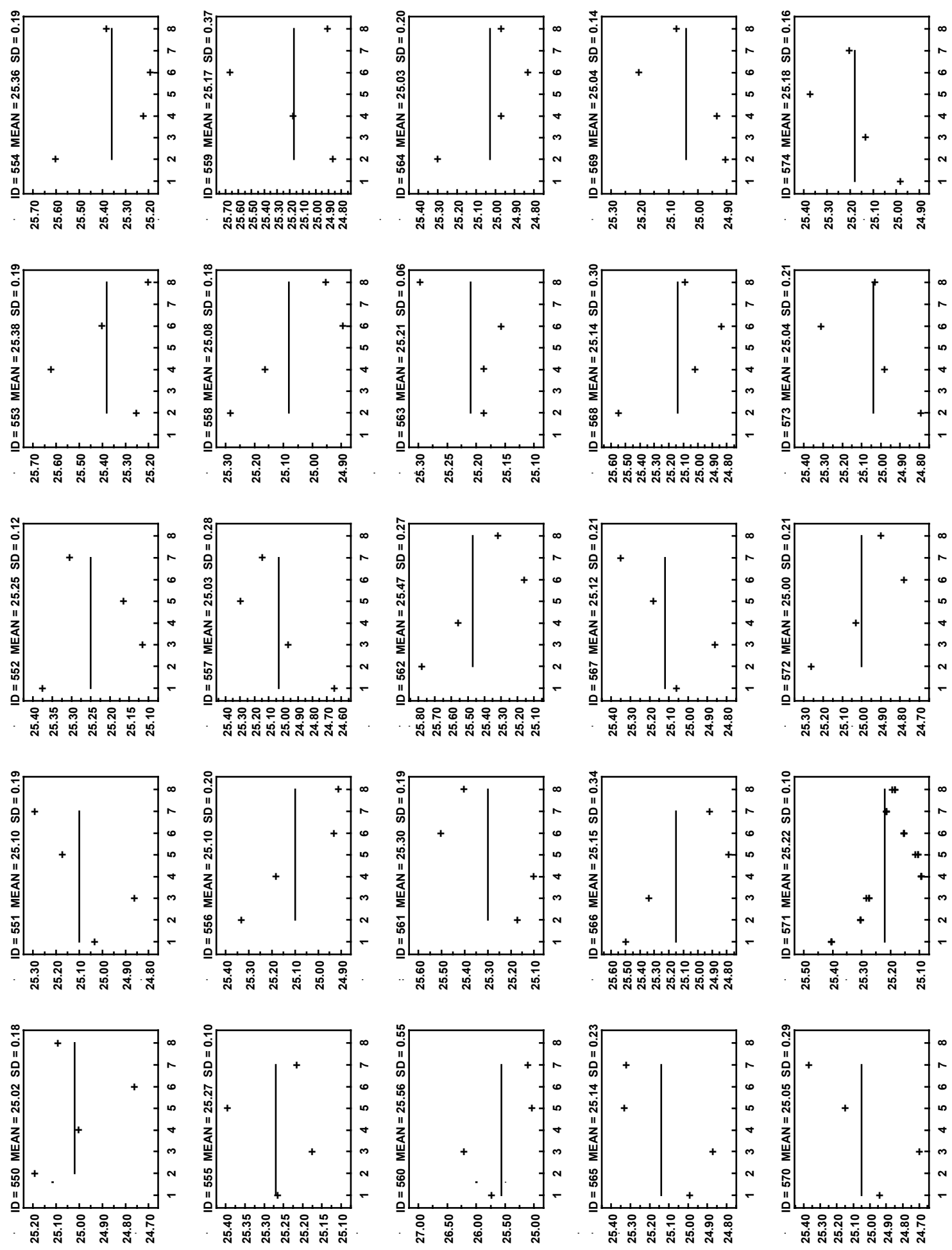

Fig. 45. Panel ID $=550-574$ : Thickness measurements (in millimeters) at locations 1 through 8 (Fig. 3) for insulation panels 550 through 574. Mean is shown as solid line (with numerical values for mean and standard deviation (SD) in the title of each frame). 
Appendix C
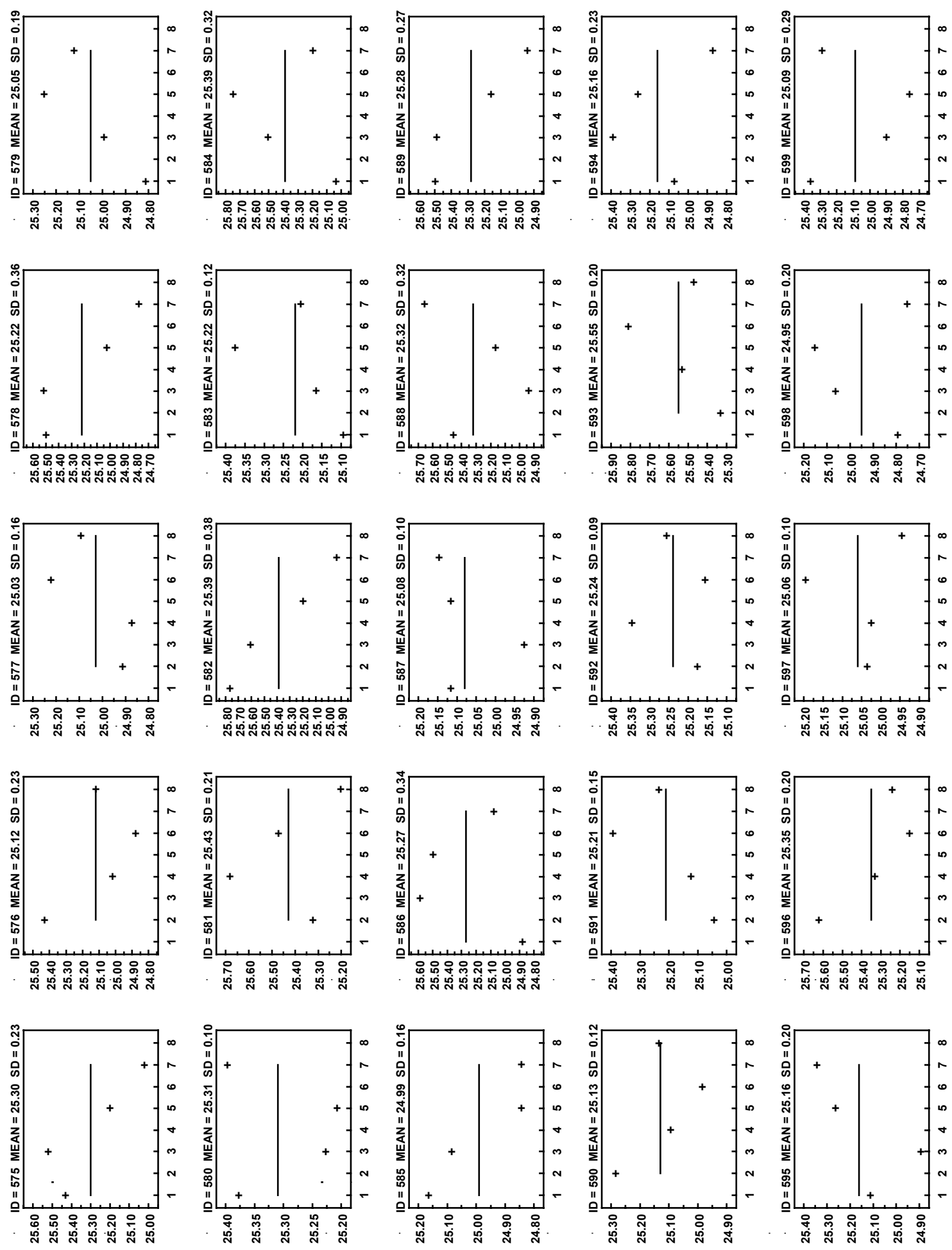

Fig. 46. Panel ID $=575-599$ : Thickness measurements (in millimeters) at locations 1 through 8 (Fig. 3) for insulation panels 575 through 599. Mean is shown as solid line (with numerical values for mean and standard deviation (SD) in the title of each frame). 
Appendix C
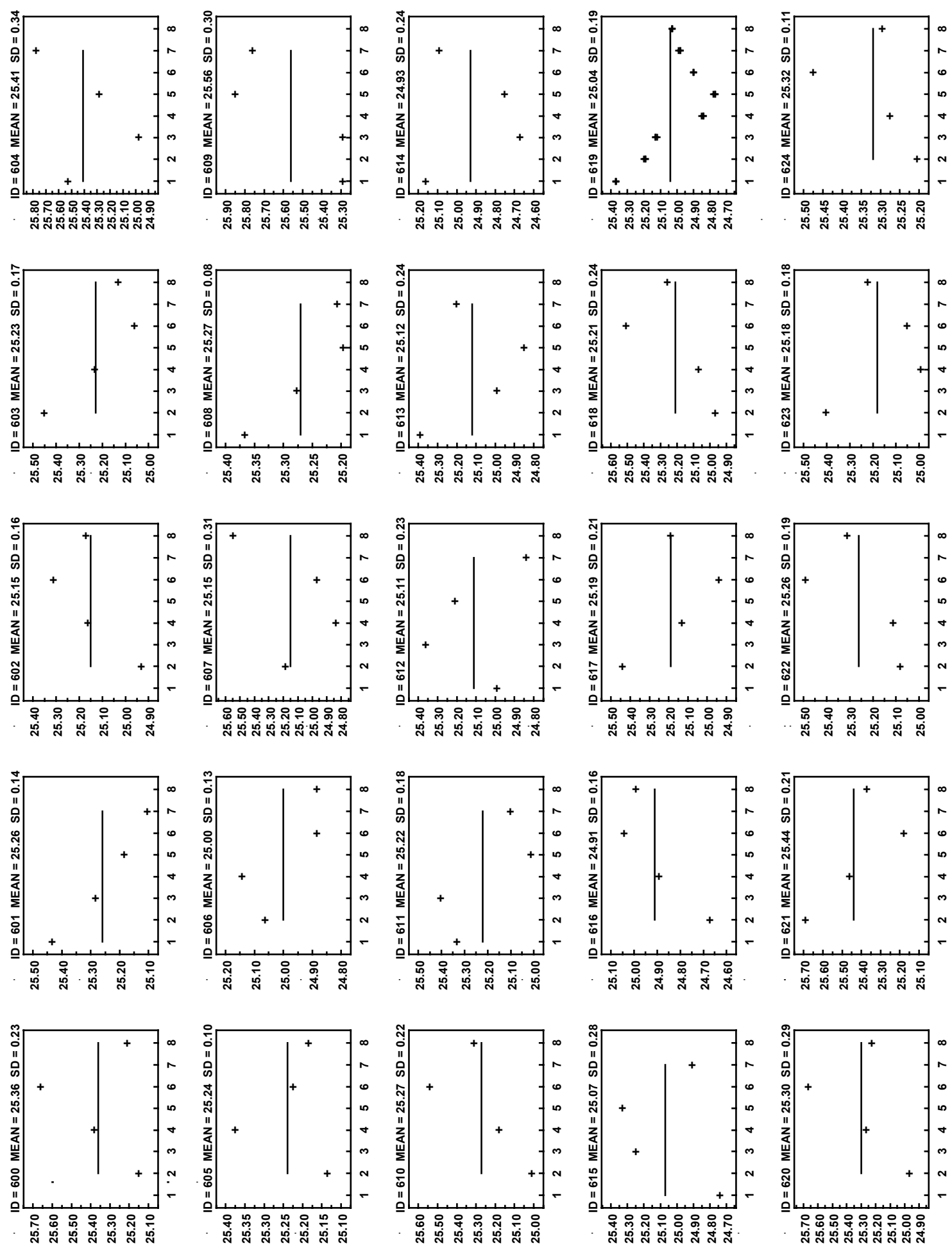

Fig. 47. Panel ID=600-624: Thickness measurements (in millimeters) at locations 1 through 8 (Fig. 3) for insulation panels 600 through 624. Mean is shown as solid line (with numerical values for mean and standard deviation (SD) in the title of each frame). 
Appendix C
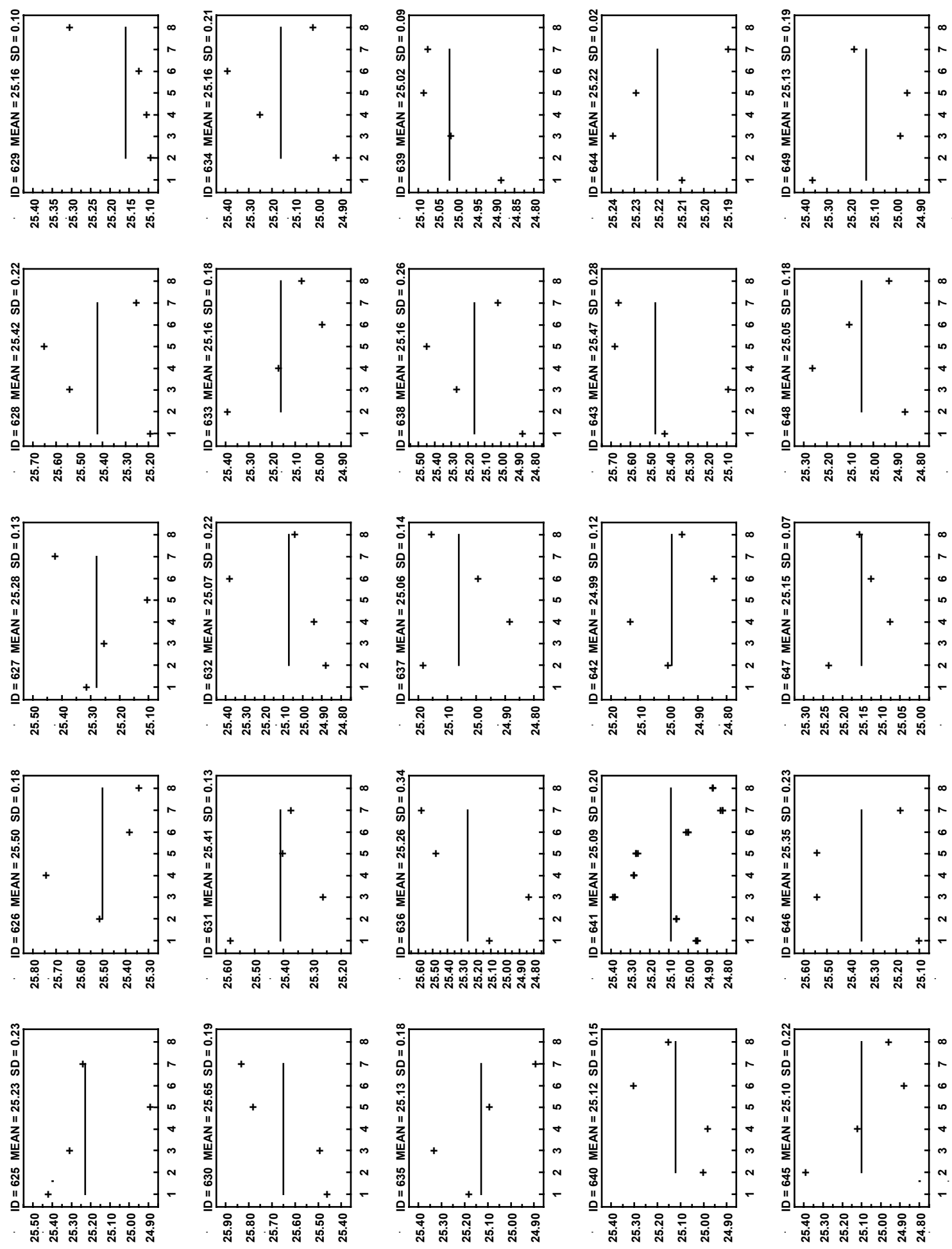

Fig. 48. Panel ID=625-649: Thickness measurements (in millimeters) at locations 1 through 8 (Fig. 3) for insulation panels 625 through 649. Mean is shown as solid line (with numerical values for mean and standard deviation (SD) in the title of each frame). 
Appendix C
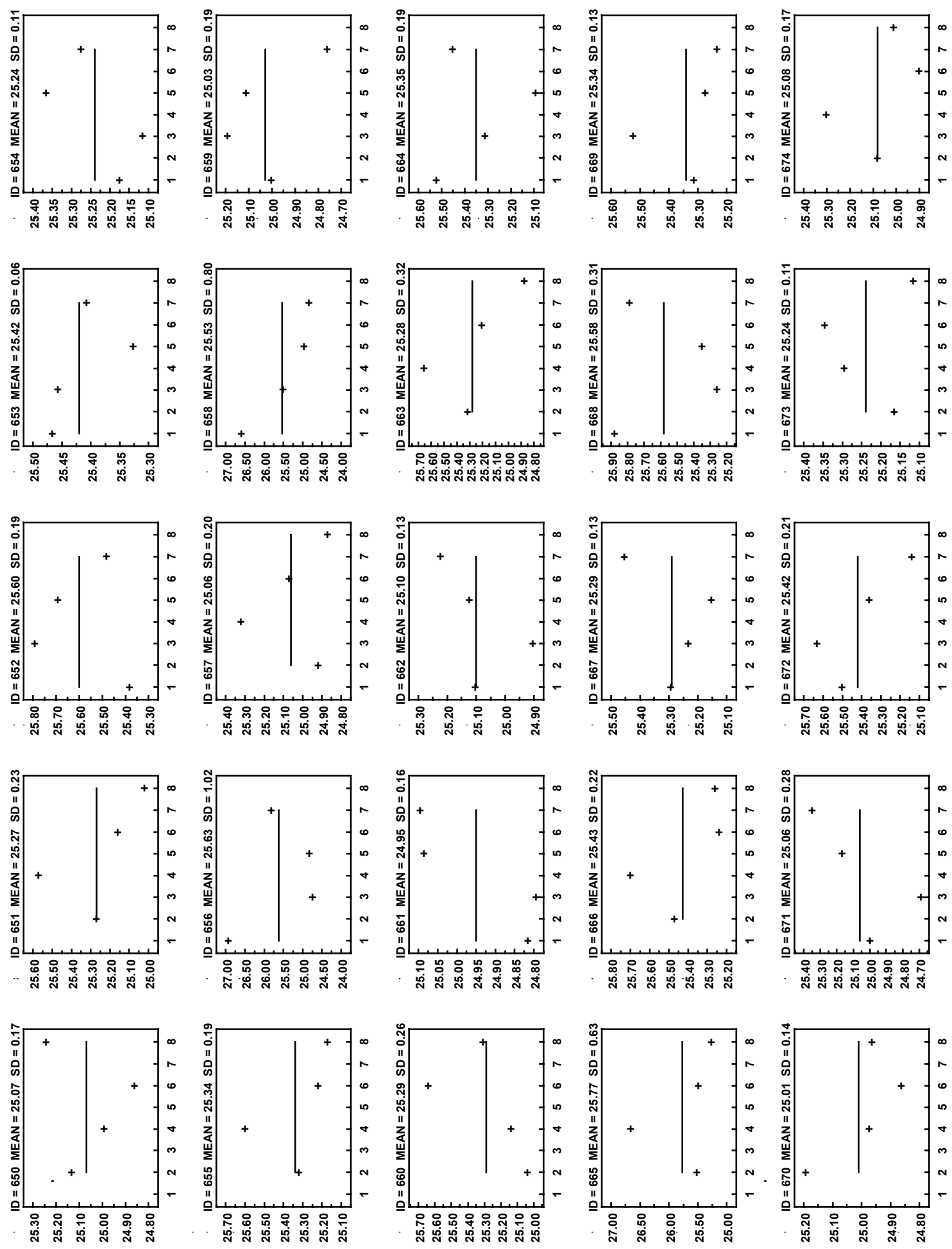

Fig. 49. Panel ID $=650-674$ : Thickness measurements (in millimeters) at locations 1 through 8 (Fig. 3) for insulation panels 650 through 674. Mean is shown as solid line (with numerical values for mean and standard deviation (SD) in the title of each frame). 
Appendix C
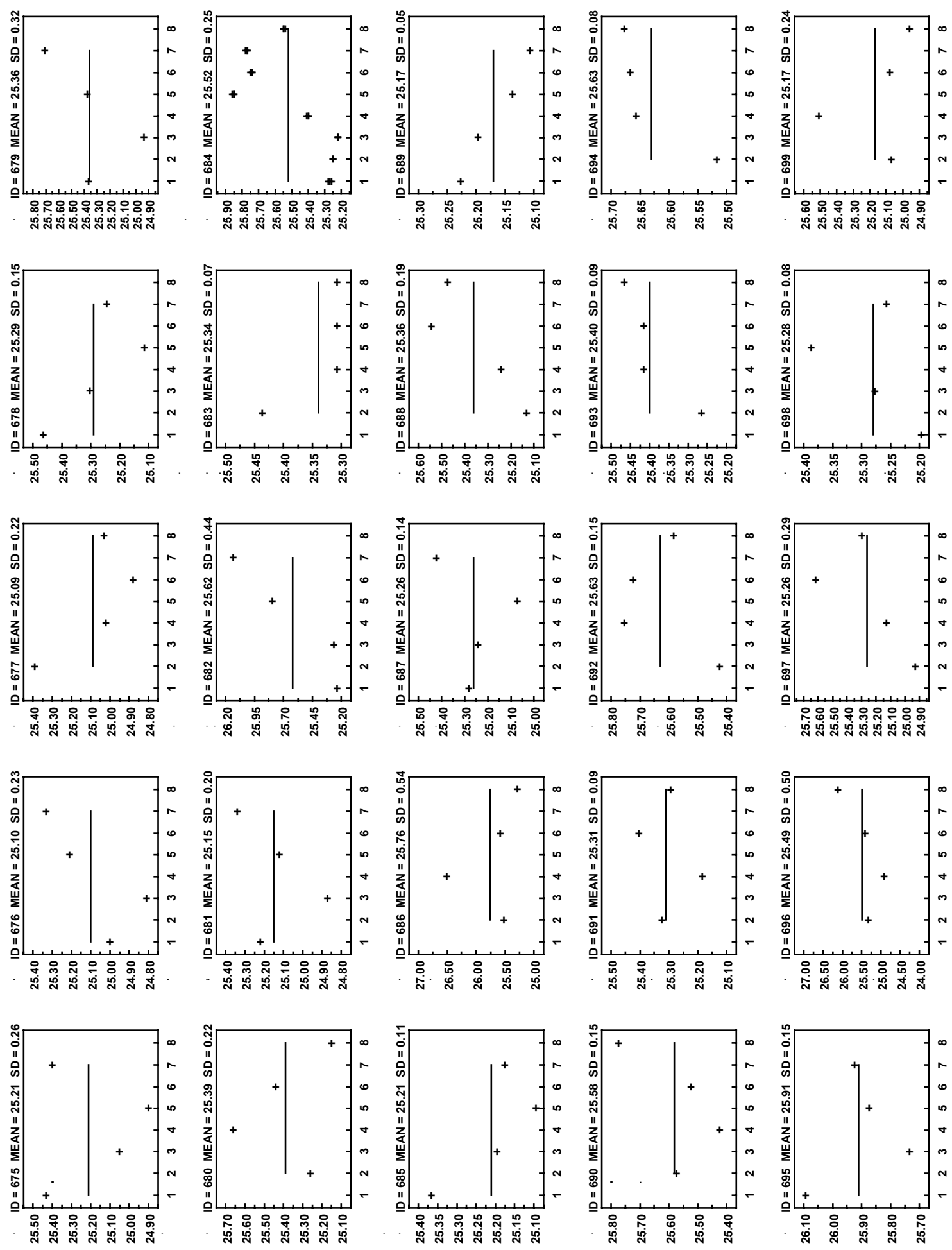

Fig. 50. Panel ID=675-699: Thickness measurements (in millimeters) at locations 1 through 8 (Fig. 3) for insulation panels 675 through 699. Mean is shown as solid line (with numerical values for mean and standard deviation (SD) in the title of each frame). 
Appendix C
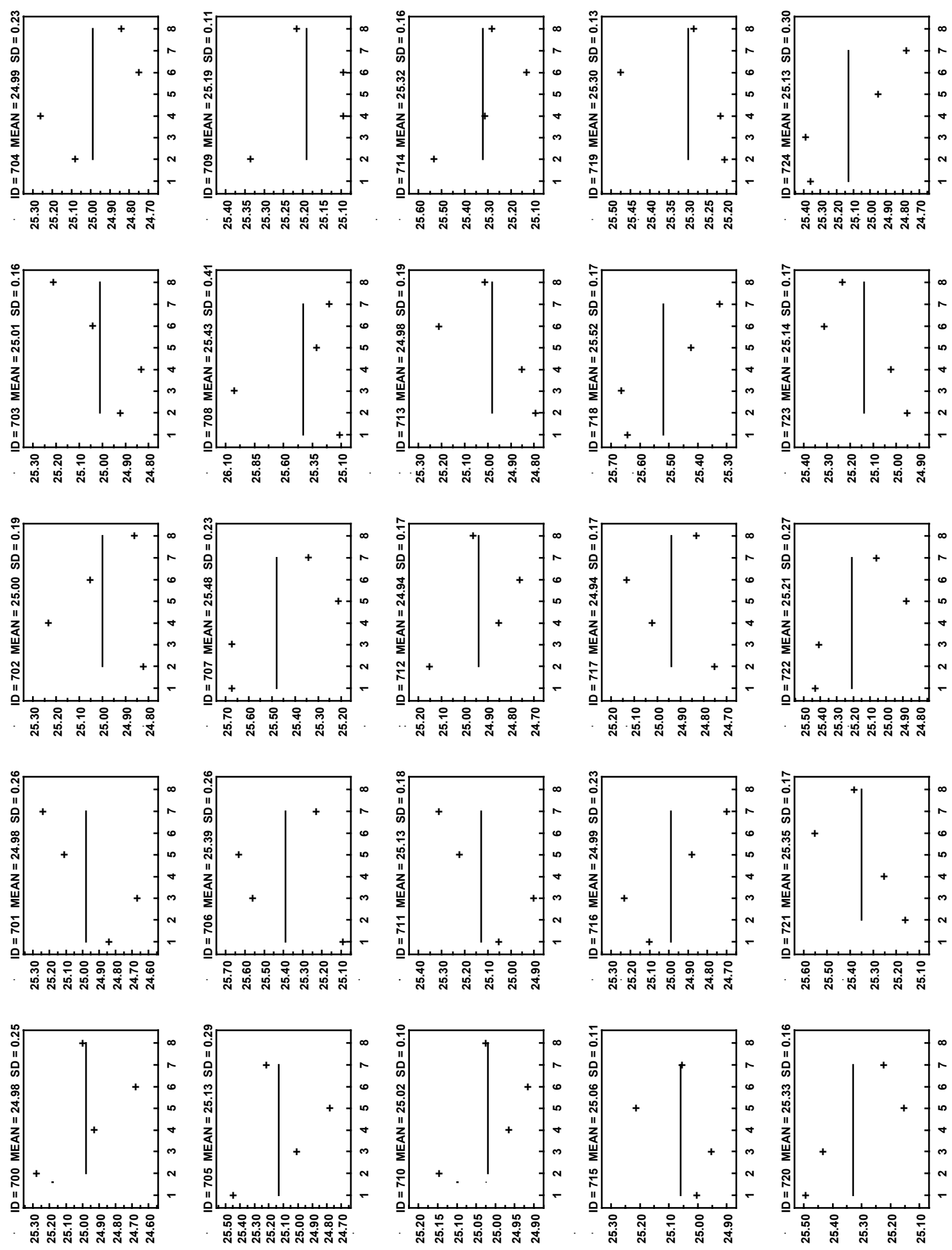

Fig. 51. Panel $I D=700-724$ : Thickness measurements (in millimeters) at locations 1 through 8 (Fig. 3) for insulation panels 700 through 724. Mean is shown as solid line (with numerical values for mean and standard deviation (SD) in the title of each frame). 
Appendix C
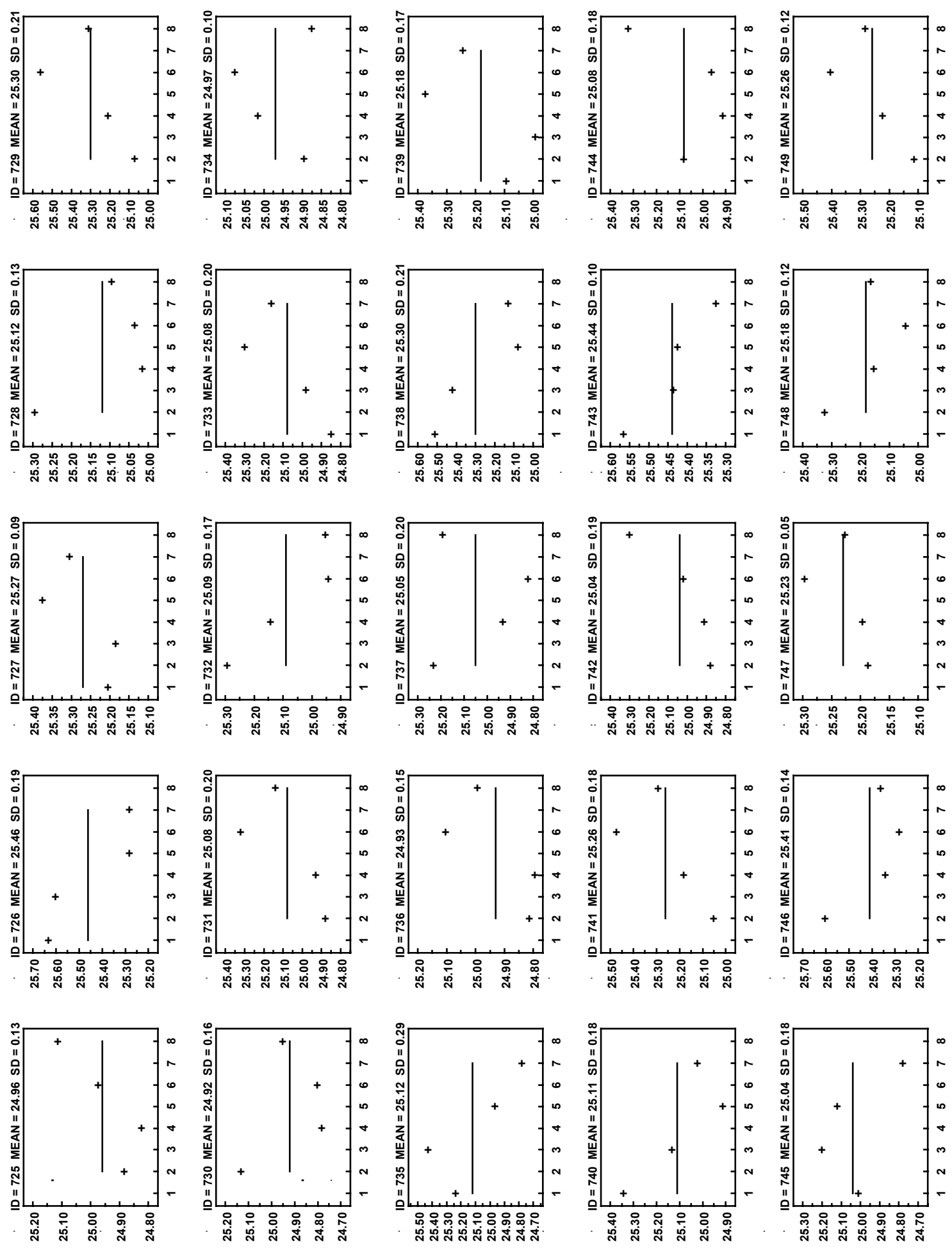

Fig. 52. Panel ID $=725-749$ : Thickness measurements (in millimeters) at locations 1 through 8 (Fig. 3) for insulation panels 725 through 749. Mean is shown as solid line (with numerical values for mean and standard deviation (SD) in the title of each frame). 
Appendix C
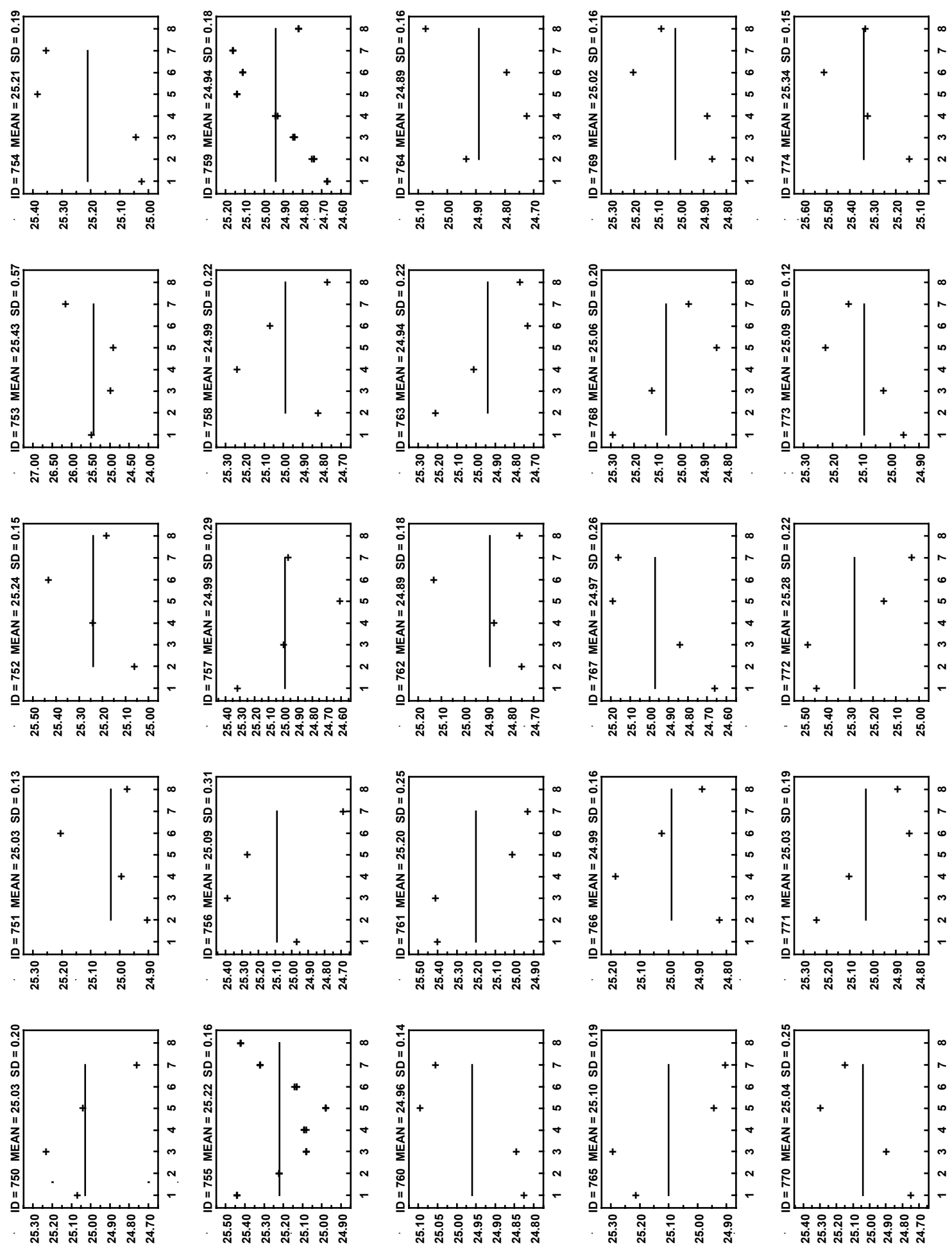

Fig. 53. Panel $I D=750-774$ : Thickness measurements (in millimeters) at locations 1 through 8 (Fig. 3) for insulation panels 750 through 774. Mean is shown as solid line (with numerical values for mean and standard deviation (SD) in the title of each frame). 
Appendix C
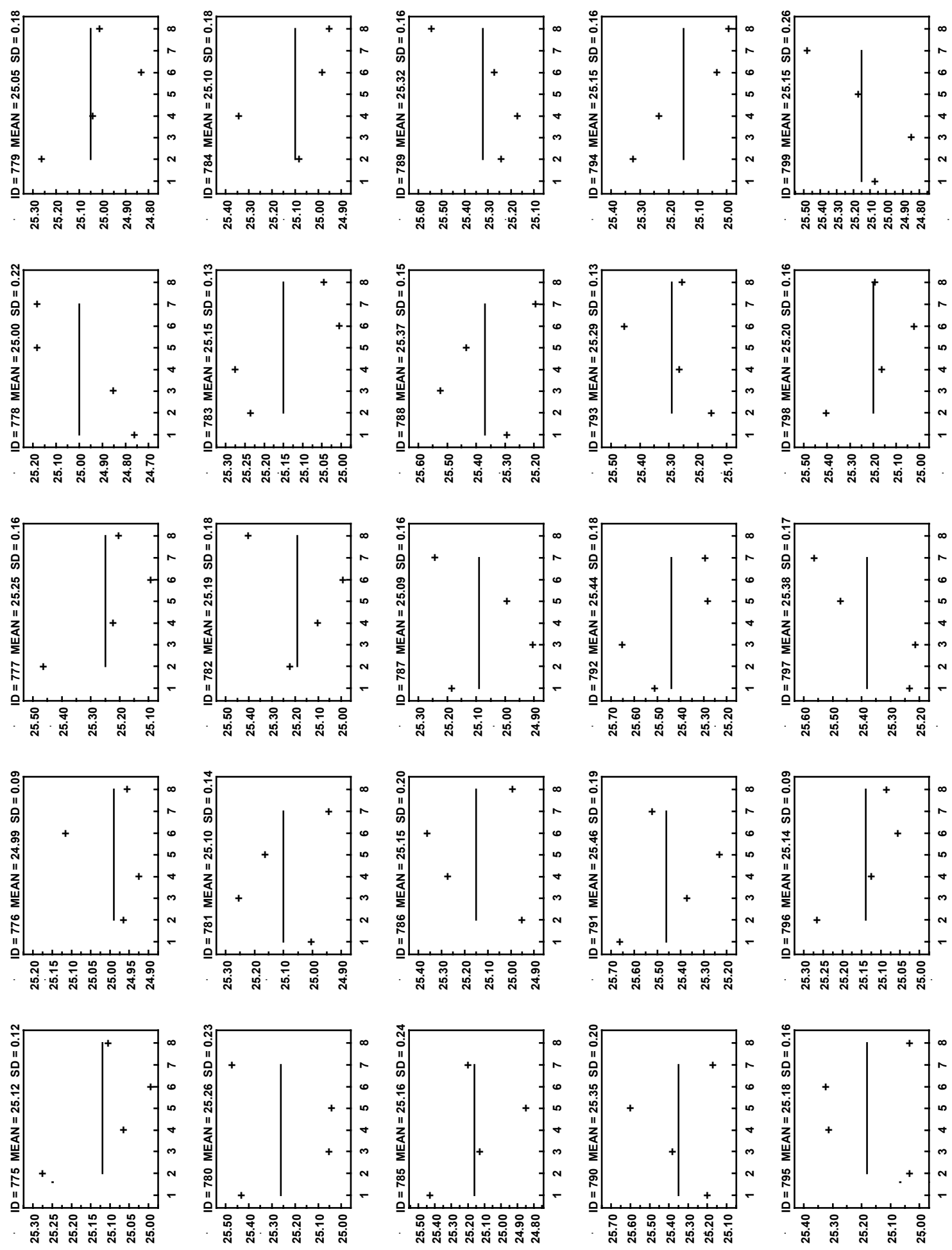

Fig. 54. Panel $I D=775-799$ : Thickness measurements (in millimeters) at locations 1 through 8 (Fig. 3) for insulation panels 775 through 799. Mean is shown as solid line (with numerical values for mean and standard deviation (SD) in the title of each frame). 
Appendix C
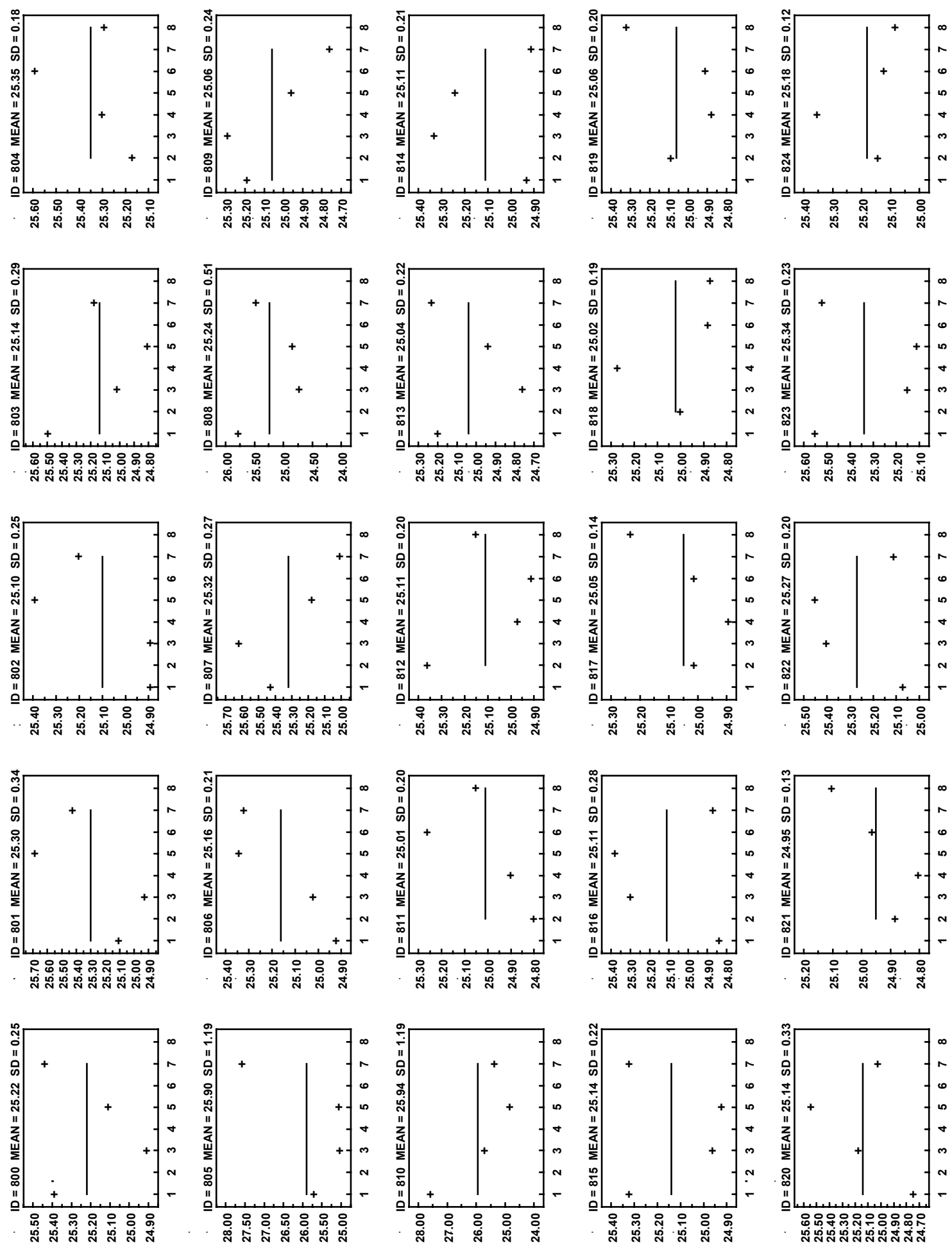

Fig. 55. Panel ID $=800-824$ : Thickness measurements (in millimeters) at locations 1 through 8 (Fig. 3) for insulation panels 800 through 824. Mean is shown as solid line (with numerical values for mean and standard deviation (SD) in the title of each frame). 
Appendix C
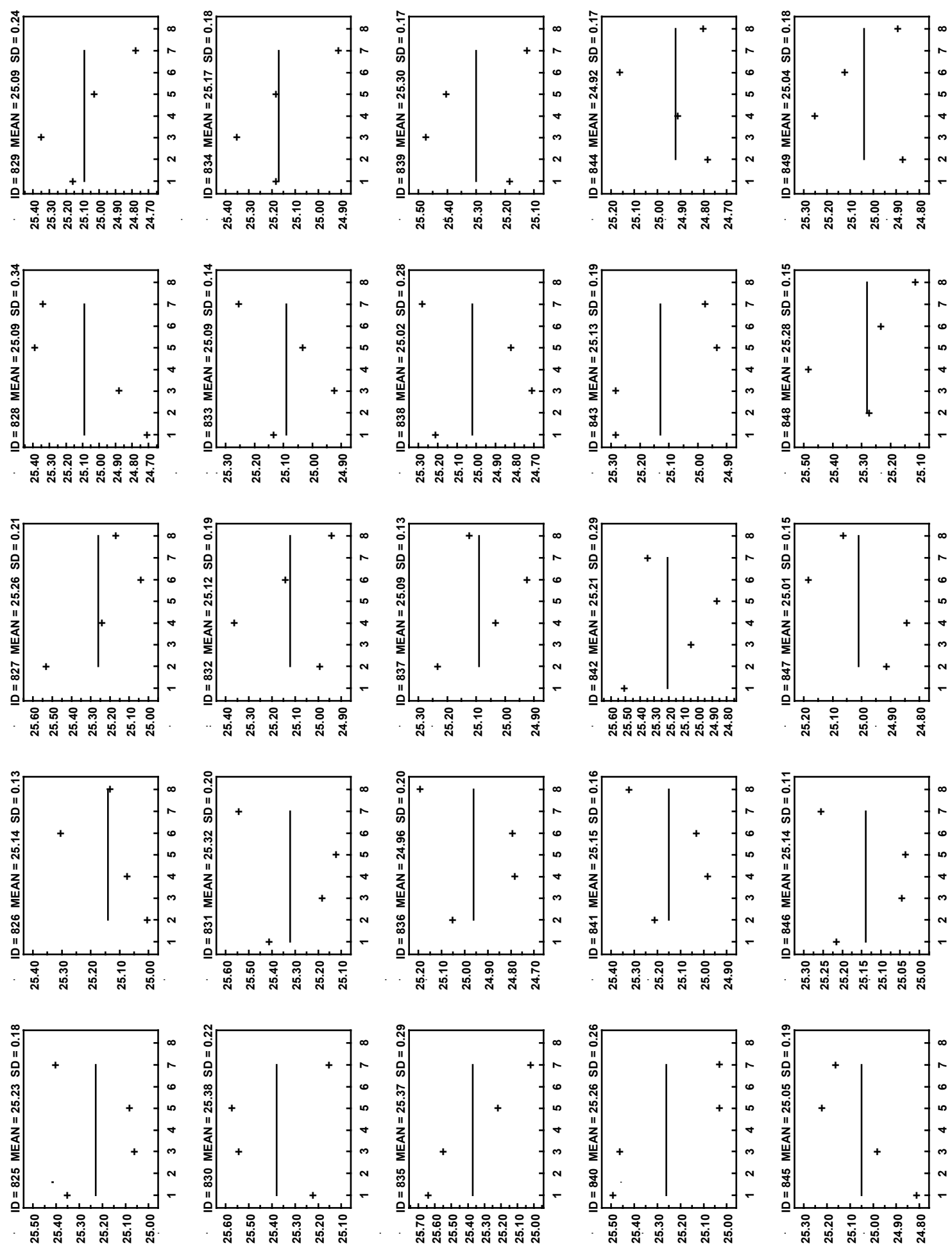

Fig. 56. Panel ID $=825-849$ : Thickness measurements (in millimeters) at locations 1 through 8 (Fig. 3) for insulation panels 825 through 849 . Mean is shown as solid line (with numerical values for mean and standard deviation (SD) in the title of each frame). 
Appendix C
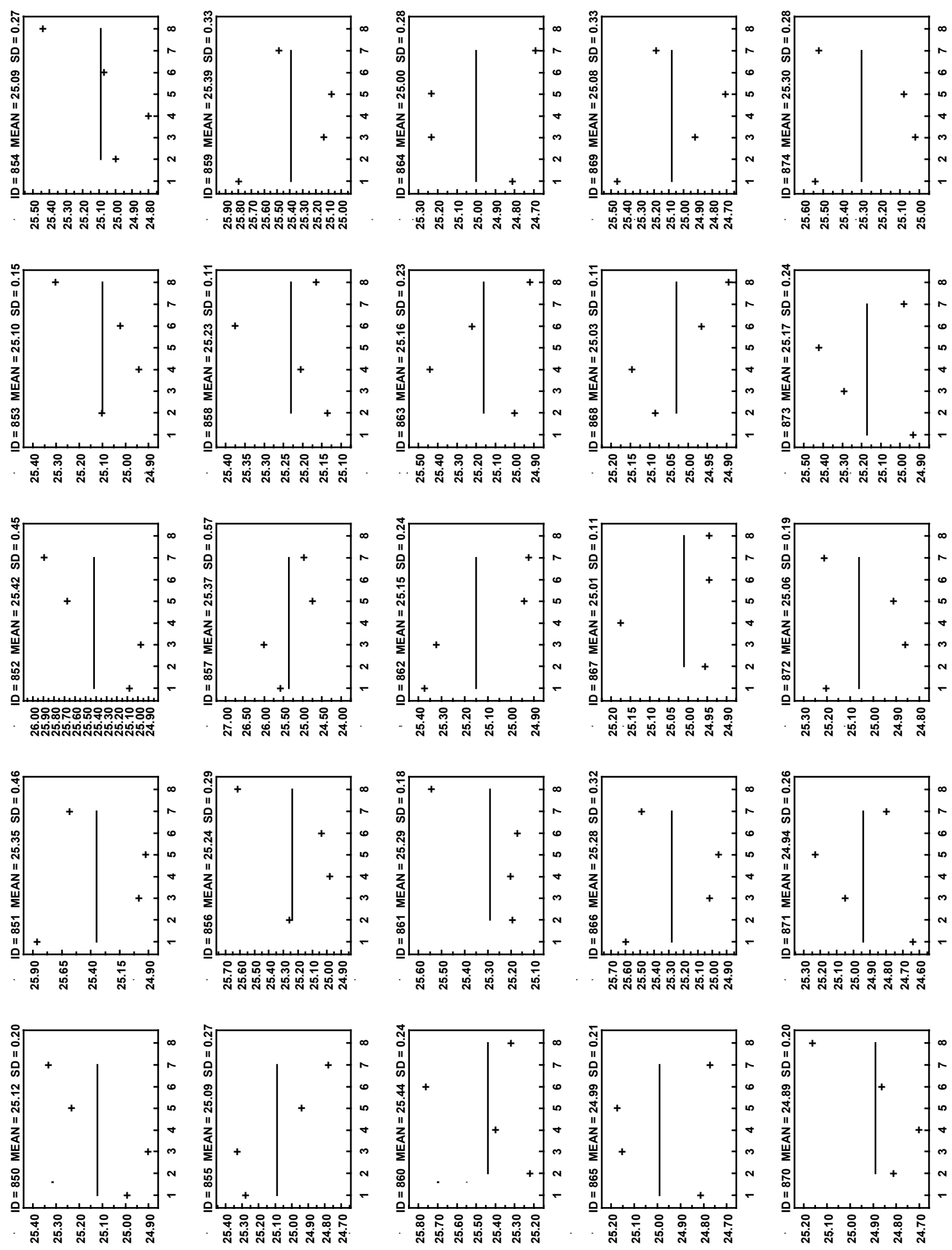

Fig. 57. Panel $I D=850-874$ : Thickness measurements (in millimeters) at locations 1 through 8 (Fig. 3) for insulation panels 850 through 874 . Mean is shown as solid line (with numerical values for mean and standard deviation (SD) in the title of each frame). 
Appendix C
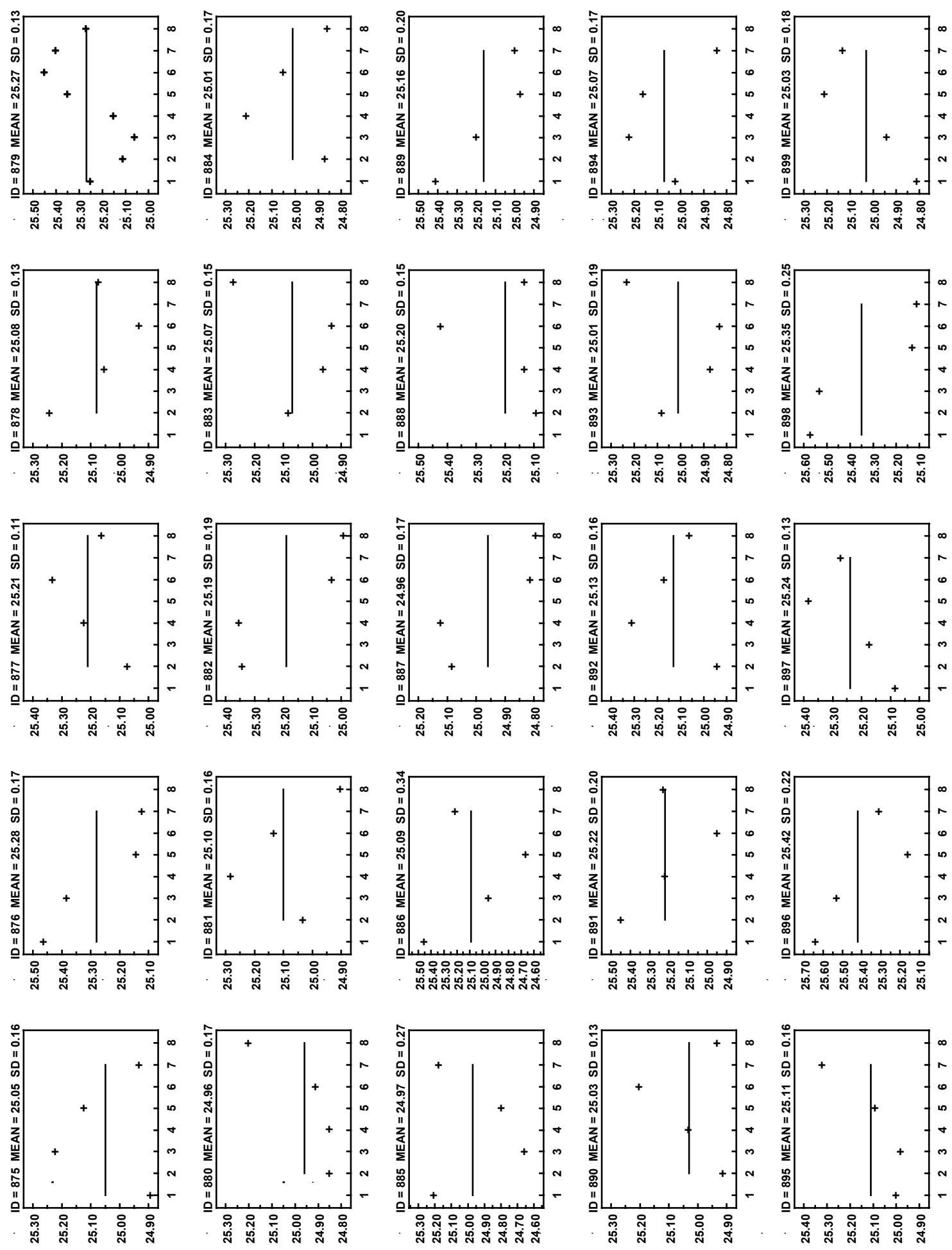

Fig. 58. Panel ID $=875-899$ : Thickness measurements (in millimeters) at locations 1 through 8 (Fig. 3) for insulation panels 875 through 899 . Mean is shown as solid line (with numerical values for mean and standard deviation (SD) in the title of each frame). 
Appendix C
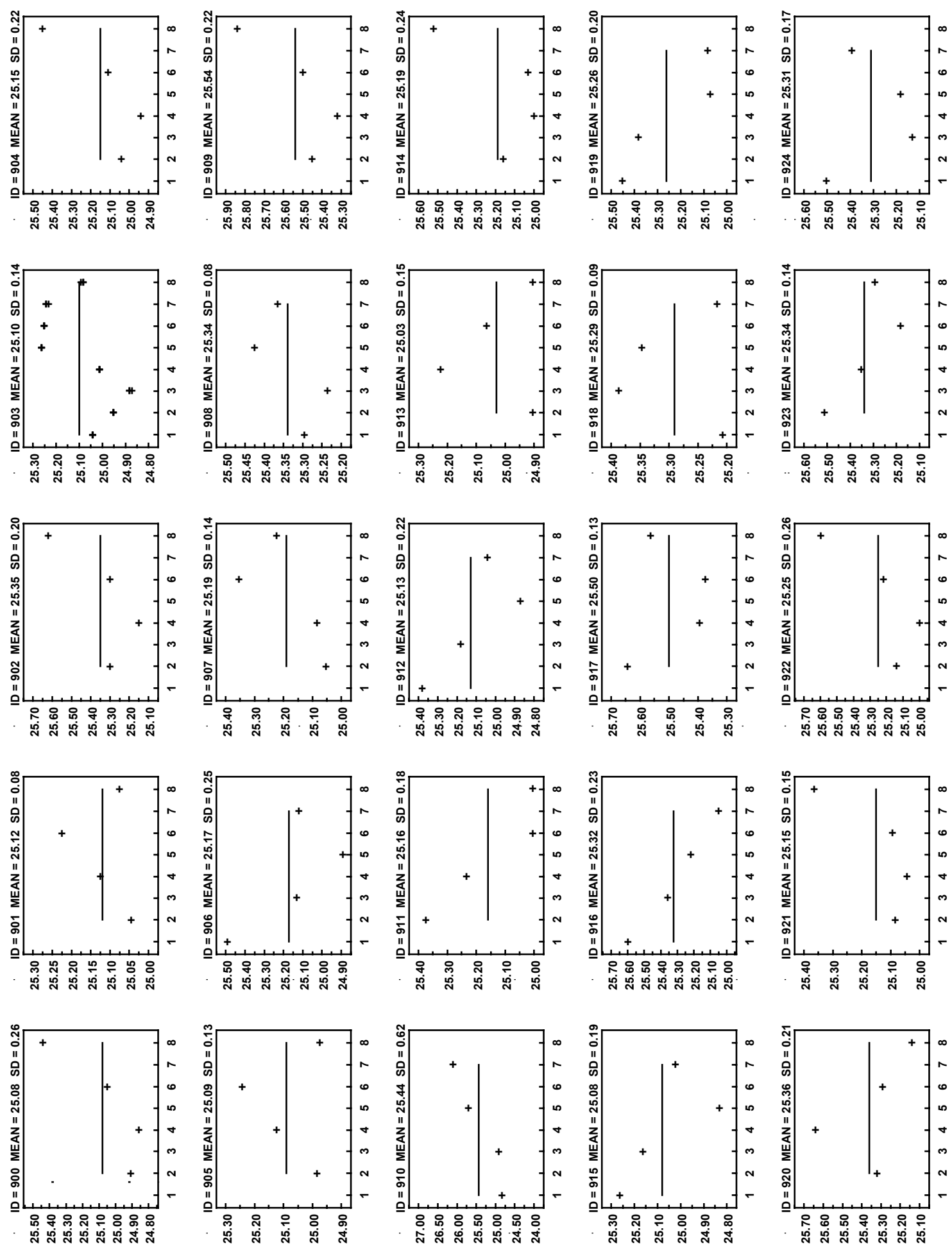

Fig. 59. Panel ID $=900-924$ : Thickness measurements (in millimeters) at locations 1 through 8 (Fig. 3) for insulation panels 900 through 924. Mean is shown as solid line (with numerical values for mean and standard deviation (SD) in the title of each frame). 
Appendix C
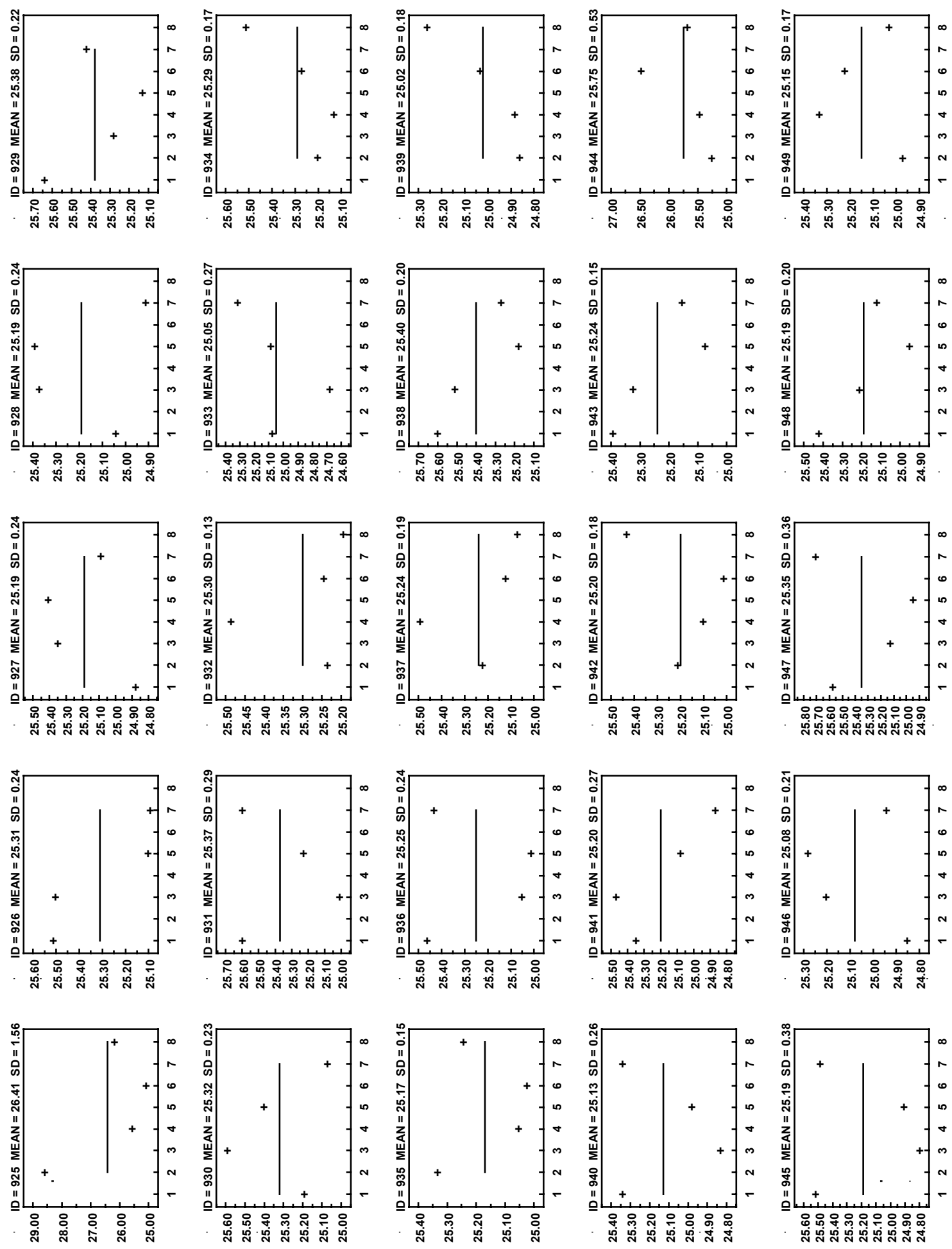

Fig. 60. Panel ID=925-949: Thickness measurements (in millimeters) at locations 1 through 8 (Fig. 3) for insulation panels 925 through 949. Mean is shown as solid line (with numerical values for mean and standard deviation (SD) in the title of each frame). 


\section{Appendix D}

\section{Appendix D - Bulk Density Uncertainty, Extensive Details}

\section{D1.1 Mass $\left(m_{0}\right)$ Uncertainty}

The measurement uncertainty of the digital weighing balance was evaluated following NIST recommended guidelines [27] for determining and reporting uncertainties for balances. For a laboratory balance in a controlled environment, the combined standard uncertainty $(k=1), u_{c}$, bal, is calculated using Eq. (D-1)

$$
u_{c, \text { bal }}=2 \sqrt{u_{s}^{2}+s_{p}^{2}}
$$

where $u_{s}$ is the standard uncertainty for the standard mass artifact; and, $s p$ is the process standard deviation. For the $1 \mathrm{~kg}$ and $500 \mathrm{~g}$ mass standard artifacts used to check the balance (Sec. 5.1), the standard uncertainties $\left(u_{s}\right)$ were obtained from the 2017 Troemner Calibration Certificate $967451-1$ to be $0.00000025 \mathrm{~kg}$ and $0.000000125 \mathrm{~kg}$, respectively. Assuming a uniform distribution, the process standard deviation $\left(s_{p}\right)$ was determined from Eq. (D-2) [27]

$$
s_{p}=\frac{b}{\sqrt{3}}
$$

where $b$ is equal to one display unit (i.e., the resolution) of the balance. For $b$ equal to $0.0001 \mathrm{~kg}, s_{p}$ is equal to $0.000058 \mathrm{~kg}$.

The combined standard uncertainty for the panel mass, $u_{c}(m)$, was determined from Eq. (D-3)

$$
u_{\mathrm{c}}(m)=2 \sqrt{u^{2}\left(m_{0}\right)_{\mathrm{A}}+u_{\mathrm{c}, \text { bal }}^{2}}=0.0004 \mathrm{~kg}
$$

where $u\left(m_{0}\right)_{\mathrm{A}}$ is evaluated as a Type A standard uncertainty by computing the standard deviations for the 450 fitted intercepts in Eq. (4). The maximum standard deviation across all the slopes, $0.000397 \mathrm{~kg}$, was taken as a conservative estimate for $u\left(m_{0}\right)_{\mathrm{A}}$. This value was the largest uncertainty in the mass uncertainty model.

\section{D1.2 Height Gage Uncertainty Assessment}

The combined standard uncertainties of the electronic height gages, $u_{c, \text { gage, were determined }}$ from Eq. (D-4)

$$
u_{\mathrm{c}, \text { gage }}=2 \sqrt{u_{s}^{2}+s_{p}^{2}+u_{1}^{2}+u_{2}^{2}+u_{3}^{2}}
$$

where:

$u_{s}=$ standard uncertainty for the gage block (standard artifact);

$s_{p}=$ standard uncertainty of the process (i.e., instrument uncertainty);

$u_{1}=$ standard uncertainty of reference datum (i.e., granite surface plate);

$u_{2}=$ standard uncertainty due to thermal expansion

$u_{3}=$ standard uncertainty due to elastic deformation of the insulation material

Table 17 summarizes the uncertainty budgets for the dimensional measurements performed with the Mitutoyo Digimatic Height Gages (Series 192 with SPC data output). The standard 


\section{Appendix D}

uncertainties, in millimeters, for the length $\left(l_{2}\right)$, width $\left(l_{5}\right)$, and thickness measurements $(L)$ are presented in the last two columns.

Table 17. Uncertainty budgets for dimensional measurements.

\begin{tabular}{|c|c|c|c|}
\hline \multirow{2}{*}{ Identifier } & \multirow{2}{*}{ Description } & \multicolumn{2}{|c|}{ Standard uncertainty, $k=1(\mathrm{~mm})$} \\
\hline & & Length $\left(l_{2}\right)$, width $\left(l_{5}\right)$ & Thickness $(L)$ \\
\hline$u_{s}$ & 1 inch gage block (EBW1) & --- & 0.000014 \\
\hline$u_{s}$ & $\begin{array}{l}12 \text { inch gage blocks (L4M041 } \\
\text { and L4M042 wrung together) }\end{array}$ & 0.000116 & --- \\
\hline$s_{p}$ & Height gage \#1 (300 mm) & --- & 0.0127 \\
\hline$s_{p}$ & Height gage $\# 2(610 \mathrm{~mm})$ & 0.01905 & --- \\
\hline$u_{1}$ & Datum surface (granite plate) & 0.01778 & 0 \\
\hline$u 2$ & Thermal expansion $\left(23.3^{\circ} \mathrm{C}\right)$ & -0.02112 & -0.00101 \\
\hline$u 3$ & $\begin{array}{l}\text { Elastic deformation of } \\
\text { insulation }\end{array}$ & neglected & 0.038 \\
\hline$u_{c, \text { gage }}$ & $\begin{array}{l}\text { Combined standard uncertainty } \\
(k=1)\end{array}$ & 0.028 & 0.044 \\
\hline
\end{tabular}

Detailed description of the standard uncertainties in Table 17 are presented below.

- $u_{s}$ : The gage blocks were calibrated in 2018 by the NIST Dimensional Metrology Group (NIST Test No. 683/290351-18). The expanded uncertainties $(k=2)$ for EBW1, L4M041, and L4M042 were $28 \mathrm{~nm}, 116 \mathrm{~nm}$, and $116 \mathrm{~nm}$, respectively. The calibration uncertainties $\left(u_{s}\right)$ of the gage blocks are negligible in comparison to the other uncertainties in Table 17.

- $s_{p}$ : The instrument uncertainties for the height gages were obtained from the manufacturer specification. The expanded uncertainties $(k=2)$ for the $300 \mathrm{~mm}$ and $610 \mathrm{~mm}$ height gages were $\pm 0.025 \mathrm{~mm}$ ( $\pm 0.001 \mathrm{in}$.) and $\pm 0.038 \mathrm{~mm}$ ( $\pm 0.0015 \mathrm{in}$.), respectively.

- $u_{1}$ : The black granite surface plate was assessed by LTI Metrology on 10/31/2017 (Calibration Certificate NIST001-17-10-41425-1). The overall flatness of the surface plate $(48 \mathrm{~W}$ by $72 \mathrm{~L}$ by $8 \mathrm{H})$ was determined to be less than or equal to $0.036 \mathrm{~mm}(0.0014 \mathrm{in}$.$) , designated as a Grade B surface plate. For the thickness$ measurement $(L), u 1$ was assumed to be zero because the height gage was not moved from its tare position.

- $u_{2}$ : The effect of thermal expansion on the gage blocks [28] was determined by Eq. (D-5) at a maximum surface plate temperature of $23.3^{\circ} \mathrm{C}$. For gage blocks of hardened steel less than $100 \mathrm{~mm}$ or greater than $500 \mathrm{~mm}$, Ref. [28] recommends $\alpha$ equal $12 \times 10^{-6}{ }^{\circ} \mathrm{C}^{-1}$ or $10.5 \times 10^{-6}{ }^{\circ} \mathrm{C}^{-1}$, respectively.

$$
\Delta L_{\mathrm{gb}}=\alpha\left(20^{\circ} \mathrm{C}-t\right) L_{\mathrm{gb}}
$$

- $u_{3}$ : The effects due to elastic deformation of the material were determined from the loading of the workpiece/touch probe (Figs. 2 and 3) and the previous compression assessment of SRM 1450d [11]. The applied loading from the workpiece $(36 \mathrm{~g})$ and the measuring force of the touch probe were $0.35 \mathrm{~N}$ and $0.4 \mathrm{~N}$, respectively. For the $32 \mathrm{~mm}$ diameter workpiece, the contact pressure was $936 \mathrm{~Pa}$ resulting in an estimated deformation (for transverse loading of the fibers) of 
$1.5 \%(0.038 \mathrm{~mm})$. Deformation in the lateral dimensions (i.e., in the axial fiber dimension) was neglected.

\section{D1.3 Panel Uncertainty Assessment (Type A Evaluation)}

The standard uncertainties due to variations in the specimen dimensions (squareness, thickness variation etc.) were computed from the square root of the pooled variances of the multiple measurements for the nine panels on which a complete set of measurements were taken (IDs: 542, 571, 619, 641, 684, 755, 759, 879, and 903)

$$
S_{\text {pool }}=\sqrt{\frac{\sum_{i=1}^{n} s_{i}^{2}}{n}}
$$

where $n$ is equal to 18 or 9 for lateral or thickness dimensional measurements, respectively.

Table 18 summarizes the lateral dimensions $\left(l_{1}, l_{2}, l_{3}, l_{4}, l_{5}\right.$, and $\left.l_{6}\right)$, average lengths and widths, and variances for the nine panels. The pooled variance for the lateral dimensional measurements is $0.098153 \mathrm{~mm}$ and the standard uncertainty (spool) is equal to $0.31329 \mathrm{~mm}$.

Table 18. Length, width dimensional data for nine panels (multiple measurements).

\begin{tabular}{cccccccccc}
\hline & \multicolumn{10}{c}{ Panel (mm) } \\
\cline { 2 - 11 } & $\mathbf{5 4 2}$ & $\mathbf{5 7 1}$ & $\mathbf{6 1 9}$ & $\mathbf{6 4 1}$ & $\mathbf{6 8 4}$ & $\mathbf{7 5 5}$ & $\mathbf{7 5 9}$ & $\mathbf{8 7 9}$ & $\mathbf{9 0 3}$ \\
\hline$l_{1}$ & 609.69 & 609.98 & 609.65 & 610.63 & 610.02 & 612.31 & 611.17 & 611.82 & 610.16 \\
$l_{1}$ & 609.69 & 609.98 & 609.65 & 610.63 & 610.00 & 612.31 & 611.16 & 611.82 & 610.16 \\
$l_{1}$ & 609.70 & 609.98 & 609.65 & 610.63 & 610.01 & 612.31 & 611.16 & 611.81 & 610.15 \\
$l_{2}$ & 609.50 & 609.96 & 609.62 & 610.05 & 609.97 & 612.24 & 610.85 & 610.85 & 610.09 \\
$l_{2}$ & 609.49 & 609.96 & 609.61 & 610.05 & 609.96 & 612.24 & 610.84 & 610.86 & 610.09 \\
$l_{2}$ & 609.49 & 609.96 & 609.61 & 610.05 & 609.96 & 612.24 & 610.83 & 610.85 & 610.09 \\
$l_{3}$ & 609.46 & 609.90 & 609.48 & 609.14 & 610.01 & 612.21 & 610.70 & 610.36 & 610.03 \\
$l_{3}$ & 609.46 & 609.89 & 609.48 & 609.13 & 610.00 & 612.21 & 610.69 & 610.41 & 610.03 \\
$l_{3}$ & 609.46 & 609.89 & 609.48 & 609.13 & 610.00 & 612.21 & 610.69 & 610.41 & 610.03 \\
\hline$l_{4}$ & 610.88 & 609.24 & 610.35 & 609.56 & 609.78 & 610.64 & 612.33 & 612.46 & 609.24 \\
$l_{4}$ & 610.88 & 609.24 & 610.35 & 609.56 & 609.77 & 610.63 & 612.33 & 612.45 & 609.24 \\
$l_{4}$ & 610.88 & 609.24 & 610.35 & 609.56 & 609.77 & 610.64 & 612.32 & 612.45 & 609.24 \\
$l_{5}$ & 610.62 & 609.19 & 610.86 & 609.68 & 609.25 & 610.33 & 612.47 & 612.69 & 608.85 \\
$l_{5}$ & 610.61 & 609.19 & 610.86 & 609.68 & 609.24 & 610.33 & 612.46 & 612.69 & 608.84 \\
$l_{5}$ & 610.61 & 609.19 & 610.86 & 609.67 & 609.24 & 610.32 & 612.46 & 612.70 & 608.84 \\
$l_{6}$ & 610.29 & 609.74 & 611.36 & 609.71 & 608.66 & 610.05 & 612.85 & 613.03 & 608.41 \\
$l_{6}$ & 610.29 & 609.74 & 611.35 & 609.71 & 608.66 & 610.04 & 612.85 & 613.03 & 608.41 \\
$l_{6}$ & 610.29 & 609.74 & 611.36 & 609.71 & 608.66 & 610.05 & 612.84 & 613.03 & 608.40 \\
\hline Avg.1,2,3 & 609.56 & 609.95 & 609.59 & 610.04 & 609.99 & 612.26 & 610.93 & 611.10 & 610.10 \\
$s_{1,2,3}$ & 0.0120 & 0.0016 & 0.0060 & 0.4271 & 0.0005 & 0.0020 & 0.0434 & 0.3959 & 0.0030 \\
\hline Avg.4,5,6 & 610.59 & 609.39 & 610.86 & 609.65 & 609.23 & 610.34 & 612.55 & 612.73 & 608.83 \\
$s^{2}{ }_{4,5,6}$ & 0.0655 & 0.0694 & 0.1900 & 0.0047 & 0.2326 & 0.0654 & 0.0545 & 0.0630 & 0.1303 \\
\hline
\end{tabular}




\section{Appendix D}

Table 19 summarizes the thickness dimensions $\left(L_{1}, L_{2}, L_{3}, L_{4}, L_{5}, L_{6}, L_{7}\right.$, and $\left.L_{8}\right)$, averages and variances for the nine panels. The pooled variance for the thickness measurements is $0.03251 \mathrm{~mm}$ and the standard uncertainty $\left(s_{\text {pool }}\right)$ is equal to $0.18029 \mathrm{~mm}$.

Table 19. Thickness dimensional data for multiple measurements of nine panels.

\begin{tabular}{cccccccccc}
\hline & \multicolumn{10}{c}{ Panel (mm) } \\
\cline { 2 - 10 } & $\mathbf{5 4 2}$ & $\mathbf{5 7 1}$ & $\mathbf{6 1 9}$ & $\mathbf{6 4 1}$ & $\mathbf{6 8 4}$ & $\mathbf{7 5 5}$ & $\mathbf{7 5 9}$ & $\mathbf{8 7 9}$ & $\mathbf{9 0 3}$ \\
\hline$L_{1}$ & 25.18 & 25.41 & 25.38 & 24.97 & 25.27 & 25.45 & 24.68 & 25.26 & 25.05 \\
$L_{1}$ & 25.19 & 25.41 & 25.38 & 24.96 & 25.29 & 25.45 & 24.68 & 25.26 & 25.05 \\
$L_{1}$ & 25.18 & 25.41 & 25.38 & 24.96 & 25.28 & 25.45 & 24.68 & 25.26 & 25.05 \\
$L_{2}$ & 25.04 & 25.31 & 25.20 & 25.07 & 25.26 & 25.23 & 24.76 & 25.12 & 24.96 \\
$L_{2}$ & 25.03 & 25.31 & 25.21 & 25.07 & 25.26 & 25.23 & 24.75 & 25.12 & 24.96 \\
$L_{2}$ & 25.03 & 25.31 & 25.20 & 25.07 & 25.26 & 25.23 & 24.75 & 25.12 & 24.96 \\
$L_{3}$ & 24.85 & 25.29 & 25.13 & 25.40 & 25.23 & 25.09 & 24.85 & 25.07 & 24.89 \\
$L_{3}$ & 24.85 & 25.28 & 25.14 & 25.39 & 25.23 & 25.09 & 24.85 & 25.07 & 24.89 \\
$L_{3}$ & 24.84 & 25.28 & 25.14 & 25.39 & 25.23 & 25.09 & 24.86 & 25.07 & 24.88 \\
$L_{4}$ & 25.04 & 25.10 & 24.85 & 25.29 & 25.41 & 25.10 & 24.95 & 25.16 & 25.02 \\
$L_{4}$ & 25.04 & 25.10 & 24.85 & 25.29 & 25.41 & 25.10 & 24.94 & 25.16 & 25.02 \\
$L_{4}$ & 25.04 & 25.10 & 24.86 & 25.29 & 25.42 & 25.09 & 24.95 & 25.16 & 25.02 \\
$L_{5}$ & 25.36 & 25.11 & 24.78 & 25.28 & 25.86 & 24.99 & 25.15 & 25.36 & 25.27 \\
$L_{5}$ & 25.35 & 25.11 & 24.78 & 25.28 & 25.86 & 24.99 & 25.15 & 25.36 & 25.27 \\
$L_{5}$ & 25.35 & 25.12 & 24.79 & 25.27 & 25.87 & 24.99 & 25.15 & 25.36 & 25.27 \\
$L_{6}$ & 25.48 & 25.16 & 24.91 & 25.01 & 25.75 & 25.14 & 25.12 & 25.46 & 25.26 \\
$L_{6}$ & 25.48 & 25.16 & 24.91 & 25.02 & 25.76 & 25.15 & 25.12 & 25.46 & 25.26 \\
$L_{6}$ & 25.48 & 25.16 & 24.91 & 25.01 & 25.75 & 25.14 & 25.12 & 25.46 & 25.26 \\
$L_{7}$ & 25.53 & 25.22 & 25.00 & 24.83 & 25.79 & 25.33 & 25.17 & 25.41 & 25.24 \\
$L_{7}$ & 25.53 & 25.22 & 24.99 & 24.83 & 25.78 & 25.33 & 25.17 & 25.41 & 25.25 \\
$L_{7}$ & 25.52 & 25.22 & 24.99 & 24.84 & 25.78 & 25.33 & 25.17 & 25.41 & 25.25 \\
$L_{8}$ & 25.27 & 25.20 & 25.04 & 24.88 & 25.56 & 25.43 & 24.83 & 25.28 & 25.09 \\
$L_{8}$ & 25.27 & 25.19 & 25.04 & 24.88 & 25.56 & 25.43 & 24.83 & 25.28 & 25.09 \\
$L_{8}$ & 25.27 & 25.19 & 25.04 & 24.88 & 25.55 & 25.43 & 24.83 & 25.28 & 25.10 \\
\hline Avg. & 25.22 & 25.22 & 25.04 & 25.09 & 25.52 & 25.22 & 24.94 & 25.27 & 25.10 \\
$S^{2}$ & 0.0509 & 0.0102 & 0.0354 & 0.0390 & 0.0605 & 0.0261 & 0.0328 & 0.0181 & 0.0196 \\
\hline & & & & & & & & &
\end{tabular}

\section{D1.4 Dimensional $\left(l_{2}, l_{5}\right.$, and $\left.L\right)$ Uncertainties}

The combined standard uncertainties $(k=1)$ for $l_{2}, l_{5}$, and $L$ were determined from Eq. (D-7). In both cases, the standard uncertainties due to variations in the panel dimensions (squareness or thickness variation) dominated the standard uncertainties associated with the measurement process.

$$
\begin{aligned}
& u_{\mathrm{c}}\left(l_{2}\right)=u_{c}\left(l_{5}\right)=\sqrt{u_{\mathrm{c}, \text { gage\# } 1}^{2}+u^{2}(l)_{\mathrm{A}}}=\sqrt{0.028^{2}+0.31329^{2}}=0.315 \mathrm{~mm} \\
& u_{\mathrm{c}}\left(L_{\mathrm{p}}\right)=\sqrt{u_{\mathrm{c}, \text { gage\# } 2}^{2}+u^{2}\left(L_{\mathrm{p}}\right)_{\mathrm{A}}}=\sqrt{0.044^{2}+0.18029^{2}}=0.186 \mathrm{~mm}
\end{aligned}
$$




\section{Appendix E}

\section{Appendix E - Thermal Conductivity Uncertainty, Extensive Details}

The uncertainty assessment for the thermal conductivity measurements follows the mandatory requirements covered in ASTM Test Method C 177 [1]. The approach considers the following four contributory uncertainties shown before in Eq. (22) .

- $\quad$ specimen heat flow $(Q)$;

- temperature difference $(\Delta T)$;

- (in-situ) thickness $(L)$; and,

- meter area (A)

Appendix E consists of four main sections for each input quantity $-Q, \Delta T, L$, and $A$. Each section presents the governing equation for the quantity and examines all known (but not exhaustive) subordinate causal standard uncertainties. The final relative standard uncertainty for each input quantity $(Q, \Delta T, L$, and $A)$ is summarized in Table 15 in the main text.

\section{E1.1 Specimen Heat Flow $(Q)$}

The specimen heat flow $Q$ is essentially determined by measuring the direct current and voltage provided to the meter-plate heater $\left(Q_{\mathrm{m}}\right)$. The measurement approach for $Q_{\mathrm{m}}$ is shown schematically in Fig. 61. A direct-current (DC) power supply provides current (I) to the circuit which is determined by the measurement $V_{s}$ across the four-terminal $0.1 \Omega$ standard resistor placed in an oil bath at $25.00{ }^{\circ} \mathrm{C}$. The voltage across the meter-plate heater $\left(V_{\mathrm{m}}\right)$ is measured with voltage taps soldered to the heater leads in the center of the guard gap. The meter plate power $\left(Q_{\mathrm{m}}\right)$ is the product of $I$ and $V_{\mathrm{m}}$.

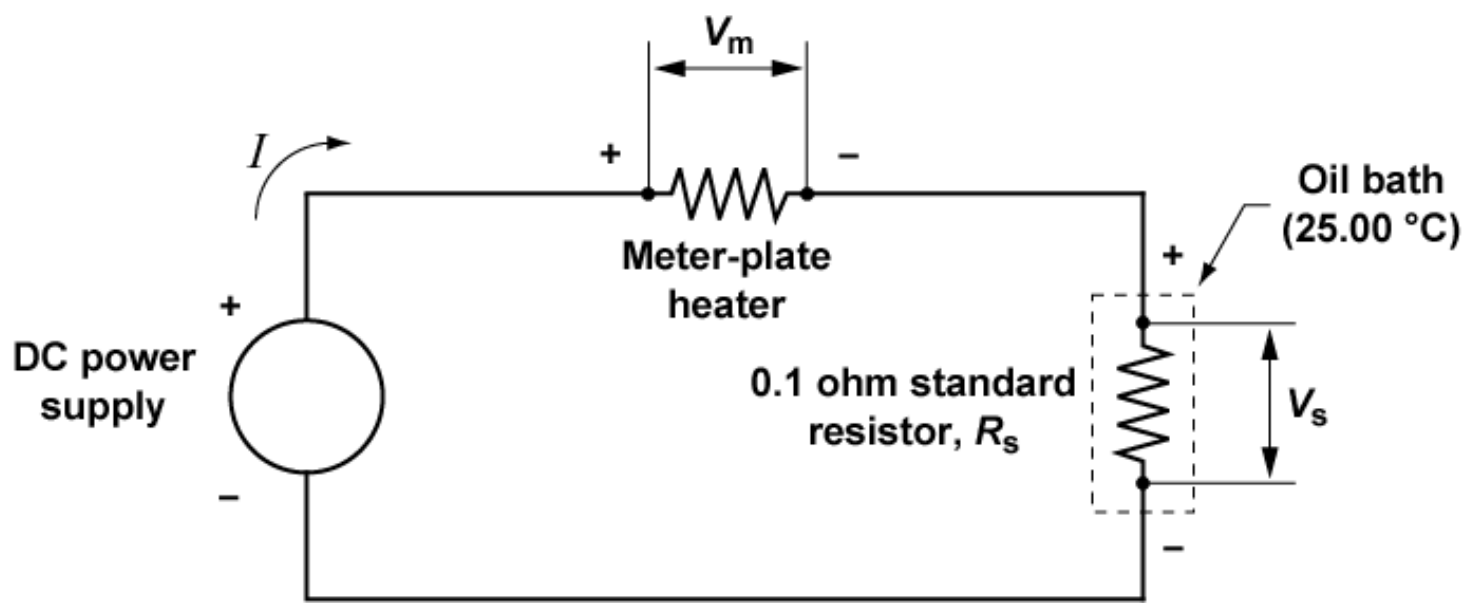

Fig. 61. Electrical schematic for the meter-plate power measurement. 


\section{Appendix E}

Equation (E-1) defines $Q_{\mathrm{m}}$, the power input to the meter-plate heater. Under ideal guarding, $Q_{\mathrm{m}}$ is equal to the specimen heat flow $Q$ in Eq. (18).

$$
Q_{\mathrm{m}}=I V_{\mathrm{m}}=\frac{V_{\mathrm{s}}}{R_{\mathrm{s}}} V_{\mathrm{m}}
$$

where $I$ is the current determined from the voltage drop $\left(V_{\mathrm{s}}\right)$ across the standard resistor $\left(R_{\mathrm{s}}\right)$; and, $V_{\mathrm{m}}$ is the voltage drop across the meter-plate heater measured with voltage taps located at the midpoint of the guard gap.

The contributory uncertainties for $u\left(Q_{\mathrm{m}}\right)$ include: a) standard platinum resistance thermometer (SPRT) resistive heating; b) calibration of the $0.1 \Omega$ standard resistor; c) repeated observations during testing; and, d) voltage measurements for $V_{\mathrm{s}}$ and $V_{\mathrm{m}}$.

- SPRT joule heating power: The long-stem SPRT in the meter-plate was continuously excited by a $1 \mathrm{~mA}$ current during each test. The joule heating power for the nominal $25 \Omega$ sensor was $0.000025 \mathrm{~W}$.

- Standard resistor: The standard resistor is an Otto Wolff Model N85-7a7, Serial No. 5350, calibrated on April 28, 2018 by the NIST Quantum Measurement Division (Test Report No. 291216-18). The electrical resistances at $0.316 \mathrm{~A}$ and $1.0 \mathrm{~A}$ are $0.10009210 \Omega$ and $0.10009221 \Omega$, respectively. The expanded uncertainty $(k=2)$ was $0.000002 \Omega(2 \mathrm{ppm})$ which was used to determine $u\left(R_{\mathrm{S}}\right)$ in Eq. (E-2).

$$
u\left(R_{\mathrm{s}}\right)=\frac{0.000002 \Omega}{2}=0.000001 \Omega
$$

- Repeated observations $u\left(\bar{Q}_{\mathrm{m}}\right)_{\mathrm{A}}$ : For each test, $4 \mathrm{~h}$ of data $(n=240$ observations) were acquired and averaged. The standard uncertainty of the mean $(\bar{Q})$ was computed from the variance of the mean (Eq. (E-3)) for each level of $T_{m}$.

$$
u\left(\bar{Q}_{\mathrm{m}}\right)_{\mathrm{A}}=\sqrt{s^{2}\left(\bar{Q}_{\mathrm{m}}\right)}=\sqrt{\frac{s^{2}\left(Q_{\mathrm{m}}\right)}{n}}
$$

- $u\left(V_{\mathrm{s}}\right)$ and $u\left(V_{\mathrm{m}}\right)$ : The input voltages $V_{\mathrm{s}}$ and $V_{\mathrm{m}}$ were measured by an Agilent $3458 \mathrm{~A}$ digital multimeter that was calibrated on April 10, 2018 by Keysight Technologies. The contributory uncertainties for $V_{\mathrm{s}}$ and $V_{\mathrm{m}}$ were estimated from the 2-year manufacturer specification for the $100 \mathrm{mV}$ and $10 \mathrm{~V}$ ranges, respectively. A uniform rectangular distribution was assumed for the accuracy specification and characteristic standard uncertainties were computed from Eq. (E-4).

$$
\begin{aligned}
& u\left(V_{\mathrm{s}}\right)=[0.000014 \times 0.100+0.000003 \times 0.100+0.000002] \mu \mathrm{V} / \sqrt{3}=2.14 \mu \mathrm{V} \\
& u\left(V_{\mathrm{m}}\right)=[0.000014 \times 10+0.0000005 \times 10+0.000002] \mu \mathrm{V} / \sqrt{3}=84.9 \mu \mathrm{V}
\end{aligned}
$$

\section{E1.1.1 Combined Standard Uncertainty for Meter-Plate Power Input $\left(Q_{m}\right)$}

Propagating the contributory uncertainties in Eq. (E-1) based on a Taylor series approximation yields Eq. (E-5)

$$
u_{\mathrm{c}}\left(Q_{\mathrm{m}}\right)_{\mathrm{B}}=\sqrt{c_{\mathrm{V}_{\mathrm{s}}}^{2} u^{2}\left(V_{\mathrm{s}}\right)^{2}+c_{\mathrm{R}_{\mathrm{s}}}^{2} u^{2}\left(R_{\mathrm{s}}\right)^{2}+c_{\mathrm{V}_{\mathrm{m}}}^{2} u^{2}\left(V_{\mathrm{m}}\right)^{2}}
$$


where the sensitivity coefficients $\left(c_{i}\right)$ are equal to the partial derivative of an input quantity $\left(\partial f / \partial X_{i}\right)$ evaluated for the input quantity equal to an input estimate $\left(X_{i}=x_{i}\right)$

$$
\begin{aligned}
& c_{\mathrm{V}_{\mathrm{s}}}=\frac{\partial Q_{\mathrm{m}}}{\partial V_{\mathrm{s}}}=\frac{V_{\mathrm{m}}}{R_{\mathrm{s}}} \\
& c_{\mathrm{R}_{\mathrm{s}}}=\frac{\partial Q_{\mathrm{m}}}{\partial R_{\mathrm{s}}}=-\frac{V_{\mathrm{s}} V_{\mathrm{m}}}{R_{\mathrm{s}}^{2}} \\
& c_{\mathrm{V}_{\mathrm{m}}}=\frac{\partial Q_{\mathrm{m}}}{\partial V_{\mathrm{m}}}=\frac{V_{\mathrm{s}}}{R_{\mathrm{s}}}=I
\end{aligned}
$$

The combined standard uncertainty for the meter plate power input is given by Eq. (E-6).

$$
u_{\mathrm{c}}\left(Q_{\mathrm{m}}\right)=\sqrt{u^{2}\left(Q_{\mathrm{SPRT}}\right)_{\mathrm{B}}+u^{2}\left(\bar{Q}_{\mathrm{m}}\right)_{\mathrm{A}}+u^{2}\left(Q_{\mathrm{m}}\right)_{\mathrm{B}}}
$$

Table 20 summarizes the standard uncertainties as a function of $T_{m}$ for the SPRT, repeated observations, and for the propagation of contributory uncertainties, $u\left(Q_{\mathrm{m}}\right)$. Input values for $\bar{Q}, V_{\mathrm{m}}$ and $V_{\mathrm{s}}$ are also included. The input value for the standard resistor was taken to be $0.10009221 \Omega$. The Type B evaluations in Table 20 are about two times greater than the Type A evaluations. As evident in Table 20, the Type A and Type B evaluations increase with $T_{m}$. The last column expresses the relative combined standard uncertainty, $u_{\mathrm{c}, \mathrm{r}}\left(Q_{\mathrm{m}}\right)$, as

\begin{tabular}{|c|c|c|c|c|c|c|c|}
\hline $\begin{array}{c}T_{m} \\
(\mathbf{K})\end{array}$ & $\begin{array}{c}u\left(Q_{\mathrm{SPRT}}\right)_{\mathrm{B}} \\
(\mathrm{W})\end{array}$ & $\underset{(\mathbf{W})}{\bar{Q}}$ & $\begin{array}{c}u\left(\bar{Q}_{\mathrm{m}}\right)_{\mathrm{A}} \\
(\mathbf{W})\end{array}$ & $\begin{array}{l}V_{\mathbf{m}} \\
(\mathrm{V})\end{array}$ & $\begin{array}{l}V_{\mathrm{s}} \\
(\mathrm{V})\end{array}$ & $\begin{array}{c}u\left(Q_{\mathrm{m}}\right)_{\mathrm{B}} \\
(\mathrm{W})\end{array}$ & $\begin{array}{c}u_{\mathrm{c}, \mathrm{r}}\left(Q_{m}\right)_{\mathrm{B}} \\
(\%)\end{array}$ \\
\hline 280 & 0.000025 & 2.0003 & 0.000020 & 2.353150 & 0.085084 & 0.000054 & 0.0032 \\
\hline 300 & 0.000025 & 2.0680 & 0.000022 & 2.494420 & 0.082979 & 0.000057 & 0.0032 \\
\hline 320 & 0.000025 & 2.2213 & 0.000033 & 2.691470 & 0.082605 & 0.000061 & 0.0033 \\
\hline 340 & 0.000025 & 2.3559 & 0.000035 & 2.882350 & 0.081809 & 0.000065 & 0.0033 \\
\hline 360 & 0.000025 & 2.5246 & 0.000028 & 3.099470 & 0.081525 & 0.000070 & 0.0031 \\
\hline
\end{tabular}
a percent of the power input $(\bar{Q})$. For all levels of $T_{m}$, the relative combined standard uncertainties are small, approximately $0.003 \%$.

Table 20. Combined standard uncertainties for meter-plate power input.

\section{E1.1.2 Imbalanced Guard Heat Flows $(\Delta Q)$}

A detrimental heat flow, occurring as either a gain or loss, arises when the temperature of a thermal guard is imbalanced causing a deviation $(\Delta Q)$ in the one-dimensional heat flow $Q$. Under steady-state conditions, the primary guard heat flows were controlled to be less than $0.001 \mathrm{~W}$. The lateral heat flows associated with the primary guard gap $\left(Q_{\mathrm{g}}\right)$ and two secondary guards - the edge guard $\left(Q_{\mathrm{e}}\right)$ and SPRT connection guard $\left(Q_{\mathrm{HPCG}}\right)$ - can cause, under imbalanced conditions, significant uncertainties in the measurement of $Q$.

As part of a previous sensitivity study [25], an imbalance model was developed for a pair of similar $25 \mathrm{~mm}$ thick, fibrous-glass specimens at a nominal temperature of $310 \mathrm{~K}$. The measurement system for this material was well described by the empirical model in Eq. (E-7) where $x_{j}$ are coded as -1 or +1 .

$$
\lambda_{\text {pred }}=\beta_{0}+1 / 2\left[\beta_{2} x_{2}+\beta_{12} x_{1} x_{2}+\beta_{3} x_{3}+\beta_{1} x_{1}\right]
$$




\section{Appendix E}

where

$$
\begin{aligned}
& \beta_{0}=0.033587 \\
& \beta_{2}=-0.004791 \\
& \beta_{12}=0.000931 \\
& \beta_{3}=-0.000034 \\
& \beta_{1}=-0.000022 .
\end{aligned}
$$

The terms $x_{1}, x_{2}$, and $x_{3}$ represent coded values ( of \pm 1 ) for the temperature differences across the specimen $(\Delta T)$, guard gap $\left(\Delta T_{\text {gap }}\right)$, and the hot plate connection guard $\left(\Delta T_{\mathrm{HPCG}}\right)$, respectively. The empirically-derived model in Eq. (E-7) does not include a term for the edge guard imbalance because the term was determined to be statistically insignificant [25].

For the uncertainty analysis, the upper and lower limits for $\Delta T, \Delta T_{\mathrm{gap}}$, and $\Delta T_{\mathrm{HPCG}}$ were based on conservative engineering assessments and estimated to be $\pm 0.01 \mathrm{~K}, \pm 0.005 \mathrm{~K}$, and $\pm 0.1 \mathrm{~K}$, respectively. A uniform rectangular distribution was assumed for each interval. Using the coded limits in Ref. [25], Eq. (E-8) calculates the standard uncertainties for each quantity and the subsequent coded values for $x_{1}, x_{2}, x_{3}$.

$$
\begin{aligned}
& x_{1}=\frac{u(\Delta T)}{5 \mathrm{~K}}=\frac{(0.01 \mathrm{~K} / \sqrt{3})}{5 \mathrm{~K}}=0.0012 \\
& x_{2}=\frac{u\left(\Delta T_{\text {gap }}\right)}{0.25 \mathrm{~K}}=\frac{(0.005 \mathrm{~K} / \sqrt{3})}{0.25 \mathrm{~K}}=0.012 \\
& x_{3}=\frac{u\left(\Delta T_{\mathrm{HPCG}}\right)}{0.5 \mathrm{~K}}=\frac{(0.1 \mathrm{~K} / \sqrt{3})}{0.5 \mathrm{~K}}=0.12
\end{aligned}
$$

Table 21 summarizes computations of $\lambda_{\text {pred }}$ from Eq. (E-7) and relative differences from the baseline case where $x_{1}=x_{2}=x_{3}=0$ and $\lambda_{0}=0.033587 \mathrm{~W} \cdot \mathrm{m}^{-1} \cdot \mathrm{K}^{-1}$ at $310 \mathrm{~K}$. For mean temperatures other than $310 \mathrm{~K}$, an additional level of uncertainty equal to $10 \%$ for every $10 \mathrm{~K}$ difference from $T_{m}$ equal to $310 \mathrm{~K}$ was applied. The final uncertainty estimates, $u(\Delta Q)$, presented in the last column dominate the measurement uncertainties (on the order of $0.003 \%$ ) calculated in Table 20.

Table 21. Relative standard uncertainties for guard temperature imbalances.

\begin{tabular}{cccccccc}
\hline $\begin{array}{c}\boldsymbol{T}_{\boldsymbol{m}} \\
(\mathbf{K})\end{array}$ & $\boldsymbol{x}_{\mathbf{1}}$ & $\boldsymbol{x}_{\mathbf{2}}$ & $\boldsymbol{x}_{\mathbf{3}}$ & $\begin{array}{c}\boldsymbol{\lambda} \\
\left(\mathbf{W} \cdot \mathbf{m}^{-\mathbf{1}} \cdot \mathbf{K}^{-\mathbf{1}}\right)\end{array}$ & $\begin{array}{c}\left(\boldsymbol{\lambda}-\boldsymbol{\lambda}_{\mathbf{0}}\right) / \boldsymbol{\lambda}_{\mathbf{0}} \\
(\boldsymbol{\%})\end{array}$ & $\begin{array}{c}\text { Uncertainty } \\
\text { Level for } \boldsymbol{T}_{\boldsymbol{m}}\end{array}$ & $\begin{array}{c}\boldsymbol{u}(\boldsymbol{\Delta} \boldsymbol{Q}) \\
(\boldsymbol{\%})\end{array}$ \\
\hline 280 & 0.0012 & 0.012 & 0.12 & 0.033557 & -0.0882 & 30 & -0.115 \\
300 & 0.0012 & 0.012 & 0.12 & 0.033557 & -0.0882 & 10 & -0.097 \\
320 & 0.0012 & 0.012 & 0.12 & 0.033557 & -0.0882 & 10 & -0.097 \\
340 & 0.0012 & 0.012 & 0.12 & 0.033557 & -0.0882 & 30 & -0.115 \\
360 & 0.0012 & 0.012 & 0.12 & 0.033557 & -0.0882 & 50 & -0.132 \\
\hline
\end{tabular}




\section{Appendix E}

\section{E1.1.3 Combined Standard Uncertainty $u(Q)$}

The combined standard uncertainty $u(Q)$ was computed from Eq. (E-9).

$$
u_{\mathrm{c}, \mathrm{r}}(Q)=\sqrt{u_{\mathrm{c}, \mathrm{r}}^{2}\left(Q_{\mathrm{m}}\right)+u^{2}(\Delta Q)}
$$

Table 22 summarizes estimates for $u_{\mathrm{c}, \mathrm{r}}(Q)$ at levels of $T_{m}$ from $280 \mathrm{~K}$ to $360 \mathrm{~K}$. The final column in Table 22 was rounded and reproduced in Table 15 (Sec. 7.4).

Table 22. Combined standard uncertainties $(k=1)$ for $Q$.

\begin{tabular}{cccc}
\hline $\boldsymbol{T}_{\boldsymbol{m}}$ & $\boldsymbol{u}_{\mathrm{c}, \mathbf{r}}\left(\boldsymbol{Q}_{\mathbf{m})}\right)$ & $\begin{array}{c}\boldsymbol{u}(\Delta \boldsymbol{Q}) \\
(\mathbf{\%})\end{array}$ & $\begin{array}{c}\boldsymbol{u}_{\mathrm{c}, \mathbf{r}}(\boldsymbol{Q}) \\
(\mathbf{\%})\end{array}$ \\
\hline 280 & 0.0032 & -0.115 & 0.115 \\
300 & 0.0032 & -0.097 & 0.097 \\
320 & 0.0033 & -0.097 & 0.097 \\
340 & 0.0033 & -0.115 & 0.115 \\
360 & 0.0031 & -0.132 & 0.132 \\
\hline
\end{tabular}

\section{E1.2 Temperature Difference $(\Delta T)$}

The term, $\Delta T$, in Eq. (18), is defined as the surface-to-surface temperature difference across the specimen pair where $T_{h}$ is the temperature of the hot plate surface and $T_{c 1}$ and $T_{c 2}$ are the temperatures of the inboard and outboard cold plate surfaces, respectively. Under steadystate operating conditions when $T_{c 1}$ is nearly the same as $T_{c 2}$ (equals $T_{c}$ ), $\Delta T$ is defined by Eq. (E-10).

$$
\Delta T=T_{h}-\left(T_{c 1}+T_{c 2}\right) / 2=T_{h}-T_{c}
$$

The primary temperature sensor, located in the geometric center of each plate, is a long-stem, metal-sheath, standard platinum resistance thermometer (SPRT), Model 162CE from Rosemont Aerospace, Inc. The SPRT sensors have a 4-wire sensing element within the sensitive portion $(50 \mathrm{~mm})$ of the sheath tip. The SPRT was placed in a well that was brazed at the midplane of the plate so that the sensing region resides at the geometric center of the plate (Fig. 62). To check the temperature uniformity of a plate, six Type $\mathrm{N}$ metal sheathed thermocouples, $1.6 \mathrm{~mm}$ in diameter, were brazed in the surface of each plate at the locations shown in Fig. 62 for the hot plate. 


\section{Appendix E}

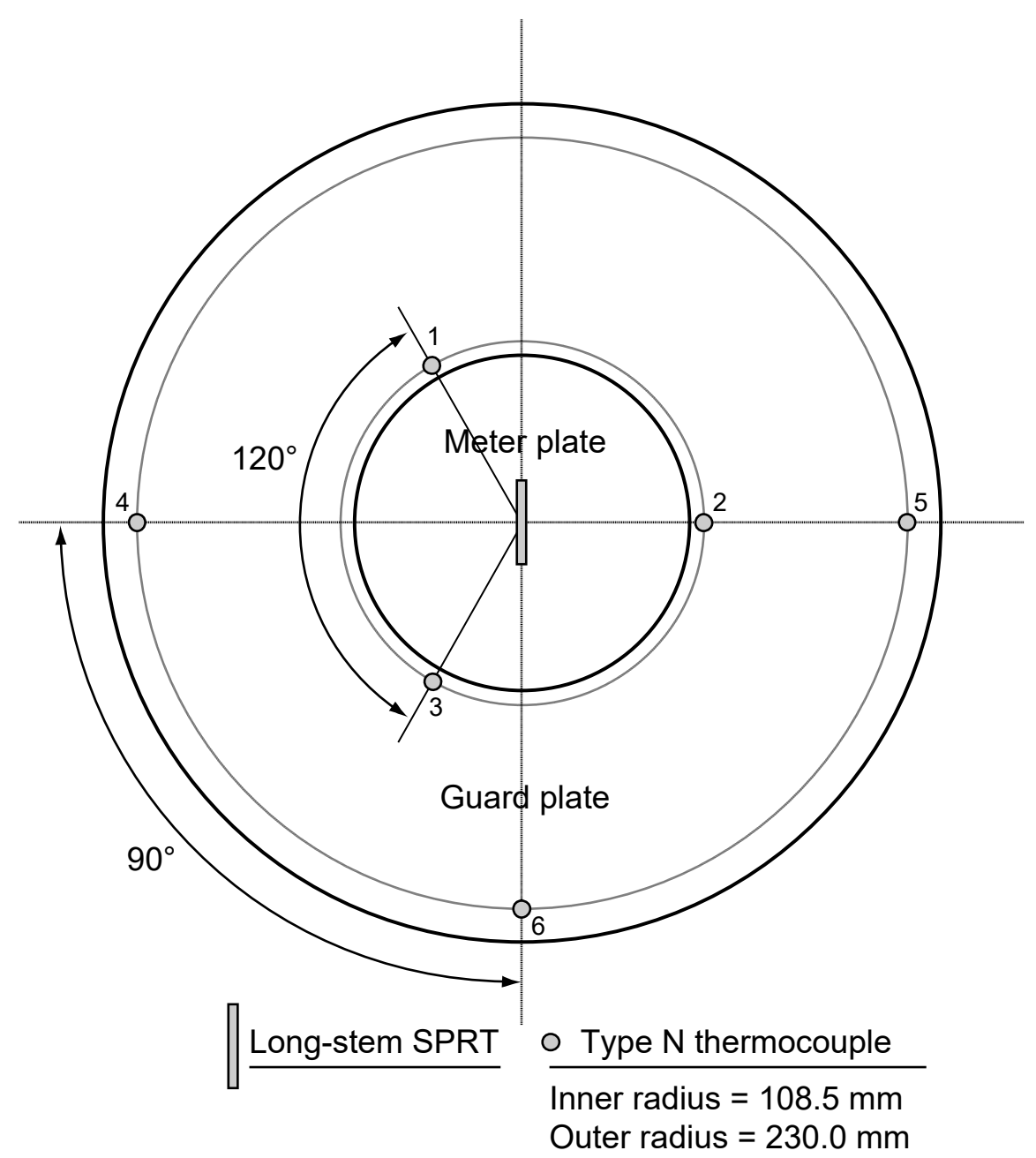

Fig. 62. Temperature sensor locations for NIST $500 \mathrm{~mm}$ diameter plates.

\section{E1.2.1 Repeated Observations, $u(\Delta \bar{T})_{\mathrm{A}}$}

The standard uncertainty for the mean temperature difference was determined using the same process as was done for $u\left(\bar{Q}_{\mathrm{m}}\right)_{\mathrm{A}}$ in Sec. E1.1. The standard uncertainties for repeated observations at levels of $\Delta \bar{T}$ (in millikelvin) from $280 \mathrm{~K}$ to $360 \mathrm{~K}$ are summarized in Table 23.

Table 23. Standard uncertainties for repeated observations of $\Delta \bar{T}$.

\begin{tabular}{ccc}
\hline $\boldsymbol{T}_{\boldsymbol{m}}$ & $\begin{array}{c}\Delta \boldsymbol{T} \\
(\mathbf{K})\end{array}$ & $\begin{array}{c}\boldsymbol{u}(\boldsymbol{\Delta} \overline{\boldsymbol{T}})_{\mathbf{A}} \\
(\mathbf{m K})\end{array}$ \\
\hline 280 & 25.0030 & 0.088 \\
300 & 25.0065 & 0.091 \\
320 & 25.0027 & 0.157 \\
340 & 25.0029 & 0.132 \\
360 & 24.9997 & 0.083 \\
\hline
\end{tabular}




\section{Appendix E}

\section{E1.2.2 Contributory Temperature Uncertainties}

The contributory uncertainties for the temperature measurements include: a) calibration of the SPRTs; b) uncertainty of the DC resistance ratio bridge; c) calibration of the external reference resistor for the DC bridge; d) contact resistance; e) plate temperature uniformity; and, f) mid-plane temperature correction.

- SPRT calibration: The long-stem SPRTs were calibrated on March 1, 2000 by the NIST Process Measurements Division (Test Report 262640-00). A conservative estimate of $0.64 \mathrm{mK}$ for the expanded uncertainty $(k=2)$ was selected from the calibration data. The standard uncertainty for the calibration is given by Eq. (E-11).

$$
u_{1}(T)=\frac{0.64 \mathrm{mK}}{2}=0.32 \mathrm{mK}
$$

- DC resistance ratio bridge : The resistances of the SPRTs were measured by an Isotech microK precision thermometer bridge with a microsKanner channel expander. The resistances were referenced against an external standard resistor providing a resistance ratio, $W$, for each SPRT. The manufacturer specification is $0.8 \mathrm{mK}$ over the full range of the instrument. A uniform rectangular distribution was assumed for the accuracy specification.

$$
u_{2}(T)=\frac{0.8 \mathrm{mK}}{\sqrt{3}}=0.46 \mathrm{mK}
$$

- Reference resistor: The standard resistor is a Tinsley Model 5685-A (Wilkens type), Serial No. 274591, calibrated on April 11, 2018 by the NIST Quantum Measurement Division (Test Report No. 291216-18). The standard resistor was calibrated in its thermal enclosure at $35.95{ }^{\circ} \mathrm{C}$. The electrical resistances at $0.01 \mathrm{~A}$ is $25.0004586 \Omega$. The expanded uncertainty $(k=2)$ was $0.2 \mu \Omega /(\Omega \cdot \mathrm{ppm})$ which was neglected in further analysis.

- SPRT joule heating temperature rise: , The joule heating power for the $25 \Omega$ SPRT was calculated to be $0.000025 \mathrm{~W}$ (Sec. E1.1). The thermal conductance of the metalto-air-to-metal interface between the sensor and the thermometer well was estimated to be $0.058 \mathrm{~W} \cdot \mathrm{K}^{-1}$. The standard uncertainty due to the temperature rise due to joule heating was estimated by Eq. (E-13).

$$
u_{3}(T)=\frac{0.000025 \mathrm{~W}}{0.000058 \mathrm{~W} \cdot \mathrm{mK}^{-1}}=0.43 \mathrm{mK}
$$

- Plate temperature uniformity (lateral variation): The spatial temperature variation of the hot plate, $\delta T_{\mathrm{s}}$, was computed for each run from the standard deviation of the measured temperatures of the inner three thermocouples $(\# 1, \# 2$, and \#3 indicated in Fig. 62). The standard deviations were subsequently pooled (see formula in Eq. D-6 where $n$ is equal to 9) across the nine runs ( 3 levels of $\rho \times 3$ levels of $p$ ) conducted at each $T_{m}$. The standard uncertainty, $u_{4}\left(\delta \bar{T}_{\mathrm{s}}\right)$ was computed at each $T_{m}$ from Eq. (E-14).

$$
u_{4}\left(\delta \bar{T}_{\mathrm{s}}\right)_{\mathrm{A}}=\sqrt{\frac{\left[S_{\text {pool }}^{2}\left(\delta \bar{T}_{\mathrm{s}}\right)\right]_{T_{m}}}{3}}
$$




\section{Appendix E}

The standard uncertainties for $\delta T_{\mathrm{s}}$ are summarized in Table 24 at levels of $T_{m}$ from $280 \mathrm{~K}$ to $360 \mathrm{~K}$. The standard uncertainties increased (considerably at $360 \mathrm{~K}$ ) as $T_{m}$ departs from ambient conditions near $293 \mathrm{~K}$.

Table 24. Standard uncertainties for spatial temperature variation, $\delta \bar{T}_{\mathrm{s}}$.

\begin{tabular}{ccc}
\hline $\begin{array}{c}\boldsymbol{T}_{\boldsymbol{m}} \\
(\mathbf{K})\end{array}$ & $\begin{array}{c}\Delta \boldsymbol{T} \\
(\mathbf{K})\end{array}$ & $\begin{array}{c}\boldsymbol{u}_{\mathbf{4}}\left(\boldsymbol{\delta} \overline{\boldsymbol{T}}_{\mathbf{s}}\right) \\
(\mathbf{m K})\end{array}$ \\
\hline 280 & 25.0030 & 34.1 \\
300 & 25.0065 & 12.1 \\
320 & 25.0027 & 46.3 \\
340 & 25.0029 & 43.3 \\
360 & 24.9997 & 71.8 \\
\hline
\end{tabular}

- Mid-plane temperature correction: The term $\Delta T$ is defined as the surface-to-surface temperature difference across the specimen pair (Sec. E1.2). Each SPRT, however, measured the temperature at the centroid of the plate (Fig. 62). The correction ( $\left.\delta T_{\text {corr. }}\right)$ due to the temperature change across the thickness of the nickel plate was calculated by Eq. (E-15) for the hot and cold plates.

$$
\begin{aligned}
& \delta T_{h}=q \lambda_{\mathrm{Ni}}\left(T_{h}\right) f_{\mathrm{mp}} \\
& \delta T_{c}=q \lambda_{\mathrm{Ni}}\left(T_{c}\right) \frac{m_{\mathrm{c}}}{2}
\end{aligned}
$$

where

$q$ is the heat flux determined from the specimen heat flow divided by the metering area $(Q / A)$;

$\lambda_{\mathrm{Ni}}$ is the thermal conductivity of the nickel thermometry plate;

$f_{\mathrm{mp}}$ is a geometrical factor for the meter plate equal to $0.00479 \mathrm{~m} \mathrm{[29]}$; and, $m_{c}$ is the thickness of the thermometry cold plate (near $293 \mathrm{~K}$ ).

The standard uncertainty due to the small temperature changes across the thickness of the nickel plates from the surface to the center midplane of the SPRT was calculated from Eq. (E-16).

$$
u_{5}\left(\delta T_{\text {corr. }}\right)=\sqrt{\left(\delta T_{h}\right)^{2}+\left(\delta T_{c}\right)^{2}}
$$

The standard uncertainties are summarized in Table 25 at levels of $T_{m}$ from $280 \mathrm{~K}$ to $360 \mathrm{~K}$.

Table 25. Standard uncertainties due to the midplane-to-surface temperature correction.

\begin{tabular}{ccc}
\hline $\boldsymbol{T}_{\boldsymbol{m}}$ & $\begin{array}{c}\Delta \boldsymbol{T} \\
(\mathbf{K})\end{array}$ & $\begin{array}{c}\boldsymbol{u}_{\mathbf{5}}\left(\boldsymbol{\delta} \boldsymbol{T}_{\text {corr. }}\right) \\
(\mathbf{m K})\end{array}$ \\
\hline 280 & 25.0030 & 2.9 \\
300 & 25.0065 & 3.2 \\
320 & 25.0027 & 3.5 \\
340 & 25.0029 & 3.8 \\
360 & 24.9997 & 4.1 \\
\hline
\end{tabular}




\section{E1.2.3 Combined Standard Uncertainty for $T$ and $\Delta T$}

Equation (E-17) computes the combined standard uncertainty $(k=1)$ for the temperature measurement of the meter plate in millikelvin.

$$
u_{\mathrm{c}}(T)=\sqrt{u_{1}^{2}(T)+u_{2}^{2}(T)+u_{3}^{2}(T)+u_{4}^{2}\left(\delta \overline{T_{\mathrm{s}}}\right)+u_{5}^{2}\left(\delta T_{\text {corr. }}\right)}
$$

Table 26 summarizes values for contributory uncertainties and $u_{\mathrm{c}}(T)$ in millikelvin as a function of $T_{m}$.

Table 26. Combined standard uncertainties for the temperature measurement.

\begin{tabular}{cccccccc}
\hline $\begin{array}{c}\boldsymbol{T}_{\boldsymbol{m}} \\
(\mathbf{K})\end{array}$ & $\begin{array}{c}\Delta \boldsymbol{T} \\
(\mathbf{K})\end{array}$ & $\begin{array}{c}\boldsymbol{u}_{\mathbf{1}}(\boldsymbol{T}) \\
(\mathbf{m K})\end{array}$ & $\begin{array}{c}\boldsymbol{u}_{\mathbf{2}}(\boldsymbol{T}) \\
(\mathbf{m K})\end{array}$ & $\begin{array}{c}\boldsymbol{u}_{\mathbf{3}}(\boldsymbol{T}) \\
(\mathbf{m K})\end{array}$ & $\begin{array}{c}\boldsymbol{u}_{\mathbf{4}}\left(\boldsymbol{\delta} \overline{\boldsymbol{T}}_{\mathbf{s}}\right) \\
(\mathbf{m K})\end{array}$ & $\begin{array}{c}\boldsymbol{u}_{\mathbf{5}}\left(\boldsymbol{\delta} \boldsymbol{T}_{\text {corr. }}\right) \\
(\mathbf{m K})\end{array}$ & $\begin{array}{c}\boldsymbol{u}_{\mathbf{c}}(\boldsymbol{T}) \\
(\mathbf{m K})\end{array}$ \\
\hline 280 & 25.0030 & 0.32 & 0.46 & 0.43 & 34.1 & 2.9 & 34.2 \\
300 & 25.0065 & 0.32 & 0.46 & 0.43 & 12.1 & 3.2 & 12.5 \\
320 & 25.0027 & 0.32 & 0.46 & 0.43 & 46.3 & 3.5 & 46.4 \\
340 & 25.0029 & 0.32 & 0.46 & 0.43 & 43.3 & 3.8 & 43.4 \\
360 & 24.9997 & 0.32 & 0.46 & 0.43 & 71.8 & 4.1 & 72.0 \\
\hline
\end{tabular}

The combined standard uncertainty for $\Delta T$ was computed using Eq. (E-18). The factor of 2 accounts for both the uncertainty of the hot plate and cold plate.

$$
u_{\mathrm{c}}(\Delta T)=\sqrt{u^{2}(\Delta \bar{T})+2 \times u_{\mathrm{c}}^{2}(T)}
$$

Table 27 summarizes the combined standard uncertainties for $\Delta T$ in kelvin as a function of mean temperature. The final column in Table 27 was reproduced in Table 15 (Sec. 7.4).

Table 27. Combined standard uncertainties $(k=1)$ for $\Delta T$.

\begin{tabular}{cccc}
\hline $\boldsymbol{T}_{\boldsymbol{m}}$ & $\begin{array}{c}\Delta \boldsymbol{T} \\
(\mathbf{K})\end{array}$ & $\begin{array}{c}\boldsymbol{u}_{\mathbf{c}}(\boldsymbol{\Delta} \boldsymbol{T}) \\
(\mathbf{K})\end{array}$ & $\begin{array}{c}\boldsymbol{u}_{\mathbf{c}, \mathbf{r}}(\boldsymbol{\Delta T}) \\
(\mathbf{\%})\end{array}$ \\
\hline 280 & 25.0030 & 0.049 & 0.19 \\
300 & 25.0065 & 0.018 & 0.07 \\
320 & 25.0027 & 0.066 & 0.26 \\
340 & 25.0029 & 0.062 & 0.25 \\
360 & 24.9997 & 0.102 & 0.41 \\
\hline
\end{tabular}




\section{Appendix E}

\section{E1.3 Thickness $(L)$}

Figure 63 schematically illustrates the calibration and measurement principles for the insitu determination of thickness during the guarded-hot-plate tests.

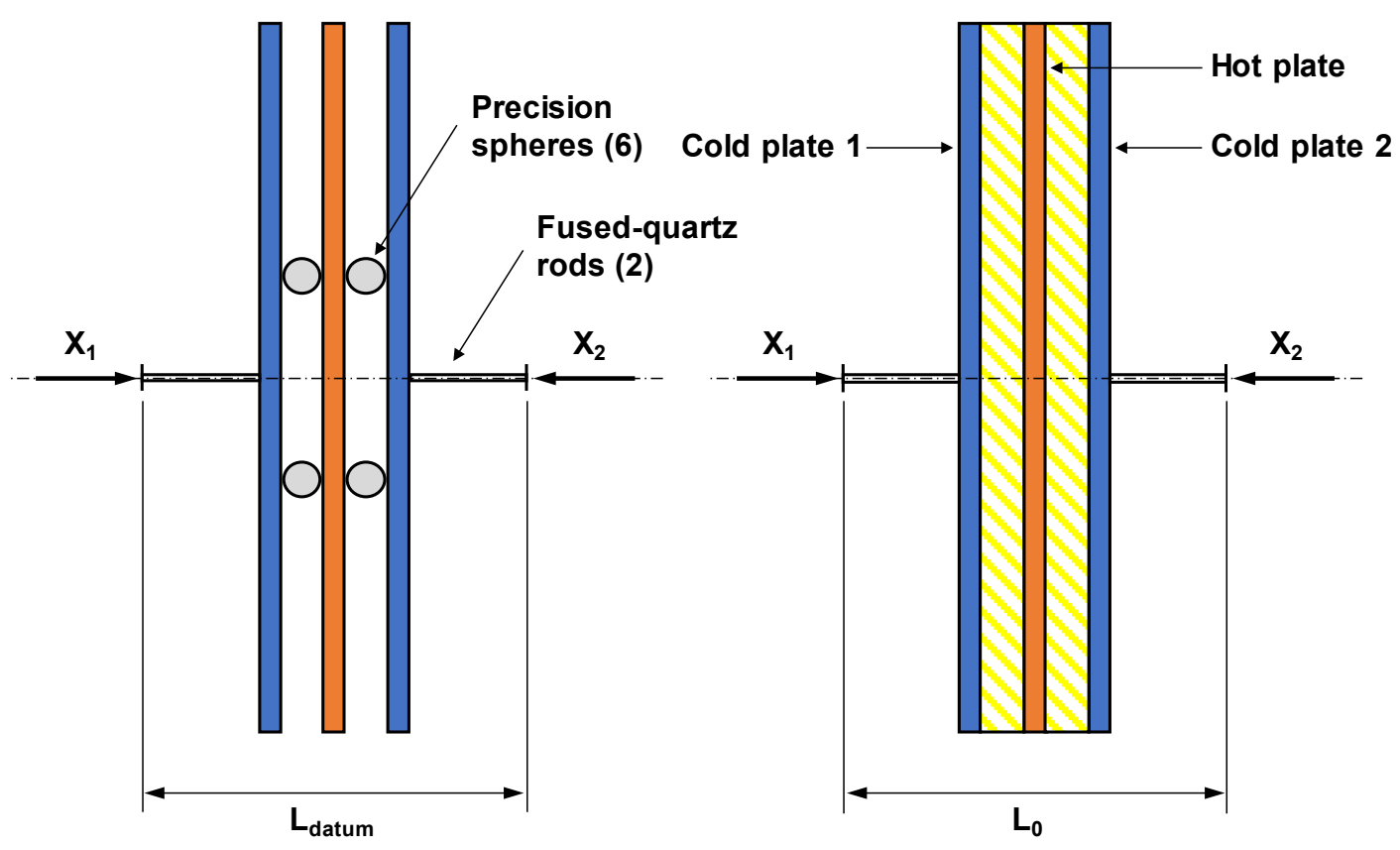

a) Calibration

b) Specimen installation

Fig. 63. a) Calibration and b) Measurement principles for in-situ thickness determination.

The dimensional quantities $L_{\text {datum }}$ and $L_{0}$ indicated in Fig. 63 were measured at ambient conditions with two Heidenhain-Metro MT12 length gages connected in additive sum mode $\left(X_{1}+X_{2}\right)$ to a Heidenhain ND231B digital display (not shown in Fig. 63). The measurement principle of the length encoders utilized photoelectric scanning of precision graduations etched on glass substrates. The length gages were mounted by a clamping shank so that the gage plunger was orthogonal to the button end of a fused quartz rod located on the axial centerline of the apparatus (Fig. 63). The rounded end of the rod was pressed gently against the center of the rear surface of the circular thermometer plate by a disc spring providing an axial force of $26.7 \mathrm{~N}(6 \mathrm{lb})$. The length gages were precisely positioned during testing on platforms utilizing kinematic components, i.e., truncated balls and rollers, having three spherical points of contact. The kinematic mount system eliminated the six degrees of motion without using clamping or other excessive constraints.

As summarized in Sec. 6.6.3, $L_{\text {datum }}$ was set at laboratory ambient conditions prior to the specimen installation using a dual arrangement of three $25.4 \mathrm{~mm}$ ( 1 in.) diameter precision spheres positioned on either side of the hot plate and spaced evenly around the circumference of a $190 \mathrm{~mm}$-diameter circle. For illustrative purposes, Fig. 63a only shows two spheres on either side of the hot plate. The datum setting $\left(L_{\text {datum }}\right)$ was defined to be $50.8064 \mathrm{~mm}$ for each test, based on the NIST calibration of the spheres' diameters. The following baseline conditions were maintained during the datum setting. 


\section{Appendix E}

- The coolant baths and heaters (for the plate and guards) were powered down (OFF) $12 \mathrm{~h}$ to $24 \mathrm{~h}$ prior to setting $L_{\text {datum. }}$.

- The water-jacket baths circulating distilled water to the apparatus were operated at a setpoint of $20.0^{\circ} \mathrm{C}$. The laboratory ambient air temperature was controlled from $23{ }^{\circ} \mathrm{C}$ to $25^{\circ} \mathrm{C}$.

- During datum entry, the clamping load applied to the plates ranged from $133 \mathrm{~N}$ to $178 \mathrm{~N}\left(30 \mathrm{lb}_{\mathrm{f}}\right.$ to $40 \mathrm{lb}$ ). After calibration, the specimen pair was installed at an initial value of $L_{0}$ (Fig. 63b) at a clamping load comparable to the calibration loading.

The average (uncorrected) specimen thickness (at $T_{m}$ ) was determined from the combined signals of the encoders $X_{1}$ and $X_{2}$ (Fig. 63) by the Heidenhain ND231B display from Eq. (E-19).

$$
L_{\text {uncorr. }}=\frac{X_{1}+X_{2}}{2}
$$

\section{E1.3.1 Thickness Correction due Thermal Expansion/Contraction}

During a test, the thickness measurement situation was somewhat more complicated since it was necessary to consider the thermal expansion or contraction of the hot plate, two cold plates and two fused-quartz rods [29] shown in Fig. 63. The change in the combined reading of the length gages $(\delta L)$, relative to the initial reading $L_{0}$ taken at room temperature [29], is given by Eq. (E-20).

$$
\delta L=2 \Delta L\left(T_{m}\right)+\Delta m_{\mathrm{h}}\left(T_{h}\right)+\Delta m_{\mathrm{c}_{1}}\left(T_{c_{1}}\right)+\Delta m_{\mathrm{c}_{2}}\left(T_{c_{2}}\right)+\Delta L_{\mathrm{q}_{1}}\left(T_{\mathrm{q}_{1}}\right)+\Delta L_{\mathrm{q}_{2}}\left(T_{\mathrm{q}_{2}}\right)
$$

where

- $\Delta L\left(T_{m}\right)$, which is to be determined, is the change in the average thickness of the specimen pair at $T_{m}$;

- $\Delta m \mathrm{~h}\left(T_{h}\right)$ is the change in the thickness of the nickel hot plate at $T_{h}$;

- $\Delta m_{\mathrm{c}}\left(T_{c}\right)$ is the change in the thickness of the nickel cold plate at $T_{c}$; and,

- $\Delta L_{\mathrm{q}}\left(T_{\mathrm{q}}\right)$ is the change in the length of the fused-quartz rod at $T_{\mathrm{q}}$.

Rearranging Eq. (E-20), the change in average specimen thickness is given by

$$
\Delta L\left(T_{m}\right)=\left[\delta L-\Delta m_{\mathrm{h}}\left(T_{h}\right)-\Delta m_{\mathrm{c}_{1}}\left(T_{c_{1}}\right)-\Delta m_{\mathrm{c}_{2}}\left(T_{c_{2}}\right)-\Delta L_{\mathrm{q}_{1}}\left(T_{\mathrm{q}_{1}}\right)-\Delta L_{\mathrm{q}_{2}}\left(T_{\mathrm{q}_{2}}\right)\right] / 2
$$

The thermal expansion corrections [29] for the plates and fused-quartz rods are computed from Eq. (E-22)

$$
\begin{aligned}
& \Delta m_{\mathrm{h}}\left(T_{h}\right)=m_{\mathrm{h}}\left(T_{r}\right) \times \bar{\alpha}_{\mathrm{Ni}}\left(T_{h}-T_{r}\right) \\
& \Delta m_{\mathrm{c}}\left(T_{c}\right)=m_{\mathrm{c}}\left(T_{r}\right) \times \bar{\alpha}_{\mathrm{Ni}}\left(T_{c}-T_{r}\right) \\
& \Delta L_{\mathrm{q}}\left(T_{\mathrm{q}}\right)=L_{\mathrm{q}}\left(T_{r}\right) \times\left(\Delta L_{\mathrm{q}} / L_{\mathrm{q} 293}\right)
\end{aligned}
$$

where $m_{\mathrm{h}}$ and $m_{\mathrm{c}}$, are the thicknesses of the hot and cold thermometry plates, respectively at the reference temperature $\left(T_{r}\right)$ of $293.15 \mathrm{~K}$. The term $L_{q}$ represents the lengths of the fused-quartz rods at the reference temperature $\left(T_{r}\right)$ of $293 \mathrm{~K}$. The mean thermal expansion coefficient for nickel $(\bar{\alpha})$ was determined from published data by Kollie [30]. The thermal 
expansion of fused quartz $\left(\Delta L_{\mathrm{q}} / L_{\mathrm{q} 293}\right)$ was determined from data for NIST SRM 739, FusedSilica Thermal Expansion [31].

Following Eq. (E-21) as a template, Eq. (E-19) was modified so that the corrected thickness at $L\left(T_{m}\right)$ was computed from the average of the combined length gages minus the thermal expansion effects due to the hot plate, cold plates, and fused quartz rods.

$$
\begin{aligned}
& L\left(T_{m}\right)=\frac{\left(X_{1}+X_{2}\right)_{T_{m}}-L_{\text {corr. }}}{2} \\
& L\left(T_{m}\right)=\frac{\left(X_{1}+X_{2}\right)_{T_{m}}}{2}-\frac{\Delta m_{\mathrm{h}}\left(T_{h}\right)+\Delta m_{\mathrm{c}_{1}}\left(T_{c_{1}}\right)+\Delta m_{\mathrm{c}_{2}}\left(T_{c_{2}}\right)+\Delta L_{\mathrm{q}_{1}}\left(T_{\mathrm{q}_{1}}\right)+\Delta L_{\mathrm{q}_{2}}\left(T_{\mathrm{q}_{2}}\right)}{2}
\end{aligned}
$$

Table 28 summarizes values for the average corrected thickness $L$, the corresponding thickness correction, and standard uncertainty at levels of $T_{m}$ from $280 \mathrm{~K}$ to $360 \mathrm{~K}$. As expected, the values of $L_{\text {corr. }}$ increase as $T_{m}$ departs from ambient conditions near $293 \mathrm{~K}$.

Table 28. Thickness corrections and corresponding standard uncertainties.

\begin{tabular}{ccccc}
\hline $\boldsymbol{T}_{\boldsymbol{m}}$ & $\begin{array}{c}\boldsymbol{L}\left(\boldsymbol{T}_{\boldsymbol{m}}\right) \\
(\mathbf{m m})\end{array}$ & $\begin{array}{c}\boldsymbol{L}_{\text {corr. }} \\
(\mathbf{m m})\end{array}$ & $\begin{array}{c}\boldsymbol{u}\left(\boldsymbol{L}_{\text {corr. }}\right) \\
(\mathbf{m m})\end{array}$ & $\begin{array}{c}\boldsymbol{u}\left(\boldsymbol{L}_{\text {corr. }}\right) \\
(\boldsymbol{\%})\end{array}$ \\
\hline 280 & 24.8619 & -0.0112 & 0.00013 & 0.0005 \\
300 & 25.2112 & 0.0017 & 0.00020 & 0.0008 \\
320 & 24.9313 & 0.0148 & 0.00018 & 0.0007 \\
340 & 25.0282 & 0.0281 & 0.00039 & 0.0015 \\
360 & 25.0721 & 0.0416 & 0.00045 & 0.0018 \\
\hline
\end{tabular}

\section{E1.3.2 Repeated Observations, $u(\bar{L})_{\mathrm{A}}$}

The standard uncertainty for the mean in-situ thickness was determined using the same process as was done for $u\left(\bar{Q}_{\mathrm{m}}\right)_{\mathrm{A}}$ in Sec. E1.1. The standard uncertainties for repeated observations at levels of $T_{m}$ from $280 \mathrm{~K}$ to $360 \mathrm{~K}$ are summarized in Table 29.

Table 29. Standard uncertainties for repeated observations of $\bar{L}$.

\begin{tabular}{cccc}
$\begin{array}{c}\boldsymbol{T}_{\boldsymbol{m}} \\
(\mathbf{K})\end{array}$ & $\begin{array}{c}\boldsymbol{L}\left(\boldsymbol{T}_{\boldsymbol{m}}\right) \\
(\mathbf{m m})\end{array}$ & $\begin{array}{c}\boldsymbol{u}(\overline{\boldsymbol{L}})_{\mathbf{A}} \\
(\mathbf{m m})\end{array}$ & $\begin{array}{c}\boldsymbol{u}(\overline{\boldsymbol{L}})_{\mathbf{A}} \\
(\mathbf{\%})\end{array}$ \\
\hline 280 & 24.8619 & 0.00011 & 0.00044 \\
300 & 25.2112 & 0.00006 & 0.00023 \\
320 & 24.9313 & 0.00012 & 0.00048 \\
340 & 25.0282 & 0.00008 & 0.00030 \\
360 & 25.0721 & 0.00013 & 0.00051 \\
\hline
\end{tabular}




\section{Appendix E}

\section{E1.3.3 Contributory Thickness Uncertainties}

The contributory uncertainties for $u(L)$ due to in-situ measurements include: a) calibration of the $25.4 \mathrm{~mm}$ diameter precision spheres (Fig. 63a); b) uncertainty in the measurement instruments; c) plate deflection; d) variation in the datum setting (Fig. 63a); and, e) plate flatness. Specific details for items a), b), and c) are discussed in this section. Separate experiments for items d) and e) are discussed in Secs. E1.3.4 and E1.3.5, respectively.

- Sphere calibration: The Bal-tec ${ }^{\mathrm{TM}}$, Grade 25, $25.4 \mathrm{~mm}$ diameter tungsten carbide balls were manufactured by Micro Surface Engineering, Inc. in 2004 and most recently calibrated on July 10, 2018 by the NIST Dimensional Metrology Group at $20^{\circ} \mathrm{C}$. Table 30 summarizes the NIST calibration data for the six balls.

Table 30. Calibration data for $25.4 \mathrm{~mm}$ diameter balls.

\begin{tabular}{ccccc}
\hline & \multicolumn{2}{c}{$\begin{array}{c}\text { Avg. Measured Diameter } \\
\text { (in.) }\end{array}$} & \multicolumn{2}{c}{$U(\boldsymbol{k}=\mathbf{2})$} \\
Ball ID & 1.000129 & 25.403267 & 6.9 & 174 \\
\hline 1 & 1.000180 & 25.404570 & 4.9 & 125 \\
2 & 1.000102 & 25.402583 & 25.4 & 644 \\
3 & 1.000064 & 25.401624 & 6.5 & 165 \\
4 & 1.000125 & 25.403180 & 4.1 & 105 \\
5 & 1.000162 & 25.404103 & 4.5 & 115 \\
6 & & & & \\
\hline
\end{tabular}

The grand average of the ball diameters was $25.4032 \mathrm{~mm}$ which was multiplied by a factor of two $(L$ datum $=50.8064 \mathrm{~mm})$ for application in the guarded-hot-plate apparatus (Fig. 63a). A conservative estimate of $\pm 644 \mathrm{~nm}$ (i.e., expanded uncertainty for ball \#3) was selected for the calibration uncertainty in Eq. (E-24).

$$
u_{1}(L)_{\mathrm{B}}=\frac{644 \mathrm{~nm}}{2}=322 \mathrm{~nm}=0.000322 \mathrm{~mm}
$$

- Instrument uncertainty: The thickness measurement was conducted with two Heidenhain-Metro MT12 Series length gages connected to the Heidenhain ND231B in sum display mode $\left(X_{1}+X_{2}\right)$. The manufacturer specification for the system accuracy was equal to $\pm 1 \mu \mathrm{m}(0.001 \mathrm{~mm})$ at a reference temperature of $20^{\circ} \mathrm{C}$. A uniform rectangular distribution was assumed for the accuracy specification and the standard uncertainty was computed from Eq. (E-25).

$$
u_{2}(L)_{\mathrm{B}}=\frac{0.001 \mathrm{~mm}}{\sqrt{3}}=0.00058 \mathrm{~mm}
$$

- Plate deflection: Because the plates were supported vertically from an overhead carriage rail system (not shown in Fig. 63) and were free to translate in the axial direction, no correction for the plate deflection during operation was necessary.

\section{E1.3.4 Datum Setting Variability}

As described in Sec. E1.3 (Fig. 63a), a datum setting of $50.8064 \mathrm{~mm}$ was established before each test using the calibrated $25.4 \mathrm{~mm}$ diameter Bal-tec ${ }^{\mathrm{TM}}$ precision spheres. For calibration, the outboard stanchion with the Metro MT12 length gage was removed and installed on a kinematic support platform. The gage plunger was retracted for removal of the gage. 
The short-term repeatability of the linear position transducers was determined from replicate measurements taken over a four-day interval from September 24, 2019 to September 27, 2019. For each day, a datum setting of $50.8064 \mathrm{~mm}$ for the Heidenhain ND231 was established using the $25.4 \mathrm{~mm}$ diameter Bal-tec ${ }^{\mathrm{TM}}$ precision spheres. After setting the datum, the outboard Metro MT12 was removed from the kinematic-mount platform and the spheres were re-installed to verify the original datum setting. The process was repeated 5 times each day.

Table 31 summarizes the replication data for Days 1 through 4. Each datum in Table 31 was set with a pre-load of about $35.6 \mathrm{~N}(8 \mathrm{lb})$ and an ultimate loading of $151 \mathrm{~N}\left(34 \mathrm{lb}_{\mathrm{f}}\right)$. The laboratory ambient conditions during measurements was $24.4{ }^{\circ} \mathrm{C}$ and $40 \%$ to $44 \%$ relative humidity.

Table 31. Short-term replication data for the in-situ thickness measurement.

\begin{tabular}{|c|c|c|c|c|}
\hline Datum setting (mm) & 50.8064 & 50.8064 & 50.8064 & 50.8064 \\
\hline Observation & $\begin{array}{l}\text { Day } 1 \\
(\mathrm{~mm})\end{array}$ & $\begin{array}{l}\text { Day } 2 \\
(\mathrm{~mm})\end{array}$ & $\begin{array}{l}\text { Day } 3 \\
\text { (mm) }\end{array}$ & $\begin{array}{l}\text { Day } 4 \\
(\mathrm{~mm})\end{array}$ \\
\hline 1 & 50.7711 & 50.7301 & 50.7755 & 50.8263 \\
\hline 2 & 50.8688 & 50.7886 & 50.7438 & 50.8791 \\
\hline 3 & 50.8005 & 50.7642 & 50.7879 & 50.7944 \\
\hline 4 & 50.7717 & 50.7294 & 50.7607 & 50.8522 \\
\hline 5 & 50.6916 & 50.6602 & 50.7367 & 50.8046 \\
\hline$\overline{L_{\text {datum }}}$ & 50.7807 & 50.7345 & 50.7609 & 50.8313 \\
\hline$s$ & 0.0638 & 0.0484 & 0.0213 & 0.0347 \\
\hline
\end{tabular}

The standard uncertainty for $u_{3}(L)$ was determined using Eq. (E-29)

$$
u_{3}(L)=\sqrt{s_{a}^{2}+\left(\frac{r-1}{r}\right) s_{d}^{2}}
$$

where $s_{a}$ is the standard deviation of the daily averages (between-day variation), $s_{d}$ is the (pooled) within-day standard deviation, and $r$ is number of replicates per day $(r=5)$. Using the last two rows of data in Table 31, $s a$ and $s d$ were computed to be $0.04094 \mathrm{~mm}$ and $0.04492 \mathrm{~mm}$, respectively. Substituting into Eq. (E-29), yields

$$
u_{3}(L)=\sqrt{0.04094^{2}+(0.8) \times 0.04492^{2}}=0.05736 \mathrm{~mm}
$$

\section{E1.3.5 Plate Surface Flatness}

Prior to assembly in the apparatus, the plate surface variation was investigated in 2004 by placing the cold thermometer plates on a granite surface plate in a conditioned laboratory. Dimensional measurements were manually taken with a Mitutoyo Series 513 dial indicator having $0.0127 \mathrm{~mm}$ (0.0005 in.) graduations. A uniform rectangular distribution was assumed, and the standard uncertainty was computed from Eq. (E-31).

$$
u\left(L_{\text {gage }}\right)=\frac{0.0127 \mathrm{~mm}}{\sqrt{3}}=0.00733 \mathrm{~mm}
$$


Figure 64 shows the measurement locations, 1 through 40, over the entire plate surface. The indicator was set to zero at the center location of the plate and all subsequent measurements were acquired relative to the center datum setting of zero. Table 32 summarizes the 40 measurements for cold plates \#1 (inboard) and \#2 (outboard). The original measurements were recorded in inches but are also presented here in SI, consistent with NIST policy on the use of the SI. The standard deviations of the data for cold plates \#1 and \#2 were $0.00622 \mathrm{~mm}$ and $0.00592 \mathrm{~mm}$, respectively (Table 32). The conservative estimate for cold plate \#1 was used in subsequent calculations.

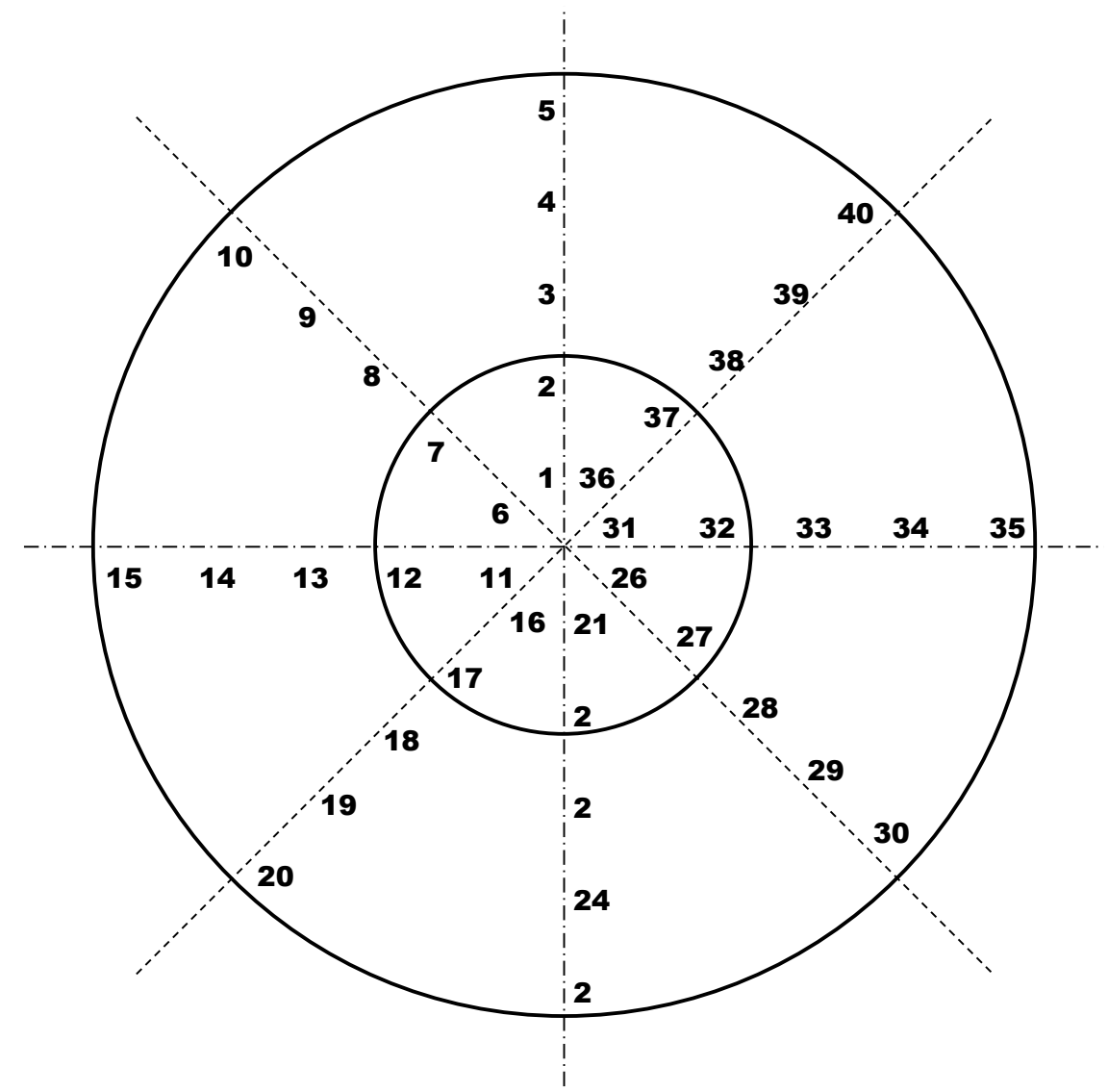

Fig. 64. Locations for surface flatness measurements for NIST $500 \mathrm{~mm}$ diameter plates.

The standard uncertainty was estimated from the variance of the mean given by Eq. (E-32).

$$
u_{\text {plate }}=\frac{0.03936 \mathrm{~mm}}{\sqrt{40}}=0.00622 \mathrm{~mm}
$$

The standard uncertainty for the surface plate flatness was computed from Eq. (E-33).

$$
u_{4}(L)=\sqrt{(0.00733 \mathrm{~mm})^{2}+(0.00622 \mathrm{~mm})^{2}}=0.00962 \mathrm{~mm}
$$


Appendix E

Table 32. Flatness variation of cold plates \#1 and \#2.

\begin{tabular}{|c|c|c|c|c|}
\hline \multirow[b]{2}{*}{ Location } & \multicolumn{2}{|c|}{ Cold plate \#1 } & \multicolumn{2}{|c|}{ Cold plate \#2 } \\
\hline & $(\mathbf{m m})$ & (inch) & $(\mathbf{m m})$ & (inch) \\
\hline 1 & -0.013 & -0.0005 & 0 & 0 \\
\hline 2 & -0.025 & -0.0010 & 0.013 & 0.0005 \\
\hline 3 & -0.038 & -0.0015 & 0.025 & 0.0010 \\
\hline 4 & -0.091 & -0.0036 & 0.038 & 0.0015 \\
\hline 5 & -0.135 & -0.0053 & 0.056 & 0.0022 \\
\hline 6 & -0.013 & -0.0005 & 0 & 0 \\
\hline 7 & 0 & 0 & 0 & 0 \\
\hline 8 & -0.018 & -0.0007 & 0.018 & 0.0007 \\
\hline 9 & -0.051 & -0.0020 & 0.025 & 0.0010 \\
\hline 10 & -0.066 & -0.0026 & 0.051 & 0.0020 \\
\hline 11 & 0 & 0 & -0.013 & -0.0005 \\
\hline 12 & 0.018 & 0.0007 & 0 & 0 \\
\hline 13 & 0.005 & 0.0002 & 0.010 & 0.0004 \\
\hline 14 & -0.018 & -0.0007 & 0.028 & 0.0011 \\
\hline 15 & -0.025 & -0.0010 & 0.064 & 0.0025 \\
\hline 16 & 0 & 0 & -0.013 & -0.0005 \\
\hline 17 & 0.005 & 0.0002 & 0 & 0 \\
\hline 18 & -0.013 & -0.0005 & 0.013 & 0.0005 \\
\hline 19 & -0.038 & -0.0015 & 0.038 & 0.0015 \\
\hline 20 & -0.064 & -0.0025 & 0.069 & 0.0027 \\
\hline 21 & 0 & 0 & 0.008 & 0.0003 \\
\hline 22 & 0 & 0 & 0.025 & 0.0010 \\
\hline 23 & -0.025 & -0.0010 & 0.038 & 0.0015 \\
\hline 24 & -0.056 & -0.0022 & 0.064 & 0.0025 \\
\hline 25 & -0.094 & -0.0037 & 0.089 & 0.0035 \\
\hline 26 & 0.005 & 0.0002 & 0.013 & 0.0005 \\
\hline 27 & 0 & 0 & 0.043 & 0.0017 \\
\hline 28 & -0.010 & -0.0004 & 0.064 & 0.0025 \\
\hline 29 & -0.025 & -0.0010 & 0.102 & 0.0040 \\
\hline 30 & -0.043 & -0.0017 & 0.165 & 0.0065 \\
\hline 31 & 0 & 0 & 0.013 & 0.0005 \\
\hline 32 & 0 & 0 & 0.033 & 0.0013 \\
\hline 33 & -0.010 & -0.0004 & 0.051 & 0.0020 \\
\hline 34 & -0.023 & -0.0009 & 0.076 & 0.0030 \\
\hline 35 & -0.023 & -0.0009 & 0.114 & 0.0045 \\
\hline 36 & -0.013 & -0.0005 & 0 & 0 \\
\hline 37 & -0.023 & -0.0009 & 0.013 & 0.0005 \\
\hline 38 & -0.061 & -0.0024 & 0.018 & 0.0007 \\
\hline 39 & -0.119 & -0.0047 & 0.043 & 0.0017 \\
\hline 40 & -0.145 & -0.0057 & 0.069 & 0.0027 \\
\hline Mean & -0.031 & -0.0012 & 0.037 & 0.0014 \\
\hline$s$ & 0.03936 & 0.0015 & 0.03743 & 0.0015 \\
\hline
\end{tabular}




\section{Appendix E}

\section{E1.3.6 Combined Standard Uncertainty for $L$}

Equation (E-34) computes the combined standard uncertainty $(k=1)$ for $L$.

$u_{\mathrm{c}}(L)=\sqrt{u^{2}(\bar{L})+u_{1}^{2}(L)+u_{2}^{2}(L)+u_{3}^{2}(L)+u_{4}^{2}(L)}$

$u_{\mathrm{c}}(L)=\sqrt{0.00013^{2}+0.000322^{2}+0.001^{2}+0.05736^{2}+2 \times 0.00962^{2}}=0.0582 \mathrm{~mm}$

As evident in Eq. (E-34), the dominant contributory uncertainty was due to the set-up of the measurement datum. A factor of 2 was included for $u 4(L)$ to account for the flatness of the hot plate (which was assumed to be the same as the cold plate). The combined standard uncertainties are summarized in Table 33 as a function of $T_{m}$. The final column in Table 33 was reproduced in Table 15 (Sec. 7.4).

Table 33. Combined standard uncertainties $(k=1)$ for $L$.

\begin{tabular}{cccccccccc}
\hline $\begin{array}{r}\boldsymbol{T}_{\boldsymbol{m}} \\
(\mathbf{K})\end{array}$ & $\begin{array}{c}\boldsymbol{L}\left(\boldsymbol{T}_{\boldsymbol{m}}\right) \\
(\mathbf{m m})\end{array}$ & $\begin{array}{c}\boldsymbol{u}\left(\boldsymbol{L}_{\text {corr. }}\right) \\
(\mathbf{m m})\end{array}$ & $\begin{array}{c}\boldsymbol{u}(\overline{\boldsymbol{L}})_{\mathbf{A}} \\
(\mathbf{m m})\end{array}$ & $\begin{array}{c}\boldsymbol{u}_{\mathbf{1}}(\boldsymbol{L}) \\
(\mathbf{m m})\end{array}$ & $\begin{array}{c}\boldsymbol{u}_{\mathbf{2}}(\boldsymbol{L}) \\
(\mathbf{m m})\end{array}$ & $\begin{array}{c}\boldsymbol{u}_{\mathbf{3}}(\boldsymbol{L}) \\
(\mathbf{m m})\end{array}$ & $\begin{array}{c}\boldsymbol{u}_{\mathbf{4}}(\boldsymbol{L}) \\
(\mathbf{m m})\end{array}$ & $\begin{array}{c}\boldsymbol{u}_{\mathrm{c}}(\boldsymbol{L}) \\
(\mathbf{m m})\end{array}$ & $\begin{array}{c}\boldsymbol{u}_{\mathrm{c}, \mathbf{r}}(\boldsymbol{L}) \\
(\mathbf{\%})\end{array}$ \\
\hline 280 & 24.8619 & 0.00013 & 0.00011 & 0.00032 & 0.00058 & 0.0574 & 0.00962 & 0.0590 & 0.24 \\
300 & 25.2112 & 0.00020 & 0.00006 & 0.00032 & 0.00058 & 0.0574 & 0.00962 & 0.0590 & 0.23 \\
320 & 24.9313 & 0.00018 & 0.00012 & 0.00032 & 0.00058 & 0.0574 & 0.00962 & 0.0590 & 0.24 \\
340 & 25.0282 & 0.00039 & 0.00008 & 0.00032 & 0.00058 & 0.0574 & 0.00962 & 0.0590 & 0.24 \\
360 & 25.0721 & 0.00045 & 0.00013 & 0.00032 & 0.00058 & 0.0574 & 0.00962 & 0.0590 & 0.24 \\
\hline
\end{tabular}

\section{E1.4 Meter Area $(A)$}

The circular meter area was calculated from Eq. (E-35),

$$
A=\frac{\pi}{2}\left(r_{o}^{2}+r_{i}^{2}\right)\left(1+\bar{\alpha}_{\mathrm{Ni}} \Delta T_{\mathrm{mp}}\right)^{2}
$$

where $r_{o}$ is the outer radius of meter plate $(\mathrm{m}) ; r_{i}$ is the inner radius of guard plate $(\mathrm{m}) ; \bar{\alpha}_{\mathrm{Ni}}$ is the coefficient of thermal expansion of nickel $\left(\mathrm{K}^{-1}\right)$; and, $\Delta T_{\mathrm{mp}}$ is the temperature difference $(\mathrm{K})$ of the meter plate $\left(T_{h}\right)$ from an ambient temperature of $20^{\circ} \mathrm{C}$.

Replacing the radius in Eq. (E-35) with the diameter (divided by 2) yields

$$
A=\frac{\pi}{8}\left(d_{o}^{2}+d_{i}^{2}\right)\left(1+\bar{\alpha}_{\mathrm{Ni}} \Delta T_{\mathrm{mp}}\right)^{2}
$$

The contributory uncertainties for $u(A)$ include the following: a) calibration uncertainties for $d_{o}$ and $d_{i}$; b) uncertainty in $\bar{\alpha}_{\mathrm{Ni}}$ as a function of temperature; and, c) uncertainty in $\Delta T_{\mathrm{mp}}$. In addition, the uncertainty analysis includes a small correction due to a portion of the meter plate that was damaged during re-installation of one of the guard gap thermopiles.

- $\quad d_{o}$ and $d_{i}$ : The outer diameter $\left(d_{o}\right)$ of the meter plate and the inner diameter $\left(d_{i}\right)$ of the guard plate were determined by the NIST Engineering Metrology Group in July 2006 (NIST Test Report 274749-07) using an error-mapped coordinate measuring machine. The expanded uncertainties $(k=2)$ for the diameter measurements from the NIST Report of Calibration are given by Eq. (E-37)

$$
U=( \pm 10.20+0.2 d) \mu \mathrm{m}
$$




\section{Appendix E}

where $d$ is in meters. For $d$ equal to a nominal meter plate diameter of $0.2 \mathrm{~m}$, the standard uncertainty $(k=1)$ is computed from Eq. (E-38).

$$
u(d)=\left(\frac{ \pm 10.20+0.2 \times 0.2}{2}\right) \mu \mathrm{m}=\frac{10.24}{2} \mu \mathrm{m}=5.12 \mu \mathrm{m} .
$$

- $\bar{\alpha}_{\text {Ni: }}$ The average values for the thermal expansion of nickel were obtained by application of the trapezoidal rule to thermal expansion coefficient data measured by Kollie [30] using a fused-quartz dilatometer. Based on the uncertainty estimate of $\pm 1.6 \%$ for the coefficient data [30], an upper limit of $2 \%$ was assumed. Table 34 summarizes interpolated estimates of $\bar{\alpha}_{\mathrm{Ni}}$ and corresponding values of $u\left(\bar{\alpha}_{\mathrm{Ni}}\right)$ for five levels of meter plate temperature $\left(T_{h}\right)$.

Table 34. Standard uncertainties for $\bar{\alpha}_{\mathrm{Ni}}$.

\begin{tabular}{ccc}
\hline $\begin{array}{c}\boldsymbol{T}_{\boldsymbol{h}} \\
(\mathbf{K})\end{array}$ & $\begin{array}{c}\overline{\boldsymbol{\alpha}}_{\mathbf{N i}} \\
\left(\mathbf{K}^{-1}\right)\end{array}$ & $\begin{array}{c}\boldsymbol{u}\left(\overline{\boldsymbol{\alpha}}_{\mathbf{N i}}\right) \\
\left(\mathbf{K}^{-1}\right)\end{array}$ \\
\hline 292.5 & $1.28 \times 10^{-5}$ & $2.56 \times 10^{-7}$ \\
312.5 & $1.29 \times 10^{-5}$ & $2.59 \times 10^{-7}$ \\
332.5 & $1.31 \times 10^{-5}$ & $2.62 \times 10^{-7}$ \\
352.5 & $1.32 \times 10^{-5}$ & $2.64 \times 10^{-7}$ \\
372.5 & $1.33 \times 10^{-5}$ & $2.66 \times 10^{-7}$ \\
\hline
\end{tabular}

- $\Delta T_{\mathrm{mp}}$ : The temperature difference for meter plate was determined from Eq. (E-39). The uncertainty was estimated to be $0.010 \mathrm{~K}$ based on the measurement uncertainty of the SPRT in the meter plate.

$$
\Delta T_{\mathrm{mp}}=T_{h}-293.15
$$

\section{E1.4.1 Combined Standard Uncertainty for the Metering Area $(A)$}

Propagating the contributory uncertainties in Eq. (E-36) based on a Taylor series approximation yields Eq. (E-40)

$$
u_{c}(A)=\sqrt{c_{d_{0}}^{2} u^{2}\left(d_{o}\right)+c_{d_{i}}^{2} u^{2}\left(d_{i}\right)+c_{\bar{\alpha}}^{2} u^{2}(\bar{\alpha})+c_{\Delta T_{\mathrm{mp}}}^{2} u^{2}\left(\Delta T_{\mathrm{mp}}\right)}
$$

with

$$
\begin{aligned}
c_{d_{o}} & =\frac{\partial A}{\partial d_{o}}=\frac{\pi}{4} d_{o}\left(1+\bar{\alpha}_{\mathrm{Ni}} \Delta T_{\mathrm{mp}}\right)^{2} \\
c_{d_{i}} & =\frac{\partial A}{\partial d_{i}}=\frac{\pi}{4} d_{i}\left(1+\bar{\alpha}_{\mathrm{Ni}} \Delta T_{\mathrm{mp}}\right)^{2} \\
c_{\overline{\mathrm{\alpha}}_{\mathrm{Ni}}} & =\frac{\partial A}{\partial \bar{\alpha}}=\frac{\pi}{4} \Delta T_{\mathrm{mp}}\left(d_{o}^{2}+d_{i}^{2}\right)\left(1+\bar{\alpha}_{\mathrm{Ni}} \Delta T_{\mathrm{mp}}\right) \\
c_{\Delta T_{\mathrm{mp}}} & =\frac{\partial A}{\partial\left(\Delta T_{\mathrm{mp}}\right)}=\frac{\pi}{4} \bar{\alpha}_{\mathrm{Ni}}\left(d_{o}^{2}+d_{i}^{2}\right)\left(1+\bar{\alpha}_{\mathrm{Ni}} \Delta T_{\mathrm{mp}}\right)
\end{aligned}
$$

Table 35 summarizes the calculations for the combined standard uncertainty of $A$. The values of $d_{o}$ and $d_{i}$ were determined to be $200.070 \mathrm{~mm}$ and $201.920 \mathrm{~mm}$, respectively, based on the 


\section{Appendix E}

calibration data from NIST Report of Test 274749-07. Values of $\bar{\alpha}_{\mathrm{Ni}}$ were taken from Table 34. The estimates for $u_{\mathrm{c}}(A)$ are quite small.

Table 35. Combined standard uncertainties for $A$.

\begin{tabular}{cccccccc}
\hline $\begin{array}{c}\boldsymbol{T}_{\boldsymbol{h}} \\
(\mathbf{K})\end{array}$ & $\begin{array}{c}\boldsymbol{c}_{\boldsymbol{d}_{\boldsymbol{o}}} \\
\mathbf{( m )}\end{array}$ & $\begin{array}{c}\boldsymbol{c}_{\boldsymbol{d}_{\boldsymbol{i}}} \\
\mathbf{( m )}\end{array}$ & $\begin{array}{c}\boldsymbol{c}_{\overline{\boldsymbol{u}}_{\mathrm{Ni}}} \\
\left(\mathbf{K} \cdot \mathbf{m}^{\mathbf{2}}\right)\end{array}$ & $\begin{array}{c}\boldsymbol{c}_{\Delta \boldsymbol{T}} \\
\left(\mathbf{K}^{-\mathbf{1}} \cdot \mathbf{m}^{\mathbf{2}}\right)\end{array}$ & $\begin{array}{c}\boldsymbol{A} \\
\left(\mathbf{m}^{\mathbf{2}}\right)\end{array}$ & $\begin{array}{c}\boldsymbol{u}_{\mathbf{c}}(\boldsymbol{A}) \\
\left(\mathbf{m}^{\mathbf{2}}\right)\end{array}$ & $\begin{array}{c}\boldsymbol{u}_{\mathbf{c}, \mathbf{r}}(\boldsymbol{A}) \\
(\mathbf{\%})\end{array}$ \\
\hline 292.5 & 0.1571 & 0.1585 & -1.2689 & $8.120 \times 10^{-7}$ & 0.031714 & $1.19 \times 10^{-6}$ & 0.004 \\
312.5 & 0.1572 & 0.1587 & 1.2283 & $8.217 \times 10^{-7}$ & 0.031746 & $1.19 \times 10^{-6}$ & 0.004 \\
332.5 & 0.1573 & 0.1588 & 2.4984 & $8.304 \times 10^{-7}$ & 0.031763 & $1.32 \times 10^{-6}$ & 0.004 \\
352.5 & 0.1574 & 0.1588 & 3.7693 & $8.386 \times 10^{-7}$ & 0.031780 & $1.52 \times 10^{-6}$ & 0.005 \\
372.5 & 0.1575 & 0.1589 & 5.0409 & $8.464 \times 10^{-7}$ & 0.031797 & $1.77 \times 10^{-6}$ & 0.006 \\
\hline
\end{tabular}

\section{E1.4.2 Meter Area Correction}

On August 26, 2005, a machinist's miscalculation resulted in a $1 / 8$ inch dowel pin being punched through the inboard surface of the meter plate during fabrication. As a result, a small semi-circular section of the meter plate near the guard gap was removed from the meter plate as illustrated in Fig. 65.

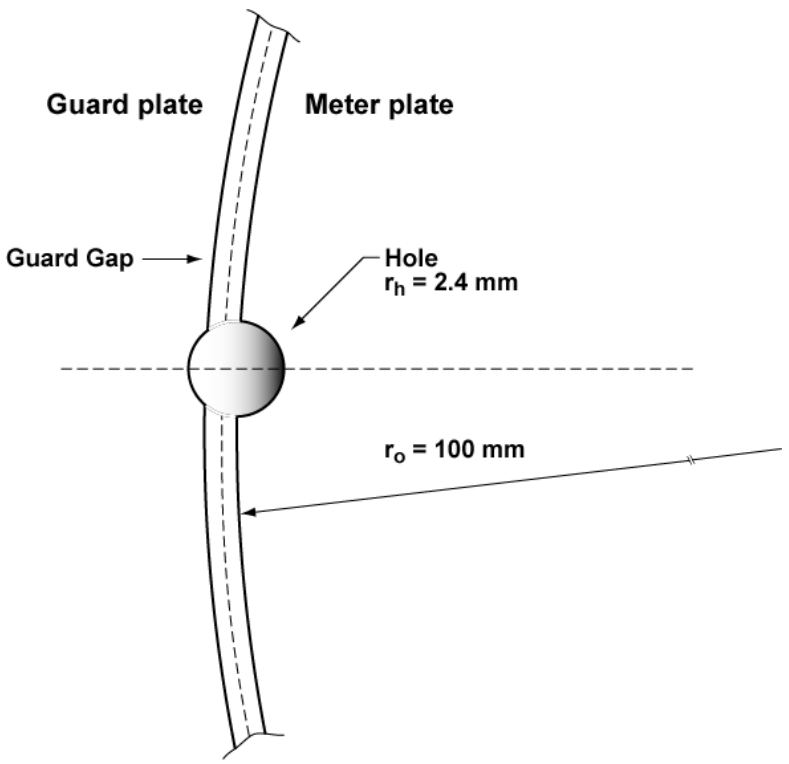

Fig. 65. Schematic illustration of the puncture hole located in the guard gap.

As shown in Fig. 65, the damaged portion of the meter plate is approximately equal to onehalf of a circular area having a radius of $2.4 \mathrm{~mm}$. The ratio of the damaged area to the meter plate area is computed from Eq. (E-41) as 0.00029 . The uncertainty is about 5 to 7 times larger than the combined standard uncertainties in Table 35 and thus was used in Table 15 (Sec. 7.4).

$$
\frac{A_{\mathrm{h}}}{A_{\mathrm{mp}}}=\frac{\pi r_{\mathrm{h}}^{2} / 2}{\pi r_{\mathrm{o}}^{2}}=\frac{(2.4 \mathrm{~mm})^{2} / 2}{(100 \mathrm{~mm})^{2}}=0.00029
$$

